University of Louisville

ThinkIR: The University of Louisville's Institutional Repository

\title{
The collective affiliation of community college, commuter and distance education students : developmental math and dropout.
}

Jeffrey Cody Davidson

University of Louisville

Follow this and additional works at: https://ir.library.louisville.edu/etd

\section{Recommended Citation}

Davidson, Jeffrey Cody, "The collective affiliation of community college, commuter and distance education students : developmental math and dropout." (2011). Electronic Theses and Dissertations. Paper 315.

https://doi.org/10.18297/etd/315

This Doctoral Dissertation is brought to you for free and open access by ThinkIR: The University of Louisville's Institutional Repository. It has been accepted for inclusion in Electronic Theses and Dissertations by an authorized administrator of ThinkIR: The University of Louisville's Institutional Repository. This title appears here courtesy of the author, who has retained all other copyrights. For more information, please contact thinkir@louisville.edu. 
THE COLLECTIVE AFFILIATION OF COMMUNITY COLLEGE, COMMUTER AND DISTANCE EDUCATION STUDENTS: DEVELOPMENTAL MATH AND DROPOUT

\author{
By \\ Jeffrey Cody Davidson \\ B.A., Georgetown College, 2001 \\ M.B.A., Gardner-Webb University, 2004 \\ M.Div., Gardner-Webb University, 2004

\begin{abstract}
A Dissertation
Submitted to the Faculty of the

Graduate School of the University of Louisville

In Partial Fulfillment of the Requirements

For the Degree of

Doctor of Philosophy

College of Education and Human Development

University of Louisville

Louisville, Kentucky
\end{abstract}

May 2011 
THE COLLECTIVE AFFILIATION OF COMMUNITY COLLEGE, COMMUTER AND DISTANCE EDUCATION STUDENTS: DEVELOPMENTAL MATH AND DROPOUT

By

Jeffrey Cody Davidson

B.A., Georgetown College, 2001

M.B.A., Gardner-Webb University, 2004

M.Div., Gardner-Webb University, 2004

A Dissertation Approved on

May 26, 2011

By the following Dissertation Committee:

Dr. Kristin Wilson, Co-chair

Dr. Joseph Petrosko, Co-chair

Dr. Rod Githens

Dr. Jay Box 


\section{ACKNOWLEDGMENTS}

First, I would like to thank my dissertation committee: Drs. Wilson, Petrosko, Githens and Box. Thank you to Dr. Wilson for all of our theoretical, practical and personal conversations, the endless editing and extraordinary effort to make this dissertation the best it can be. Thank you to Dr. Petrosko for your tireless efforts, patience, expertise and willingness to work with me through these exhausting statistical analyses. Thank you to Dr. Githens for your knowledge and insight into the critical content elements of this work. Thank you to Dr. Box for your willingness to give your time, professional expertise and attention to this dissertation; your presence is both personal and symbolical of the entire Kentucky Community \& Technical College faculty, staff and students that this work will affect. Also, thank you to my classmates and professors for encouragement and assistance along the way.

This dissertation would not be complete without the continued and unwavering dedication of my family. Thank you to my parents, Jeff and Pat Davidson, for teaching me to believe in myself and to value an education; your sacrifices have made this dream a reality. Thank you to my brother and sister, Christian and Tiffany, for your encouragement and support. Thank you to Carrie, my wife, words cannot express nor does justice in describing the part you have played in this experience; none of this would be possible without you. Thank you to Evie, my daughter, even though you are too young to understand, I hope this accomplishment will have meaning in your life as it does mine. 


\begin{abstract}
THE COLLECTIVE AFFILIATION OF COMMUNITY COLLEGE, COMMUTER AND DISTANCE EDUCATION STUDENTS: DEVELOPMENTAL MATH AND DROPOUT
\end{abstract}

\author{
Cody Davidson
}

May 17, 2011

From 1988 to 2006 , between $40 \%$ and $60 \%$ of all first-time community college students are referred to and enroll in at least one developmental education course; some colleges reported as high as 80 percent (e.g. Attewell, Lavin, Domina, \& Levey, 2006; Bers \& Smith, 1991; Bettinger \& Long, 2005; Boughan \& Clagett, 1995; Brawer, 1996). More students begin college less prepared in math than any other developmental area (e.g. ACT, 2006, 2007, 2008, 2009; Attewell, Lavin, Domina, \& Levey, 2006; Bettinger \& Long, 2005; Cartnal, 1999).

The purpose of this quantitative study was to examine the relationship between a set of predictor variables and student persistence for persons enrolled at a state-supported two-year community and technical college system. The Collective Affiliation model, based on previous student persistence research in the Tinto tradition, was created and used was in this study specifically for community college, commuter and distance education students. The participants were Kentucky Community and Technical College students enrolled in the developmental math course, MT065, Basic Algebra. The predictor variables were student demographic characteristics, and variables related to 
work, family and academic factors. The dependent variable was persistence (defined as re-enrollment or the awarding of a credential or transfer).

The results revealed academic factors have the greatest influence on persistence. It provides nuances and further insight into developmental education students while calling into question the validity of sociological constructs. Lastly, the study shows how state and local policy can have an impact on student persistence. 


\section{TABLE OF CONTENTS}

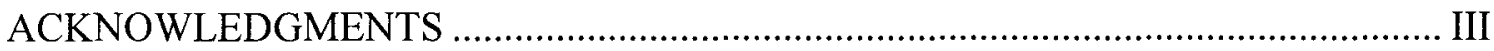

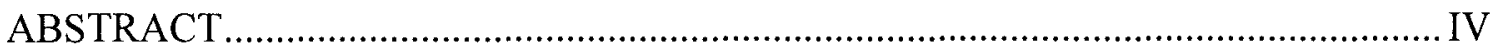

LIST OF TABLES .............................................................................................. XII

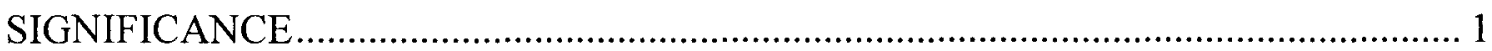

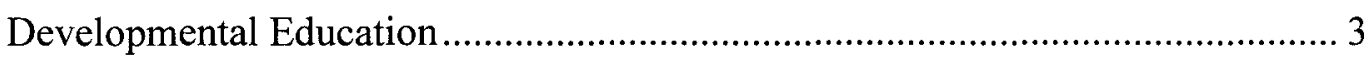

Developmental Math..................................................................................... 5

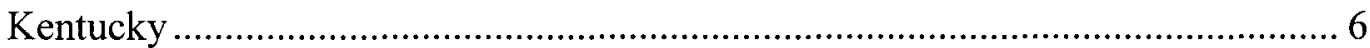

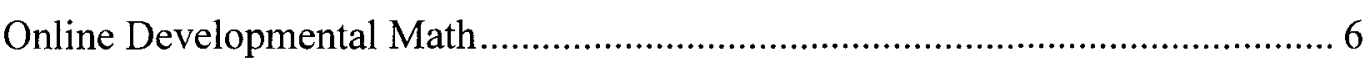

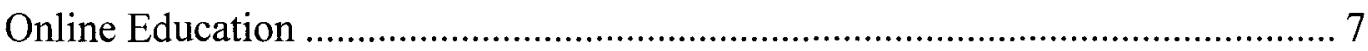

CONCEPTUAL FRAMEWORK: PERSISTENCE THEORIES ...................................... 7

Tinto: Institutional Distinction and Academic and Social Integration .................... 8

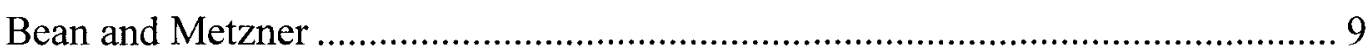

Tinto and Community Colleges ........................................................................... 9

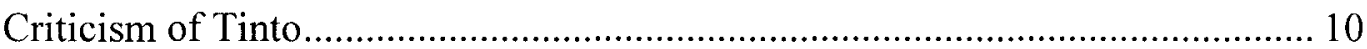

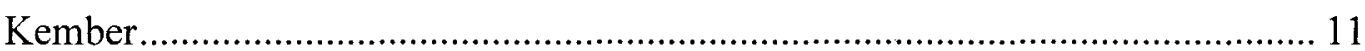

Kember: 1989 and 1995 Models Compared ................................................. 12

Proposed Collective Affiliation Model ................................................................ 13

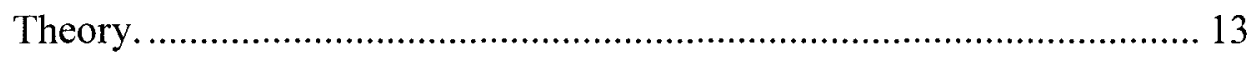

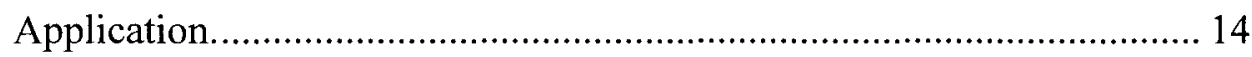

COMMUNITY COLLEGES, DEVELOPMENTAL EDUCATION AND ONLINE

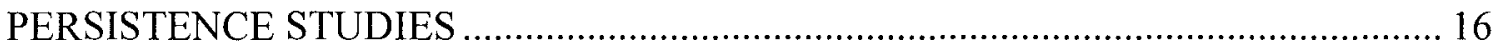

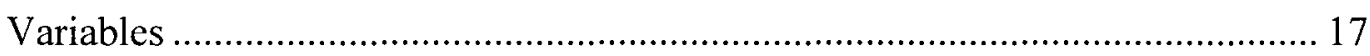

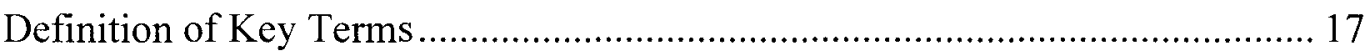

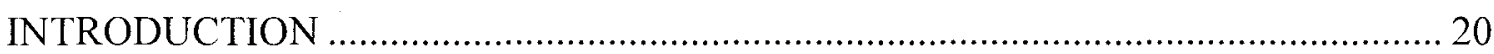

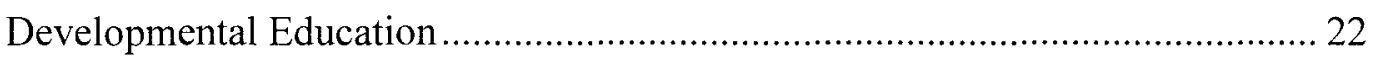

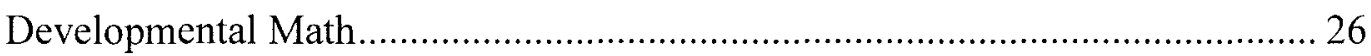

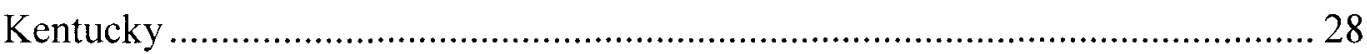


Online Developmental Education ...................................................................... 30

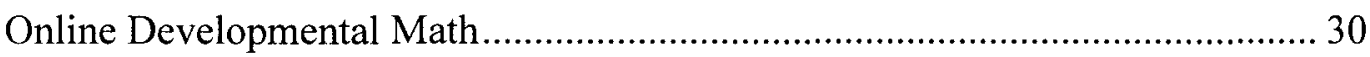

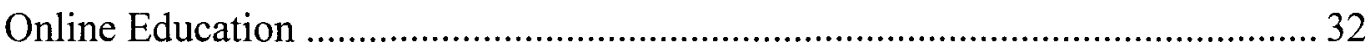

CONCEPTUAL FRAMEWORK: RETENTION THEORIES ……………………........ 36

Beginnings of Sociological Integration and Student Dropout: Spady (1970/71) . 36

Sociological Integration and Student Dropout Popularized: Tinto (1975) ............ 38

Institutional Contexts: Academic Compared to Social Integration ........................ 41

Nontraditional Students and Student Dropout: Bean \& Metzner (1985/87)......... 43

Tinto's Model and Community Colleges............................................................... 45

Criticism of the Tinto Model ............................................................................. 51

Distance Education and Student Dropout: Kember (1989) ................................. 53

Distance Education and Tinto's Social and Academic Integration Model ........... 54

Kember's Longitudinal-Process Model of Drop-Out from Distance Education

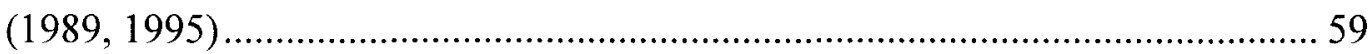

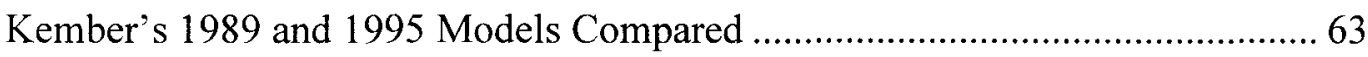

Social integration and external attribution (1995) and social and work

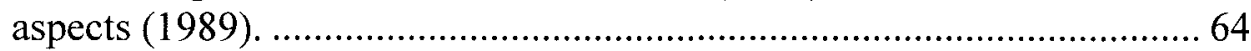

Academic integration and academic incompatibility (1995) and goal commitment $\&$ academic integration and environment (1989)................. 65

Grade point average (GPA), cost/benefit analysis, outcome and recycling

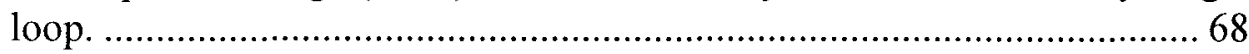

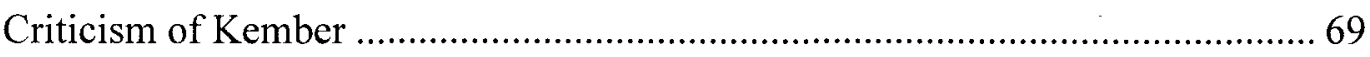

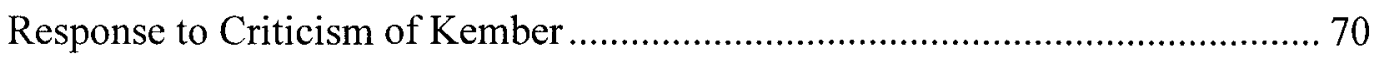

ADDITIONAL DISTANCE EDUCATION PERSISTENCE MODELS AND

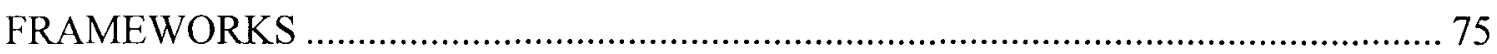

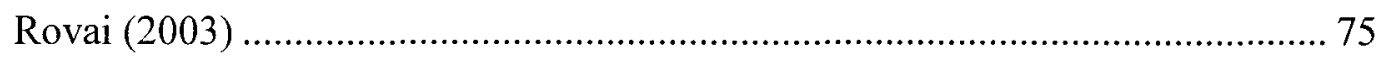

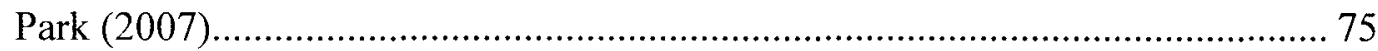

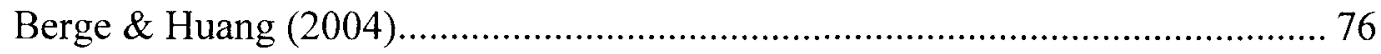

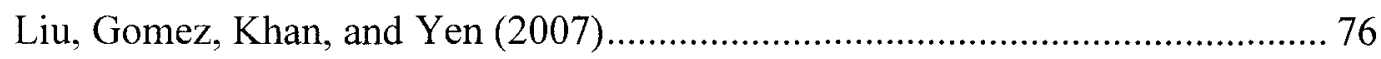

COLLECTIVE AFFILIATION MODEL THEORY ………………………………...... 77

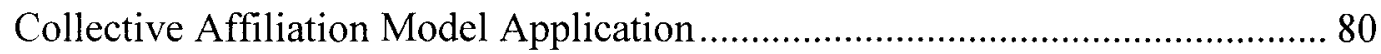

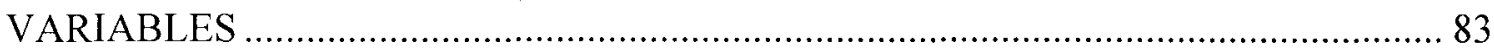

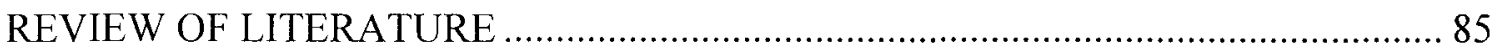


Community Colleges, Developmental Education and Online Persistence Studies 85

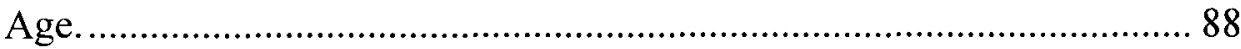

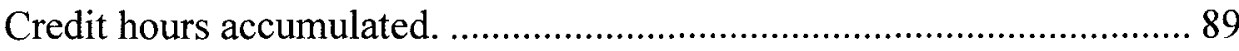

Degree program.

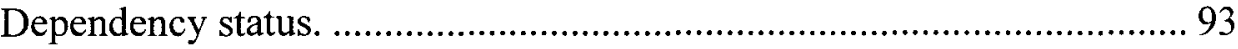

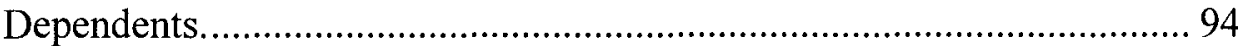

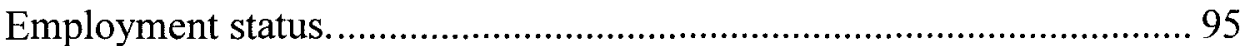

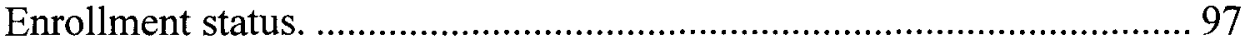

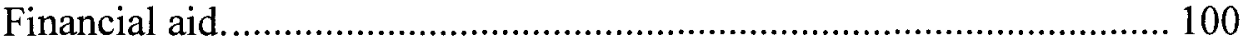

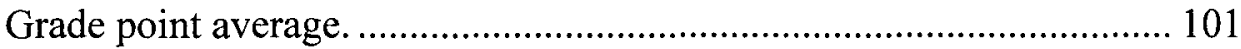

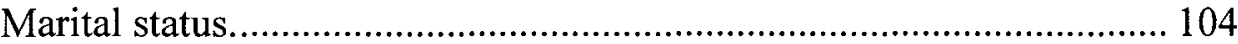

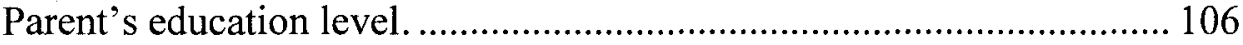

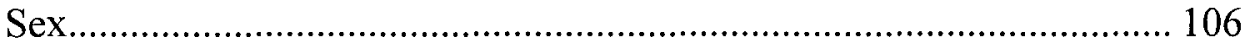

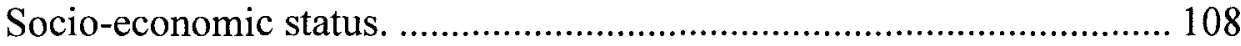

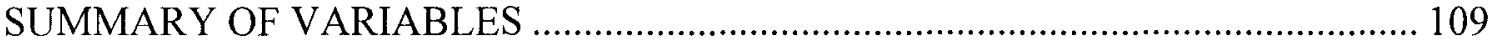

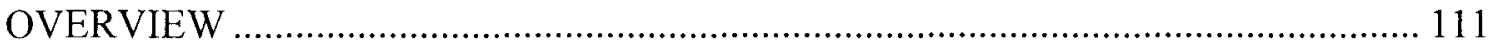

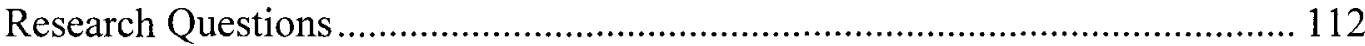

Context: Kentucky Community \& Technical College System (KCTCS) ........... 115

Research Considerations ..................................................................................... 118

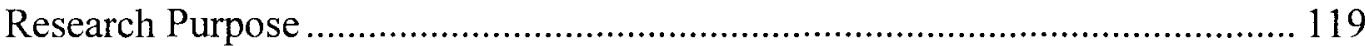

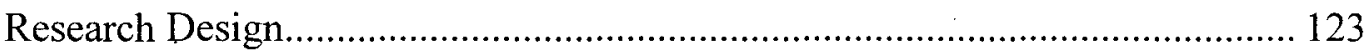

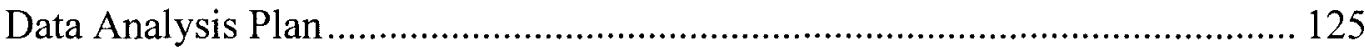

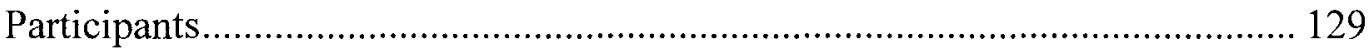

Data Collection: Assumptions and Limitations ................................................... 130

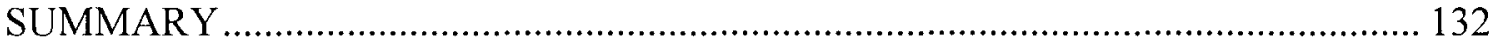

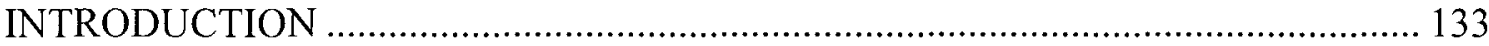

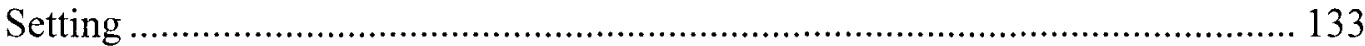

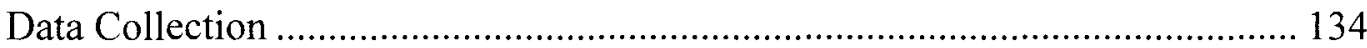

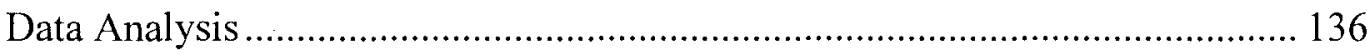

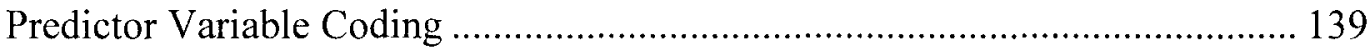

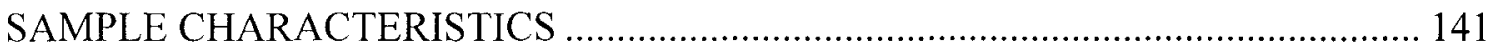

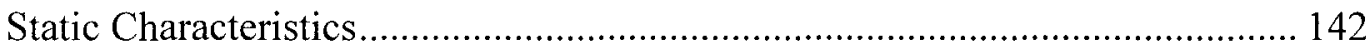


Sex. 142

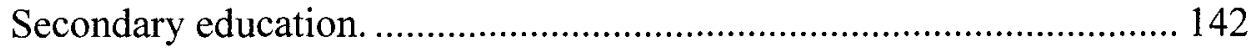

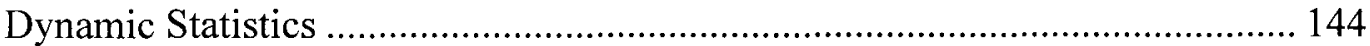

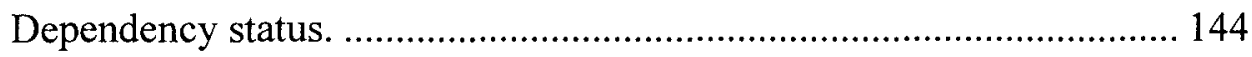

Age

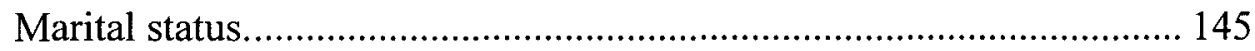

Single mother, dependents and children. .............................................. 146

Student's and parent's adjusted gross income. ........................................ 147

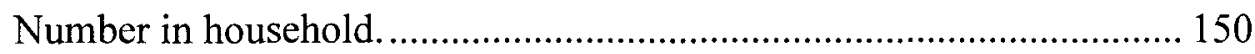

Number of household members in college. ........................................... 151

Federal work-study and waiver/third party ............................................ 153

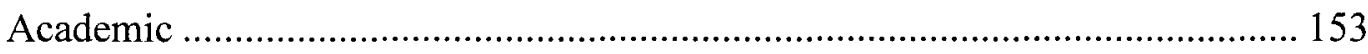

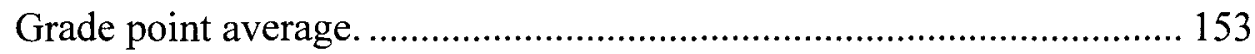

Enrollment status. ............................................................................ 154

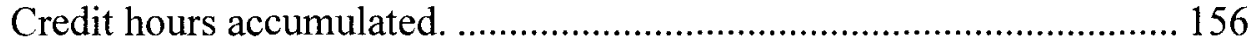

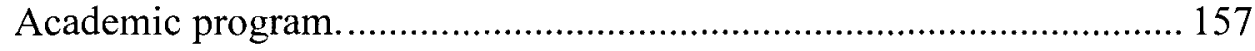

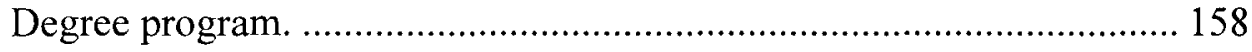

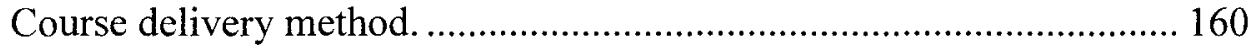

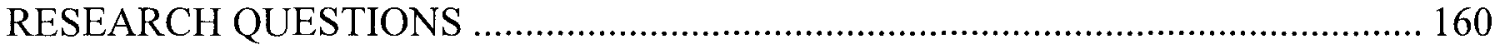

Statistically Significant Predictor Variables on Persistence ............................... 160

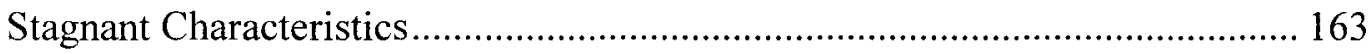

Is there a significant relationship between sex and persistence? ............. 163

Is there a significant relationship between mother's level of education and persistence? ................................................................................. 163

Is there a significant relationship between father's level of education and persistence?

Is there a significant relationship between secondary education and persistence?

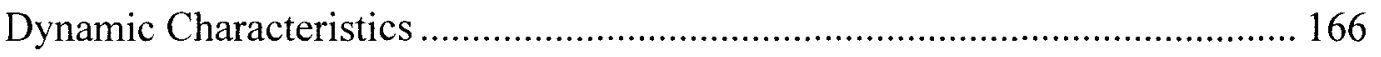

Is there a significant relationship between dependency status and

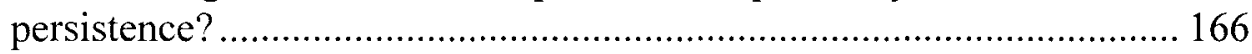

Is there a significant relationship between waiver/third party and persistence?

Is there a significant relationship between the number in household and persistence? 
Is there a significant relationship between adjusted gross income and persistence?

Is there a significant relationship between a student's (and spouse, if married) adjusted gross income and persistence?

Is there a significant relationship between a parent's adjusted gross income of a dependent student and persistence? ................................................ 169

Is there a significant relationship between age and persistence? ?............ 170

Is there a significant relationship between federal work-study and persistence?

Is there a significant relationship between the number of household members in college and persistence?

Is there a significant relationship between being a single mother and persistence?

Is there a significant relationship between having dependents/children and persistence?

Is there a significant relationship between marital status and persistence?

Academic Factors

Is there a significant relationship between grade point average and persistence?

Is there a significant relationship between current grade point average and persistence?

Is there a significant relationship between cumulative grade point average and persistence?

Is there a significant relationship between academic program and persistence?

Is there a significant relationship between degree program and persistence?

Is there a significant relationship between credit hours accumulated and persistence?

Is there a significant relationship between enrollment status and persistence?

Is there a significant relationship between course delivery method and persistence?

Sequential Logistic Regression for Cohorts with the Variable Instructional Mode 


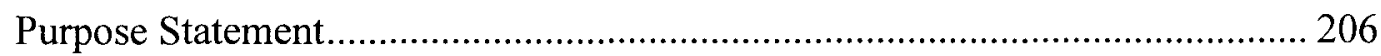

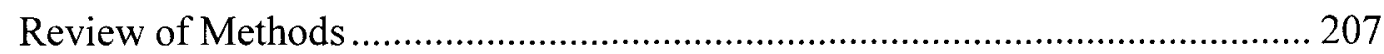

SUMMARY OF FINDINGS: STATIC, DYNAMIC AND ACADEMIC SPHERES... 209

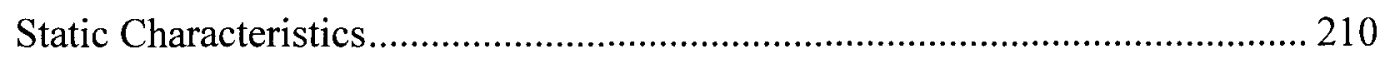

Mother's level of education. ................................................................. 210

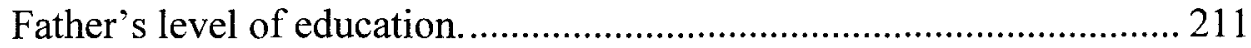

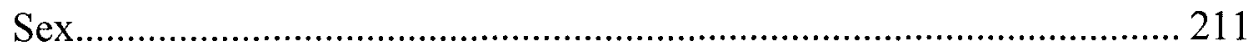

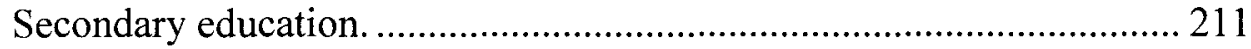

Dynamic Characteristics ............................................................................ 212

Adjusted gross income and parent's adjusted gross income.................... 212

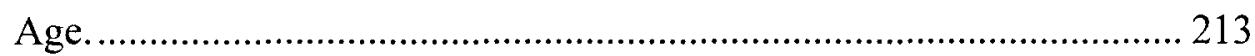

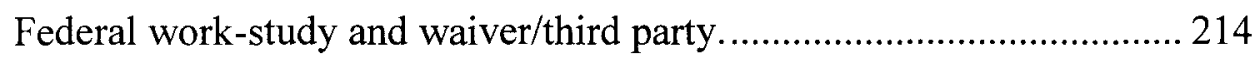

Number of household members in college and household size............... 214

Single mother, dependents and children.............................................. 214

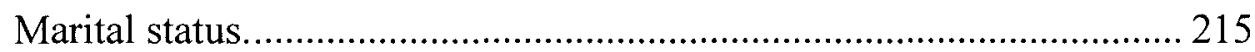

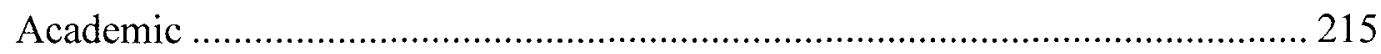

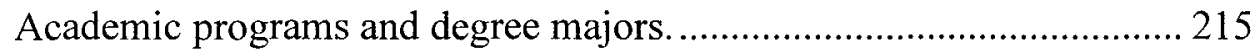

Total credit hours accumulated............................................................. 216

Enrollment status. ............................................................................. 217

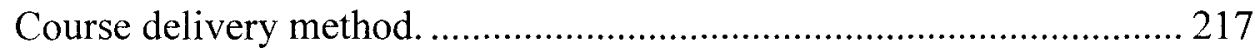

COLLECTIVE AFFILIATION MODEL ..................................................................... 217

Collective Affiliation Model compared to Spady and Tinto …………………... 222

Practical Implications and Policies ..................................................................... 223

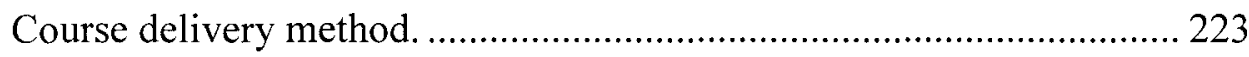

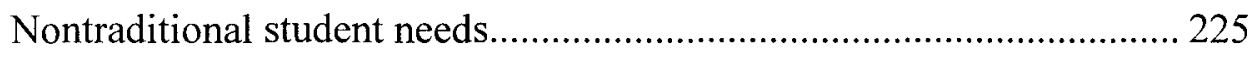

Non-institutionally controlled variables and stereotypes......................... 226

College grading policies and faculty feedback. ...................................... 226

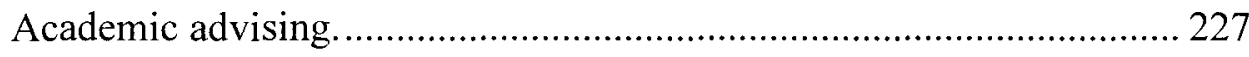

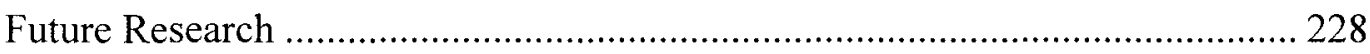

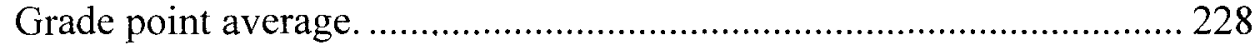

Nontraditional student conceptual frameworks. …………………….... 229

Change in predictor variables. ............................................................. 229

Modularized online developmental math............................................... 230 
Qualitative research. ............................................................... 231

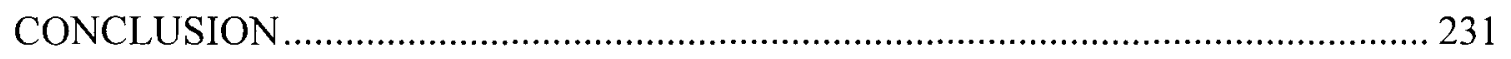

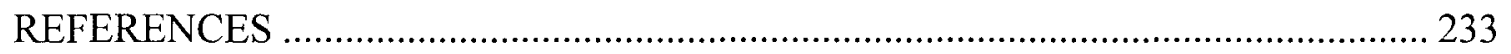

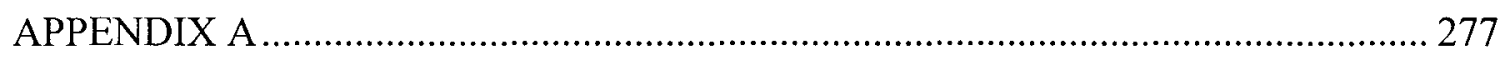

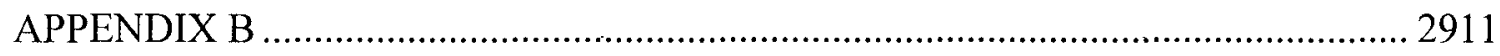

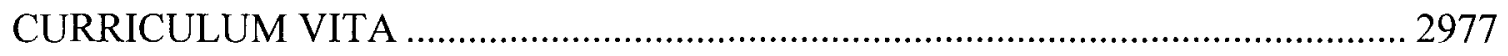




\section{LIST OF TABLES}

TABLE

PAGE

Percentage of High School Students' ACT Scores Meeting Benchmark Standards ........ 21

Kember's 1995 Two-Track Model Subscales of Each Component.................................... 64

National Center for Education Statistics Risk Factors as Variables and Definition....... 120

Variables and Definition of all Non-National Center for Education Statistics Risk Factors

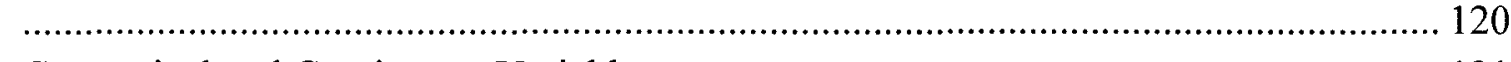

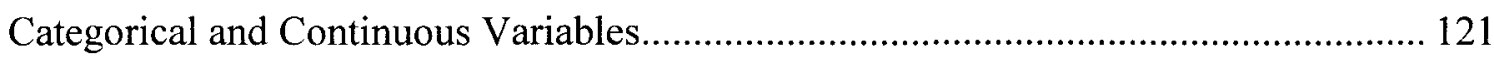

Logistical Regression Analysis of the Entering Cohort and Term in Which Dependent

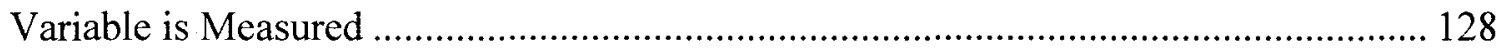

Example of First Logistical Regression Analysis for Fall 2006 Cohort........................ 129

All Logistic Regression Analyses Cohorts and Term in Which Persistence is Assessed129

Responses Used to Define the Variable Secondary Education....................................... 135

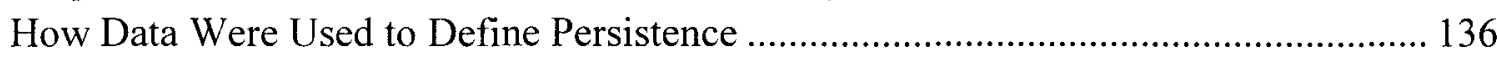

Predictor Variable Coding or Methods of Measurement............................................... 139

Interpretation of Regression Coefficients (B Coefficients) That Were Significant

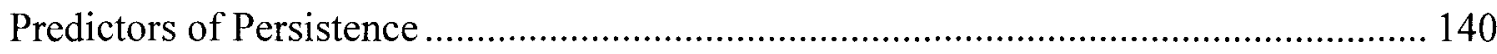

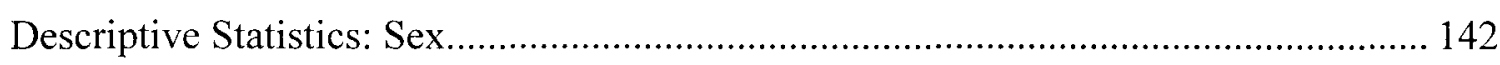

Descriptive Statistics: Secondary Education ................................................................ 142

Descriptive Statistics: Father's Education Level ........................................................ 143

Descriptive Statistics: Mother's Education Level........................................................... 144

Descriptive Statistics: Dependency Status of Student ............................................... 145

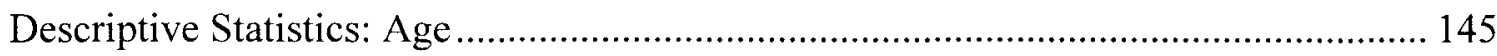

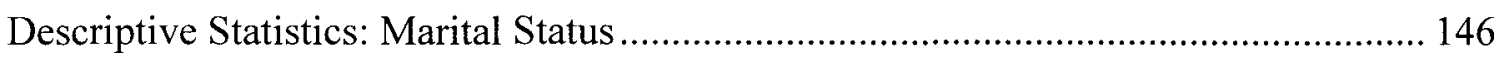

Descriptive Statistics: Student with One or More Children........................................... 146

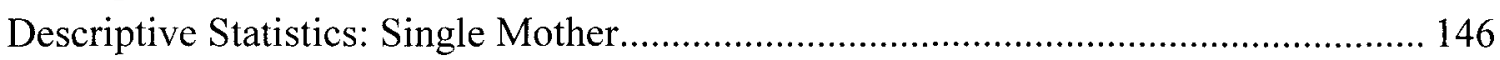

Descriptive Statistics: Student with One or More Dependents..................................... 147

Descriptive Statistics: Student's Adjusted Gross Income ............................................. 147

Descriptive Statistics: Independent Student's Adjusted Gross Income by Category ..... 148

Descriptive Statistics: Dependent Student's Adjusted Gross Income by Category ........ 148

Descriptive Statistics: Parent's Adjusted Gross Income.............................................. 149

Descriptive Statistics: Parent's Adjusted Gross Income by Category ............................ 149

Descriptive Statistics: Number in Household (Independent)......................................... 150

Descriptive Statistics: Number in Household (Dependent) ........................................... 151 
Descriptive Statistics: Number of Household Members in College (Independent)........ 152

Descriptive Statistics: Number of Household Members in College (Dependent) .......... 152

Descriptive Statistics: Federal Work Study …………….......................................... 153

Descriptive Statistics: Waiver and Third Party …………............................................. 153

Descriptive Statistics: Current GPA and Cumulative GPA ......................................... 153

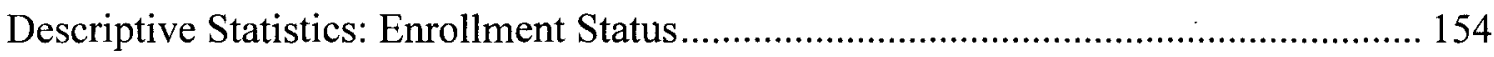

Descriptive Statistics: Frequency Distribution for Enrollment Status........................... 154

Descriptive Statistics: Dependents Credit Hours by Category ………………………... 155

Descriptive Statistics: Enrollment Status for Dependents ............................................. 155

Descriptive Statistics: Independents Credit Hours by Category ...................................... 155

Descriptive Statistics: Enrollment Status for Independents........................................... 156

Descriptive Statistics: Total Credit Hours Accumulated ................................................ 156

Descriptive Statistics: Independent Students Earned Credits when Enrolled in MT065 156

Descriptive Statistics: Dependent Students Earned Credits when Enrolled in MT065 .. 157

Descriptive Statistics: Academic Program................................................................. 157

Descriptive Statistics: Academic Program Transfer and Not Transfer Categories......... 158

Descriptive Statistics: Degree Programs by CIP Categories ........................................ 158

Descriptive Statistics: Course Delivery Method........................................................ 160

Cohorts that Had Sex as a Significant Predictor of Persistence..................................... 163

Cohorts that Had Mother's Level of Education as a Significant Predictor of Persistence

Cohorts that Had Father's Level of Education as a Significant Predictor of Persistence165

Cohorts that Had Waiver/Third Party as a Significant Predictor of Persistence ............ 166

Cohorts that Had Household Size as a Significant Predictor of Persistence .................. 167

Cohorts that Had Adjusted Gross Income as a Significant Predictor of Persistence...... 168

Cohorts that Had Parent's Adjusted Gross Income as a Significant Predictor of

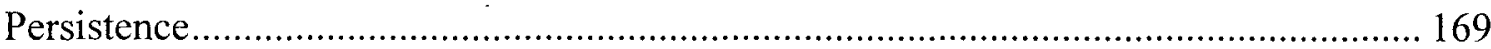

Cohorts that Had Age as a Significant Predictor of Persistence .................................... 170

Cohorts that Had Federal Work-study as a Significant Predictor of Persistence ........... 171

Cohorts that Had Household Members in College as a Significant Predictor of Persistence

Cohorts that Had Single Mother as a Significant Predictor of Persistence.................... 172

Cohorts that Had Dependents as a Significant Predictor of Persistence......................... 173

Cohorts that Had Children as a Significant Predictor of Persistence............................. 174

Cohorts that Had Academic Program as a Significant Predictor of Persistence............. 175

Cohorts that Had Business Major as a Significant Predictor of Persistence................... 176

Cohorts that Had Allied Health Major as a Significant Predictor of Persistence ........... 177

Cohorts that Had General Studies Major as a Significant Predictor of Persistence ...... 177

Cohorts that Had Total Number of Credit Hours Accumulated as a Significant Predictor of Persistence 
Cohorts that Had Enrollment Status as a Significant Predictor of Persistence 179

Cohorts that Had Course Delivery Method as a Significant Predictor of Persistence.... 180 Results of Sequential Logistic Regression Analyses for Cohort Fall 2006 Term: Spring 2007 Independent Students, Including Secondary Education $(n=301)$. 183 Results of Sequential Logistic Regression Analyses for Cohort Fall 2006 Term: Spring 2007 Independent Students, Not-Including Secondary Education $(n=666)$ 184 Results of Sequential Logistic Regression Analyses for Cohort Fall 2006 Term: Spring 2007 Dependent Students, Including Secondary Education $(\mathrm{n}=290)$ 184 Results of Sequential Logistic Regression Analyses for Cohort Fall 2006 Term: Spring 2007 Dependent Students, Not-Including Secondary Education $(n=447)$ 185 Results of Sequential Logistic Regression Analyses for Cohort Fall 2007 Term: Spring 2008 Independent Students, Including Secondary Education $(\mathrm{n}=418)$ 186 Results of Sequential Logistic Regression Analyses for Cohort Fall 2007 Term: Spring 2008 Independent Students, Not-Including Secondary Education $(n=558) \ldots \ldots \ldots \ldots \ldots . . .186$ Results of Sequential Logistic Regression Analyses for Cohort Fall 2007 Term: Spring 2008 Dependent Students, Including Secondary Education $(n=227)$. 187 Results of Sequential Logistic Regression Analyses for Cohort Fall 2007 Term: Spring 2008 Dependent Students, Not Including Secondary Education $(n=355) \ldots \ldots \ldots \ldots \ldots \ldots \ldots . . .188$ Results of Sequential Logistic Regression Analyses for Cohort Fall 2008 Term: Spring 2009 Independent Students, Including Secondary Education $(n=300)$. 188 Results of Sequential Logistic Regression Analyses for Cohort Fall 2008 Term: Spring 2009 Independent Students, Not-Including Secondary Education $(\mathrm{n}=372)$ 189 Results of Sequential Logistic Regression Analyses for Cohort Fall 2008 Term: Spring 2009 Dependent Students, Including Secondary Education $(n=218)$ 190 Results of Sequential Logistic Regression Analyses for Cohort Fall 2008 Term: Spring 2009 Dependent Students, Not Including Secondary Education $(\mathrm{n}=218)$ 190 Results of Sequential Logistic Regression Analyses for Cohort Spring 2007 Term: Fall 2007 Independent Students, Including Secondary Education $(n=481)$ 191

Results of Sequential Logistic Regression Analyses for Cohort Spring 2007Term: Fall 2007Independent Students, Not Including Secondary Education $(n=754)$.

Results of Sequential Logistic Regression Analyses for Cohort Spring 2007 Term: Fall 2007 Dependent Students, Including Secondary Education $(n=243) \ldots$

Results of Sequential Logistic Regression Analyses for Cohort Spring 2007 Term: Fall 2007 Dependent Students, Not Including Secondary Education $(n=434)$.

Results of Sequential Logistic Regression Analyses for Cohort Spring 2008 Term: Fall 2008 Independent Students, Including Secondary Education $(n=318)$.

Results of Sequential Logistic Regression Analyses for Cohort Spring 2008 Term: Fall 2008 Independent Students, Not Including Secondary Education $(n=399)$

Results of Sequential Logistic Regression Analyses for Cohort Spring 2008 Term: Fall 2008 Dependent Students, Including Secondary Education $(n=134)$ 
Results of Sequential Logistic Regression Analyses for Cohort Spring 2008 Term: Fall 2008 Dependent Students, Not Including Secondary Education $(\mathrm{n}=185)$

Results of Sequential Logistic Regression Analyses for Cohort Spring 2009 Term: Fall 2009 Independent Students, Including Secondary Education $(n=199)$

Results of Sequential Logistic Regression Analyses for Cohort Spring 2009 Term: Fall

2009 Independent Students, Not Including Secondary Education $(n=237)$.

Results of Sequential Logistic Regression Analyses for Cohort Spring 2009 Term: Fall

2009 Dependent Students, Including Secondary Education $(\mathrm{n}=108)$

Results of Sequential Logistic Regression Analyses for Cohort Spring 2009 Term: Fall 2009 Dependent Students, Not Including Secondary Education $(n=121) \ldots \ldots \ldots \ldots \ldots . . . . . . .198$

All Cohorts and Logistic Regression Analyses ......................................................... 199

Static, Dynamic and Academic Variables as Statistically Significant Predictors .......... 209 


\section{CHAPTER I}

\section{Significance}

Developmental education provides access to college for traditional and nontraditional age students. Ever year from 1995 to 2009, less than half of all traditional students' composite score in mathematics reached the benchmark of 22 set by the American College Testing Program (ACT, 2009). Likewise, nontraditional students such as: high schools dropouts, GED recipients, returning adults and new immigrants, also enroll in developmental education courses (Ignash, 1997; Jenkins \& Boswell, 2002; Roueche \& Roueche, 1999). The Obama Administration has made developmental education programs and persistence a fiscal priority (Killough, 2009; Moore, Shulock, \& Offenstein, 2009). Today, developmental education programs and persistence are a fiscal priority for the Obama Administration (Bailey \& Cho, 2010; Killough, 2009; Moore, Shulock, \& Offenstein, 2009). It was first reported, that The College Access and Completion Fund would allocate $\$ 500$-million annually over five years for retention efforts to states, specifically completion rates and low-income students (Killough, 2009; Moltz, 2009a). How these funds will be allocated is yet to be determined, but it is certain some would like to see a "performance-based funding -- a model that would appropriate state dollars for higher education based on course completion and graduation rates instead of enrollment figures" (Moltz, 2009a). This shift in allocating funds from enrollment count to completion and graduation rates would follow similar trends in states such as Indiana and Ohio. 
Moltz (2009a) reported that this funding model was "geared" toward four-year institutions, but an altered formula could be implemented to improve completion rates at community colleges. Richard M. Rhodes, president of El Paso Community College noted a similar discussion in Texas that varied slightly for community colleges, "an altered formula would award funds to community colleges based on their ability to improve these rates from year to year and to attract low-income students" (Moltz, 2009a). The actual legislation allocated \$600 million from 2010 to 2014 ("Details of Proposed Student Aid", 2009). A percentage of these funds were allocated to various projects, but the largest portion, fifty percent, was allocated for 'State Innovation Completion Grants' (Section 782): "Matching grants to be made available to states on a competitive basis to promote student persistence in, and completion of, postsecondary education" ("Details of Proposed Student Aid", 2009, para. 10).

On June 22, 2009, "the Bill \& Melinda Gates Foundation and MDC, Inc. announced $\$ 16.5$ million in grants to 15 community colleges and five states to expand groundbreaking remedial education programs that experts say are key to dramatically boosting the college completion rates of low-income students and students of color" ("Community Colleges and States", 2009, para. 1). In this group of 15 colleges, a portion of the grant is allocated to expand El Paso Community College and Houston Community College's "modular math" programs. A few months later, the Bill \& Linda Gates foundation made another $\$ 5$ million dollar grant to the Monterey Institute for Technology and Education for developmental math project. Specifically, "the program will combine four courses required in most remedial math sequences. Often students have taken these classes before and know some, but not all, of the material. Pre-assessment tests will 
determine the specific areas and knowledge students need to work on and the flexible nature of the online courses will allow students and teachers to select the appropriate modules for their particular needs" ("Solving America's Math Problem", 2009, para. 4).

In addition, on December 3, 2009, the Bill \& Melinda Gates Foundation announced "12.9 million in technology-related grants" ("Emerging Technologies", 2009, para. 1). These grants would directly affect developmental education. One of the ways in which "the recipients will use their grants" is to "create web 2.0 tools and social media to being together that nation's best professors in a virtual community to create a national certification for teachers of remedial (i.e. developmental) education" ("Emerging Technologies", 2009, para. 6). Other portions of the grant focused on developmental mathematics will be used to (a) "innovate math and writing basic skills pedagogy via Web 2.0 and social media that consistently results in increased student pass rates (b) produce developmental mathematics course materials that will be made available as an OER [open educational resource] and (c) engage community colleges in redesigning developmental math based on proven methods of integrating technology and learnercentered pedagogy” (“Emerging Technologies”, 2009, para. 9). Accelerated, self-paced developmental math programs with flexible scheduling (e.g. open entry/open exit) are selected for funding purposes (Biswas, 2007) and receive praise (Bailey \& Cho, 2010; Jaschik, 2010b).

\section{Developmental Education}

Almost all community colleges have an open admission policy (Provasnik \& Planty, 2008) and provide the majority of developmental education (Ignash, 1997; Kozeracki, 2002). Some states and large urban public college systems are regulating 
developmental education solely to the community college (Attewell, Lavin, Domina, \& Levey, 2006; Bettinger \& Long, 2005; Jenkins \& Boswell, 2002; Kozeracki, 2002;

Merisotis \& Phipps, 2000; Phipps, 1998; Shaw, 1997). If developmental programs are not successful at community colleges, then the college has not succeeded in the mission of open access. Twenty-eight states "clearly require" placement testing for students, but less than half, require mandatory placement (Dougherty \& Reid, 2007, p.15). Lewis and Farris (1996) reported $71 \%$ of public 2-year institutions were required to offer remedial education and that $53 \%$ of 2-year public institutions have state policy or laws that govern the "limitation on the length of time a student may a take a remedial courses at the higher education institution" (p.31). These policy changes highlight the importance of term-toterm persistence (Clergy, 2008c; Murtaugh, Burns, \& Schuster, 1999). Research has found that students usually leave in the first year (Clergy, 2006d; Horn, 1998) or even before the second semester (Brooks-Leonard, 1991). This study will focus on persistence from one term to the following term (Bers \& Smith, 1991; Driscoll, 2007; Napoli \& Wortman, 1996, 1998; Romano, 1995; Webb, 1988) and from one term to one year later (e.g. from the fall term to the following fall term) (Fike \& Fike, 2008).

From 1988 to 2006 , between $40 \%$ and $60 \%$ (some colleges reported as high as $80 \%$ ) of all first-time community college students enrolled in at least one developmental education course (Attewell, Lavin, Domina, \& Levey, 2006; Bailey, 2009; Bers \& Smith, 1991; Bettinger \& Long, 2005; Boughan \& Clagett, 1995; Brawer, 1996; Clergy, 2006b, 2008d; Collins, 2009; Colorado Commission on Higher Education, 2009; Fujita \& Oromaner, 1992; Horn, Peter, \& Rooney, 2002; Kielbaso, Dirkx, Min, \& Allen, 1998; Lewis \& Farris, 1996; Maryland Higher Education Commission, 1996; McCabe, 2000; 
Parsad \& Lewis, 2003; Perry, Bahr, Rosin, \& Woodward, 2010; Shults, 2000). With 40\% to $60 \%$ or more of all community college students enrolling in at least one developmental education course success in developmental education is paramount to retention, persistence and degree obtainment. Studies have also shown students who tested into and completed developmental education courses compared to students who do not test into developmental education courses performed as well or better in college (Bahr, 2008; Easterling, Patten, \& Krile, 1998; Grosset, 1989; Kolajo, 2004; Schoenecker, Bollman, \& Evans, 1996; Simmons, 1995).

\section{Developmental Math}

More students begin college less prepared in math than any other developmental area (e.g. English and reading) (ACT, 2006, 2007, 2008, 2009; Attewell, Lavin, Domina, \& Levey, 2006; Bettinger \& Long, 2005; Cartnal, 1999; Clergy, 2006a, 2006f; Colorado Commission on Higher Education, 2009; Horn \& Berger, 2004; Horn, Peter, \& Rooney, 2002; Kielbaso, Dirkx, Min, \& Allen, 1998; King \& Crouse, 1997; Lewin, 2008; Lewis \& Farris, 1996; Maryland Higher Education Commission, 1996; McCabe, 2003; Parsad \& Lewis, 2003; Phipps, 1998; Provasnik \& Planty, 2008; Virginia Community Colleges Office of Institutional Research and Effectiveness, 2008; Washington State Board for Community and Technical Colleges, 2006, 2007, 2009). Persistence studies have shown only about half of all developmental math students successfully complete the course (Bailey, Jeong, \& Cho, 2009; Cuesta College, 1999; Curtis, 2002; Fike \& Fike, 2007; Jaschik 2010a; Kangas, 1992a, 1992b, 1992c; Maricopa Community Colleges Institutional Effectiveness Office and Maricopa Governance, 2003; Rienties, Tempelaar, Waterval, Rehm, \& Gijselaers, 2006). Smith, O'Hear, Baden, Hayden, Gorham, Ahuja, 
and Jacobsen (1996) noted, "limited research has been completed to provide insight as to why some students succeed and others fail in this course [developmental math]" (p.33).

\section{Kentucky}

In 2009 , only $15 \%$ of Kentucky high school graduates who took the ACT test, reached the benchmark in all four areas (e.g. math, English, science and reading); only $26 \%$ reached this benchmark in mathematics (ACT, 2009). In the same 2009 class $74 \%$ "indicated an interest in obtaining a bachelor's degree or higher" (ACT, 2009, p.5). In effort to meet the aforementioned challenges, the state of Kentucky formed the Kentucky Developmental Education Task Force. "More than half of the first-time freshmen entering Kentucky's colleges are underprepared in at least one subject. Even worse, for those underprepared students, the first-year college drop-out rate is twice the rate of academically prepared freshman" (Kentucky Developmental Education Task Force, 2007, p.5). In the summer of 2010, the Kentucky Community and Technical College System will launch online, modularized, self-paced, open-entry/closed exit developmental math courses (A. Parker, personal communication, October, 10, 2009; Moltz, 2009b). In effort to improve developmental success rates in developmental education and "reduce the time-to-degree for many students", the Kentucky Developmental Education Task Force specifically called for a "self-paced, brief, online modules for students with minimal developmental need" (Kentucky Developmental Education Task Force, 2007, p.13).

\section{Online Developmental Math}

The internet (Epper \& Baker, 2009; Hoyles, Newman, \& Noss, 2001; Peschke, 2009; Rienties, Tempelaar, Waterval, Rehm, \& Gijselaers, 2006; Phillip, 2011; Rienties, 
Tempelaar, Dijkstra, Rehm, \& Gijselaers, 2008; Tempelaar, Rienties, Rehm, Dijkstra, Arts, \& Blok, 2006) and other technologies (Gonzalez, 2010; Jacobson, 2005, 2006; Khalili \& Shashaani, 1994; King \& Crouse, 1997; Kolowich, 2011) are being used to assist students in developmental math. "Many experts in the world of mathematics and beyond contend that we cannot meet our developmental math student success goals without incorporating technology" (Epper \& Baker, 2009, p.3). New technologies in distance education have been used for closing "the retention gap" (Kolowich, 2010b).

\section{Online Education}

Distance education plays an important role in the mission of community colleges by providing access for disadvantaged students. "Two-year associate's institutions have the highest growth rates and account for over one-half of all online enrollments for the last five years" (Allen \& Seaman, 2007, pg. 1). In the fall of 2008, 4.6 million students took at least one online course, which accounted for $25 \%$ of all students in higher education (Allen \& Seaman, 2010).

Attrition is a challenge for online education (Carr, 2000; Diaz, 2002; Flood, 2002; Frankola, 2001; Martinez, 2003; Moody, 2004; Parker, 2003; Patterson \& McFadden, 2009; Phipps \& Merisotis, 1999; Royer, 2006; Shin \& Kim, 1999; TylerSmith, 2006; Valasek, 2001; Zavarella \& Ignash, 2009). In addition, research has shown the first semester (and first courses) and year is most important period for student persistence in distance education (Chyung, Winiecki, \& Fenner, 1998; Martinez, 2003).

\section{Conceptual Framework: Persistence Theories}

The conceptual framework used in this study is based Tinto's theory of student integration. Tinto's work was based on the work of Spady, which was derived from 
Durkheim's theory of suicide. "Basically, Tinto contended that the cumulative interaction over time of categories of variables that included backgrounds, initial commitment to college study, and interactions with peers and faculty contributed to both social integration and academic integration" (Summers, 2003, p.67). Tinto's framework has been widely used with slight variations (Ashar \& Skenes, 1993; Cabrera, Castaneda, Nora, \& Hengstler, 1992; Cabrera, Nora, Castaneda, 1993; Conway, 2009; Kember, 1989a; Mason, 1998; Napoli \& Wortman, 1998; Webb, 1989). Tinto believed social integration was a stronger predictor than academic integration; therefore, most Tinto studies have focused on social integration and were conducted solely at residential institutions.

\section{Tinto: Institutional Distinction and Academic and Social Integration}

In the late 70 's and early 80 's, studies using the Tinto framework began to focus on both residential and nonresidential institutions (Pascarella \& Chapman, 1983a, 1983b; Pascarella, Duby, \& Iverson, 1983; Pascarella, Duby, Miller, \& Rasher, 1981, Williams \& Creamer, 1988). When studies differentiated between institutional settings, academic integration and background variables have shown to have a greater impact on persistence than social integration in commuter and other nonresidential contexts (Pascarella \& Chapman, 1983a, 1983b; Pascarella, Duby, Miller, \& Rasher, 1981; Pascarella, Duby, \& Iverson, 1983; Williams \& Creamer, 1988) In 1982, Tinto said the following regarding his model, "it is not readily suited to the study of attrition at commuting institutions where forms of institutional communities are tenuous at best. The notions of academic and social integration is not as appropriate in these settings as in four-year residential institutions where those communities are essential elements of individuals' educational 
experiences" (p.693). Tinto (1988) said, "in the particular case of nonresidential two-year colleges, such transitions are rarely required; nor is full integration into the life of the institution required" (p.445). Also, Tinto (1998) said, "academic and social involvement, it seems, matter somewhat differently in different educational settings....the clearest differences seem to arise between two- and four-year institutions....academic and social integration are more important to persistence in the four-year institutions than in the twoyear ones" (p.169). Given this distinction, other researchers have studied persistence differentiating between traditional and nontraditional students.

\section{Bean and Metzner}

In 1985, Bean and Metzner published a definitive study regarding traditional and nontraditional students. Bean and Metzner (1985) classified nontraditional students as being 25 years of age and older, enrolled part-time and usually do not live on campus. They said, "while traditional students attend college for both social and academic reasons (Tinto, 1975), for nontraditional students, academic reasons are paramount" (Bean \& Metzner, 1985, p.489). In the Bean and Metzner model, they identified the "lack of social integration" for the nontraditional student. Thus, they introduced the variable of "noncollegiate environment" replacing social integration (p.490).

\section{Tinto and Community Colleges}

After Bean and Metzner's publication in 1985, other studies began to apply Tinto's model to community college institutions (Baird, 1991; Bers \& Smith, 1991; Borglum \& Kubala, 2000; Boughan, 1998; Goel, 2002; Grosset 1989, 1991; Halpin, 1990; Karp, Hughes, \& O'Gara, 2008; Mutter, 1992; Napoli \& Wortman, 1996, 1998;

Nippert, 2000-2001; Nora, 1987; Pascarella, Smart, \& Ethington, 1986; Sorey \& Duggan, 
2008; Strauss \& Volkwein, 2005; Townsend \& Wilson, 2006, 2008-2009; Voorhees, 1987; Webb, 1988, 1989). Many studies found that only academic integration affected student persistence at community colleges (Baird, 1991; Fox, 1986; Goel, 2002; Grosset, 1991; Haplin, 1990; Mulligan \& Hennessy, 1990; Mutter, 1992; Nippert, 2000-2001;

Nora, Attinasi, \& Matonak, 1990; Webb, 1988). Following a study at Seattle Community College, Tinto (1997) re-addressed academic and social integration in a community college context; he said, "a more accurate representation would have been academic and social systems appear as two nested spheres, where the academic occurs within the broader social system that pervades campus....social communities emerge out of academic activities" (p.619). This distinction was affirmed by other research (Karp, Hughes \& O'Gara, 2008; Strauss \& Volkwein, 2005; Townsend \& Wilson, 2006, 20082009)

\section{Criticism of Tinto}

First, Kember (1989a) noted that Tinto's model applied to students in face-to-face classroom settings and does not take into consideration the distance student. Distance education, commuter and the majority of community college students share the same trait of nonresidential life on the college campus. Secondly, Young (2002) argued, "while Tinto's work has gained acceptance and notoriety, it does not speak directly to the essence of the underprepared student's most basic concern: that he/she is not ready for college-level work" (p.7). Thirdly, Tierney (1992) criticized a number of points related to Tinto's idea that students need to leave one community and integrate into another. 


\section{Kember}

Kember (1989a) noted the model developed by Tinto and Spady as "the best starting point" (p.284). The foundation of Tinto's model, rooted in Durkheim (1961), was that students dropout when they are not integrated into the "college collective". However, in a distance model, students are not required to integrate into a new college collective because they do not change geographical locations for the purpose of education. Kember said, "collective affiliation is also established through the interactions associated with academic support for the course" (Kember, 1989a, p.293). Likewise, Kember (1989b) distinctly noted, the "collective affiliation side of academic integration is the quality and quantity of contact between the students and the organisation. The personal contact of tutorials seems to be particularly effective at providing collective affirmation" (p.204). Kember (1989b) said "the component [social integration] cannot be directly transported into the distance education context" (p.207). In the distance education context, some of the factors, which Tinto defined as social integration, Kember defined as academic integration.

First, Kember's model begins with the student's characteristics, including individual, family and home, work and educational background (1989a, 1995). Secondly, these characteristics impact goal commitment, which is divided into two components: intrinsic and extrinsic motivation. Thirdly, Kember maintained an integration component for academic as well as social and work environment, which also impacts academic integration and social and work integration. Lastly, based on these components the student makes an ongoing decision based on the costs and benefits of staying or dropping out of the higher education with a recycling loop (Kember, 1989a, 1989b). 
Kember's model has been tested in different institutions (Kember, Lai, Murphy, Siaw, \& Yuen, 1992, 1994; Kember, Murphy, Siaw, \& Yuen, 1991; Roberts, Boyton, Buete, \& Dawson, 1991). Also, Kember and others developed "The Distance Education Students' Progress (DESP) inventory" (Kember, Lai, Murphy, \& Yuen, 1992; Kember, Murphy, Siaw, \& Yuen, 1991). Kember (1995) noted, "factor analysis of the data collected with the DESP inventory produced factors which split social and academic integration variables into positive and negative factors." Kember (1995) said, "entry characteristics direct them [students] toward one of two tracks. Those with favorable situations tend to proceed on the positive track and are able to integrate socially and academically. Others take the lower, negative track where they have greater difficulties achieving social and academic integration" (p.64). In 1995, Kember changed his original model into a "two-track model" (p.64).

\section{Kember: 1989 and 1995 Models Compared}

Kember's 1989 and 1995 models have some similarities and differences. First, extrinsic and intrinsic motivation, which were a component to themselves in the 1989 model are now within other components in 1995 model. Extrinsic motivation is now a subcomponent of academic incompatibility and intrinsic motivation is a subcomponent of academic integration. Secondly, in the 1989 model, academic environment, academic integration, social and work environment and social and work integration components are now replaced with the social integration, external attribution, academic integration and academic incompatibility in the 1995 model (Kember, 1995). Thirdly, GPA is considered as an individual component before the cost/benefit analysis in the 1995 model. Kember (1995) said, "the original intention was to treat GPA purely as an outcome variable. 
However, the quantitative analysis suggested that GPA functioned to some extent as an intervening variable between academic incompatibility and drop-out" (p.128).

\section{Proposed Collective Affiliation Model}

\section{Theory.}

The Collective Affiliation model was designed to specifically address student dropout in nonresidential contexts such as community colleges and distance education settings. The decisions for this model were based on previous theoretical persistence research (Bean \& Metzner, 1985, 1987; Kember, 1989a, 1995; Spady, 1970, 1971; Tinto, $1975,1982,1988,1.997,1998)$ and an extensive literature review. The Collective Affiliation model does not attempt to understand the individual nor the individual's decision to persist outside of social structures (e.g. family and work), but identifies a college student's decisions as a consideration of collectively affiliating with all these groups and an academic affiliation.

In 1975, Tinto summarized Durkheim (1961) by saying, "suicide is more likely to occur when individuals are insufficiently integrated into the fabric of society. Specifically, the likelihood of suicide in society increases when two types of integration are lacking-namely, insufficient moral (value) integration and insufficient collective affiliation" (p.91). Tinto expected a student to "disassociate themselves, in varying degrees, from membership in the past communities... and perhaps reject those past communities" (Tinto, 1988, p.443). Thus, the student must integrate into the college community and be isolated from former relationships, cultures, etc. (Tierney, 1992). The Collective Affiliation model proposes that Durkheim's theory of suicide is applicable to college student attrition because it focuses on insufficient moral integration and 
insufficient collective affiliation. However, rather than expect a student to find a new self-identification with the college community, due to residential relocation, the student would incorporate the academic affiliation within their pre-college understanding of selfidentify, which is formed from various spheres of influence such as family, work and social environments. Collective affiliation was defined by Kember (1995) as "a student's sense of belonging in a course or to an institution" (p.257). In this model, collective affiliation is the "sense of belonging" that an individual has with any external entity and in the academic context promotes persistence.

\section{Application.}

The Collective Affiliation model recognizes that positive and negative influences will correspond to the persistence decision and differentiates between stagnate and dynamic characteristics, which is necessary because of the recycling loop. The most dramatic change to the model, based on previous research, is the pictorial description of the model. Bean and Metzner (1985) and Kember (1989a, 1995) described the "social" component as focused on two spheres of the individual's life: family and work. Also, Tinto (1997) said, "our current two-dimensional graphic representation of interaction, which depicts social and academic systems of colleges as two separate boxes, masks the fuller relationships between these two spheres of activity. Tinto (1997) also said, "a more accurate representation would have been academic and social systems appear as two nested spheres, where the academic occurs within the broader social system that pervades campus....social communities emerge out of academic activities" (p.619). Also, as noted by Stage (1989), as a student is more academically integrated the student becomes more socially integrated. Therefore, this relationship is not parallel and separate, but 
overlapping and embedded, thus, rather than portraying the model in boxes connected by solid and dotted lines, the model is best depicted as overlapping circles. With the exception of stagnate characteristics, these circles are dynamic, flexible and exert various levels of influence on the decision making process at various time in the process. At different times, different variables may become dominate and be the greatest influence on the persistence decision.

Lastly, the other significant change is this model is not a linear process. Rather, the process is a cost/benefit analysis in which all the factors are weighted. As previously noted, at different times, each factor can hold a different and greater or lesser weight than before. In this case, it is similar to Tinto's idea of rites of passage. However, the difference is that the rites of passage are not limited to college experiences. These experiences are throughout life: marriage, having children, changing jobs, death of a parent, etc. Also, the student is not continually choosing to go to school; rather, the student is choosing whether to integrate the academic sphere of influence into the person's life. This is a small, but very important distinction. Rather than seeing the process as the college attempting to integrate the student into the life of the college, the person is making the decision whether or not to integrate the college into his or her life and collectively affiliate with the college, developing self-identity as a student. Therefore, the decision making process is essentially a decision of collective affiliation on behalf of the individual, not outside the identity of the person's family, work and social communities. If the person decides to withdrawal from school, nothing changes except the person simply loses the academic sphere within the collective affiliation. 


\section{Community Colleges, Developmental Education and Online Persistence Studies}

Even after Bean and Metzner's (1985) definitive work, retention and persistence research is still mostly concerned with traditional age, residential and full-time status students. In 1991, Pascarella and Terezini's first volume of "How College Affects Students", the authors stated, "first, the evidence has bias. It focuses largely (although not exclusively) on nonminority students of traditional college age (18-22), attending fouryear institutions full-time and living on campus....It is clear, nonetheless, that the impacts of college on such 'nontraditional' students are underrepresented in the existing evidence" (p.13). This criterion limits research to four-year institutions and neglects the role of nontraditional, distance and community college students, which has led to a neglect of community college research in mainstream higher education journals (Bailey \& Alfonso, 2005; Townsend, Donaldson, \& Wilson, 2009). In addition, there is also a lack of research regarding community college and online student persistence (Muse, 2003; Liu, Gomez, Khan, \& Yen, 2007)

This study includes a review of persistence studies from the past 30 years (19802010). The review included studies from community colleges regardless of the delivery method. Also, distance education courses from any educational context were included because previous research showed that academic integration significantly impacted persistence in both settings whereas social integration did not. Twenty-one studies were reviewed in a distance education context. Forty-five studies were reviewed in a community college context. Sixty-six total studies were reviewed. 


\section{Variables}

The National Center for Education Statistics (NCES) identified seven risk factors affecting persistence: delayed postsecondary enrollment, students who were high school dropouts or GED recipients, students enrolled part-time, financially independent students, students with dependents other than spouse, single-parent students and those employed full-time (Horn \& Premo, 1995). This study takes six of these seven factors into consideration: age, secondary education, enrollment status, dependency status, dependents and marital status. Also, the following variables will be considered: (a) degree program, (b) adjusted gross income, (c) college grade point average, (d) sex, (e) father's education level, (f) mother's education level, $(\mathrm{g})$ course delivery method, (h) number of credit hours accumulated, (i) number in household, (j) number of household member in college, $(\mathrm{k})$ federal work-study and (1) waiver/third party payment. These variables have been used in other research studies and have been shown to be useful in predicting variance.

\section{Definition of Key Terms}

At-risk students: students with "academic, social, and economic conditions guarantee failure if there are no appropriate interventions" (Young, 2002, p.3).

Attrition: "anyone leaving a college at which [the student] is enrolled" (Spady, 1970, p. 665). Attrition is a corollary measure of persistence (Park, Boman, Dean Care, Edwards, \& Perry, 2008-2009).

Blended/hybrid course: course in which web-based technology facilitates $30 \%$ to $79 \%$ of the face-to-face content (Allen \& Seaman, 2007). 
Completion rate: "the proportion of students receiving a grade (i.e., not withdrawing from the course)" (McCabe, 2003, p.41).

Developmental education course: non-college level credit bearing course, which are to prepare the student for credit-bearing classes (Boylan \& Bonham, 2007; Lewis \& Farris, 1996; http://www.nade.net/aboutDevEd/definition.html).

Modularization: the process in which the content of a course is subdivided into smaller portions.

Nontraditional student: a student over the age of twenty-four, attends part-time and does not have residency. on the college campus (Bean \& Metzner, 1985).

Online course: course in which web-based technology facilitates more than $80 \%$ face-toface content and typically has no face-to-face meetings (Allen \& Seaman, 2007) Persistence: a measure that assess if a student who is enrolled in a term (e.g. fall) is enrolled, has transferred to another institution or achieved an educational objective (e.g. earned a degree or certificate) in the following term of enrollment (e.g. spring) (Crawford, 1999; E. Wright, personal communication, December 9, 2009; Rovai, 2003; Wild \& Ebbers, 2002).

Success rate: "the proportion of students who earned a grade that would allow them to progress to the next course or level" (McCabe, 2003, p.41). A student may receive a "failing" grade (e.g. E or F), which would be considered a positive regarding a completion rate, but this would be a negative for the success rate.

Traditional course: course delivery orally or written and includes no online technology (Allen \& Seaman, 2007). 
Underprepared students: "represent the academic subset of at-risk characteristics"

(Young, 2002, p.3).

Web facilitated course: course in which web-based technology facilitates $0 \%$ to $29 \%$ of the face-to-face content (e.g. syllabus, assignments, etc.) (Allen \& Seaman, 2007). 


\section{CHAPTER II}

\section{Introduction}

Anthony Bryk, president of the Carnegie Foundation for the Advancement of Teaching and Uri Treisman, senior partner with Carnegie and founder and executive director of the Charles A. Dana Center at the University of Texas at Austin (2010) describe in narrative the factual reality of the relationship that exists between many community college students and remedial math.

The story is a familiar one: A high-school dropout and single mother works the supermarket late shift. Motivated to earn a four-year degree so she can have a better life for herself and her 4-year-old daughter, she enrolls in a community college after earning a GED. Three years later, she still hasn't completed the sequence three remedial math courses required before she can take college-level math. Defeated, she says, 'I just couldn't do it anymore.' For this student and too many others, the dream stops here. (para. 1)

Every year from 1995 to 2009, students' average composite scores on mathematics have not reached the benchmark of 22 set by the American College Testing Program (ACT, 2009). This benchmark tests "the level of preparation needed for students to have at least a 50 percent chance of achieving a grade of $B$ or higher, or at least a 75 percent chance of a grade of $\mathrm{C}$ or higher in an entry-level, credit bearing college English Composition, Algebra, Social Science, and Biology courses" (ACT, 2009, p.3). From 2006 to 2009 more than 5.38 million students have taken the ACT exam. During these years, on average, between $21 \%$ and $23 \%$ have successfully reached the benchmark set in all of the three subject areas. For each of the three subject areas, the average number of 
students who achieved these benchmarks remained steady. Every year 67\%-69\% reached the mark in English, $53 \%$ in reading, but only $42 \%-43 \%$ reached the benchmark in math (ACT, 2006, 2007, 2008, 2009).

\section{Table 1}

Percentage of High School Students' ACT Scores Meeting Benchmark Standards

\begin{tabular}{|c|c|c|c|c|c|}
\hline Year & Students & All 3 Subjects & Math & Reading & English \\
\hline 2006 & 1.2 million & $21 \%$ & $42 \%$ & $53 \%$ & $69 \%$ \\
\hline 2007 & 1.3 million & $23 \%$ & $43 \%$ & $53 \%$ & $69 \%$ \\
\hline 2008 & 1.4 million & $22 \%$ & $43 \%$ & $53 \%$ & $68 \%$ \\
\hline 2009 & 1.48 million & $23 \%$ & $42 \%$ & $53 \%$ & $67 \%$ \\
\hline
\end{tabular}

These ACT reports are only representative of high school students who graduated high school and planned to attend college. This does not include students who did not plan to attend college and therefore did not take the ACT nor does it include students who took qualifying examinations other than the ACT. Also, some students only take local forms of a placement test, such as COMPASS. Merisotis and Phipps (2000) posited that an even a greater number of students need developmental course work than known. Some institutions, who do not report offering developmental education courses, are still offering developmental services to underprepared students (Phipps, 1998).

Developmental education provides access to college for nontraditional age students. In 1992-1993, 54\% of students taking a developmental class were between the ages of 18 and 22, while $46 \%$ were older than 22 (Ignash, 1997). In 1999, Roueche and Roueche (1999) said, "only about half of high school graduates go on to college and only about 25 percent of remedial education students are recent high school graduates" (p.13). 
Also, the need for developmental education will only grow for these nontraditional students. According to McCabe (2003), "eighty percent of Americans will need some postsecondary education for personal and professional purposes; the majority will enroll in community colleges with almost fifty percent having some basic skills deficiency" (p.17). In addition to unprepared high school graduates, the following groups of persons are representative of this nontraditional group often enrolled in developmental education courses: high schools dropouts, GED recipients, returning adults and new immigrants (Ignash, 1997; Jenkins \& Boswell, 2002; Roueche \& Roueche, 1999). Jenkins and Boswell (2002) reported approximately $60 \%$ of resident aliens who were first-time students at public two-year colleges in 1999-2000 took at least one developmental course. This phenomenon is not limited to the United States. Because of the Treaty of Bolonga, European nations (Brants \& Struyven, 2009; Hoyles, Newman, \& Noss, 2001; Rienties, Tempelaar, Dijkstra, Rehm, \& Gijselaers, 2008) and Japan (Mori, 2002) are now offering developmental education due to national secondary programs, international students and barriers for lifelong learners. In particular, this is affecting mathematics education (Hoyles, Newman, \& Noss, 2001).

\section{Developmental Education}

In $2005-2006$, over $95 \%$ of all community colleges had an open admissions policy (Provasnik \& Planty, 2008). Since the 1960s, community colleges have maintained a mission and commitment to all persons and a priority on open access (Cohen \& Brawer, 2003; McGrath \& Spear, 1987; Shults, 2000). Even though some other institutions of higher education have an open admissions policy, Roueche and Roueche (1999) posited the ideal that education is necessary for the maintenance of the democracy is unique to 
community colleges. Once a student has completed high school or obtained their GED, they are no longer eligible to return to a secondary arena of education to improve their academic skills. Therefore, when students are still underprepared for college level work, developmental programs are the point of access for many students. Even though some public and private institutions provide some form of developmental education, community colleges provide the majority of developmental education (Ignash, 1997; Kozeracki, 2002). Even so, some states and other large urban public college systems have or are considering policies that would regulate developmental education solely to the community college (Attewell, Lavin, Domina, \& Levey, 2006; Bettinger \& Long, 2005; Jenkins \& Boswell, 2002; Kozeracki, 2002; Merisotis \& Phipps, 2000; Phipps, 1998; Shaw, 1997). For community colleges, if developmental programs are not successful, the school has not succeeded in their own mission of open access.

There are a number of arguments against developmental education. Kozeracki (2002) noted the following issues: (a) drain on resources for other academic priorities (e.g. transfer), (b) cost of educational content that should have been learned in high school, (c) lowers motivation for college students, (d) results in higher attrition rates, and (e) lowers the standards and academic quality. Given these debates, colleges and legislators have been involved in making policy decisions regarding developmental education (Ignash, 1997; Kozeracki, 2002; Lewis \& Farris, 1996; Phipps, 1998; Shults, 2000). Of the fifty states, twenty-eight "clearly require" placement testing for students, but less than half, require mandatory placement (Dougherty \& Reid, 2007, p.15). Since some state policies require students to be tested and placed in developmental education courses, it heightens the importance for these courses to be effective and necessitates 
identifying factors that affect persistence, since students must succeed in these classes in order to meet their educational objective. Lewis and Farris (1996) reported $71 \%$ of public 2-year institutions were required to offer remedial education and that $53 \%$ of 2 -year public institutions have state policy or laws that govern the "limitation on the length of time a student may a take a remedial courses at the higher education institution" (p.31). For example, Colorado, Georgia, Massachusetts, Oklahoma, South Carolina and Texas all have mandated timeframes in which developmental courses must be completed; most range between 24 and 30 credit hours (Shults, 2000). While 53\% of 2-year public schools are affected, only $6 \%$ of public 4 -year and $1 \%$ of 4 -year private report any governing state policy or law; they are governed by institutional policy (Lewis \& Farris, 1996). California, Florida, Illinois, Louisiana, Tennessee, Virginia and Washington all have regulations regarding the number of times a student can repeat a course or at least pay for the course (Shults, 2000). The state of Florida passed a bill that limits the developmental student to two attempts per developmental course. If the student takes the course a second time, the student is required to pay the full cost of instruction for the course, which is four times greater than regular tuition (Ignash, 1997). "Critics argue that remedial education costs taxpayers twice, teaching academic skills in college that should have been acquired in high school" (Saxon \& Boylan, 2001, p.2). Some policy makers have suggested outsourcing remedial education to private companies, which is in effort to defer the cost solely upon the student (Kozeracki, 2002; Phipps, 1998). These policy decisions indicate the importance of developmental education and open access. If policies limit student's access to financial resources or the amount of time they are given to successfully 
complete developmental education, then these decisions directly affect open access and opportunity for underprepared students.

From 1988 to 2006 , between $40 \%$ and $60 \%$ of all first-time community college students are referred to and enrolled in at least one developmental education course; some colleges reported as high as $80 \%$ (Attewell, Lavin, Domina, \& Levey, 2006; Bailey, 2009; Bers \& Smith, 1991; Bettinger \& Long, 2005; Boughan \& Clagett, 1995; Brawer, 1996; Clergy, 2006b, 2008d; Collins, 2009; Colorado Commission on Higher Education, 2009; Fujita \& Oromaner, 1992; Horn, Peter, \& Rooney, 2002; Kielbaso, Dirkx, Min, \& Allen, 1998; Lewis \& Farris, 1996; Maryland Higher Education Commission, 1996; McCabe, 2000; Parsad \& Lewis, 2003; Perry, Bahr, Rosin, \& Woodward, 2010; Shults, 2000). This accounts for around twice the number of community college students enroll in developmental education compared to four-year public universities (Attewell, Lavin, Domina, \& Levey, 2006; Levin \& Calcagno, 2008).

Attrition rates are higher at community colleges than four-year private and public universities (Mann \& Walker, 1981; Marti, 2008; Stratton, O’Toole \& Wetzel, 2007; Tinto, 1975). In 1968, John Roueche's first study of remedial education at community colleges found "terrible rates of success"..."that's still the case today" (Jaschik, 2009, para. 5). According to McCabe (2000), nearly half of community college developmental education students successfully complete their developmental education program. Studies in Texas and Florida show that $25 \%$ to $50 \%$ of students taking developmental courses do not complete them. Only $15 \%$ of these non-persisting developmental students remain in college after two years with less than $1 \%$ having earned any type of certificate and none with degrees (Clergy, 2008b). 
With $40 \%$ to $60 \%$ or more of all community college students enrolling in at least one developmental education course, success in developmental education is paramount to retention, persistence and degree obtainment. Also, studies have shown students who tested into and completed developmental education courses compared to students who do not test into developmental education courses performed as well or better in academic college outcomes (e.g. class grades, graduation rates, etc.) (Bahr, 2008; Easterling, Patten, \& Krile, 1998; Grosset, 1989; Kolajo, 2004; Schoenecker, Bollman, \& Evans, 1996; Simmons, 1995).

\section{Developmental Math}

More students begin college less prepared in math than any other developmental area (ACT, 2006, 2007, 2008, 2009; Attewell, Lavin, Domina, \& Levey, 2006; Bettinger \& Long, 2005; Cartnal, 1999; Clergy, 2006a, 2006f; Colorado Commission on Higher Education, 2009; Horn \& Berger, 2004; Horn, Peter, \& Rooney, 2002; Kielbaso, Dirkx, Min, \& Allen, 1998; King \& Crouse, 1997; Lewin, 2008; Lewis \& Farris, 1996;

Maryland Higher Education Commission, 1996; McCabe, 2003; Parsad \& Lewis, 2003; Phipps, 1998; Provasnik \& Planty, 2008; Virginia Community Colleges Office of Institutional Research and Effectiveness, 2008; Washington State Board for Community and Technical Colleges, 2006, 2007, 2009). Persistence studies have shown only about half of all students enrolled in a developmental mathematics course successfully complete the course (Bailey, Jeong, \& Cho, 2009; Cuesta College, 1999; Curtis, 2002;

Fike \& Fike, 2007; Jaschik 2010a; Kangas, 1992a, 1992b, 1992c; Maricopa Community Colleges Institutional Effectiveness Office and Maricopa Governance, 2003; Rienties, Tempelaar, Waterval, Rehm, \& Gijselaers, 2006). In 1995, Parsad and Lewis (2003) 
noted $75 \%$ of institutions reported a mandatory placement for students in need of developmental math courses, but in 2000 that percentage had increased to $81 \%$. Clergy (2006a) found that after two years only $17 \%$ of students referred to developmental math met all of the qualifications to continue on to college-level math. Swager, Campbell and Orlowski (1995) found within a sample of 15,918 community college students who had withdrawn, mathematics was the class from which most students withdrew. Clagett (1996) noted, "students needing remediation in mathematics and at least one other area reading, English composition or both - were at greatest risk of not succeeding" (p.55). In O'Hear and MacDonald's (1995) review of 52 developmental education studies only three of the studies pertained to math. The only two subjects that had fewer studies were two studies pertaining to tutoring and two studies pertaining to multiple skills. Twenty studies pertained to reading and six pertained to writing.

Lesik (2007) found, even though there is a high rate of attrition for students in developmental education, "participating in the developmental mathematics course has a positive impact on student retention suggests to policy-makers that developmental education programs can be effective in helping to keep students enrolled in college" (p.605). Conway (2009) found, "given higher math scores in many transfer programs and the lower math preparation of native students on entry, there might be a connection between math ability, program choice and persistence" (p.335). Likewise, Fike and Fike (2008) found, "although we do not know the reasons for this finding [taking a developmental math course (pass or fail) compared to not taking a developmental math course], it highlights the importance of developmental mathematics and warrants further study" (p.81). Smith, O’Hear, Baden, Hayden, Gorham, Ahuja, and Jacobsen (1996) 
noted, "limited research has been completed to provide insight as to why some students succeed and others fail in this course [developmental math]" (p.33).

\section{Kentucky}

In 1991, Baird found that one characteristic of low retention in Kentucky's community colleges was having students who needed help in math. In 2002, Kentucky reported that $52 \%$ of students entering a two-year college would need remediation (Jenkins \& Boswell, 2002). In 2009, only $15 \%$ of Kentucky high school graduates, who took the ACT test, reached the benchmark in all four areas (e.g. math, English, science and reading). In particular only $26 \%$ reached this benchmark in mathematics (ACT, 2009). Seventy-four percent of the class of 2009 in Kentucky "indicated an interest in obtaining a bachelor's degree or higher" (ACT, 2009, p.5). Even though Kentucky has an increasing need for developmental education, research has shown that "students" educational plans do not decline with increasing remediation" (Deil-Amen \& Rosenbaum, 2002, p. 252). Thus, if students can be successful in developmental education, they will remain motivated to achieve their original educational plans.

In effort to meet the aforementioned challenges, the state of Kentucky formed the Kentucky Developmental Education Task Force to identify particular problems and evidence for change. Kentucky faces the same changes that other states in the United States face. "More than half of the first-time freshmen entering Kentucky's colleges are underprepared in at least one subject. Even worse, for those underprepared students, the first-year college drop-out rate is twice the rate of academically prepared freshman" (Kentucky Developmental Education Task Force, 2007, p.5). 
Before this report, the thresholds for mathematics, English and writing were each an ACT score of 18. The Kentucky Community and Technical College adopted the following policy regarding the new ACT minimums. "For students seeking any associate degree, a minimum score of 20 on the ACT in reading, 19 in mathematics, and 18 in English qualifies the student to enroll in an appropriate entry-level course in the discipline" ("KCTCS Administrative Policies and Procedures", 2009, p.4.13.1.1). Kentucky Community and Technical College officials estimate that between 17,400 and 20,000 new students will need remediation. This is a thirty to fifty percent increase over the preceding fall and would cost between $\$ 3$ and $\$ 4$ million in additional faculty salaries and benefits ("Kentucky Predicting Sharp Increase in Remedial Classes, Costs", 2009). This level of increase would create an institutional strain on the community and technical college system to provide the additional amount of developmental mathematics courses, particularly given that more KCTCS students take MT065 than any other single class. The taskforce also noted that "a significant percentage of students who enter Kentucky postsecondary institutions underprepared in mathematics never enroll in any mathematics course during their first year in college, which is a recipe for failure" (Kentucky Developmental Education Task Force, 2007, p.13).

The Kentucky Community and Technical College System responded by adding the following to their policies and procedures: "Students requiring developmental education will be placed in the appropriate course(s) during the first two terms of enrollment" ("KCTCS Administrative Policies and Procedures", 2009, p.4.13.1.1). This new legislation creates significant changes to the administration of developmental education. First, higher exam standards will require more students to enroll in 
developmental education. Secondly, students will be required to enroll in developmental education within their first two semesters and, thirdly, take the appropriate credit-bearing class immediately following the developmental class. These changes are in line with other state practices and policies (Collins, 2009; Illich, Hagan, \& McCallister, 2004; Johnson \& Kuennen, 2004; Rouche \& Rouche, 1999; Shults, 2000) as well as research to increase persistence (Campbell \& Blakey, 1996; Clergy, 2008b).

\section{Online Developmental Education}

In 1996, Lewis and Farris reported that $100 \%$ of two-year public colleges offered remedial courses during the day, $88 \%$ in the evening, $31 \%$ on the weekend, $86 \%$ in a summer session and 4\% in an "other" category. Lewis and Farris (1996) noted 3\% of all institutions offered remedial courses through distance education, such as television or cable. In 2003, Parsad and Lewis reported 13\% of institutions used distance education in providing developmental education classes. In the fall of $2000,25 \%$ of two-year institutions used technology in developmental classes compared to $8 \%$ of four-year public and $4 \%$ of private four-year (Parsad \& Farris, 2003). The primary mode of delivery for distance developmental courses is the internet using asynchronous computerbased instruction (Parsad \& Lewis, 2003). One of the recent trends in developmental education is offering more classes in modular forms of education rather than traditional 16 week courses (Biswas, 2007; Collins, 2009; Epper \& Baker, 2009; Kolowich, 2010c).

\section{Online Developmental Math}

The internet (Epper \& Baker, 2009; Hoyles, Newman, \& Noss, 2001; Jaggers, 2011; Peschke, 2009; Rienties, Tempelaar, Waterval, Rehm, \& Gijselaers, 2006; Phillips, 2011; Rienties, Tempelaar, Dijkstra, Rehm, \& Gijselaers, 2008; Tempelaar, Rienties, 
Rehm, Dijkstra, Arts, \& Blok, 2006) and other technologies (Gonzalez, 2010; Jacobson, 2005, 2006; Khalili \& Shashaani, 1994; King \& Crouse, 1997; Kolowich, 2011) are being used to assist students in developmental math. Not only are online, self-paced classes being used for college students, but they are also being used for math teachers (Carey, Kleiman, Russell, Venable, \& Louie, 2008; Russell, Kleiman, Carey, \& Douglas, 2009). In 2000 , Shults reported that $45 \%$ of institutions offered self-paced developmental courses. In both traditional and online delivery methods, new technology is being used to allow the student to work self-paced in developmental math classes ("Community College Learning”, 2008; Epper \& Baker, 2009; Rienties, Tempelaar, Waterval, Rehm, \& Gijselaers, 2006; Spence, 2007). "Many experts in the world of mathematics and beyond contend that we cannot meet our developmental math student success goals without incorporating technology" (Epper \& Baker, 2009, p.3). New technologies in an online context have also been used for the purpose of closing "the retention gap" (Kolowich, 2010b). Likewise, Brants and Struyven (2009) noted, "the key components of successful remedial education are linked with the success factors of online education" (Online remedial education section, para. 1). Even though technology can assist developmental students, there is still resistance to use it. Phipps (1998) reported, "mathematics professors at a growing four-year university were reluctant to consider purchasing highly effective computer software for remedial mathematics courses because to do so would be an admission that their students actually need remediation" (p.5). Studies have assessed various aspects of online developmental math, such as self-efficacy and achievement (Spence \& Usher, 2007), but few have addressed persistence. 


\section{Online Education}

Since written correspondence, audio and video tapes, film, radio, televisions and satellite transmissions have been for educational purposes (Curran, 2001; Kerka, 1996, Phipps \& Merisotis, 1999). Now, computers, the internet and the World Wide Web function as a popular means of communication (Kerka, 1996) and distance education (Horn, Peter, \& Rooney, 2002; Waits \& Lewis, 2003). The computer has become widely vital for work and personal purposes in the United States and Europe, which have greatly affected global education (Curran, 2001). For example, the recent economic downturn has resulted in more than half of institutions reporting an increased demand for online education. Distance education plays an important role in the mission of community colleges because it can provide access for disadvantaged students, even though socioeconomic status continues to play an important part in this opportunity (Curran, 2001). Thompson (1998) reported that the typical online student is older than the typical undergraduate student, female (in the United States, Canada, New Zealand and Israel), married and works. Also, students who take online courses geographically do not live in an area that is convenient for them to take on campus courses and is more appealing to lower socioeconomic groups (Thompson, 1998). Parsad and Lewis (2008) noted additional factors that affected distance education decisions (a) student demand for flexible schedules, (b) access to students who would otherwise have no access, (c) make more courses available, (d) and increase enrollment.

In 2000-2001, " $56 \%$ of all 2-year and 4-year Title IV-eligible, degree-granting institutions offered distance education courses...representing an estimated 2,320 institutions" (Waits \& Lewis, 2003). In 2000-2001, 90\% of public two-year institutions 
offered distance education courses and comprised $48 \%$ of the more than three million enrollments (Waits \& Lewis, 2003). Also, two and four-year institutions reported offering an estimated 127,400 different courses with 2,810 college-level degree programs to be completed completely online (Waits \& Lewis, 2003). In 2006-2007, “66\% of 2-year and 4-year Title IV degree-granting postsecondary institutions reported offering online, hybrid/blended online, or other distance education courses....an estimated 12.2 million enrollments" (Parsad \& Lewis, 2008, p.3-4). In 2006-2007, 97\% of public two-year institutions offered distance education courses and 50\% offered noncredit distance education courses (Parsad \& Lewis, 2008). In 2006-2007, 32\% of all 2-year and 4-year institutions reported offering complete degree and/or certificate programs through distance education, which amounted to 11,200 college-level programs (Parsad \& Lewis, 2008). This accounted for more than 4.8 million enrollments in 1,020 two-year institutions (Parsad \& Lewis, 2008, p.8). Gleason (2004) reported online programs represent a $\$ 2$ billion dollar industry.

"Two-year associate's institutions have the highest growth rates and account for over one-half of all online enrollments for the last five years" (Allen \& Seaman, 2007, pg. 1). In the fall of 2008, 4.6 million students took at least one online course, which was more than $25 \%$ of all students in higher education (Allen \& Seaman, 2010). From 2003 to 2008 , the annual growth rate for online enrollment has increased $23 \%, 18.2 \%, 36.5 \%$, $9.7 \%, 12.9 \%$ and $16.9 \%$ respectively (Allen \& Seaman, 2010). In the same time period, 2003 to 2008 , the annual growth rate total of higher education total enrollment has increased $1.8 \%, 2.1 \%, 1.2 \%, 1.6 \%, 1.2 \%$ and $1.2 \%$ (Allen \& Seaman, 2010 ). In the fall of $2002,9.6 \%$ of all higher education enrollments were through online education. In the 
fall $2008,25.3 \%$ of all higher education enrollments were through online education for a total of more than 18 million students (Allen \& Seaman, 2010). Students in 2-year public institutions are $10 \%$ more likely to take a distance education course than students in public or private 4-year institution (Horn, Peter, \& Rooney, 2002). In the fall of 2009, $73.6 \%$ of public institutions, more than 20 percentage points higher than private for-profit and private nonprofit, reported online education as critical to the long-term strategy of their institution. Likewise, Doctoral/Research (69.7\%) and Associate's (65.7\%) were the two highest groups that reported online education as critical to the long-term strategy of their institution (Allen \& Seaman, 2010). Also, the larger the institution's student body, the more likely the institution reported online education as critical to the long-term strategy (Allen \& Seaman, 2010). The growth in online enrollment in higher education is greatest for nontraditional students at community colleges and that demand for the availability of online courses is expected to continue to grow (Allen \& Seaman, 2007). Many of the phenomena which occur in a traditional course also occur in an online environment. Attrition is a challenge for online education (Carr, 2000; Diaz, 2002; Flood, 2002; Frankola, 2001; Martinez, 2003; Moody, 2004; Parker, 2003; Patterson \& McFadden, 2009; Phipps \& Merisotis, 1999; Royer, 2006; Shin \& Kim, 1999; TylerSmith, 2006; Valasek, 2001; Zavarella \& Ignash, 2009). However, some studies and programs have shown high rates of online persistence (Meyer, Bruwelheide, \& Poulin, 2009) including at a community college (Royer, 2006). Phipps and Merisotis (1999) identify high rates of dropout and lack of conceptual framework as two major gaps in research. Likewise, Moody (2004) noted, "only a minimal amount of that [attrition rate] 
research has been directed toward gaining insight in to attrition rates in distance education" (p.206).

However, even though most researchers report that attrition rates are higher for online compared to traditional classes, these comparisons are most often made between online and traditional classes at the same institutions (Carr, 2000). For example, Carr (2000) noted in 1998 that the University of Central Florida reported a $9 \%$ withdrawal rate from web-based courses and 5\% withdrawal rate from traditional courses. Tyler Junior College, one of Texas' largest community colleges, reported a 58\% course completion rate for online classes and $71 \%$ for traditional classes. Thus, in various institutional settings, the attrition rates for online courses are higher than the traditional course, but the differences in withdrawal and attrition percentages demonstrate that the delivery method itself does not innately account for the variance in the percentage of students who withdrawal. Also, Allen and Seaman (2010) note that online courses are available to students who may not otherwise be able to attend traditional classes; the nature of the student as opposed to the nature of the class adds to the likelihood of dropout. When asked if "retaining students is a greater problem for online courses than it is for face-toface?" both the majority institutions who offer and do not offer online education responded: "neutral" (Allen \& Seaman, 2010). Also, as research has shown in traditional classes, the first semester (or courses) and year are most important for students in traditional classroom settings (Chyung, Winiecki, \& Fenner, 1998; Martinez, 2003).

Diaz (2002) asks, "should we consider a drop necessarily as a sign of academic failure?" Diaz's question is in the context of arguing that online education is not inferior to traditional education given the higher rates of dropouts. This study does not infer that 
any one course delivery method is superior to another, but does argue that students who do not complete courses are unable to achieve educational objectives.

\section{Conceptual Framework: Retention Theories}

Forty years later, Spady's (1970) statement may be more true now than ever when he said, "no one theoretical model can hope to account for most (let alone all) of the variance in dropout rates either within or across institutions" (p.64). However, Tinto (1982) also noted, "recognizing theoretical limits should not, however, constrain it from seeking to improve our existing models or replace them with better ones" (p.689). These studies acknowledge some variables which have been shown to be important in other distance education persistence studies, but are not included in this study. However, the conceptual framework of this study is built upon sociological rather than psychology concepts. For example, locus of control has shown to be an important variable in many studies (Parker, 1995, 2003). Likewise, situational, institutional, dispositional and epistemological variables (Garland, 1993; Morgan \& Tam, 1999) have proven valuable as well.

\section{Beginnings of Sociological Integration and Student Dropout: Spady (1970/71)}

After completing his doctorate degree from the University of Chicago in 1967,

William G. Spady (1970) wrote "Dropouts from Higher Education: An Interdisciplinary Review and Synthesis" in which he noted that "at least six reviews of the literature on college dropouts have been published within the last decade" (p.64). Spady continued on to say, "the task before us, then, is to move beyond a mere summary of available studies of 'college success' toward a more interdisciplinary-based, theoretical synthesis of the most methodologically satisfactory findings and conceptually fruitful approaches to this 
problem" (p.64). Thus, Spady applied the work of Durkheim (1951) to development one of the earliest conceptual models of college student attrition (Spady, 1970; Summers, 2003). Spady (1970) said

Our basic starting point is the assumption that the dropout process is best explained by an interdisciplinary approach involving an interaction between the individual student and his particular college environment in which his attributes (i.e., dispositions, interest, attitudes and skills) are exposed to influences, expectations, and demands from a variety of sources (including courses, faculty members, administrators and peers) (p. 77).

The connection between Durkheim's findings that an increase in suicidal tendency was linked to persons not being socially integrated into their surroundings influenced the idea of increased likelihood of students dropping out of school because they did not share similar orientations and values (Summers, 2003). Spady's model consisted of five independent variables, four of which (grade performance, intellectual development, normative congruence, and friendship support) influenced the fifth variable (social integration). These five variables were indirectly linked to dropout through two intervening variables: satisfaction and institutional commitment (Spady, 1970; Summers, 2003). This model was applied to first-year undergraduate students at the University of Chicago in 1965 for a longitudinal study (Spady, 1971). Even though Spady included academic variables, such as grade performance and intellectual development, the model focused heavily on social integration; "the focus of the study concerned the effect of the social integration and related sociological influences on college attrition" (Spady, 1971, p.40). (See Appendix B illustration \# 1)

This study caused Spady to revise his model (1971) to incorporate two more elements. "The first was the inclusion of a separate component comprised of structural relations and friendship support. The second improvement was revision of the 
relationships among the components in the model" (Summers, 2003, p.67). (See Appendix B illustration \# 2)

\section{Sociological Integration and Student Dropout Popularized: Tinto (1975)}

After Vincent Tinto completed his doctorate degree at the University of Chicago in 1971, John Cullen and he (1973) published an extensive report entitled "Dropout in Higher Education: A Review of Theoretical Synthesis of Recent Research." Two years later, Tinto (1975) published "Dropout from Higher Education: A Theoretical Synthesis of Recent Research", which builds upon the previous publication. Tinto, like Spady, acknowledged that "most studies of dropout have been limited to descriptive statements" (Tinto, 1975, p.90). Tinto set forth a conceptual framework to better understand dropout rooted in Durkheim's theory of suicide and "takes, from the field of economics of education, notions concerning the cost-benefit analysis of individual decisions regarding investment in alternative educational activities" (Tinto, 1975, p.91). Tinto's theory posited that a student stayed in college to the degree to which the student felt academically and socially integrated into the life of the college. "Basically, Tinto contended that the cumulative interaction over time of categories of variables that included backgrounds, initial commitment to college study, and interactions with peers and faculty contributed to both social integration and academic integration" (Summers, 2003, p.67).

Also, since Tinto's framework was introduced, the basic model has been widely used with slight alterations in various contexts and environments (Ashar \& Skenes, 1993; Cabrera, Castaneda, Nora, \& Hengstler, 1992; Cabrera, Nora, Castaneda, 1993; Conway, 2009; Kember, 1989a; Mason, 1998; Napoli \& Wortman, 1998; Webb, 1989). Tinto has 
published numerous articles and research studies regarding this dropout model including two editions of the book, "Leaving College: Rethinking the Causes and Cures of Student Attrition" $(1987,1993)$. Most Tinto studies have focused on social as opposed to the academic integration because Tinto believed social integration was a stronger predictor than academic integration. Therefore, most Tinto studies were conducted solely at residential institutions.

Tinto (1988) also noted that reasons for students' departure varied depending upon the stage (e.g. first six weeks, first year, second year, etc.) in which the student was enrolled. Tinto, building on the work of Van Gennep (1960), said, "the first stage of the college career, separation, requires students to disassociate themselves, in varying degrees, from membership in the past communities, most typically those associated with the local high school and place of residence" (Tinto, 1988, p.443). This statement makes two assumptions. First, it assumes that the student has recently graduated from high school, which is limited to traditional students. Second, the statement notes a geographical location change, which assumes a change of residency for the purpose of education. This does not apply to commuter or distance education students.

Tinto (1988) did acknowledge this reality and notes that nonresidential students may not "reap the full social and intellectual rewards" (p.443). Tinto's use of the word "rewards" referred to a publication by Pascarella (1985). Pascarella explored intellectual and interpersonal self-concept between on-campus living and commuting college students. Pascarella (1985) stated, "Generally, students living on campus were significantly more likely than commuters to (a) be less religious; (b) have higher level of liberalism, interpersonal self-esteem, and artistic interest; (c) be more satisfied with 
college; (d) have higher degree of aspiration; and (e) persist in college" (p.292). However, this particular Pascarella study did not find this to be true. Pascarella (1985) found, "living on campus (versus commuting to college) had no significant, direct effects on any of the four outcome measures. Rather, its influence was at best small and indirect, and mediated through levels of involvement with faculty and peers" (p.292-293). Pascarella (1985) also noted that living on campus had a direct effect on two variables: social integration and social interaction with faculty, but residential status was not significantly associated with academic integration, which had a direct effect on intellectual and academic self-concept. Pascarella (1985) noted significant limitations to the study: "(1) the sample included only nonminority students....(2) the study assessed influences in student self-concept or self-image after 2 years of college....(3) precollege assessments of both self-concept measures for control purposes would have been preferable...(4) the correlational nature of the data and because the integration and selfconcept measures were collected concurrently" (p.299).

Tinto (1988) said, "in the particular case of nonresidential two-year colleges, such transitions are rarely required; nor is full integration into the life of the institution required" (p.445). Tinto used the word "transition" to refer to "the second stage of the college career... a period of passage between the old and the new, between associations of the past and hoped for associations with communities of the present" (p.444). Within this section of his work entitled "Stages of Student Departure: Reflections on the Longitudinal Character of Student Leaving", Tinto (1988) focused heavily on "the norm and patterns of behavior appropriate to integration in the new communities of the college. They have not yet established the personal bonds which underline community 
membership" (p.444). These "norms and patterns of behavior" and "personal bonds" are examples of social integration. (See Appendix B, illustration \# 3)

\section{Institutional Contexts: Academic Compared to Social Integration}

Tinto's model has been widely validated in a university setting (Munro, 1981; Pascarella \& Terenzini, 1980; Pascarella \& Chapman, 1983a, 1983b; Stoecker, Pascarella, \& Wolfle, 1988; Terenzini, Lorang, \& Pascarella, 1981; Terenzini \& Pascarella, 1977, 1978). In the late 70's and early 80's, studies began to focus on both residential and nonresidential institutions (Pascarella \& Chapman, 1983a, 1983b; Pascarella, Duby, \& Iverson, 1983; Pascarella, Duby, Miller, \& Rasher, 1981, Williams \& Creamer, 1988). These studies revealed academic integration and social integration do not have an equal impact on persistence/withdrawal behavior among community college and commuter students. When studies differentiated between institutional settings, academic integration and background variables showed a greater impact on persistence than social integration in commuter and other nonresidential contexts. Pascarella, Duby, Miller and Rasher (1981) found, "for the urban nonresidential institution, academic performance is a particularly salient dimension of institutional integration" (p. 346). Pascarella and Chapman (1983a) stated, "social integration played a stronger role in influencing persistence at 4-year, primarily residential institutions, while academic integration was more important at 2- and 4-year, primarily commuter institutions" (p.87). Pascarella, Duby and Iverson (1983) in a non-residential university setting found, "regardless of the type of post-secondary institution attended, it seems evident that persistence is predicted to a significant extent on the individuals' attaining sufficient levels of structural integration and normative integration in the institution's academic 
system" (p. 96). The authors went on to say, "the negative influence of social integration on persistence is inconsistent with the model and with previous research at residential institutions" (p. 96). Pascarella and Chapman (1983b) found that students in residential universities and liberal arts colleges "had significantly more nonclassroom interaction with faculty members", but "persisters in the two-year commuter sample had significantly less informal contact with both faculty and peers than did the voluntary withdrawals" (p.42). Williams and Creamer (1988), attempted to replicate Munro (1981) and found, "only academic integration directly affected persistence for 2-year student" (p.216). In 1982, Tinto said the following regarding his model, "it is not readily suited to the study of attrition at commuting institutions where forms of institutional communities are tenuous at best. The notions of academic and social integration are not as appropriate in these settings as in four-year residential institutions where those communities are essential elements of individuals' educational experiences" (p.693).

In 1998, Tinto noted the importance of academic integration at two-year colleges. Tinto (1998) said, "academic and social involvement, it seems, matter somewhat differently in different educational settings....the clearest differences seem to arise between two- and four-year institutions....academic and social integration are more important to persistence in the four-year institutions than in the two-year ones" (p.169). Tinto (1998) noted that because of the limited amount of time that commuter students spend on campus, peer and faculty interactions in classroom and laboratories - "academic involvements" - are more important than social involvement in residential areas (p.169). This is not to say that social "interaction", in some form, is not important (Boston, Diaz, 
Gibson, Ice, Richardson, \& Swan, 2009), but that social "integration" is not as important as academic integration.

\section{Nontraditional Students and Student Dropout: Bean \& Metzner (1985/87)}

After these institutional distinctions were made, in the early 80's, Bean and Metzner published a definitive study regarding traditional and nontraditional students. Bean and Metzner (1985) conducted an extensive literature review noting significant differences between what they defined as traditional and nontraditional students. Bean and Metzner (1985) classified nontraditional students as being 25 years of age and older, enrolled part-time and usually does not live on campus. They said, "while traditional students attend college for both social and academic reasons (Tinto, 1975), for nontraditional students, academic reasons are paramount" (Bean \& Metzner, 1985, p.489). Bean and Metzner identified the "lack of social integration" for the nontraditional student (p.489). Therefore, they introduced the variable of "noncollegiate environment" replacing social integration (p.490).

Bean and Metzner's model posits that a student's dropout decision is primarily based on four sets of variables: (a) academic performance as measured by grade point average; (b) intent to leave, which is influenced primarily by psychological outcomes and academic variables; (c) background and defining variables, primarily high school performance and educational goals; and (d) environmental variables, which are expected to have substantial direct effect on dropout decisions (Summers, 2003, p.68).

The first interaction that this model creates is between "academic variables" and “environmental variables." Bean and Metzner (1985) placed a greater weight on environmental variables than academic variables. They suggested if a nontraditional student's environmental variables are good, but academic variables are poor, then the student would persist. However, if the nontraditional student's situation was reversed, 
environmental variable are poor, but academic variables are good, then the student would not persist. Also, background variables were included in the model, "because past behavior is expected to predict future behavior" (Bean \& Metzner, 1985, p.492). Secondly, this model creates interaction between "academic outcomes" and "psychological outcomes." Similar to the first interaction, Bean and Metzner believed that psychological outcomes were more important to nontraditional students than academic outcomes. Therefore, if the student had poor academic outcomes, but had a positive psychological outcome, then the student would stay in school. However, if the situation was reversed, with positive academic outcomes and low psychological outcomes the student would dropout (Summers, 2003). (See Appendix B, Illustration \# 4) Metzner and Bean (1987) validated their model noting that nontraditional student reasons for leaving were unrelated to social factors at the institution. Metzner and Bean (1987) found dropout for part-time commuter students was a function of academic performance and commitment to the institution. They went on to say, "if an institution retains an open admission policy, academic performance (GPA) might be improved if entering students were tested for deficient academic skills and content and offered more appropriate course placement or referral to remediation" (Metzner \& Bean, 1987, p.34). Metzner and Bean presented another model in 1987, which they said "differs only slightly" from the 1985 model (p.16). (See Appendix B, Illustration \# 5)

Bean and Metzner's work on the nontraditional student further highlights the important differences between models focused on residential, full-time, traditional aged student populations as compared to other models which take age, enrollment status and geographical location into consideration. Nontraditional students are more likely to be 
found at two-year colleges, but, as shown by Stahl and Pavel (1992), simply because nontraditional students are a larger portion of the student population at community colleges does not mean that Bean and Metzner's model (1987) is ideal for community colleges. Given their study, Stahl and Pavel (1992) developed "The Community College Retention Model" (p.28).

\section{Tinto's Model and Community Colleges}

After the aforementioned studies in the late 70's and early 80's and Bean and Metzner's publication in 1985 , other studies began to apply Tinto's model to community college institutions (Baird, 1991; Bers \& Smith, 1991; Borgulm \& Kubala, 2000; Boughan, 1998; Goel, 2002; Grosset 1989, 1991; Halpin, 1990; Karp, Hughes, \& O'Gara, 2008; Mutter, 1992; Napoli \& Wortman, 1996, 1998; Nippert, 2000-2001; Nora, 1987; Pascarella, Smart, \& Ethington, 1986; Sorey \& Duggan, 2008; Strauss \& Volkwein, 2005; Townsend \& Wilson, 2006, 2008-2009; Voorhees, 1987; Webb, 1988, 1989). In 1982, Tinto noted that his original model "is not very sensitive to forms of disengagement that occur within the two-year college sector (p.689). Fox (1986) found the greatest direct influence was academic integration, "within the range of developmental tasks that shape the transition from high school to college, academic adjustment must be considered paramount, especially for students who were not very successful academically in high school" (p.420). Likewise, Nora, Attinasi, Matonak (1990) found, "the direct, positive effect of academic integration on retention was consistent with the theoretical expectations based on the [Tinto] model....the negative influence of social integration on retention was inconsistent with the hypothesized model" (p.353). Mutter (1992) found similar results stating, "The [community college] 
students...reported less social than academic links to the college.....a pronounced relationship was found, however, between academic integration and persistence" (p.314). Haplin (1990) said, "the apparent greater influence of academic integration compared to social integration is particularly noteworthy....the Tinto model, particularly academic integration aspect, does predict persistence or exit outcomes (p.30). Webb (1988) found "adding the first semester academic performance data to this knowledge base substantially increases the chance of predicating that student's future accurately" (p.240). "Mulligan and Hennessy (1990)...found that social integration was not associated with persistence of two-year college students" (as cited in Bers \& Smith, 1991, p.541). Goel (2002) noted, "this study found some support for the greater role academic integration (GPA, hours attempted), placement tests, and student educational objectives play at twoyear colleges in the prediction of several measures of student outcomes and retention" (p.26). Nippert (2000-2001) found, "no significant relationship existed for social integration with persistence behavior of two-year college students....two-year colleges offer an environment in which students, with appropriate academic integration, can be successful" (p.37-38). The 2006 Community College Survey of Student Engagement showed that only $7 \%$ of part-time and $11 \%$ of full-time students responded as "often" or "very often" when asked "In your experience at this college during the current school year about how often have you done each of the following? Worked with instructors on activities other than coursework" (p.15)? This was the single lowest response and the only response that reflected an aspect of social integration. All other activities were academically integrative in nature, such as discussing grades or assignments, talked about career plans, and feedback on performance, which had the highest percentage. Baird 
(1991) noted a similar finding, "the causes of attrition in community colleges are probably not strongly related to social and campus activities, i.e. "social integration," because the level of contrast in participation is relatively low. In contrast, the more academic aspects may be more important in community colleges" (p.17). Grosset (1991) found, "the two most important variables in this discriminate function were academic integration variables related to the quality of out-of-classroom integrations with faculty and the amount of cognitive progress the students felt they made during the semester" (p.172). The importance of academic over social integration will be discussed in greater detail, later, regarding distance education.

Some studies found mix results regarding academic and social integration variables. Bers and Smith (1991) found that both academic and social integration affected community college persistence. However, Bers and Smith (1991) actually found, "students' educational objectives and intent to reenroll combined, and their precollege characteristics and employment status, provide more insights into persistence than either academic or social integration" (p.551-552). Sorey and Duggan (2008) found that academic integration affected traditional age community college students, but both academic and social integration affected nontraditional aged community college students. Sorey and Duggan (2008) borrowed their measure of "student's satisfaction with the formal and informal social systems of the college, including the quality of informal interactions a student had with faculty", which they classified as social integration, from Bers and Smith (1991), "who revised a scale used by Pascarella and Terenzini (1980)" (p.85). Sorey and Duggan (2008) noted they used "quality of informal interactions a student has with faculty" (p.85). Bers and Smith (1991) classified two sections of their 
survey as reflective of social integration. These two sections were titled "peer group interaction" and "faculty interest in students and teaching" (p.547-548). The section titled "faculty interest in students and teaching" included questions such as: "few of my courses have been intellectually stimulating this year", "few of the faculty members I have had contact with are generally outstanding or superior teachers", "few of the faculty members I have had contact with are willing to spend time outside of class to discuss issues of interest and importance to students" and "few of the faculty I have had contact with are generally interested in students" (p.547). These questions could also be classified as academic integration. For example, "few of my courses have been intellectually stimulating" would reflect more of the instructor's ability to integrate the student into the classroom and engage that course material rather than social aspects. Also, another question, "few of the faculty members I have had contact with are willing to spend time outside of the class to discuss issues of interest and importance to students" does not clarify whether or not "issues of interest and importance to the students" is of the social or academic nature. These issues may be based around the course materials, academic advising and/or career advice, which would all be more reflective of academic integration as opposed to social integration.

Karp, Hughes and O'Gara (2008) found that both academic and social integration affected persistence. Karp, Hughes and O'Gara (2008) found, "this sense of attachment [social integration] is related to their persistence in the second year of college. Second, we find that this integration is both academic and social...we find that these two forms of integration develop in concert for community college students. The same activities lead to both academic and social relatedness" (p.1). Likewise, Deil-Amen (2005) also found, 
"the nature of academic influence appears highly couples with social integration, which suggests that it may not be plausible to think of academic and social integration as distinct concepts when applied to two-year colleges students" (p.17).

These findings are contrary to those reported by Braxton and Lien (2000), who reported that "tests conducted in community colleges, however, offer modest support since two of the four tests made yielded statistically significant results" (p.18). However, Braxton and Lien only used four community college tests; two tests from Pascarella, Smart and Ethington, (1986) as well as one from Nora (1987) and Pascarella and Chapman (1983). Braxton and Lien used three times as many tests for four-year colleges and universities. This review included the four tests examined by Braxton and Lien and others to provide a broader understanding of research related to academic integration, which Braxton and Lien said, "little consensus exists among scholars on the meaning of academic integration" (p.13).

In Tinto's (1975) publication regarding a persistence model he summarized remarks from Spady (1971) by saying, "interaction with faculty not only increase social integration and therefore institutional commitment, but also increases the individual's academic integration" (p.109). However, Tinto (1997) re-addressed the issue of academic and social integration with regard to student-student and student-faculty contact made in the classroom at Seattle Central Community College. Tinto (1997) said, "a more accurate representation would have been academic and social systems appear as two nested spheres, where the academic occurs within the broader social system that pervades campus....social communities emerge out of academic activities" (p.619). Townsend and Wilson (2006, 2008-2009) confirmed this assertion in their study of community college 
transfer students. In 2006, Townsend and Wilson said, "the community college transfer students were accustomed to the classroom as a site for social as well as academic engagement" (p.450). In a subsequent follow-up study, Townsend and Wilson (20082009) said, "community college students become socially integrated through classroom or academically focused activities" (p.418). Karp, Hughes and O'Gara (2008) reported, "this [activities related to social and academic integration] is particularly true for information networks that students develop in the classroom" (p.1). Likewise, Strauss and Volkwein (2005) compared two and four-year institutions and found, "the social integration measure is an even stronger prediction of institutional commitment for students at four-year institutions than for students at two-year institutions....classroom experience may be a better predictor of institutional commitment at two-year institutions than at four-year institutions" (p.217-218). Strauss and Volkwein went on to say, "this finding is consistent with the Tinto argument (1997) that classroom experiences are the basis for forming a supportive community environment at a community college" (p.220).

In Napoli and Wortman's (1996) six study meta-analysis of the impact of academic and social integration on persistence of community college students, they found academic integration effected term-to-term and year-to-year measures of persistence, but social integration was only positively linked to term-to-term and less to year-to-year persistence. This was found in other community college studies (Bers \& Smith, 1991; Romano, 1995; Webb, 1988).

This review acknowledges that not all Tinto studies applied to commuter and community colleges found that academic integration had a greater impact than social integration. Some community college studies found both forms of integration to have 
equal effect (Pascarella, Smart, \& Ethington, 1986). Other studies found academic integration to have no direct effect on persistence (Ashar \& Skenes, 1993; Voorhees, 1987) or neither academic nor social integration had an effect on persistence (Borgulm \& Kubala, 2000; Nora, 1987). Napoli and Wortman's (1996) meta-analysis found varying results. However, the majority of these studies showed that academic integration is more important than social integration for non-residential community college students.

\section{Criticism of the Tinto Model}

Tinto's integration model has been criticized for a number of reasons. This study recognizes three important criticisms. First, Kember (1989a) noted that Tinto's model applies to students in face-to-face classroom settings and does not take into consideration the distance student. Therefore, there is a theoretical difference in the practical application of Tinto's original model, which was developed for residential students. This lack of face-to-face interaction affects components of the model, most importantly the components of social integration, which Tinto believed to be the most critical component. However, in the absence of this particular interaction, modifications must be made to the model.

Secondly, Young (2002) argued, "while Tinto's work has gained acceptance and notoriety, it does not speak directly to the essence of the underprepared student's most basic concern: that he/she is not ready for college-level work" (p.7). Young (2002) went on to say, "recognize that Tinto's model of college retention describes at-risk, not underprepared, students. Researchers should seek to provide a comparable model for underprepared students" (p.18). Thus, Young argued, based on Rouche and Rouche's (1993) definitions of at-risk and underprepared, that Tinto's model was too generic based 
on the fact that his model addressed at-risk students, which involves academic, social and economic conditions. Rather, an underprepared student is simply a subset of at-risk, which only refers to an academic situation. Young referenced Haplin's (1990) study, which found that only academic integration affected community college students. Likewise, underprepared students are the academic subset of at-risk, which excludes the "social" factor.

Thirdly, Tierney (1992) criticized a number of points related to Tinto's idea that students need to leave one community and integrate into another and the use of "ritual", which he said creates, "potentially harmful consequences for racial and ethnic minorities (p.603). Wolf-Wendel, Ward and Kinizie (2009) had the same criticism and said, "students who are not traditional in terms of race/ethnicity, age, and full-time enrollment status, the assumption is that in order to succeed in college (i.e. to persist) students must become integrated into the college environment by abandoning their history, heritage, and outside interests" (p.415). Tierney's (1992) criticism is well researched, similarly to Bean and Metzner (1985), to the extent new persistence models have been developed to include these cultural components (Griffrida, 2006). Likewise, other research (Nishimoto \& Hagedorn, 2003) has demonstrated how cultural identity cannot be grouped into categories, but recognized each particular ethnic group.

All of these criticisms of Tinto essentially revolve around the idea of traditional students and social integration as necessary for success, but not all student populations fit into this category. Therefore, his original model is not the best explanation for attrition regarding nontraditional students. 


\section{Distance Education and Student Dropout: Kember (1989)}

In 1981, David Kember first "attempted to identify which factors had an important bearing on attrition and which groups of students were most likely to drop out" (p.168). Kember (1981) found that age, number of children, housing conditions, sex, sponsorship and region of residence were most important in persistence. Likewise, this study takes into consideration: age, number of dependents, federal work-study, wavier/third party payments, adjusted gross income and sex. Kember's housing condition variable was specific to his educational situation in Papua New Guinea. The term "sponsorship" related to a student's employer paying for the class and fees, air fare and release time from work with full-pay (Kember, 1981). Region of residence was used as a variable because the different regions had different tutorial services. Kember (1981) said, "the model of Tinto is consistent with the findings in this study that retention rates and performances were better in areas where there were longer tutorials and larger attendances" (p.185). Kember noted that where more students had gathered there were fewer dropouts, thus, attributing some form of integration to the larger gatherings. Kember (1981) did not specify whether this integration would be classified as social or academic integration. Even though Kember's initial research did not utilize a conceptual framework, it did influence his later longitudinal model.

Before Kember published his Longitudinal-Process model of drop-out from distance education, other studies advocated for a distance education conceptual framework for attrition (Garrison, 1987; Woodley \& Parlett, 1983). Some studies specially advocated for (Thompson, 1984) or used Tinto's attrition model in a distance education context (Bernard \& Amundsen, 1989; Sweet, 1986; Taylor, et al., 1986). 
Likewise, some studies simply examined factors without a conceptual framework (Scales, 1984), while others attempted to understand the phenomenon in the context of general distance education theories unrelated to attrition (Eisenberg \& Dowsett, 1990; Roberts, 1984). A year before Kember published his model, Billings (1988), published "A Conceptual Model of Correspondence Course Completion", which was adapted from Bean's model. A year after, Kember published his model, Powell, Conway and Ross (1990) proposed "A Multivariate Framework for Analyzing Success and Persistence in Distance Education" which included predisposing characteristics, institutional factors and life changes through interaction effects all determined success/persistence.

\section{Distance Education and Tinto's Social and Academic Integration Model}

Kember (1989b) said, "a key characteristic of the [Tinto] model is the integrative effects of student-faculty and student-student contacts of an academic or social nature" (p. 203). The relationship, whether it be academic or social plays an important part in utilizing Kember's model. However other distance education persistence studies have not used this distinction. Sweet's (1986) study, which utilizes Tinto's model, found that social integration did impact nontraditional student persistence. However, "student ratings of their exchange with tutors were used as a measure of social integration. Specifically, students were asked to 'assess how helpful to their studies the tutor had been'" (Sweet, 1986, p.207). These phone conversations addressed the following topics: "course-related and organizational matters, career concerns, personal problems, and social (non-course related) exchange" (Sweet, 1986, p.207). This finding highlighted two issues. 
First, this assessment was the only factor used in determining social integration. Not only is this a very limited measurement of social integration, but social interaction with tutors could also be classified as either social or academic integration, because the tutor is addressing both academic and social matters.

Secondly, Sweet (1986) and Taylor, et al. (1986) used phone contact between students and the institution. Sweet (1986) noted that this measure (i.e. student faculty/institution contact through phone calls) of social integration paralleled the Pascarella and Terenzini (1979) study. Taylor and others argued, from Tinto's perspective, that "regular, rapid contacts" would increase persistence (p.71). However, Taylor et al.'s study noted the data needed to be interpreted "with some caution" (p.85). Students who dropped out earlier in the semester have a limited timeframe to accrue contacts with the institution. Therefore, the very nature of time that a student is enrolled may determine the number of contacts made with the institution. Thus, students who are enrolled longer will naturally have more contacts with the institution compared to those who withdraw at an earlier time (Taylor, et al, 1986). To further complicate matters, Taylor, et al. (1986) said, "it was evident from the data that a significant proportion of students managed to meet requirements without seeking additional contact with the institution" (p.87). Therefore, success was not dependent upon contact (i.e. as defined as social integration).

Conversely, other studies defined student-faculty contact as academic in nature. Wolfe (1993) said, "informal student-faculty contacts have also been positively associated with academic performance, intellectual and personal development of students, and hence with academic integration" (p.321). Wolfe noted studies by Spady 
(1971) and Terenzini and Pascarella (1978) to support this statement. First, in 1977, Terenzini and Pascarella used "interacting informally with faculty members outside of class for ten minutes or more" as a measure of social integration (p.28). They noted their rationale for doing so based on Tinto's (1975) model which included "faculty interactions" within the "social system" of his persistence model (p.95). However, one year later, Terenzini and Pascarella (1978) published an article entitled, "The Relation of Students' Precollege Characteristics and Freshman Year Experience to Voluntary Attrition" in which they noted and asked, "particular attention needs to be given to the nature of informal student-faculty contact and its influence in facilitating the academic and social integration of students. What kinds of contact promote what kinds of integration" (p.365)? That same year, the same authors published another article entitled, "Student-Faculty Informal Relationships and Freshman Year Educational Outcomes", in which they said "frequency of interactions focusing on intellectual or course-related matters had the strongest partial correlations with both freshman year academic performance (GPA) and self-perceived intellectual growth. Similarly, interactions focusing on students' career concerns had the strongest partial correlation with perceived personal development" (Pascarella \& Terenzini, 1978, p.189). Therefore, Terenzini and Pascarella actually distinguished between faculty-student interactions that revolved around academic and personal matters and found that the differing conversation led to different effects regard the type of perceived integration by the student.

In the 1979 study, which was noted by Sweet (1986), Terenzini and Pascarella used the "operational measure of student-faculty informal contact that was drawn from an instrument developed by Wilson, Graff, Dienst, Wood and Bavry" (p.215). Terezini and 
Pascarella (1979) asked the students six questions regarding informal (i.e. outside the classroom) contact with faculty. Three questions asked about academic content while three others were focused on social and personal purposes. The results of this study showed differences for males and females, but for both sexes the "frequency of contacts focusing on intellectual or course-related matters had the largest significant partial correlation with freshman year persistence" (p.217).

Whittington (1995) also noted this differentiation regarding student-faculty contact. Kember (1989a) included "any tutorial assistance provided" under the rubric of "academic aspects" (p.293). He also said, "collective affiliation is also established through the interactions associated with academic support for the course" (Kember, 1989a, p.293). Likewise, Kember (1989b) distinctly noted, the "collective affiliation side of academic integration is the quality and quantity of contact between the students and the organisation. The personal contact of tutorials seems to be particularly effective at providing collective affirmation" (p.204). Kember (1989b) noted "the component [social integration] cannot be directly transported into the distance education context" (p.207).

Likewise, in a study by Bernard and Amundsen (1989), which explored the Tinto's model in communication, business administration and accounting courses, found "academic integration is important in all of the courses" (p.40). However, they only found that social integration was important in one course, communication, which they noted "exactly the position one might expect considering the learning requirements in the Communication course versus the others" (p.43).

Shin and Kim (1999) found "social integration" to be a significant variable, which negatively affected GPA. However, when testing for social integration, this variable was 
classified based on four questions on a mailed survey. These questions would be better classified as "work/family integration" rather than social. For example, the first question, on a four point Lickert scale, was "How many of your colleagues and/or employers in your work place are aware that you are taking courses at KNOU" (p.94)? This question specifically addressed work environment, rather than social integration and other than a quantitative value it lends no insight to the encouragement or discouragement that these colleagues and employers provide for the student. The second question, with a "yes or no" response was "People around me encourage me a lot to continue my studies" (p.94). This question does not specific the origination of the encouragement. The encouragement could be coming from the employer, work colleagues, family, etc. Regardless, the question is not directly measuring other KNOU students, staff or faculty members. Lastly, the final two yes or no questions were "I encourage fellow learners when they are in trouble" and "I hardly feel that I belong to KNOU as a student" (p.94). The third question addressed whether or not the student provided encouragement not received encouragement. Also, it did not directly classify the learner as a KNOU student. The last question addressed a sense of belonging, but did not connect the sense of belong with any social relationship, work, family, student, faculty or otherwise. The results of this study found, "the amount of study time learners spent was the most influential factor among the three variables of study time, social integration, and face-to-face activities" (p.88). This is another example of how academic integration showed to be more important than other "social" integration factors. Regarding face-to-face activities, Shin and Kim noted, "with the information from this study, it is difficult to discern the significance of face-to-face activities. 
Also, Kolowich (2010a) reported that some institutions are offering extracurricular organizations for online students. These social interactions focus "mostly on career advice....so online students can learn more about where their degrees can take them and what steps they will need to take to get there" (para.3-4). According to a 2008 survey at the University of Maryland at University College, eighty percent of the virtual club members joined for "professional reasons" (para.9). "Since many online learners are adults who are back in school because they want to advance or change their careers, student clubs at online universities tend to be career oriented, perhaps more so than their counterparts at brick-and-mortar institutions that cater mainly to young adults" (para.9). Kolowich (2010b) also noted that new technologies are being used to connect students with faculty members in efforts to increase retention rates.

Thus, even though some distance studies found social integration as positively linked to persistence, there are methodological factors and classification issues that complicate interpreting this data as reliable. It is apparent that some factors, which Tinto is defining as social integration, Kember is defining as academic integration.

Kember's Longitudinal-Process Model of Drop-Out from Distance Education (1989, 1995)

Kember (1989a) considered other models, but said the model developed by Tinto and Spady was "the best starting point" (p.284). Kember's model has been tested in different institutions (Kember, Lai, Murphy, Siaw, \& Yuen, 1992, 1994; Kember, Murphy, Siaw, \& Yuen, 1991; Roberts, Boyton, Buete, \& Dawson, 1991). Also, Kember (1990) noted polices from the model to reduce dropout. In developing his model, Kember noted the differences between distance education and nontraditional students as identified 
by Bean and Metzner (1985). Kember (1989a) noted that Bean and Metzner's definition of nontraditional students included not living on campus and therefore commuting to and from campus. Therefore, these students "receive instruction via face-to-face classes" (p.283). However, distance education students do not receive face-to-face in instruction; Kember noted "this difference is very significant" (Kember, 1989a, p.283). Kember (1989a) noted distance education students are characterized by "part-time and mainly mature students", which is two of the three characteristics Bean and Metzner used to define nontraditional students (p.284). Even though Kember uses Tinto's model as a starting point, he notes the following difficulty, "the Tinto model was derived for fulltime education by face-to-face teaching of students who recently left school and stresses the importance of social and intellectual involvement within an institution upon student behavior" (Kember, 1989a, p.284). Given this, Kember modified Tinto's theory to accommodate the distance education student (Kember, 1989a, 1989b). (See Appendix B, Illustration \# 6)

The foundation of Tinto's model, related to Durkheim (1961), was that students dropout when they are not integrated into the college collective. However, in a distance model, students are not required to integrate into a new college collective based on a geographical change for the purpose of education. Therefore, Kember broadened Tinto's background variables (Kember, 1989a, 1995). First, Kember's model begins with the student's characteristics, including individual, family and home, work and educational background (1989a, 1995). Kember (1989a) said, "the individual situation and family life assume greater importance" (pg.285). Kember (1989a, 1989b, 1995) noted that high school grades and schooling are less associated with mature students as compared to 
traditional students. Therefore, Kember (1989a) noted that "more recent data on educational aptitude, common to all entrants, can only be included if applicants, are subject to some form of testing by the institution" (p.291). Likewise, with grade inflation, some Kentucky high school seniors graduate with the highest grade point average in their class still test into developmental math (J. Box, personal communication, May 26, 2011). This is why high school grade point average is not considered as a variable for the study. The COMPASS test, which is used to place the students into the particular developmental math classes, would meet the qualification as a common test by the institution. The student's employment situation is included in Kember's model, which is absence from Tinto's model (Kember, 1989a, 1989b, 1995).

Secondly, these characteristics impact goal commitment, which is divided into two components: intrinsic and extrinsic motivation. "Intrinsic motivation refers to the interest students have in the subject matter for its own sake. Extrinsic motivation is concerned with the student's commitment to obtaining a qualification" (Kember, 1989a, p.287). Kember (1989a) said intrinsic motivation is "particularly important" for adult students (p.288). Kember (1989a) noted that some students enroll in courses with intentions of not completing a program. These students take one, two or three courses, then stop taking classes and become part of the attrition statistics. Therefore, their level of motivation was limited to specific classes and not a program. This is why degree program is considered as a variable in this study.

Thirdly, Kember maintained an integration component for both academic and social and work environment, which also impacts academic integration and social and work integration. "It is these integration components, based on Durkheim's theory of 
suicide, which makes the model a longitudinal one" (Kember, 1989a, p.289). Kember favored a longitudinal model because it allowed consideration to be given to the compatibility of the institution and the student's lifestyle as well as intervention by the institution and events in the life of the student rather than "relating drop-out phenomenon to a set of apparently predestined variables" (p.289). Kember did not utilize the instrument developed by Pascarella and Terenzini (1980) to measure social and academic integration because he said, [the instrument] "could not be used with distance education students" (Kember, Lai, Murphy, Siaw, \& Yuen, 1992, p.286). Therefore, Kember and others developed "The Distance Education Students' Progress (DESP) inventory" (Kember, Lai, Murphy, Siaw, \& Yuen, 1992; Kember, Murphy, Siaw, \& Yuen, 1991). The DESP had four social and academic integration factors: academic accommodation, academic incompatibility, emotional support and external attribution (Kember, Murphy, Siaw, \& Yuen, 1991). Within social and work aspects, Kember (1989a) included the immediate family as a "major factor" (p.294). Therefore, marital status, dependency status, number in household, number of household members in college and number of dependents are considered in this study.

Lastly, based on these components the student makes an ongoing decision based on the costs and benefits of staying or dropping out of the higher education with a recycling loop (Kember, 1989a, 1989b). Kember (1989a) said, "the exact nature of the variables will differ between institutions depending on the type of distance education operation" (p.290.). This model does assume that the students are making rational decisions. 
In 1992, The DESP had four social and academic integration factors: academic accommodation, academic incompatibility, emotional support and external attribution (Kember, Murphy, Siaw, \& Yuen, 1991). Kember (1995) noted, "factor analysis of the data collected with the DESP inventory produced factors which split social and academic integration variables into positive and negative factors." Kember (1995) said, "entry characteristics direct them [students] toward one of two tracks. Those with favorable situations tend to proceed on the positive track and are able to integrate socially and academically. Others take the lower, negative track where they have greater difficulties achieving social and academic integration" (p.64). Both of these tracks lead to grade point average (GPA), which lead to the cost/benefit analysis and the recycling loop. In 1995, Kember changed his original model into a "two-track model" (p.64). (See Appendix B, Illustration \# 7)

\section{Kember's 1989 and 1995 Models Compared}

There are similarities and differences from Kember's 1989 model to the 1995 two-track model (see pictorial depiction for visual differences). Kember's 1989 model included: "individual, family and home, work and educational" factors as part of "characteristics", which impacted goals (which were later included directly into academic capability and academic incompatibility) and then integration. Likewise, in 1995, Kember noted "the characteristics, demographic status, educational background and experience of students will play a major part in determining how well the students are able to achieve academic and social integration" (p.76-77). First, from the pictorial depictions it would appear that goal commitment (extrinsic and intrinsic motivation) is missing from the two-track model. However, extrinsic motivation is now a subcomponent 
of academic incompatibility and intrinsic motivation is a subcomponent of academic integration. Secondly, academic environment, academic integration, social and work environment and social and work integration components are now replaced with the social integration, external attribution, academic integration and academic incompatibility (Kember, 1995). Also, Kember noted students are on one of these two tracks, which neither necessarily leads to withdrawal/dropout, but they are associated with "positive and negative factors" (Kember, 1995, p.64). Table 2 shows the subscales of each component (Kember, 1995).

\section{Table 2}

Kember's 1995 Two-Track Model Subscales of Each Component

\begin{tabular}{|l|l|l|l|}
\hline Social Integration & $\begin{array}{l}\text { External } \\
\text { Attribution }\end{array}$ & $\begin{array}{l}\text { Academic } \\
\text { Integration }\end{array}$ & $\begin{array}{l}\text { Academic } \\
\text { Incompatibility }\end{array}$ \\
\hline $\begin{array}{l}\text { Enrollment } \\
\text { Encouragement }\end{array}$ & Insufficient Time & Deep Approach & Surface Approach \\
\hline $\begin{array}{l}\text { Study } \\
\text { Encouragement }\end{array}$ & Unexpected Event & Intrinsic Motivation & Extrinsic Motivation \\
\hline Family Environment & Distractions & $\begin{array}{l}\text { Positive Course } \\
\text { Evaluation }\end{array}$ & $\begin{array}{l}\text { Negative Course } \\
\text { Evaluation }\end{array}$ \\
\hline & & Reading & Poor Language Skills \\
\hline
\end{tabular}

Even though these components are given different titles, the examples Kember gave to describe the subscales and situations to describe the factors of each component are the same as the descriptions and examples that were given for the previous components used in the 1989 model.

\section{Social integration and external attribution (1995) and social and work aspects (1989).}

Social integration is the first step on the "positive" track. Within the social integration component of the 1995 model, Kember noted three "sub-components". The 
following is how Kember (1995) described three sub-components: "employer, friends and family support to enroll....the degree of co-operation and moral support the students receives when studying ....whether a warm supporting environment exists within the family unit" (p.80). These sub-components measure the same factors that were measured in the social and work aspects. In describing the social and work aspects, Kember (1989a) said, "the attitude of the employer is important in reinforcing the student's goal commitment...the immediate family is another major factor in the degree of congruence of the study process with the student's lifestyle" (p.294).

Kember (1995) listed the following sub-components of external attribution: insufficient time, unexpected events, and distraction. (p. 89). When Kember (1995) listed examples of these sub-components, he consistently noted three spheres from which these "negative" factors arise: work, family and home and friends (p.90-98). Again, these are the same social and work aspects that Kember (1989a) noted in previous publications.

\section{Academic integration and academic incompatibility (1995) and goal} commitment \& academic integration and environment (1989).

As noted earlier, goal commitment is simply moved from being the second stage in the 1989 model into the academic aspects of the 1995 model. Kember (1995) listed the following subscales of academic integration: deep approach, intrinsic motivation, positive evaluation and reading. Kember (1995) listed the following subscales of academic incompatibility: surface approach, extrinsic motivation, negative course evaluation and poor language skills. It is evident from these subscales that the subcomponents are mirror images of each other, but one factor is the positive and the other negative. Academic integration served as the positive track, with academic incompatibility as the negative 
track. Also, Kember linked surface approach with extrinsic motivation and deep approach with intrinsic motivation based on Ramsden and Entwistle (1981). Likewise, positive and negative course evaluation is simply the outcome of the student's evaluation. Kember noted the diversity of the student's primary language. For example, "most of the students in the Hong Kong project were studying in a second language, a phenomenon which is common in many other parts of the world" (Kember, 1995, p.110). Thus, reading and poor language ability is simply the student's "command of the language of instruction" and "enthusiasm for reading" (Kember, 1995, p.110).

Also, Yorke (2004) made an observation regarding the two-track model, “Kember's model can almost be reduced from a dual pathway to a single pathway based upon the extent to which the student (a) is able to accommodate study with other aspects of their life and (b) can engage with all aspects of the course on which they are enrolled. High levels of accommodation and engagement are likely to lead to academic success, whereas low level would engender the reverse" (p.26). As noted by Yorke, the two-track model simply implies that students who have negative influences are more likely to drop than those with positive influences, which is the case with any persistence model. Also, the two-track model does not pictorially show that students are able to move from one track to the other as was the case in the 1989 model. Also, as noted in the comparison of the two models, the two tracks are essentially mirror images of the same factors. It seems contradictory to describe some of these factors as negative and positive when Kember (1995) even noted the importance of both extrinsic and intrinsic motivation. Regarding extrinsic motivation, Kember (1989a) said, "It seems clear that there is a relationship between the level of student's extrinsic goals and persistence" (p.288). He also said, 
"intrinsic motivation is seen as particularly important for adult students, because the adults' concept of self-directivity is in direct conflict with the traditional practice of the teacher telling the student what is to be learnt" (p.288). In Kember's 1989 publication, he does not extrapolate on how extrinsic motivation is related to persistence, but in the 1995 publication he does. Kember (1995) defined extrinsic motivation as "rewards external to the course such as increased promotion opportunities for pay raises if a course is passed" (p.102). Kember, referring to Ramsden and Entwistle (1981), related extrinsic motivation to surface approach and intrinsic motivation to deep approach. Kember (1995) said, "students who are extrinsically motivated probably enrolled for the qualification rather than out of interest in the subject matter" (p.109). However, Kember's notation of "probably" was not empirically determined. He simply noted this observation on two interviews and the previous aforementioned work.

Concordantly, Roberts, Boyton, Buete and Dawson's (1991) study, which used Kember's original model, noted, "it was found to be very difficult to maintain a division between academic environment and academic integration and between social and work environment and social and work integration" (p.55). Also, because of the nature of the model, some variables are "relevant to one component may well be viewed as an influence on subsequent components of the model" (Kember, 1989b, p.198). For example, some variables could be considered student characteristics (individual, family and home, work, educational) as well as social and work environment, which Kember (1989a) includes under the same subheading, "family and home" (p.286). Likewise, Kember (1989b) gives an illustration of how "individual characteristics affect goal commitment, academic, social and work integration" (p.199). It is also important to note 
that Kember and others (1992) specifically addressed the fact that a path analysis showed that "the limited direct correlation between background variables and either grades or persistence measures suggests that students are not predestined by their entry characteristics to fail, succeed or drop by the wayside" (p.296) In 1995, Kember reiterated this point and said, "entry characteristics are just a starting point in determining how much difficulty a student is likely to face in coping with a course. Many students with apparently adverse circumstances do succeed. Entry characteristics are not good predictors of final outcomes" (p.77).

\section{Grade point average (GPA), cost/benefit analysis, outcome and recycling}

\section{loop.}

The major change in this portion of the model is including GPA as an individual component before the cost/benefit analysis. Kember (1995) specifically addressed this and said, "the original intention was to treat GPA purely as an outcome variable. The quantitative analysis, though, suggested that GPA functioned to some extent as an intervening variable between academic incompatibility and drop-out" (p.128). Kember also noted "changes to the cost/benefit equation." Kember said that all of the background characteristics, goals commitments, factors, etc. will change throughout the time the student is enrolled. However, Kember (1995) made a point to note, "once the heavy alternative demands of the first semester have passed, the balance tilts in favor of continued study" (p.123). The recycling loop remains a constant in both models. "After a change of circumstances, increase in motivation, or efforts by the institution or themselves to achieve better integration it is possible that the students could recycle through the longitudinal model" (p.127). 


\section{Criticism of Kember}

In Walker's (1995) review of Kember's 1995 book, it was noted, “in the 1980's distance education was as stand along term; it is much less so today, and one must question the research outcomes possible from comparing cohorts of students from the UK, Papua New Guinea, Australia and Hong Kong, over the period pre-1972 to 1990 ” (p.16).

Shin and Kim (1999) criticized Kember's results and said, "the results of our study, which used a longitudinal approach, suggest that Kember's assumption may be incorrect because it is derived from the limitations of his research design which heavily relies on cross-sectional data" (p.81).

Woodley, Lange, and Tanewski (2001) replicated Kember's 1995 model using students in four business course at the Open University in the United Kingdom. Woodley, Lange and Tanewski (2001) were highly critical on two main components of Kember's work. First, they reported that "Kember failed to report reliabilities on four-sub-scales (that is, deep approach, intrinsic motivation, surface approach, and extrinsic motivation) in the DESP inventory...the DESP suffers from excessive measurement error" (p.120). Furthermore, Woodley, Lange, and Tanewski (2001) stated, "further development of the DESP would be needed before one could claim that it has both internal validity and generalisability" (p.127). Secondly, they noted, "the key change is that whereas Tinto saw social and academic integration as being separate and parallel (i.e. independent), Kember sees them as linearly associated. In the positive dimension social integration leads to academic integration whereas in its negative form external attribution produces academic incompatibility" (p.127-128). 


\section{Response to Criticism of Kember}

All of these criticisms are taken into consideration when constructing the Collective Affiliation model. First, regarding the diversity and time span of the data Kember used to create the model, Kember noted (1995), "given the diversity of source of input data the model can reasonably be assumed to be generic" (p.55). Compared to other conceptual frameworks (e.g. Spady, Tinto, Bean and Metzner), many models have been tested over decades of research, however, Kember's model has been tested in locations that allowed for the most ethnically, culturally and geographically diverse groups of student. The majority of frameworks created within the United States have solely been tested on student groups within the same country. Also, many of these studies have been tested on homogenous groups of students (e.g. full-time, first-time residential freshman) or even excluded minority races (e.g. Pascarella, 1985). This diversity does not impede successful research, but elects to address one of the more difficult aspects of education, which is cultural sensitivity in a global society. Secondly, regarding Shin and Kim's (1999) criticism, this study will use longitudinal and cross-sectional data. Thirdly, Woodley, Lange, and Tanewski (2001) are correct when they noted that most of the changes made to the 1989 Kember model were based on analysis from the DESP inventory. Initially, Woodley, Lange, and Tanewski (2001) criticized the reliability of

and the fact that Kember did not report particular subscales on the DESP inventory. The reliability sub-scales, "on both cases [the academic integration and academic incompatibility components of the DESP] the approach to study and motivation subscales are adapted from the Approaches to Studying Inventory (ASI) (Entwistle \& Ramsden, 1983)" (Kember, 1995, p.137). Therefore, Kember may not have reported 
these four reliability sub-scales because these four sub-components were adapted from a previously tested instrument. Ramsden and Entwistle (1983) said, "it is now possible to speak with confidence about two principle orientations towards studying, defined in terms of self-reported inventories, which are closely similar to Marton's categorisations of deep and surface approaches to reading and academic article. The repeated analysis of our own inventory, together with the parallel work of Biggs $(1978,1979)$, clearly indicates the stability and replicability of these two orientations" (p.380).

Regarding learning approaches, the questionnaire items related to surface and deep approach were taken from the work of Marton and Pask (1976) and the motivational states were taken from the work of Biggs (1979) (Kember \& Harper, 1987; Ramsden \& Entwistle, 1981). Kember and Harper (1987) found that "surface approach was the variable which discriminated the highest level between those who persist (persisters) and those who withdraw or fail (non-persisters)" (p.39). Ramsden and Entwistle (1981) noted, "Fransson (1977) was able to demonstrate that the approach to learning depended on perceived relevance and anxiety: interest in the subject matter of the article encouraged a deep approach, while a stressful learning situation produced more surface learning" (p.368). A "stressful learning situation" would have a direct application to the family and work life of a distance education student, which could led to a surface learning approach. However, Harper and Kember (1987) also said, "a surface approach should be considered with academic failure at the tertiary level since graduate students, surely, are expected to learn with understanding rather than rely on the reproduction of factual information" (p.40). Even though this may be true, specifically for graduate students, teaching techniques with developmental students, even though not favored, often utilize "drill-and- 
skill" as a means of learning. Levin and Calcagno (2008) noted, "if there is any consensus among educators concerning remediation, it is that so called drill-and-skill approaches are falling out of favor. Yet, though there is no reliable national survey of the teaching techniques used in remedial courses at community colleges, causal observation at many sites suggests that drill-and-skill approaches are still dominant (e.g. Grubbs \& Associates, 1999)" (p.185). Also, the 2006 Community College Survey of Student Engagement noted that when asked, "during the current school year, how much has your coursework at this college emphasized the following mental activities? Memorizing facts, ideas or methods from your courses and readings so you can repeat them in pretty much the same form?" $64 \%$ of student responded "quite a bit" or "very much" (p.14). Therefore, this particular type of instruction may lend itself to students with a surface approach because the nature of the course is to "employ repetitive practice (often in learning laboratories) to master what is being taught" (Levin \& Calcagno, 2008, p.185).

Regarding motivation, Kember (1995) said, "extrinsic motivation is related to the rewards a student might receive by obtaining the degree or other reward" (p.108). Kember (1995) goes on to say that this type of motivation often leads to enrolling for the qualification rather than the subject matter, which leads to no interest in the reading and "adopt a surface approach and attempt to memorize facts which appear important in the hope that they can be used to answer examination questions" (p.109). However, this extrinsic motivation has been found to be a motivation for developmental education students. "Based on the previous literature on remediation in higher education and adult learning, Levin and Koski (1998) found the following ingredients to be central for designing successful interventions for underprepared students in higher education: 
motivation: building on the interests and goals of the students and providing institutional credit toward degrees or certificates" (Levin \& Calcagno, 2008, p.186). In concluding, Harper and Kember (1987) noted, "the results of this study show that the inventory cannot be viewed as a clear predictor of either persistence or performance. However, Entwistle and Ramsden never designed it for that purpose (1983, p.44). The fact that there are significant relationships between inventory variables and output measures is therefore noteworthy" (p.44).

Ramsden and Entwistle (1983) also noted other variables which are considered in the DESP, "a positive evaluation of departments is associated with positive attitudes to studying. As it has already been demonstrated that positive attitudes and a deep study approach are linked with academic progress, a chain of causality, and of potential educational influence, begins to be established" (p.381). This statement identifies a positive course evaluation, another factor which Kember (1995) included in the two track model, as linked to deep study approach. Thus, it is evident that the "positive" track has related factors which were drawn from the ASI and work from other researchers. Likewise, this statement noted "a chain of causality", which further illustrates a "track" model for student progress.

Woodley, Lange, and Tanewski (2001) and Kember, et al are not the only researchers to have used (Joughin, Lai, \& Cottman, 1992; Richardson, 1990, Thompson, 1999) or affirmed the DESP inventory (Moody, 2004). When Joughin, Lai and Cottman (1992) administered a modified version of the DESP on 1843 students at a university in Australia, they found four factors as did Woodley, Lange, and Tanewski (2001). Joughin, Lai and Cottman (1992) found discrepancies with questions related to surface and deep 
approach. Also, Joughin, Lai and Cottman (1992) said, "our results indicate that students are memorising within a deep approach" (p.8). Richardson (2000) noted, "there are two basic reasons for questioning the validity of the inferences drawn by Joughin et al. The first has to do with the phrasing of the relevant item.....as used by Entwistle and Ramsden" (p.134). Joughin included the term "lectures", which may have lead distance education students to think the question did not apply to them, whereas Kember and Harper (1987) used the terms "books or study materials" (Richardson, 2000). Richardson (2000) also criticized the fact that Joughin, Lai and Cottman did not use comparison data from campus-based students and said, "few studies have reported results of factor analysis carried out on responses to the individual items in the ASI" (p.134.) Also, Richardson (1990), when using the ASI on campus based students, found difficult with questions related to deep approach loading (Richardson, 2000). Likewise, Thompson (1999) said, "in contrast, none of the four ASI sub-scales were useful discriminators of withdrawal or persistence in the current study ("deep approach" correctly classified $51.8 \%$; "extrinsic motivation" correctly classified $55.2 \%$; "intrinsic motivation" correctly classified 51.4\%; and "surface approach" correctly classified 47.6\%)" (p.82). Thompson (1999) also noted, "it seems evident, therefore, that items in the DESP Inventory are useful in developing a model for persistence in distance education when the outcome variables are defined as either GPA of the number of modules failed. They are, however, only moderately useful in determining which student might withdraw from a unit or course" (p.83). In conclusion, given the methodological and theoretical concerns regarding the DESP inventory, the DESP inventory will not be used in this study. 


\section{Additional Distance Education Persistence Models and Frameworks}

\section{Rovai (2003)}

Rovai (2003) proposed the "Composite Persistence Model", which synthesized the work of Tinto and Bean and Metzner with online student skills, needs, learning and teaching styles. Rovai's model incorporates the majority of Tinto's model (commitments and academic system) along with aspects of Bean and Metzner's model into a component called "internal factors" (2003, p.16). The significant changes Rovai made was to differentiate between "prior to admission" and "after admission" as well as incorporate student skills and external factors identified by Bean and Metzner. Rovai (2003) noted the following regarding the purpose of the study, "to synthesize a composite model to better explain persistence and attrition among nontraditional students that enroll in online courses" (p.1).

Park (2007)

Following the work of Rovai (2003), Park (2007) presented "The Revised Model of Dropout from Distance Learning in Organizations." This new model made four significant changes to Rovai's original model. First, the literature highlighted the little impact that "learner skills" had on previous studies. Thus, the component was shown in a grayed box with dotted line effects on "leaner characteristics" and internal factors.

Secondly, external factors were moved from "after admission" to encompass both "prior to admission" and "after admission." Thirdly, Rovai's model showed external factors affecting internal factors, which affected persistence decision. In Park's model internal and external factors affect each other. Lastly, Rovai's model showed internal factors 
affecting the persistence decision, but Park's model showed both external and internal factors affecting dropout or persistence decision (Park, 2007).

\section{Berge \& Huang (2004)}

A number of other researchers have proposed various frameworks from which to study online student persistence, but neither of these presented an actual predictive model. Berge and Huang (2004) proposed "A Model for Sustainable Student Retention" that "takes into account personal, circumstantial, and institutional factors, as well as the interconnectedness of these factors" (Editorial section, para. 2). This model does differentiate between blended, online and in-person delivery methods, but as the authors noted, "it is hoped the reader can see that using this model as a framework for the planning process within a particular organization is more important than any static, generic model that could be designed by someone outside the specific organization" (Figure 6, para. 1). Therefore, this framework is not intended to be a model to explain attrition, but a model of considerations for possible institutions to explore and create their own model.

\section{Liu, Gomez, Khan, and Yen (2007)}

Liu, Gomez, Khan, and Yen (2007), in effort to "fill the gap" between persistence studies of online students and community college students, proposed "A LearnerOriented Community College Online Course Dropout Framework." The authors said this research created a "framework" that involved psychological, technical and social aspects, but not a specific model for exploring attrition of online community college students. Regarding social factors, the authors listed the following: association, peer and instructor interaction, peer consultation, online participation, help seeking, partnership/teamwork, 
and learning community. As noted previously, for these factors to be considered "social integration", as defined by Tinto, the researcher must delineate between the interactions that are academic or social in nature. Some aspects of these models are used in the development of the proposed Collective Affiliation model.

\section{Collective Affiliation Model Theory}

The Collective Affiliation model was designed to specifically address student drop in nonresidential contexts such as community colleges and distance education settings. The decision to make these changes to the model was based on previous theoretical persistence research (Bean \& Metzner, 1985; Kember 1989, 1995; Spady, 1970, 1971; Tinto, 1975, 1982, 1988, 1997, 1998), and an extensive literature review. As shown in the literature, students must not be forced to disregard their previous communities in effort to achieve an educational objective; distance education and commuter students need not geographically relocate or withdrawal from existing social communities to be successful. Therefore, the existing social structures play a greater role in these situations. Thus, the Collective Affiliation model does not attempt to understand the individual nor the individual's decision to persist outside of these social structures, namely, family and work, but also identifies a college student decisions as a consideration of collectively affiliating with all these groups and, in particular, an academic affiliation. Also, the sample is community and technical college students who took a developmental math class; some in the classroom and others online. This sample was selected based on the importance of developmental and distance education to the success of the community college population. Also, both group of students are 
nonresidential students and developmental and distance education groups of students provide a good cross section of needs that community college students face.

In 1975, Tinto summarized Durkheim (1961) by saying, "suicide is more likely to occur when individuals are insufficiently integrated into the fabric of society. Specifically, the likelihood of suicide in society increases when two types of integration are lacking-namely, insufficient moral (value) integration and insufficient collective affiliation" (p.91). Tinto and others have used this theory in a manner that demands the student "withdraw" from his/her current community collective affiliation and replace it with the college community. Also, Tinto has expected a college student to "disassociate themselves, in a varying degrees, from membership in the past communities...and perhaps reject those past communities" (Tinto, 1988, p.443). Thus, the student must integrate into the college community and be isolated from former relationships, cultures, etc. (Tierney, 1992). The Collective Affiliation model proposes that Durkheim's theory of suicide is applicable to college student attrition because it focuses on reasons, such as insufficient moral integration and insufficient collective affiliation, but rather than expect the student to find a new self-identification with the college community (geographical relocation or otherwise), the student would incorporate the academic affiliation within their own understanding of their self-identify, which is formed from various spheres of communities, such as family, work and social environments.

To expand upon this important concept, the Collective Affiliation model takes into consideration the pertinent critique Tierney (1992) made regarding racial and ethnic minorities. Rather than expecting the students to abandon their family and cultural community, this model locates the student within their own family and community. This 
highlights another salient function of the model in which the student's family, collective affiliation and identity are not separate from the student's decision to persist. Collective affiliation was used by Durkheim, Tinto and Kember. Kember (1995) defines collective affiliation as "a student's sense of belonging in a course or to an institution" (p.257). More specifically, Kember (1989b) defined the academic side of collective affiliation as, "quality and quantity of contract between the student and the organization" (p.204). In this model, collective affiliation is the "sense of belonging" that an individual has with any external entity. For example, is a person does not feel a "sense of belong" in a group (e.g. church, club, lodge, etc.) or with another person, the individual will disassociate with the organization or person. By the same means, individuals associate themselves with social, work and family relationships. All of these associations comprise the collective affiliation of a person. When an individual becomes a student, the individual must determine if he/she will integrate this new organization into their sense of belonging. This is different than other models, which have expected individuals to leave one sense of belong for a new college sense of belonging. However, this is not necessary, nor is it always a healthy process for all students to undertake. Also, some persons have a strong sense of belonging to a college or university even though they may not have attended the institution. For example, this "sense of belonging" may be foster through affiliation with a college sports team. If the student can no longer incorporate association with college then the student withdraws. This "sense of belonging" may also be related to a work association. If the employer is paying for the certificate, diploma or degree, then education directly relates to the student's work and these associations overlap. 


\section{Collective Affiliation Model Application}

Many models use the terms "entry" or "student" characteristics. However these terms are different because "entry characteristic" implies that these are characteristics applicable at the initial point in which the student enters college, a class or program; similar to Rovai (2003) and Park's (2007) "prior to admission" factors. Since the Collective Affiliation Model utilizes a recycling loop it necessitates a differentiation between two groups of characteristics. In Kember's model (1989a, 1995), a recycling loop showed that all the same characteristics are considered in an ongoing decision making process. However, some student characteristics are stagnate, which means they are the same upon entering and leaving college, whereas other student characteristics are dynamic, which means they are subject to change while the student is in college. This distinction was also made by Powell, Conway and Ross (1990) who said, "these predisposing characteristics are either fixed or slowly changing throughout the duration of a student's involvement with a distance institution and, as such, exert a relatively constant influence on students' chances of success" (An Empirical Model of Student Success and Persistence section, para.1).

In the Collective Affiliation model, student characteristics are still considerations in the decisions making process, but they are divided into two categories based on stagnate or dynamic characteristics. For example, secondary education (high school diploma, GED, etc.), race and sex are considered stagnate characteristics because they do not change while the student is in college. However, dependency status, age, marital status and number in college are examples of student characteristics that can change. Therefore, as the student continues through the recycling loop these dynamic 
characteristics are reconsidered. However, stagnate characteristics are not part of the reconsideration because they are unchanging.

Also, the most dramatic change to the model, based on previous research, is the pictorial description of the model. Bean and Metzner (1985) and Kember (1989a, 1995) described the "social" component as focused on two spheres of the individual's life: family and work. Also, Tinto (1997) said, "our current two-dimensional graphic representation of interaction, which depicts social and academic systems of colleges as two separate boxes, masks the fuller relationships between these two spheres of activity. A more accurate representation would have academic and social systems appear as two nested spheres, where academic occurs within the broader social system that pervades the campus" (p.619). Tinto (1997) also said, "a more accurate representation would have been academic and social systems appear as two nested spheres, where the academic occurs within the broader social system that pervades campus....social communities emerge out of academic activities" (p.619). Also, as noted by Stage (1989), as a student is more academically integrated the student becomes more socially integrated. Therefore, this relationship is not parallel and separate, but overlapping and embedded. Therefore, rather than portraying the model in boxes connected by solid and dotted lines, the model is best depicted as overlapping circles. With the exception of stagnate characteristics, these circles are dynamic, flexible and exert various levels of influence on the decision making process and various time in the process. At different times, one variable or another may become dominate and be the greatest influence on the persistence decision. Lastly, the other significant changes to the model is the fact that it is not a process in which the student's individual attributes, family background and pre-college schooling 
moves through commitment, to the institution, then through commitment to a decision. Rather the process is a cost/benefit analysis in which all the factors are weighted. Thus, at different times, each factor can hold a different and greater or lesser weight than before. In this case, it is similar to Tinto's idea of rites of passage. However, the difference is that the rites of passage are not limited to college experiences. These experiences are throughout life: marriage, having children, changing jobs, death of a parent, etc. For example, a student may choose to drop out of school because of an illness or giving birth to a child. However, later, when the student has recovered from the illness or the child is older, the student may then elect to return to college. Each of these experiences as well as the college experience of grades, course completion, etc., is part of the ongoing process to persist or dropout. Also, the student is not continually choosing to go to school. Rather the student is choosing whether to integrate the academic sphere of influence, time and energy into the person's life. This is a small, but very important distinction. Rather than seeing the process as the college attempting to integrate the student into the life of the college, the person is making the decision whether or not to integrate the college into his or her life and collectively affiliate with the college, becoming a student. Therefore, the decision making process is essentially a decision of collective affiliation on behalf of the individual, but not outside the identity of the person's family, work and social communities. If the person decides to withdrawal from school, nothing changes except the person simply loses the academic sphere within the collective affiliation. The model shows the individual's spheres of influence in the decision-making process and how different variables affect the individual's decision within these overlapping spheres of influence. (See Appendix B, Illustration \# 8 and Illustration \# 9) 


\section{Variables}

The National Center for Education Statistics (NCES) identified seven risk factors affecting persistence: delayed postsecondary enrollment, students who were high school drop outs or GED recipients, students enrolled part-time, financially independent students, students with dependents other than spouse, single-parent students and those employed full-time (Horn \& Premo, 1995). This study takes six of these seven factors into consideration: age, secondary education, enrollment status, dependency status, dependents and marital status. Also, the following variables will be considered: degree program, adjusted gross income, college grade point average, sex, parent's education level, course delivery method, number of credit hours accumulated, number in household and number of household member in college. These variables parallel the factors that Kember and others included on The Distance Education Students' Progress (DESP) instrument. The DESP included: "age, sex, marital status, family size, housing conditions, salary and previous education" (Kember, Lai, Murphy, Siaw, \& Yuen, 1992, p.287). Also, these variables have been used in other research studies and have been shown to be useful in predicting variance.

In 2006-2007, there were 1,045 United States community colleges, which was a 17\% increase since 1974-1975. Also, in 2006-2007, community colleges enrolled 6.2 million students ( $35 \%$ of all students enrolled in college), which is a $741 \%$ increase since 1963. Four-year public and privates increased $197 \%$ and 170\% respectively (Provasnik \& Planty, 2008). Community colleges are more geographically diverse compared to fouryear institutions with $29 \%$ in cities, $29 \%$ in rural areas, $24 \%$ in towns and $18 \%$ in suburban areas (Provasnik \& Planty, 2008). Community college students tend to be 
equally represented by both sexes (Factbook, 2008; Horn, Peter, \& Rooney, 2002;

Provasnik \& Planty, 2008). Community colleges also tend to enroll students with the lowest family incomes and the majority of all students over the age of 30 (Horn, Peter, \& Rooney, 2002; Provasnik \& Planty, 2008). Even though community colleges enroll the largest majority of low-income students, they have the smallest portion of students receiving any form of financial aid (Romano \& Millard, 2006). Only $37.8 \%$ of students receive any form of aid and only $20.7 \%$ received any federal aid (Horn, Peter, \& Rooney, 2002). These students have families and work responsibilities and more likely to attend on a part-time basis (Horn, Peter, \& Rooney, 2002; Provasnik \& Planty, 2008). Over $40 \%$ of students 24 years of age and older are enrolled in an associate's degree program, while another $20 \%$ of students 30 years of age and older are enrolled in a certificate program. Over $65 \%$ of students who reported one or more dependents other than spouse or as a single parent enroll in a certificate or associate's degree program (Horn, Peter, \& Rooney, 2002). Over $54 \%$ of 2 -year students attended part-time for the full year and over $68 \%$ attended part-time for part of the year (Horn, Peter, \& Rooney, 2002). In fall 2006, Provasnik and Planty (2008) reported about $62 \%$ of community college students attended part-time. In 1999-2000, more than 50\% of all independent students (no dependents and unmarried, married with no dependents, single parent and married parents) attended a 2year institution and in 2003-2004 more than $60 \%$ of all independent students attend a community college (Horn, Peter, \& Rooney, 2002; Provasnik \& Planty, 2008). In 19992000 , of the students that reported parents with a high school diploma or less more than $53 \%$ attend a 2 -year institution compared to $46 \%$ of those students who reported parents with some postsecondary education and only $33.5 \%$ with parents with a bachelor's 
degree or higher (Horn, Peter, \& Rooney, 2002). In 2003-2004, 40.8\% of all community college students reported parents' highest level of education as high school or less, $27.1 \%$ with some secondary education and 32.1\% with a bachelor's degree or higher (Provasnik \& Planty, 2008). Over $60 \%$ of 2-year institution students worked full-time (Horn, Peter, \& Rooney, 2002).

Within the sixteen Kentucky community and technical colleges, only three have any form of residential on-campus housing, which is used by a small percentage of the total student population. This is consistence with community colleges nationally, as noted by. Pascarella and Terenzini (1991) "very few two-year colleges have residential facilities" (p.414). Thus, the majority of the more than one hundred thousand KCTCS students do not live on campus and commute to class. Between 2005 and 2008 the percentage of students attending full-time ranged from $36 \%$ to $40 \%$. Between 2005 and 2008 the percentage of students attending part-time ranged from $60 \%$ to $64 \%$ (Factbook, 2008, p.106). Between 2004 and 2008, the percentage of students 18-24 years of age has ranged from $42 \%$ to $46 \%$. Between 2004 and 2008, the percentage of student 25 years of age and older has ranged from $43 \%$ to $45 \%$ and in no year has the difference been greater than $3 \%$. Also, in 2008, the percentages were $44 \%$ for both sexes (Factbook, 2008, p.147).

\section{Review of Literature}

\section{Community Colleges, Developmental Education and Online Persistence Studies}

Even after Bean and Metzner's (1985) definitive work, retention and persistence research is still mostly concerned with traditional age, residential and full-time status students. In 1991, Pascarella and Terezini's first volume of "How College Affects 
Students", the authors stated, "first, the evidence has bias. It focuses largely (although not exclusively) on nonminority students of traditional college age (eighteen to twenty-two), attending four-year institutions full-time and living on campus....It is clear, nonetheless, that the impacts of college on such 'nontraditional' students are underrepresented in the existing evidence" (p.13). This criterion limits research to four-year institutions and neglects the role of non-traditional and in particular community college students, which has led to a neglect of community college research in mainstream higher education journals (Bailey \& Alfonso, 2005; Townsend, Donaldson, \& Wilson, 2009). In Pascarella and Terezini's second volume of "How College Affects Students" (2005), they stated, "we witness an appreciably greater volume of evidence in the 1990s that attempts to account for variations in many factors-such as age, work responsibilities, ethnicity, sex, full- or part-time (or even interrupted) attendance, and resident versus commuter status in estimating the impact of college" (p.2.) All of these factors are more closely associated with nontraditional students. Likewise, they noted, "the literature of the 1990s evidenced an expanded notion of the kinds of postsecondary institutions worthy of study....it is perhaps most pronounced in the case of the two-year, community colleges" (p.2).

Not only are community colleges often absent from mainstream higher education journals, but there is also a lack of research regarding community college and online student persistence. Likewise, because the majority of developmental education occurs within community colleges and community colleges have been neglected in research; developmental education students have been neglected. Muse (2003) noted, "little is known about why students succeed or fail in this environment [web-based courses]. 
Empirical data describing who may be successful in web-based learning environments at the community college are scare" (p.242). Likewise, four years later, Liu, Gomez, Khan, and Yen (2007) noted, "most past studies focused primarily on either community college dropout in a traditional face-to-face setting or distance learning dropout in general. There is a lack of research to better understand the community college online course dropout" (p.520).

Pantages and Creedon (1978) reported an extensive review of attrition studies from 1950 through 1975 focusing on many aspects included variables and their affects. In the same year, Diane Pezzullo (1978) compiled a review of persistence studies and community colleges from 1973 to 1978 . This study includes a review of persistence studies from the past 30 years (1980-2010). The following persistence studies included developmental students (Amey \& Long, 1998; Bettinger \& Long, 2005; Boylan, Bliss, \& Bonham, 1997; Campbell \& Blakey, 1996; Cantone, 2001; Clagett, 1996; Feldman, 1993; Fike \& Fike, 2008; Fox, 1986; Grimes, 1997; Hoyt, 1999; Kielbaso, Dirkx, Min, \& Allen, 1998; Nora, Attinasi, \& Matonak, 1990; Smith, O’Hear, Baden, Hayden, \& Gorham, 1996; Umoh, Eddy, \& Spaulding, 1994, Waycaster, 2001; Zhao, 1999). The majority of these studies, which were concluded in the 1990s, included students in reading, English and math, but four of them specifically addressed developmental math students (Cantone, 2001; O'Hear, Baden, Hayden, \& Gorham, 1996; Umoh, Eddy, \& Spaulding, 1994, Waycaster, 2001).

This study chose to include persistence studies from community colleges regardless of the delivery method. Also, the study included distance education courses in any educational setting (e.g. 2-year and 4-year) because previous research showed that 
academic integration significantly impacted persistence in both settings whereas social integration did not. Twenty-one studies were reviewed in a distance education context. Forty-five studies were reviewed in a community college context. Sixty-six total studies were reviewed. Even when Liu, Gomez, Khan, and Yen (2007) proposed a framework for online community college student dropout, they did not note any significant differences between these groups of students as opposed to distance education students at other institutions. They simply noted the high dropout rates at community college

\section{Age.}

The majority of studies found that age had no effect on persistence. However, all five online studies that found age to be significant found older students persist at a higher rate than younger students (Dillie \& Mezack, 1991; Doherty, 2006; Moore, Bartkovich, Fetzner, \& Ison, 2003; Muse, 2003; Valasek, 2001; Xenos, Pierrakeas \& Pintelas, 2002). In the traditional community college studies, four studies found younger students persist at a higher rate, while two other studies found older students persisted at higher rates. Clergy's (2008a) study of traditional community college students confirmed younger students (age 24 and younger) persist at a higher rate than older students (age 25 and older). However, Clergy (2008a) also found that older students "accumulated more credential-bearing credits, completed higher percentages of credits attempted, and had slightly high grade point averages than students less than 20 years old and students 20 to 24 years old" (p.2). Some traditional community college studies did not differentiate between traditional and nontraditional aged students, but found that particular age groups such as $20-24,23-34$, and over 30 had the highest persistence rates. One study (Fike \& Fike, 2008) found age had mixed results based on length of time persistence was 
measured (semester to semester or year to year). Another study (Swager, Campbell, \& Orlowski, 1995) found age affected persistence differently based on sex. Some studies limited the age range of the sample. Conway (2009) only included student ages 18-24 and Kemp (2002) only selected students between the ages of 30 and 45 .

Age was a consistent factor for distance education students, but varied greatly for traditional community college classes. For distance education students, the older the student the higher rates the student persisted. One reason for this is that many online programs are "targeted" at adult learners. Also, many adult learners note that they prefer distance education because of the flexibility that it provides as they manage work, family and other responsibilities. Therefore, when comparing older and younger students in a distance education context the fact those older students persist at a higher rate than younger students likely does not identify younger students doing poorly in distance education, but the necessity of success for adult student. The distance education context may be the only delivery method in which adult learners can obtain higher education, because they do not have the option of taking classes during the day on campus, whereas younger students may have the flexibility to take classes on campus, online, etc. Also, these assertions are under the working assumption that the term "younger" student is actually a function not of biological age, but of responsibilities and life status. Younger would refer to students who are not married, do not have dependents and do not work full-time (they may have part-time employment).

\section{Credit hours accumulated.}

The distance education compared to traditional community college classes showed a distinct difference regarding credit hours accumulated. Six distance studies 
considered total credit hours accumulated as a factor. Three studies only considered other previous online classes, while three others considered all credit hours accumulated. Two studies (Inan, Yukselturk, \& Grant, 2009; Parker, 1999) tested how previous online classes affected persistent, but found they had no effect. However, Dupin-Bryant (2004) found previous online classes to increase persistence. Three other studies (Doherty, 2006; Tidewater Community College, 2001; Moore, Bartkovich, Fetzner, \& Ison, 2003) found mixed results. Tidewater Community College found no effect on persistence. Doherty (2006) found more total credit hours increased persistence and Moore, Bartkovich, Fetzner, and Ison (2003) found less total credit hours increased persistence.

Six traditional community college studies consider total credit hours accumulated as a factor and found more total credit hours increased persistence. Also, Clergy (2008b) found "students fully completing their developmental requirements during the first academic year" accumulated more credit hours than students who did not (p.2). Also, Clergy (2009b) found, "older students were more likely to stop out early in their academic program; however, those persisting to the second and third academic years were less likely to stop out then younger students" (p.1). Calcagno, Crosta, Bailey, and Jenkins (2006) found the number of credit hours earned has less of an impact on older students (over age 25) on completion than younger students (age 25 and younger). Calcagno, Crosta, Bailey and Jenkins's finding may provide the necessary insight to understanding this difference in the two contexts. If distance education is attracting a greater portion of adult learners compared to the traditional community college setting attracting an equal or larger portion of younger students, then this would account for the difference in the two groups of studies. 
Also, most of the online studies test other online courses. This provides insight into the nature of the students in these studies. The distance education persistence studies do not often clarify if their sample is from students who are completing an online class or an online program. Likewise, many of the traditional community college persistence do not include the likelihood that these students, who are predominately taking in person class, could also be taking online courses. Fike and Fike (2008) used taking an online class as factor in their persistence study and found that it increased persistence for community college students for fall to fall persistence.

This finding has implications for developmental education policy. As more states make polices that require students to complete developmental education within the first 24 to 30 credit hours, this would negatively impact for younger students regarding their persistence rates. However, it may have positive affects regarding nontraditional students or at least have a less significant effect on their persistence rates.

\section{Degree program.}

At the community college level, the institution may award a certificate, diploma, or degree in that order of total credit hours. Degrees may or may not be transferable to a four-year institution. Often times, transfer degrees are referred to as academic, whereas terminal two-year degrees are technical in nature. Only one distance study (Richard \& Riley, 1997) included degree program as a factor in their study. They found having an educational objective increased persistence. To the contrary, Goel (2002), which was one of thirteen traditional community college studies, found that having an unknown educational objective increased persistence. Three traditional studies (Cofer \& Somers, 
2000; Fischbach, 1990; Hippensteel, St. John, \& Barkley, 1996) found degree program had no effect on persistence.

Feldman (1993) found a certificate degree program decreased persistence, while Brooks-Leonard (1991) found that technical certificates and associates of science degrees increased persistence. Two studies found students in vocational programs had higher persistence rates than academic programs, while three different studies found associates and transferable program programs to increase persistence. Bers and Smith (1991) also noted that students in academic and/or transferable programs increased persistence. Romano (1995) found nontransferable degree programs decreased persistence. The only consistent finding in the review was that Daniels (1990) found undecided majors decreased persistence and Price (1993) found non-degree program statuses decreased persistence. This finding was supported by Provasnik and Planty (2008). Campbell and Blakey (1996) found degree seeking intent was a significant predictor of persistence and Voorhees (1987) found purpose for enrolling was related to persistence. Mohammadi (1994) found, “the students' goals for attending college is a very strong predictor of retention....a high percentage of students ( 288 or 40 percent of the fall 1988 cohort) who left the college after one year had no intention of completing a degree or a certificate program" (p.14-15).

Degree program is a dynamic factor and may change at any time in the student's career. Lajubutu, Oyebanjo, and Yang (1998) found that students who changed their choice of curriculum were more likely to be successful that those that did not. This change may indicate that the student has better determined their academic path and, thus, increase persistence. 
From this literature review, neither the type of program nor the type of award (certificate, diploma or degree) appears to have a distinct impact on the student's level of persistence. However, the intent of the student-to complete a certificate, diploma, degree, transfer or take a class or classes-does impact persistence. If a student enrolls with the intent of only taking a specific class, which would ideally put the student in a non-degree program, then the student would not return in a subsequent semester; thus increases persistence. This distinction is what separates retention and persistence studies. This persistence study recognizes that students who transfer or meet an educational objective have successfully completed their college career. Thus, students who transfer or complete a certificate or diploma and do not return to the community college are not considered negatively.

\section{Dependency status.}

Dependency status was not considered as a factor in any of the online studies reviewed. However, three traditional community college studies used it as a factor. Two studies (Hippensteel, St. John, \& Barkley, 1996; St. John \& Barkley, 1994) found that dependency status had no effect on persistence. Cofer and Summer (2000) found that dependent students were more likely to persist. This was confirmed by O'Toole, Stratton, and Wetzel (2003) in a national data study on community colleges.

Dependency status is determined by a number of variables. If a student is (a) twenty-four years of age or older, (b) married, (c) has a dependent(s), (d) a veteran, or (e) a graduate student, the he/she is considered independent. Therefore, students who are considered dependent would also be considered traditional students because they are under the age of 24 and are not married or have children. Also, dependency status is determined by the federal government and these standards may change based on the year. 
For example, the federal regulations were recently changed to include persons who were "at risk of homelessness" as independent. Likewise, colleges have the authority to use "professional judgment" and change a student's status from dependent to independent. Therefore, rather than using this as a factor, most studies utilize the other components that comprise this factor, such as age, marital status and dependents.

\section{Dependents.}

Only one distance education study tested the effects of having a dependent (Dillie \& Mezack, 1991) and found dependents to have no effect on persistence. In Kinser and Deitchman (2007) interviews they noted, "Wanda, one of the two standard persisters with children living at home, only mentions her children as motivating her to do well in school, not as motivating or delaying her return (George, the other standard persister with children, does not talk about them as being a factor at all). Children, then, may influence tenacious persisters in different ways" (p.90). Moore (1995) found that "family responsibilities" was the second most popular response when students were asked why they did not re-enroll. Likewise, Hawley and Harris (2005-2006) found that "family responsibilities" and Zhai and Monzon (2001) found that "family obligations" decreased persistence. Grosset (1991) and Kinser and Deitchman (2007) found dependents increased persistence. Hoyt (1999) and Baird (1991) found dependents decreased persistence. Maack (2002) was the only traditional community college study that found dependents to have no effect.

The lack of studies, which included the effect of dependents in distance education, allows for a very limited level of understanding to the extent that no real inferences can be made. Having dependents is similar to marital status because the status (no dependents 
or any number of dependents) does not necessarily have direct affect persistence, but the affect varies depending on the nature of the dependents. For example, some students may find that the time and energy that is required for caring for child conflicts with school, but others may find children as a motivating factor. As Wanda noted the children are a motivation for pursing higher education. However, for other students, children may prevent the parent from enrolling in college or cause dropout. Also, dependents may affect students differently based on the sex of the parent. As showed in Kinser and Deitchman (2007) interviews Wanda mentions the children, whereas George does not. Based on cultural expectations, dependent children could affect males and females differently. Females could feel a strong cultural expectation to physically and emotionally care for the children. This could motivate females withdraw from college. Males could feel a strong cultural expectation to financially care for the children. This could motivate males to not withdraw. Also, Mason (1998) found that a supportive wife or parent increased persistence for males, so other family members could provide the needed support for those students in which dependents motives withdrawal. Lastly, the term "dependents" is used in all of these studies as referring children of students. However, a dependent can refer to any person who is "dependent" upon another for support, often financial. Therefore, adult learners may find themselves financially supporting their own children and aging parent(s).

\section{Employment status.}

Employment is a factor in twenty-three of the studies reviewed. Only five, two online and three traditional community college class, found employment to have no effect on persistence. Employment is often differentiated between part-time and full-time 
employment. Three of the studies specifically noted full-time employment decreased persistence. Whereas two studies noted that part-time employment increased persistence and two other decreased persistence. However, one online study (Taplin \& Jegede, 2001) found students who work less than 20 hours are less likely to persist. Whereas a second online study (Muse, 2003) found students who worked more hours increased persistence. Price (1993) found that unemployment decreased persistence. Some studies simply treated employment as a dichotomous variable (e.g. employed or not employed), while others noted more general job-related student responses such as "work demands" or "job conflicts" (Conklin, 1997; Farahani, 1993; Swager, Campbell, \& Orlowski, 1995). When employment is classified as "work demands" or "job conflicts" these have led to decreasing persistence. Moore (1995) found that "job responsibilities" and "work related course" were the third and fourth most popular responses to why a student did not reenroll (p.8). Likewise, Woodley and Parlett (1983), who reported the findings of two other studies (Woodley \& McIntosh, 1980; Phythian \& Clements, 1982), noted Woodley and McIntosh (1980) found, "[reasons for not completing final registration] 77 per cent were related to domestic and work circumstances" and Phythian and Clements (1982) noted, "domestic and job factors were given by 61 per cent of respondents as their main reason [for dropout]" (as cited in Woodley \& Parlett, 1983, p. 8). Overall, fourteen studies found that some level of employment decreased persistence and four studies found that employment increased persistence.

Taplin and Jegede (2001) qualitatively explained some of the discrepancy between employment status and persistence. Their research found that the number of hours was not the determining factor in the students' success, but the intensity of the 
workload and regularity of the work. In some cases, highly motivated full-time employees can possess the time management skills to be successful both at work and in college. This high level of competency may aid them in finding full-time employment. Also, current employment may require employees to become students for employment purposes. In these situations, work may be the most influential component. However, some people may have become students because of unemployment. Therefore, if they gain employment in their college career, they may have seen their educational objective met because they have obtained full-time employment. This may be a common situation in community and technical colleges which serve the workforce population.

\section{Enrollment status.}

This literature review found a great discrepancy between online and traditional community college classes regarding enrollment status. Six online studies used enrollment status as a factor. Four studies (Aragon \& Johnson, 2008; Cheung \& Kan, 2002; Dillie \& Mezack, 1991; Morris, Wu, \& Finnegan, 2005) found that enrollment status had no effect. One study (Doherty, 2006) found more credit hours decreased persistence. Another study (Moore, Bartkovich, Fetzner, \& Ison, 2003) found that less than full-time enrollment increased persistence. Therefore, enrollment status has little effect on persistence, but in instances in which it does, distance education students who take less credit hours (e.g. part-time) are more likely to persist.

In traditional community college class, nineteen studies used enrollment status as a factor and all nineteen studies found it to affect persistence. Eleven of the studies found full-time enrollment increased persistence. Four additional studies (Clagett, 1996;

Lajubutu, Oyebanjo, \& Yang, 1998; Mohammadi, 1994; Zhao, 1999) found that the more 
credit hours in which a student is enrolled in a term, the more likely the student would persist. Three studies (Feldman, 1993; Goel, 2002; Price, 1993) found that part-time enrollment decreased persistence. Clergy (2007b) confirmed students enrolled full-time have higher persistence rates than part-time students. However, Clergy also reported that full-time students had a lower GPA than part-time students. Clergy posited that these students "take more difficult courses, such as upper-level math and English requirements or because they are less academically prepared" (p.2). Only one study (St. John \& Barkley, 1994), which was one of the only two studies to report that a higher GPA negatively affected persistence, found that full-time enrollment decreased persistence. Regarding enrollment status, St. John and Barkley (1994) reported, "for the average student, full-time attendance decreased the probability of persistence by about $4 \%$. We suspect this negative association was attributable to higher costs of attending full time and the fact that full-time students usually do not earn as much from working as do parttime students" (p.208).

The function of enrollment status in the distance and traditional community college contexts could be attributable to the student population. As noted earlier, distance education programs regularly attract adult learners who often attend on a part-time basis. Therefore, a part-time enrollment status in distance education being positively associated with persistence could be reflective of nontraditional students. Whereas, the opposite, a full-time enrollment status in traditional community college classes being positively associated with persistence could be reflective of traditional students.

Also, all the studies reviewed assessed enrollment status as either full-time, parttime or some degree of variance between one class or some small number of credit hour 
(e.g. 3) and full-time enrollment, which is often defined as twelve credit hours or more. For all the studies that report "full-time" enrollment it must be assumed that they are reporting students in enrolled in twelve credit hours or more, but those students who are actually enrolled in more than twelve credit hours are never identified. Thus, none of the studies report the effect of enrollment status on persistence for students who actually enroll in more than twelve credit hours. One may assume, as shown in the traditional community college classes, that a full-time enrollment does increase persistence rates, but at some point, the increased number of credit hours may have a negative effect on persistence. Therefore, the idea that "more credit hours increase persistence" is not an accurate way in which to portray the relationship between enrollment status and ideal persistence. In a distance education context, compared to a traditional community college context, the ideal number of credit hours may be six credit hours for online students and twelve credit hours for traditional students. This may be a function of external pressures rather than a quantitative function of the actual enrollment status. If nontraditional students are taking classes through distance education, then the responsibility of work, family and other obligations may only allow for a part-time enrollment status for the student to persistent, but the traditional student in traditional classes may be best suited for full-time enrollment.

Enrollment status as a variable is often used in persistence studies to identify academic integration (see Tinto, 1975). In these studies, the more credit hours in which a student is enrolled the higher a level of academic integration is considered for the student. Academic integration has found to be an important predictor of community college students. However, it is often assumed that in all cases the more credit hours a student 
takes the more integrated they will be, thus the more likely they will persist. Tinto's original theory was based on traditional students in a residential setting. Therefore, the literature review would confirm this idea. However, in a distance education setting, when enrollment status is used to determine academic integration, students taking more than half-time enrollment may actually we creating an unbalanced level of responsibility, thus increasing the likelihood that they will withdraw. As evident in the studies that report employment, dependents and other responsibilities, these are the factors that are reported as reasons for withdrawal. Rather than attempting to find ways to fully "integrate" the student into the institution for the purpose of persistent, the institution should seek to find a responsible level of balance, so the student may persist while also attending to responsibilities outside the classroom.

\section{Financial aid.}

Two online studies explored financial aid as a factor. Morris, $\mathrm{Wu}$, and Finnegan (2005) found that financial aid increased persistence. However, Aragon and Johnson (2008) found that financial aid eligibility had no effect on persistence. Four traditional community college studies tested financial aid. Two studies found that financial aid increased persistence (Cofer \& Summer, 2000; Hoyt, 1999), but two others (Romano, 1995; St. John \& Barkley, 1994) found that it decreased persistence. Also, a multiple community college study found receiving some financial aid increased persistence for full-time students (Clergy, 2007a) and a national data study of two and four-year colleges found receiving financial aid increased persistence (Strauss \& Volkwein, 2004).

Some persistence studies test specific forms of financial aid. St. John and Barkley (1994) specifically tested the effect of grants, which showed they decreased persistence. 
However, an Indiana state-wide study of full-time, resident undergraduate students at public two and four-year institutions, found students who received a state grant were more likely to persist (St. John, Hu, \& Weber, 2001). A multiple community college study found receiving a Pell grant increased persistence (Clergy, 2006c) and a national data study found students who have a work-study job are more likely to persist (Stratton, O'Toole and Wetzel, 2007). Clergy (2006c) also found that being a Pell grant recipient increased enrollment status, $61 \%$ were full-time. This may be because Pell grants are awarded based on three credit hour increments and reaches its maximum award at 12 credit hours. However, Clergy (2006c) also found that students who did not receive a Pell grant accumulated more credit hours and had a higher completion ratio than students who did, but "there was minimal difference in the grade point averages" for both groups (p.2).

Financial aid studies have found mixed results, but it is apparent that collectively testing financial aid does not provide specific enough information to make the most accurate determination of how the various forms of financial aid impact the student. For example, grants, which are monies that they student does not pay back as opposed to loans, which the student must pay back, compared to work-study which is work and compensation for the job performed have shown to have different effects on persistence.

\section{Grade point average.}

Every online and traditional community college study, except two (Morris, $\mathrm{Wu}, \&$ Finnegan, 2005; Umoh, Eddy, \& Spaulding, 1994) found a higher grade point average increases persistence.. Umoh, Eddy, and Spaulding (1994) and Morris, Wu, and Finnegan (2005) found grade point average to have no effect on persistence. Strauss and Volkwein (2004) confirmed this finding with their national data study of two and four-year colleges 
Five studies (Hippensteel, St. John, \& Starkey, 1996; Patterson \& McFadden, 2009; St. John, Oescher, \& Andrieu, 1992; St. John, \& Starkey, 1994; Willging \& Johnson, 2009) found different effects of grade point average. Patterson and McFadden (2009) and Willging and Johnson (2009) were not included in the literature review because the single university samples were graduate students. Willging and Johnson (2009) found a higher grade point average to be associated with a student dropping the course. The authors noted, "because the focus of this study was on a single program with a small number of dropout students, the generalizability of the results of this study is greatly limited" (Summary and Conclusion section, para. 1). However, Patterson and McFadden (2009) conducted a similar study on students in two master's level programs at one university. They found that undergraduate GPA had no effect on persistence for students in either online program. Patterson and McFadden (2009) also noted limits to generalizability, but noted, "this supports the possibility that other factors beyond student characteristics such as situational factors external to the individual and instructor may be impacting dropout" (Conclusions section, para. 2.). Given that this research was conducted on masters level students, it is possible that external factors, such as work and family, which have been identified in previous studies as having a significant impact on nontraditional student persistence as an even greater affect than academic achievement as the student progresses academically and/or professionally. Parker (1995) noted, "review of the interview scripts for external, self-paying students indicated that outside pressure of job and family took precedence over the loss of tuition monies and the importance of completion" (p.402). 
Likewise, St. John and Starkey (1994), noted, "we suspect this finding [GPA negative effect on persistence] was attributable to institutional polices that penalize students who withdrew with low academic standing during the middle of the academic semester" (p.208). Hippensteel, St. John and Starkey (1996) repeated this idea when they assessed the same factors regarding nontraditional aged students, "this situation [GPA negative effect on persistence] could be attributable to institutional polices that make it difficult for students with low grades to reenroll if they do not complete the academic year (St. John, et al., 1992)" (p.239). Both of these studies referred to an earlier study by St. John, Oescher and Andrieu (1992). St. John, Oescher and Andrieu was conducted on traditional college age students in four-year colleges and found the same outcome related to grade point average. They offer the previously noted rationale for the finding.

Grade point average has shown to be an important predictor in student persistence, particularly with students that are early in their postsecondary career. As noted, grade point average does not have the same level of effect on graduate level students. Likewise, it is likely that grade point average will not have the same effect on undergrad students in their third and four years of college. After a student has successfully academically integrated into college, this variable may not be such as robust predictor of persistence. Clergy (2008b) found, "students who partially completed their developmental education requirements earned GPAs either equivalent to or lower than students who did not complete any developmental education requirements. In a more expected outcome, students not referred to developmental education and those completing all requirements earned the highest average GPAs" (p.3). Clergy's suggestion for this finding was, "students not completing any developmental education may have 
enrolled in courses that did not require the same level of mathematical or reading comprehension, and would therefore be likely to complete more of these credits and obtain higher GPAs. On the other hand, students who have partially completed their developmental education may have begun enrolling in more challenging courses, but be struggling, thus, completing fewer credits with lower GPAs (p.3). This is important to note regarding developmental education because many state policies are such that these classes are to be taken and completed within the students first year of study (first 24 to 30 credit hours) (Shultz, 2000).

Also, depending on.how GPA is reported, studies could be showing the effects of GPA after a withdrawal has occurred. For example, if a student completed 12 credit hours in the fall term, then the student has a 4.0 GPA. However, if the student enrolls in 12 credit hours in the spring term and completely withdraws, then the GPA becomes a 2.0. Therefore, if the study assumes the students GPA is 2.0 , withdrawal may be associated with a low GPA, but the student's actual GPA, before the time of withdrawal, was a 4.0. Thus, the lower GPA (e.g. 2.0) is an outcome of the withdrawal not a predictor of withdrawal. Therefore, studies should evaluate the student's GPA at the end of the term prior withdrawal rather than the student's GPA at the end of the term in which the student withdrawals.

\section{Marital status.}

Marital status was initially examined by Ross and Powell (1990), who said, "marital status has been tied to academic achievement, indicating that students who have supportive spouses (or partners) increase their chances of success (Powell, et al., 1989); however women reported that they had someone other than a spouse/partner to rely on for 
support" (p.11). Mason (1998) found a supportive parent or wife increased persistence. Likewise, Taplin and Jegede (2001) also validated Ross and Powell's finding, which implied that the act of being married does not affect persistence, but a spouse's encouragement or discouragement does affect persistence. Other studies confirmed this finding (Grosset, 1991; Mason, 1998; Park \& Choi, 2009; Sorey \& Duggan, 2008).

For traditional community college classes five studies found marital status to have no effect. One study (Price, 1993) found being single lower student's persistence rates, while another study (Baird, 1991) found being married lowered student's persistence rates. Strauss and Volkwein (2004) found that married students' level of commitment to the institution was greater than students who were not married at both two and four-year institutions. For distance classes two studies found marital status to increase persistence while two others found marital status to have no effect. Kemp (2002) found that family, personal, home and community had no effect on course completion for first time university students in an online course.

Marital status may increase or decrease persistence depending on the spouse. If the spouse is support this often increases persistence, but if the spouse is discouraging this is often decreases persistence. Powel et al. (1989) and Mason (1998) showed that other family members, such as a parent may have a strong positive or negative impact on persistence, particularly with females. The strength of influence and extent that personal relationships have on persistence may greatly vary depending on the course delivery method. Likewise, other family members, friends and mentors may have a significant impact on persistence. 


\section{Parent's education level.}

No online studies, but six traditional community college studies considered parent's level of education as a factor for persistence. Three studies (Hippensteel, St. John, \& Barkley, 1996; St. John \& Barkley, 1994; Umoh, Eddy, \& Spaulding, 1994) found that parent's level of education had no effect on persistence. Likewise, a national study (Choy, 2001) noted, "among 1995-96 beginning postsecondary students with certification or associate's degree goals, there were no meaningful differences between first-generation and other students in either the percentage who had attained degrees or certificates by 1998 or the percentage who had left without attaining" (p. 24). Hoyt (1999) and Cofer and Somers (2000) found that having parent's with a college degree (or some level of college education) increased persistence. Fike and Fike (2008) found that comparing the student's mother and father's level of education affected student's persistence differently. Fike and Fike found that the mother's college education did not affect persistence, but that the father having some college increased persistence when testing for fall to spring persistence. However, when they tested fall to fall persistence both father and mother having some level of college education was significant.

\section{Sex.}

Thirteen online studies considered sex as a factor. Eight studies found that sex had no effect on persistence, but five studies showed that being female increased persistence. No online studies showed that being male increased persistence. Likewise, twenty-three traditional community college studies tested sex as a factor. Twelve studies found that sex had no effect on persistence and six studies found being female increased persistence. Also, Clergy (2008d) found "female students are doing better in developmental courses 
and persisting at higher rates than male students" (p.2). The findings between online and traditional community college classes were very similar. However, there were some traditional community college studies that found some different results.

Two studies found that being male actually decreased persistence (Baird, 1991; Feldman, 1993). Also, two studies showed that being female decreased persistence (Price, 1993; Zhai \& Monzon, 2001). None of these community college or online studies found that being male increased persistence, but a single university study (Boyer, 2005) and a national data study (Stratton, O’Toole \& Wetzel, 2007) found males have a higher persistence rate than females.

Kim (2002) noted that other factors affected affect why males and females persistence rates decreased. Kim said, "the greater tendency of female students to drop appeared to result from reduced parental financial aid. The more male students tended to drop, the higher the status of their mother's job and the more they plan to transfer to another institution" (p.25). Clergy (2008d) also found that females had a higher GPA and completed a larger percentage of credits attempted than males. Inan, Yukselturk, and Grant (2009) reported that Xenos, Pierrakeas and Pintelas (2002) found that sex had no effect on persistence. However, Xenos, Pierrakeas and Pintelas (2002) actually reported that females were more likely than males to not start a course for which they had registered, but once the classes started females were more likely than males to complete an online course.

Sex appears to have little effect on persistence, but it appears to favor females in an online and community college context. However, sex itself does not appear to be the factor that contributes to success. Rather it appears that other factors that are linked to sex 
are influential in the success or failure of either sex. Actually, with females have been showed to have greater success in online and community college settings, it appears that these two contexts provide necessary support system to make for a successful environment. For example, if female students have children and are in need of childcare, online context may not necessitate that childcare be found. Likewise, community colleges may also provide childcare as a service to students.

\section{Socio-economic status.}

No online studies, but eleven traditional community college studies considered socio-economic status as a factor for persistence. Four studies (Brooks-Leonard, 1991; Clagett, 1996; Cofer \& Somers, 2000; St. John \& Barkley, 1994) found that socioeconomic status, adjusted gross income or income had no effect on persistence. Also, Nippert, (2000-2001) found that the parent's level of income had no effect on persistence. Two studies (Gates \& Creamer, 1984; Hippensteel, St. John, \& Barkley, 1996) found that higher level socio-economic students had higher persistence rates. Likewise, Hoyt (1999) found that lower level socio-economic students had lower persistence rates. Also, Mendoza, Mendez and Malcolm (2009) confirmed that student who had earned less than $\$ 20,000$ per year had lower rates of persistence, but students who earned more than $\$ 40,000$ per year had higher rates of persistence. These findings are consistent with other studies that included two and four-year institutions (St. John, Hu \& Weber, 2001; Stratton, O'Toole \& Wetzel, 2007). Deil-Amen (2003) said, "family income shows a small insignificant effect on dropout for community college students....However, further analysis could reveal that larger variations in age, family composition, and financial 
dependency status among community college students mediates the influence of family income on dropout" (p.14).

Contrary to these findings, Conklin (1995) found at one community college that students with a high socio-economic level had lower persistence rates. Also, Zhai and Monzon (2001) found that students who earned than $\$ 33,000$ per year had lower rates of persistence. They also noted that students cited "financial difficulties" as a reason for withdrawing from classes.

\section{Summary of Variables}

Some studies showed each variable having little to no effect when comparing community college and distance education students, while some studies showed the variables to differ greatly. For example, some variables and studies showed distinctive results, such as, all five online studies showed that older students persisted at higher rates than younger students did and six traditional community college studies found that as credit hours were accumulated persistence increased. However, other variables, such as degree program showed no consistency other than a non-degree status decreased persistence. Some variables, such as dependency status, dependents, employment status, financial aid, marital status, and parent's level of education showed no consistency whatsoever. One variable, enrollment status, found a great discrepancy between distance and traditional community college students; as the enrollment status increased (e.g. threequarter time, full-time) for community college students persistence increased, but as enrollment status deceased for online students persistence increased. Two variables, grade point average and sex, affected both distance education and community college 
students in the same manner. As grade point average increased, persistence increased and being female increased persistence compared to being male.

In conclusion, many of these variables differ based on their effect on persistence, but some appear to have consistent affects. Given these discrepancies and similarities, this study will be able to add to the literature regarding these variables effects on these groups of students and be able to add insight to their function with regard to persistence. 


\section{CHAPTER III}

\section{Overview}

From 1988 to 2006 , between $40 \%$ and $60 \%$ of all first-time community college students are referred to and enroll in at least one developmental education course; some colleges reported as high as $80 \%$ (Attewell, Lavin, Domina, \& Levey, 2006; Bers \& Smith, 1991; Bettinger \& Long, 2005; Boughan \& Clagett, 1995; Brawer, 1996; Clergy, 2006b, 2008d; Collins, 2009; Colorado Commission on Higher Education, 2009; Fujita \& Oromaner, 1992; Horn, Peter, \& Rooney, 2002; Kielbaso, Dirkx, Min, \& Allen, 1998; Lewis \& Farris, 1996; Maryland Higher Education Commission, 1996; McCabe, 2000; Parsad \& Lewis, 2003; Perry, Bahr, Rosin, \& Woodward, 2010; Shults, 2000). Around twice the number of community college students enroll in developmental education compared to four-year public universities (Attewell, Lavin, Domina, \& Levey, 2006; Levin \& Calcagno, 2008).

More students begin college less prepared in math than any other area (ACT, 2006, 2007, 2008, 2009; Attewell, Lavin, Domina, \& Levey, 2006; Bettinger \& Long, 2005; Cartnal, 1999; Clergy, 2006a, 2006f; Colorado Commission on Higher Education, 2009; Horn \& Berger, 2004; Horn, Peter, \& Rooney, 2002; Kielbaso, Dirkx, Min, \& Allen, 1998; King \& Crouse, 1997; Lewin, 2008; Lewis \& Farris, 1996; Maryland Higher Education Commission, 1996; McCabe, 2003; Parsad \& Lewis, 2003; Phipps, 1998;

Provasnik \& Planty, 2008; Virginia Community Colleges Office of Institutional Research 
and Effectiveness, 2008; Washington State Board for Community and Technical Colleges, 2006, 2007, 2009).

In effort to meet the aforementioned challenges, the state of Kentucky formed the Kentucky Developmental Education Task Force to identify particular problems and evidence for change. Kentucky faces the same changes that other states in the United States face. "More than half of the first-time freshmen entering Kentucky's colleges are underprepared in at least one subject. Even worse, for those underprepared students, the first-year college drop-out rate is twice the rate of academically prepared freshman" (Kentucky Developmental Education Task Force, 2007, p.5).

In 2003, Parsad and Lewis reported $13 \%$ of institutions used distance education in providing developmental education classes. In the fall of $2000,25 \%$ of two-year institutions used technology in developmental classes compared to $8 \%$ of four-year public and 4\% of private four-year (Parsad \& Farris, 2003). "Many experts in the world of mathematics and beyond contend that we cannot meet our developmental math student success goals without incorporating technology" (Epper \& Baker, 2009, p.3).

"Two-year associate's institutions have the highest growth rates and account for over one-half of all online enrollments for the last five years" (Allen \& Seaman, 2007, pg. 1). Attrition is a challenge for online education (Carr, 2000; Diaz, 2002; Flood, 2002; Frankola, 2001; Martinez, 2003; Moody, 2004; Parker, 2003; Patterson \& McFadden, 2009; Phipps \& Merisotis, 1999; Royer, 2006; Shin \& Kim, 1999; Tyler-Smith, 2006; Valasek, 2001; Zavarella \& Ignash, 2009).

\section{Research Questions}

Is there a significant relationship between age and persistence? 
H1 There is no significant relationship between age and persistence

Is there a significant relationship between secondary education and persistence?

H1 There is no significant relationship between secondary education and persistence.

Is there a significant relationship between father's level of education and persistence?

H1 There is no significant relationship between father's level of education and persistence.

Is there a significant relationship between mother's level of education and persistence?

H1 There is no significant relationship between mother's level of education and persistence.

Is there a significant relationship between dependency status and persistence?

H1 There is no significant relationship between dependency status and persistence.

Is there a significant relationship between marital status and persistence?

H1 There is no significant relationship between marital status and persistence. Is there a significant relationship between having dependents/children and persistence?

H1 There is no significant relationship between having dependents/children and persistence.

Is there a significant relationship between the number of household members in college and persistence? 
H1 There is no significant relationship between the number of household members in college and persistence.

Is there a significant relationship between course delivery method and persistence?

H1 There is no significant relationship between course delivery method and persistence.

Is there a significant relationship between adjusted gross income and persistence?

H1 There is no significant relationship between adjusted gross income and persistence.

Is there a significant relationship between the number in household and persistence?

H1 There is no significant relationship between the number in household and persistence.

Is there a significant relationship between degree program and persistence?

H1 There is no significant relationship between degree program and persistence.

Is there a significant relationship between grade point average and persistence?

H1 There is no significant relationship between academic program and persistence.

Is there a significant relationship between grade point average and persistence?

H1 There is no significant relationship between grade point average and persistence. 
Is there a significant relationship between credit hours accumulated and persistence?

H1 There is no significant relationship between credit hours accumulated and persistence.

Is there a significant relationship between enrollment status and persistence?

H1 There is no significant relationship between enrollment status and persistence.

Is there a significant relationship between sex and persistence?

H1 There is no significant relationship between sex and persistence.

Is there a significant relationship between waiver/third party and persistence?

H1 There is no significant relationship between waiver/third party and persistence.

Is there a significant relationship between federal work-study and persistence?

H1 There is no significant relationship between federal work-study and persistence.

Is there a significant relationship between being a single mother and persistence?

H1 There is no significant relationship between being a single mother and persistence.

\section{Context: Kentucky Community \& Technical College System (KCTCS)}

The Kentucky Postsecondary Education Improvement Act of 1997 (House Bill 1) created the Kentucky Community and Technical College System (KCTCS), which is the state of Kentucky's public two-year comprehensive college system. KCTCS was established in 1998 through the merger of the community colleges, which were 
previously part of the University of Kentucky, and the technical colleges, which were previously part of the Frankfort Cabinet for Workforce Development. This formation created sixteen community and technical colleges operating as one state system (Metamorphosis, 2008).

KCTCS has the following sequence of developmental math courses: ARI 030, MT055, MT065 and MT108. First, all "students enrolling in KCTCS colleges for the purpose of earning credit applicable toward an educational credential (certificate, diploma, or associates degree) must demonstrate through the submission of scores on specified assessment instruments that they possess the minimum academic skills essential for success in curses required for the credential" ("KCTCS Administrative Polices", para. 1). KCTCS prefers assessment instruments from ACT, Inc., but SAT scores may be accepted. There are four groups of students who are exempt from this policy; they are: (a) students with a non-degree status, (b) students in continuing education certificate programs, (c) students earning credentials have 18 credits or below, and (d) students who have been granted the college waiver process ("KCTCS Administrative Polices", Attachment 1). There are "special provisions" for "students with borderline scores". If the student scores "within three points of the minimum admission level" and "have taken the diagnostic portion of the relevant subtest(s)" may be placed into that course if the course offers "supplementary academic support" (e.g. extra class sessions, additional labs, tutoring, and increased monitoring of students) ("KCTCS Administrative Polices", Special Provision). Students who do not submit ACT scores or whose ACT scores are below the subject area minimum (e.g. 19 in mathematics) are placed in a developmental course based on their COMPASS (or ASSEST) test score ("KCTCS Administrative 
Polices", Associate Degree-Seeking Students). A student who scores below a 17 on the COMPASS test may be placed into ARI 030 or referred to Adult Basic Education. A student who scores a 17 to 40 on the COMPASS test places into MT055 Pre-Algebra, which is a non-credit bearing developmental math course. A student who scores a 41 to 100 on the COMPASS test places into the next course sequential course, MT065 Basic Algebra, which is also a non-credit bearing developmental math course. After successfully completing MT065, a student may take any KCTCS credit-bearing math course that would fulfill the requirement for a technical degree program. These courses would include, but are not limited to: MT105, MT110, MT115, and MT125 (Factbook, 2008). For a student to complete a credit-bearing transferable math course, an additional developmental math course would need to be completed, MA108R/MT120. The particular course designations for these three developmental math sequence has changed over the past ten years. From 2000 to 2006, the KCTCS Factbook (2008) noted the course sequence: MAH080, MAH083, and MA108 as developmental with the following courses as credit bearing: MA109, MT109, MT145, and MT150. In the fall of 2004, this included MT120/MT122 as developmental with the following, previous courses (e.g. MT145, MT150, MA/MT109) as credit bearing (p.27).

For the purpose of this study, the second sequential developmental math course, MT065, will be utilized. Selecting this particular course does limit the idea of open admission because students with the lowest level of math ability would test into MT055. However, studies have shown that the success and graduation rates for students in college's lowest level developmental math course (e.g. ARI 030 and MT055 PreAlgebra) are very low (Bailey, Jeong, \& Cho, 2009; Boatman \& Long, 2010; Kangas, 
1992a, 1992b; Perry, Bahr, Rosin, \& Woodward, 2010). Not only do students who test into Pre-Algebra have great need in developing math skills, but they also exhibit other high levels of educational need often in the areas of reading and writing, which lower persistence and success rates (Bahr, 2007).

\section{Research Considerations}

O'Hear and MacDonald (1995) reviewed studies on developmental education from 1985 to 1995 and reported that, "quantitative research is much more prevalent than qualitative or research reviews. Of the 52 studies examined, 40 employed quantitative methods, seven were categorized as qualitative, and five were classified as research reviews. Overall, 33 of $52(63 \%)$ research studies were judged unacceptable" (p.3). Of the three aforementioned types of studies, quantitative, qualitative and research review, quantitative studies were found to have the greatest number of errors, "most research (76.9\%) in developmental education is quantitative, and that most of those quantitative studies are seriously flawed" (O'Hear \& MacDonald, 1995, p.4). Of the quantitative studies, the majority of the errors were made within the design of the study, followed by the analysis, and, lastly, the operations. The types of design errors were subdivided and reported in the following categories: "eight errors were attributed to imprecise purpose, manifested in each case in nonexistent or overgeneralized research questions. Errors in reviewing the research occurred 15 times. Sampling errors occurred 19 times. Eight errors occurred in the adequacy of the measure used for the research purpose, and three errors occurred in term definition" (O'Hear \& MacDonald, 1995, p.4). O'Hear and McDonald (1995) said, "clearly, the field could greatly benefit from more research studies and more researchers. Methodology employed in developmental education 
research does not seem to have reached a level of attainment commensurate with the needs of the profession" (p.4).

In 1996, O'Hear and MacDonald published a second article that expanded upon the flaws found in the reviewed studies as well as examples and solutions to the problems. Within the design, they reported the problems as being: vague research questions, trying to accomplish too much in a project, citation of an insufficient number of meaningful sources as well as noncurrent or complete reviews, unclear key definitions, sample size, lack of control groups, and poor choice of types of measure (p.8-10).

This study recognizes the previously noted common flaws in design and other methodological areas. The purpose of the study is to add to the body of research related to developmental math and persistence in a manner that is both philosophically and methodologically sound. Thus, these areas of concern will specifically be addressed in the study to ensure the quality of the research.

\section{Research Purpose}

The purpose of this study is to examine the relationship between student demographic information, work and family and academic variables at a public state twoyear community and technical college system and student persistence.

The National Center for Education Statistics (NCES) identified seven risk factors affecting persistence: delayed postsecondary enrollment, students who were high school drop outs or GED recipients, students enrolled part-time, financially independent students, students with dependents other than spouse, single-parent students and those employed full-time (Horn \& Premo, 1995). This study will take these seven factors into

consideration: (a) age (as a measure of delayed postsecondary enrollment), (b) secondary 
education, (c) enrollment status, (d) dependency status, (e) dependents (e.g. children), (f) single parents (e.g. single mothers) and (g) federal work-study and wavier/third party (as indicator of employment). Table 3 shows these variables.

\section{Table 3}

National Center for Education Statistics Risk Factors as Variables and Definition

\begin{tabular}{|l|l|}
\hline NCES Variable & Definition \\
\hline Delayed postsecondary enrollment & Age in number of years \\
\hline High school dropout followed by GED & $\begin{array}{l}\text { Secondary education (GED }=0, \text { HS } \\
\text { Diploma = 1) }\end{array}$ \\
\hline Part-time enrollment & Enrollment status in number of credit hours \\
\hline Financially independent & $\begin{array}{l}\text { Dependency status (Independent }=1, \\
\text { Dependent = 0) }\end{array}$ \\
\hline Dependents other than spouse & $\begin{array}{l}\text { Dependents (numerical value as reported } \\
\text { on FAFSA) }\end{array}$ \\
\cline { 2 - 2 } & Children (Yes $=1$, No $=0)$ \\
\hline Single parents & $\begin{array}{l}\text { Marital Status (Yes, married }=1, \text { No, not } \\
\text { married }=0) \text { sex (female }=1, \text { male }=0) \text { and } \\
\text { children (Yes }=1, \text { No }=0)\end{array}$ \\
\hline Employed full-time & Waiver/Third Party (Yes $=1$, ELSE $=0)$ \\
\cline { 2 - 2 } & Federal Work-study (Yes $=1$, ELSE $=0)$ \\
\hline
\end{tabular}

Also, table 4 shows the other variables that will be considered: (a) academic program (transfer and nontransfer), (b) degree program(allied health, general studies, and business management), (c) adjusted gross income, (d) current college grade point average, (e) cumulative college grade point average, (f) sex, (g) father's education level, (h) mother's education level, (i) course delivery method (online and traditional), (j) number of credit hours accumulated, (k) number in household and (1) number of household members in college.

\section{Table 4}

Variables and Definition of all Non-National Center for Education Statistics Risk Factors

\begin{tabular}{|l|l|}
\hline Variable & Definition \\
\hline Academic program & Transfer $=1$, Technical, Certificate, \\
\hline
\end{tabular}




\begin{tabular}{|l|l|}
\hline & Diploma, Undecided =0 \\
\hline Adjusted gross income & $\begin{array}{l}\text { Numerical value as reported on FAFSA } \\
\text { Dependent }- \text { parent's AGI and student's } \\
\text { AGI separately } \\
\text { Independent }- \text { student's (if married, and } \\
\text { spouse) AGI combined }\end{array}$ \\
\hline Current College grade point average & $\begin{array}{l}\text { Numerical value as reported by college for } \\
\text { specific term }\end{array}$ \\
\hline Cumulative College grade point average & $\begin{array}{l}\text { Numerical value as reported by college for } \\
\text { duration of academic achievement at } \\
\text { institution }\end{array}$ \\
\hline Sex & Male $=0$, Female $=1$ \\
\hline Father's level of education & $\begin{array}{l}\text { Elementary }=1, \text { High school }=2 \text {, College }= \\
3\end{array}$ \\
\hline Mother's level of education & $\begin{array}{l}\text { Elementary }=1, \text { High school }=2 \text {, College }= \\
3\end{array}$ \\
\hline Course delivery method & Traditional $=0$, Online $=1$ \\
\hline Number of credit hours accumulated & Numerical value as reported by college \\
\hline Number in household & Numerical value as reported on FAFSA \\
\hline Number of household members in college & Numerical value as reported on FAFSA \\
\hline Degree program & $\begin{array}{l}\text { Allied health }=1, \text { all others }=0 \\
\text { General studies }=1, \text { all others }=0 \\
\text { Business management }=1, \text { all others }=0\end{array}$ \\
\hline Marital Status & Married or Separated =1, Single =0 \\
\hline
\end{tabular}

These variables reflect the factors that Kember and others included on The

Distance Education Students' Progress (DESP) instrument: “age, sex, marital status, family size, housing conditions, salary and previous education" (Kember, Lai, Murphy, Siaw \& Yuen, 1992, p.287). Also, these variables were used in other research studies and have been shown to be useful in predicting variance. These variables are either categorical or continuous. The chart below shows how each variable is classified.

\section{Table 5}

Categorical and Continuous Variables

\begin{tabular}{|c|c|}
\hline Categorical & Continuous \\
\hline Secondary Education & Age \\
\hline Father's Level of Education & Dependents \\
\hline Mother's Level of Education & Number of Household Members in College \\
\hline Dependency Status & Adjusted Gross Income \\
\hline
\end{tabular}




\begin{tabular}{|c|c|}
\hline Marital Status & Number in Household \\
\hline Course Delivery Method & $\begin{array}{c}\text { Current and Cumulative Grade Point } \\
\text { Average }\end{array}$ \\
\hline Degree Program & Credit Hours Accumulated \\
\hline Sex & Enrollment Status \\
\hline Waiver/Third Party & \\
\hline Federal Work-study & \\
\hline Children & \\
\hline Academic Programs & \\
\hline Single Mother & \\
\hline
\end{tabular}

Pell eligibility and social programs (e.g. supplemental security income, free lunch, WIC, TANF, food stamps) were considered, but not selected as independent variables because of the correlation between these two factors and adjusted gross income. In effort to obtain a high R, Stevens (2002) noted that the predictors should significantly correlate to the dependent variable and no other predictor variables. It is problematic if predictor variables highly correlate to one another. This problem is called multicollinearity. Stevens (2002) states three reasons why this is a problem: (a) limits the size of $R$ because they identify the same variance on $y,(b)$ effects of the predictors are confounded, and (c) increases the variance of the regression coefficients which makes the prediction equation unstable.

Likewise, substantive knowledge was the rationale for the variables selected. "As Weisberg (1985) noted, 'the single most important tool in selecting a subset of variables for use in a model is the analyst's knowledge if the substantive area under study' (p.210)" (as cited in Stevens, 2002, p.93). Effort was made to include a wide variety of variables that have historically demonstrated successful explanation of variance while not abusing multiple regression by including every variable that was available from the data.

The dependent variable is persistence, which is determined at the beginning of each term, and awarding a credential. Therefore, the outcome is either "yes" or "no" and 
is coded as " 0 " for no and " 1 " for yes. Because the dependent variable is dichotomous and the relationship between the predictor variables and the dependent variable is nonlinear, logistic regression was selected (Cohen \& Cohen, 1983).

\section{Research Design}

Logistic regression, as a means to study persistence, has proven to be appropriate and successful. Tinto (1975) suggested the use of logistic regression, "given the categorical nature of dropout as a dependent variable (e.g., drop-out or persist), it is further suggested that such a longitudinal regression analyses look to the utilization of logit analysis, arcsine transformations, and/or the disaggregation of regression equations according to selected categories of interest as a means of dealing with the problems of carrying out regression analysis when qualitative dependent variables are present" (p.120).

Logistic regression is a popular technique for persistence and retention studies. Peng, So, Frances and St. John (2002) reported between 1988 and 1999 "more than half of the studies [which used logistic regression] (29, or $55.77 \%)$ were related to university enrollment and retention. One explanation for this phenomenon is that, in these types of studies, the outcome measures considered were typically dichotomous or categorical, and at least one predictor was also categorical. Therefore, logistic regression was a suitable analytical tool" (p.273). Also, Cabrera, Stampen and Hanse (1990) advocated for the use of logistic regression and noted, "logistic regression analysis not only captures the probabilities distribution embedded in dichotomized distributions, but also avoids violating the assumptions of homoscedasticity and functional specification that the direct application of either path analysis or LISREL to binary variables are likely to impose" 
(p.317). Likewise, Press and Wilson (1978), "found logistic regression with MLE outperforming classical linear discriminant analysis in both cases (supporting the results of Halperin, Blackwelder, and Verter 1971)" (p.705). Also, Peng, So, Frances and St. John (2002) noted, "compared to the other three alternative techniques [discriminant function analysis, log-linear models, and linear probability models] logistic regression is superior because it (a) can accept both continuous and discrete predictors, (b) is not constrained by normality or equal variance/covariance assumptions for the residuals, and (c) is related to the discriminant function analysis through the Bayes theorem" (p.262). Likewise, Pedhazur (1997) noted, "among suggested models for data with a dichotomous dependent variable are linear probability, logistic, and probit....I present only logistic regression, as it is the most versatile" (p.715). Dey and Astin (1993) specifically addressed the issue of various methodological techniques (logistic regression, probit analysis and linear regression) in retention studies. The authors used a sample of 947 fulltime, full-time community college freshman from the 1987-89 annual Cooperative Institutional Research Program (CIRP) Follow-Up Survey (FSU). They noted concerns with the use of linear regression when studying attrition because, "several of regression's assumptions are violated, and in certain cases these violations can lead to biased estimates" (p.571). Dey and Astin noted the following assumptions, "linear regression typically assumes that the dependent variable is measured on a continuous scale....another concern is whether or not, when dealing with probabilities, the relationship can truly be linear" (p.571). "Logistic regression and probit analysis are based on different assumptions than those used by linear models, and as such are 
theoretically more appropriate for studying dichotomous phenomena such as retention issues" (Dey \& Astin, 1993, p.572). Therefore, logistic regression was used in this study.

\section{Data Analysis Plan}

In 1989-1990, Horn (1998) reported that $42 \%$ of students at two-year public institutions did not return the second year. Therefore, the most critical juncture for community college students enrolled in developmental education is the completion of the first semester. Kentucky has recently passed legislation to require students to take developmental courses within in their first two semesters of college (Kentucky Developmental Education Task Force, 2007). These policy changes also highlight the importance of term-to-term persistence within the large context of degree completion and persistence. Noel, Levitz and Salri (1985) found that "research consistently indicates that college students who dropout usually do so by the time they finish their first year" (as cited in Lau, p.127). This is supported by other research (Clergy, 2008c; Murtaugh, Burns, \& Schuster, 1999). Research has found that students usually leave in the first year; not returning the second year (Clergy, 2006d; Horn, 1998) or even the second semester (Brooks-Leonard, 1991). Thus, this study will focus on persistence from one semester to the next (Bers \& Smith, 1991; Driscoll, 2007; Jaggars \& Xi, 2010; Napoli \& Wortman, 1996, 1998; Romano, 1995; Webb, 1988) and from one term to the same term in the following year (e.g. from fall to following fall) (Fike \& Fike, 2008). Also, the newly established Kentucky state law regulates that students enroll in developmental math within the first two semesters and take the appropriate credit bearing math class immediately following the developmental math class. Therefore, the student's ability to persistence on a term-by-term basis is very important. 
All predictor variables will be entered in three blocks (static, dynamic, academic) with course delivery method added, singularly, last. The first block of variables will be all of the static characteristics measured on subjects, such as sex and secondary education. The second block of variables will contain all of the dynamic characteristics such as age and marital status. The third block of variables will be the academic factors such as enrollment status and academic program (see illustration \# 9). Delivery method will be treated differently from the other independent variables. Since this variable is only tested when the student is enrolled in MT065 (students are only included in one cohort of students, which is the cohort in which the student first enrolled in MT065. Even if a student re-enrolls in MT065 they are not considered in the subsequent cohort), then it will only be tested in the initial cohort logistic regression analysis. In these cohort logistic regression analyses, delivery method will be entered last. This will allow a test of whether delivery mode significantly influences persistence, controlling for all other variables. The dependent variable will be whether or not the student enrolled in the following term. If the student was awarded a credential in the current term or transferred to a non-KCTCS colleges in the following term, the student will be considered a "persister" even though they do not have enrollment at KCTCS in the following term because an awarded credential and/or transfer is considered a successful student.

In each cohort's term, four logistic regression analyses will be conducted for two reasons. First, the data, as provided by KCTCS, reports two variables, number in household and number in college, differently based on dependency status. This was reported as different variables because the FAFSA collects the data differently. For dependent students the household is considered their parent(s)'s household; whereas an 
independent's household is their own household. Likewise, the number in college differs similarly. Therefore, the logistic regression is conducted for independent students, then dependent students separately. When the logistic regression is conducted for dependent students, the following variables are not included: single mother, dependents, children, and marital status. These variables are not included for dependent students because the nature of being dependent makes all students in this group have the same value for these variables (e.g. not married, no children, etc.). This also limits the range of the variable age from 18 to 23 . For dependent students, the parent and student adjusted gross incomes are considered as two different variables. However, for independent students, the student and spouse's (if married) adjusted gross income are considered as the student's income. The second reason these two groups will be separated is to analyze differences between traditional and nontraditional students. All of the steps outlined above will be repeated several times, since multiple cohorts of student data will be analyzed.

Furthermore, two logistic regressions will be conducted for dependent student and two for independent students. First, for dependent and independent students, the logistic regression will include secondary education. The second time, for dependent and independent students, secondary education will be removed from the analysis. This decision was made based on the low number of cases that reported this data. All other variable data was aggregated based on institutional records and the FAFSA. Thus, all cases had institutional record data and those students who completed the FAFSA had the corresponding data. However, secondary education was the only variable gathered from an admission application and this response is not required for admissions. There was a significantly low number of responds and cases that contained this data. Therefore, the 
logistic regression analysis was conducted without this variable to increase the sample size. Given there are four logistic regressions for each analysis, there will be 128 logistic regressions.

Table 6 shows the planned analyses.

\section{Table 6}

Logistical Regression Analysis of the Entering Cohort and Term in Which Dependent Variable is Measured

\begin{tabular}{|l|l|l|}
\hline Analysis & Entering date of cohort & Cohort measured dependent data at end of: \\
\hline $1^{\text {st }}$ & Fall 2006 & Fall 2006 \\
\hline $2^{\text {nd }}$ & Fall 2006 & Spring 2007 \\
\hline $3^{\text {td }}$ & Fall 2006 & Fall 2007 \\
\hline $4^{\text {th }}$ & Fall 2006 & Spring 2008 \\
\hline $5^{\text {th }}$ & Fall 2006 & Fall 2008 \\
\hline $6^{\text {th }}$ & Fall 2006 & Spring 2009 \\
\hline $7^{\text {th }}$ & Fall 2006 & Fall 2009 \\
\hline $8^{\text {th }}$ & Spring 2007 & Spring 2007 \\
\hline $9^{\text {th }}$ & Spring 2007 & Fall 2007 \\
\hline $10^{\text {th }}$ & Spring 2007 & Spring 2008 \\
\hline $11^{\text {th }}$ & Spring 2007 & Fall 2008 \\
\hline $12^{\text {th }}$ & Spring 2007 & Spring 2009 \\
\hline $13^{\text {th }}$ & Spring 2007 & Fall 2009 \\
\hline $14^{\text {th }}$ & Fall 2007 & Fall 2007 \\
\hline $15^{\text {th }}$ & Fall 2007 & Spring 2008 \\
\hline $16^{\text {th }}$ & Fall 2007 & Fall 2008 \\
\hline $17^{\text {th }}$ & Fall 2007 & Spring 2009 \\
\hline $18^{\text {th }}$ & Fall 2007 & Fall 2009 \\
\hline $19^{\text {th }}$ & Spring 2008 & Spring 2008 \\
\hline $20^{\text {th }}$ & Spring 2008 & Fall 2008 \\
\hline $21^{\text {st }}$ & Spring 2008 & Spring 2009 \\
\hline $22^{\text {nd }}$ & Spring 2008 & Fall 2009 \\
\hline $23^{\text {rd }}$ & Fall 2008 & Fall 2008 \\
\hline $24^{\text {th }}$ & Fall 2008 & Spring 2009 \\
\hline $25^{\text {th }}$ & Fall 2008 & Fall 2009 \\
\hline $26^{\text {th }}$ & Spring 2009 & Fall 2009 \\
\hline $27^{\text {th }}$ & Spring 2009 & \\
\hline & & \\
\hline
\end{tabular}

Table 7 shows the four planned logistic regression analysis for the first analysis

\section{Table 7}


Example of First Logistical Regression Analysis for Fall 2006 Cohort

\begin{tabular}{|l|l|l|}
\hline $\begin{array}{l}\text { Fall 2006 Cohort - } \\
\text { measured at end of Fall } \\
2006 \text { term }\end{array}$ & Dependent Students Only & $\begin{array}{l}\text { With Secondary Education } \\
\text { Predictor Variable }\end{array}$ \\
\hline $\begin{array}{l}\text { Fall 2006 Cohort - } \\
\text { measured at end of Fall } \\
2006 \text { term }\end{array}$ & Independent Students Only & $\begin{array}{l}\text { With Secondary Education } \\
\text { Predictor Variable }\end{array}$ \\
\hline $\begin{array}{l}\text { Fall } 2006 \text { Cohort - } \\
\text { measured at end of Fall } \\
2006 \text { term }\end{array}$ & Dependent Students Only & $\begin{array}{l}\text { Without Secondary } \\
\text { Education Predictor } \\
\text { Variable }\end{array}$ \\
\hline $\begin{array}{l}\text { Fall 2006 Cohort - } \\
\text { measured at end of Fall } \\
2006 \text { term }\end{array}$ & Independent Students Only & $\begin{array}{l}\text { Without Secondary } \\
\text { Education Predictor } \\
\text { Variable }\end{array}$ \\
\hline
\end{tabular}

\section{Participants}

The data will be collected from the Kentucky Community and Technical College System Office in Versailles, Kentucky. Each group of student in the fall and spring terms is considered a cohort. These cohorts will be tracked throughout the following fall and spring terms until the spring of 2010 term. Table 8 shows the points at which each cohort will be tested regarding persistence.

\section{Table 8}

All Logistic Regression Analyses Cohorts and Term in Which Persistence is Assessed

\begin{tabular}{|l|c|c|c|c|c|c|c|}
\hline \multicolumn{1}{|c|}{ Cohort } & $\begin{array}{c}\text { Spring } \\
2007\end{array}$ & $\begin{array}{c}\text { Fall } \\
2007\end{array}$ & $\begin{array}{c}\text { Spring } \\
2008\end{array}$ & $\begin{array}{c}\text { Fall } \\
2008\end{array}$ & $\begin{array}{c}\text { Spring } \\
2009\end{array}$ & $\begin{array}{c}\text { Fall } \\
2009\end{array}$ & $\begin{array}{c}\text { Spring } \\
2010\end{array}$ \\
\hline Fall 2006 & $\mathrm{X}$ & $\mathrm{X}$ & $\mathrm{X}$ & $\mathrm{X}$ & $\mathrm{X}$ & $\mathrm{X}$ & $\mathrm{X}$ \\
\hline Spring 2007 & & $\mathrm{X}$ & $\mathrm{X}$ & $\mathrm{X}$ & $\mathrm{X}$ & $\mathrm{X}$ & $\mathrm{X}$ \\
\hline Fall 2007 & & & $\mathrm{X}$ & $\mathrm{X}$ & $\mathrm{X}$ & $\mathrm{X}$ & $\mathrm{X}$ \\
\hline Spring 2008 & & & & $\mathrm{X}$ & $\mathrm{X}$ & $\mathrm{X}$ & $\mathrm{X}$ \\
\hline Fall 2008 & & & & & $\mathrm{X}$ & $\mathrm{X}$ & $\mathrm{X}$ \\
\hline Spring 2009 & & & & & & $\mathrm{X}$ & $\mathrm{X}$ \\
\hline
\end{tabular}

Shavelson (1996) stated, "the minimal sample size needed to provide adequate estimates of the regression coefficients is something like 50 cases, and a general rule of thumb is that there should be at least 10 times as many cases (subjects) as independent 
variables" (p.536). In this study there are 20 independent variables. Thus, by Shalevson's "general rule of thumb", a sample size would need to be 200 or more students. However, Stevens (2002) required a larger ratio when he said, "for social science research, about 15 subjects per predictor are needed for a reliable equation, that is, for an equation that will cross-validate with little loss in predictive power" (p.88). The cohorts in this study will met the more stringent criteria set forth by Stevens, which would require a sample size of 300 students. Therefore, the R squared value should be representative of the population. $\mathrm{R}$ squared measures "the proportion of total variance on $\mathrm{y}$ that is accounted for by the set of predictors" (Stevens, 2002, p.90).

\section{Data Collection: Assumptions and Limitations}

All data for this study will be compiled through the KCTCS Office of Research and Policy Analysis from the student records and financial aid departments at the Kentucky Community and Technical College System Office and provided through the.

The assumptions to the study are as follows:

1. All the information provided by the student on the FAFSA and KCTCS is accurate.

The limitations to the study are as follows:

1. Students could have withdrawn because of the influence of a variable that would have changed had the student completed the FAFSA. For example is the student was attending a spring term and completed that academic year FAFSA having no dependents, but had a child in the summer and did not return, then student would not have completed a new FAFSA and the influence of the change in dependents could not be recorded as a factor in the analysis 
2. Third Party and Waivers quantitatively measure an employer's willingness and policy regarding fiscal assistance for paying for higher education, but it does not demonstrate if an employer is actively encouraging higher education. Kember utilized this factor in his students, but further information would need to be obtained to better clarify this variable as in the Taplin and Jegede (2001) study.

3. Also, Third Party and Waivers do not capture all students who are actually receiving a third party or waiver. This study could only identify the students in which the employer directly paid the college. If the employer directly compensated or reimbursed the student, the college would have no information regarding this transaction and thus was not present in the college's database.

4. Not every student completed a FAFSA. Thus, there will be incomplete information. This limitation had a significant impact on the study because there were a large number of students who did not complete the FAFSA creating missing data. Therefore, even though the academic information was collected the social and family information was not identified.

5. This study entailed a large number of statistical tests. The author is aware that inflation of Type I error probability occurred, resulting of some cases of spurious statistical significance. While the latter likely occurred, it is not likely that Type I errors distorted the overall conclusions of the study. These were based on trends in data over a number of cohorts, not a single significance test. Given and the exploratory nature of the study, the numerous logistic regression equations was judged to be the most productive way to address the research questions. 
6. Other statistical analyses are also options with these data. For example, discrete time hazard modeling, a form of survival analysis (Singer \& Willett, 2003) would be a possible approach to use with these data. Future researchers might consider this approach, since it allows the modeling of variables that might change over time (e.g., marital status, number of dependents).

\section{Summary}

The purpose of this study is to examine the relationship between developmental math student demographic information, work and family and academic variables at a public state two-year community and technical college system and student persistence. This study takes into consideration methodological practices and concerns that have arisen in other studies pertaining to developmental students. The variables tested were determined by substantial knowledge. They were identified by the National Center for Educational Statistics, other persistence studies (Kember, 1989a) and new factors determined in the literature review. The sample size for the study is adequate for the number of variables. Consideration was given to the type of analysis that best suited the study. Logistic regression was considered both the most common and appropriate based on past studies and general practice. 


\section{CHAPTER IV}

\section{Introduction}

The purpose of this quantitative study was to examine the relationship between a set of predictor variables and student persistence for persons enrolled at a state-supported two-year community and technical college system. Predictors were student demographic characteristics, and variables related to work, family and academic performance. The participants were students enrolled in the second sequential developmental mathematics course offered by the campuses in this college system, MT065. Each group of MT065 students in the fall and spring terms was considered a cohort. These cohorts were tracked throughout the following fall and spring terms until the spring of 2010 term.

\section{Setting}

The Kentucky Postsecondary Education Improvement Act of 1997 (House Bill 1) created the Kentucky Community and Technical College System (KCTCS), which is the state of Kentucky's public two-year comprehensive college system. KCTCS was established in 1998 through the merger of the community colleges, which were previously governed by the University of Kentucky, and the technical colleges, which were previously part of the Frankfort Cabinet for Workforce Development. This formation created sixteen community and technical colleges operating as one state system (Metamorphosis, 2008). 
Kentucky faces the same challenges that other states in the United States face; academic skills of incoming students are low. "More than half of the first-time freshmen entering Kentucky's colleges are underprepared in at least one subject. Even worse, for those underprepared students, the first-year college drop-out rate is twice the rate of academically prepared freshman" (Kentucky Developmental Education Task Force, 2007, p.5).

In the summer of 2010, the Kentucky Community and Technical College System launched an online, modularized, self-paced, open-entry/closed exit developmental math courses (A. Parker, personal communication, October, 10, 2009; Moltz, 2009b). In effort to improve success rates in developmental education and "reduce the time-to-degree for many students", the Kentucky Developmental Education Task Force called for a "selfpaced, brief, online modules for students with minimal developmental need" (Kentucky Developmental Education Task Force, 2007, p.13).

\section{Data Collection}

The data were collected from the Office of Research and Policy Analysis at the Kentucky Community and Technical College System Office in Versailles, Kentucky. The data were compiled from two sources: (a) college records and (b) the Free Application for Federal Student Aid (FAFSA). This study used the following predictor variables: (a) age, (b) secondary education, (c) enrollment status, (d) dependency status, (e) dependents (e.g. children), (f) single mother status, (g) federal work-study, (h) wavier/third party, (i) academic program (allied health, general studies, and business management), (j) degree program, (k) adjusted gross income, (l) sex, (m) father's education level, (n) mother's 
education level, (o) course delivery method, (p) number of credit hours accumulated, (q) number in household, and (r) number of household members in college.

The data sometimes had conflicting information about a student. First, there were situations in which a student completed multiple years of the FAFSA and reported different responses to the same question. For example, the student reported having a general equivalency diploma (GED) in one year, then a high school diploma in another year. Likewise, this same conflicting information occurred between the response on the FAFSA and the college application.

Table 9 shows what data were retained for the variable secondary education. As can be seen in the last column, the variable as used in the analysis had two possible values: (a) high school diploma, or (b) GED.

\section{Table 9}

Responses Used to Define the Variable Secondary Education

\begin{tabular}{|l|l|l|}
\hline \multicolumn{2}{|c|}{ Conflicting Data Elements } & \multicolumn{1}{c|}{ Data Retained } \\
\hline High School Diploma & Other & High School Diploma \\
\hline GED & Other & GED \\
\hline Home Schooled & Other & Not considered \\
\hline High School Diploma & GED & GED \\
\hline High School Diploma & Home Schooled & Not considered \\
\hline GED & Home Schooled & GED \\
\hline
\end{tabular}

The last term in which persistence was measured depended upon two events: (a) transfer, or (b) awarding of credential (certificate, diploma, or degree). Regarding transfer, if a student transferred from one KCTCS college to another KCTCS college, this was not considered non-persistence because the data for the study included all 16 KCTCS colleges. Therefore, KCTCS colleges were treated as a single institution. The first date of transfer was considered as the transfer date. For example, if a student attended KCTCS in the fall of 2006 and spring of 2007, then transferred to another institution, but returned 
to KCTCS in the spring of 2008 , persistence was only measured to the spring of 2007 and not beyond. Likewise, KCTCS students may obtain multiple credentials. For example, a student may start in the fall of 2006 attend the spring of 2007 and be awarded a certificate. Then, the student may attend the fall of 2007 and be awarded a diploma. Next, the student may attend the spring of 2008 and fall of 2008 and be awarded a degree. In these situations, the term in which the last credential was awarded was considered the final term of enrollment to reach an educational objective. Therefore, that was the last term in which persistence was measured. In cases in which the student transferred and had a credential awarded, the term in which the credential was awarded was considered the final term to measure persistence. Table 10 shows what term was used to define whether persistence was defined.

\section{Table 10}

How Data Were Used to Define Persistence

\begin{tabular}{|l|l|}
\hline \multicolumn{1}{|c|}{$\begin{array}{c}\text { Information in student data files on } \\
\text { transfers and credentials awarded }\end{array}$} & $\begin{array}{c}\text { College term at which persistence } \\
\text { was measured }\end{array}$ \\
\hline Transfer date only & Term that transfer occurred \\
\hline One credential awarded & Term that credential was awarded \\
\hline Multiple credentials awarded & Term last credential was awarded \\
\hline $\begin{array}{l}\text { Transfer date and credentials (one or more) } \\
\text { awarded }\end{array}$ & Term last credential was awarded \\
\hline
\end{tabular}

\section{Data Analysis}

Data analyses were carried out using the Statistical Package for Social Sciences (SPSS). The statistical procedure used was logistic regression. Logistic regression has shown to be appropriate and successful for determining dichotomous outcomes (Cabrera, Stampen \& Hanse, 1990; Dey \& Astin; 1993; Pedhazur, 1997; Peng, So, Frances \& St. John, 2002; Peng, Lee \& Ingersoll, 2002; Press \& Wilson, 1978; Tinto, 1975). 
For all nineteen research questions persistence was the dependent variable. For all nineteen research questions the following were considered as predictor variables: (a) age, (b) secondary education, (c) enrollment status, (d) dependency status, (e) dependents (e.g. children), (f) single mother status, (g) federal work-study, (h) wavier/third party, (i) academic program (allied health, general studies, and business management), (j) degree program, (k) adjusted gross income, (l) sex, (m) father's education level, (n) mother's education level, (o) course delivery method, (p) number of credit hours accumulated, (q) number in household, and (r) number of household members in college.

Federal work-study and third party/waiver were not considered when the logistic regression analysis was conducted for dependent students. This decision was made based on the few students that had a third-party/waiver.

It was originally planned to use current grade point average and cumulative grade point average as predictors in logistic regression analyses. The researcher decided to omit these variables. This decision was made based on both empirical and theoretical considerations. When preliminary logistic regressions were conducted with the grade point average variables in the analyses, they were often the only variables having a statistically significant relationship with the dependent variable. This finding meant that the possible influences of other predictors were obscured. Further, Kember (1995) argued that grade point average is not a useful predictor in college outcome studies, since it inevitably correlates with outcome variables such as persistence or completion.

The predictor variables were entered in three blocks that were classified in terms of the nature of the variables: (a) static, (b) dynamic, and (c) academic. For the analyses when the original cohorts were used, the variable course delivery method was the single 
variable added in the last step. Nineteen research questions, as stated in chapter 3, directed the statistical analyses. Lastly, none of the logistic regressions was conducted to determine persistence in the spring 2010 because the sample sizes were too small for meaningful analyses.

After the changes to the analysis, there were 20 independent variables (including secondary education) for the logistic regression analysis for students defined as independent. There were 17 independent variables (including secondary education) for the logistic regression analysis for students defined as dependent. As noted earlier, Shavelson (1996) stated, "the minimal sample size needed to provide adequate estimates of the regression coefficients is something like 50 cases, and a general rule of thumb is that there should be at least 10 times as many cases (subjects) as independent variables" (p.536). Peng, Lee and Ingersoll (2002) noted, "in terms of the adequacy of sample sizes, the literature has not offered specific rules applicable to logistic regression" (p.10). The authors also noted, "several authors on multivariate statistics have recommended a minimum ratio of 10 to 1 , with a minimum sample size of 100 or 50 " (p.10). This study used 50 as a minimum number of cases for conducted logistic regression analysis for two reasons. First, this study is exploratory in nature. Therefore, the researcher wanted to obtain as much information from the data as possible and the suggestion of 50 cases made by Shalevson was used. Secondly, when the number of cases was between 50 and 150 , which reasonably meets the criteria for 10 times as many cases as the independent variables, the researcher further investigated the particular statistically significant predictor variables. In these cases, if the results of the predictor variable differed greatly from other analyses it was noted. In general, the predictor variables maintained the same 
positive or negative $B$ coefficient value, but the $B$ coefficient values were occasionally

inflated. For example, in all analyses, except two, for predictor variable age, the absolute value of the B coefficient ranges from .046 to .809 . In two analyses, the B coefficient value is 2.131 and 2.154 and the sample size is 73 and 83 cases. Another example is General Studies majors in which two analyses the number of cases was 50 and 51, respectively. In these outcomes, the corresponding B coefficient values are -5.462 and 5.608, which are inflated.

\section{Predictor Variable Coding}

Table 11 shows the variables, categorical and continuous, and how they were coded for analysis purposes.

\section{Table 11}

Predictor Variable Coding or Methods of Measurement

\begin{tabular}{|c|c|}
\hline Categorical Variable & Coding or method of measurement \\
\hline Secondary Education & $(' G E D '=0)($ 'HS Diploma'=1) \\
\hline Father's Level of Education & $\begin{array}{l}\left(' \mathrm{U} \text { known'=0) }\left(\text { 'Elementary'=1) }\left(\text { 'High } \mathrm{Sch}^{\prime}=2\right)\right.\right. \\
(\text { 'College' }=3) \\
\text { For this variable, a value of zero was defined as } \\
\text { missing data. }\end{array}$ \\
\hline Mother's Level of Education & $\begin{array}{l}(' \mathrm{U} \text { known' }=0)(\text { 'Elementary'=1) }(\text { 'High } \mathrm{Sch}=2) \\
(\text { 'College' }=3) \\
\text { For this variable, a value of zero was defined as } \\
\text { missing data. }\end{array}$ \\
\hline Marital Status & ('Married or Separated' $=1)($ 'Single' $=0)$ \\
\hline Course Delivery Method & 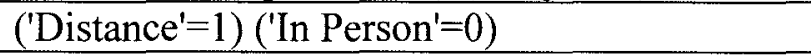 \\
\hline $\begin{array}{c}\text { Degree Program: } \\
\text { Allied Health, Business and General Studies }\end{array}$ & $(' Y e s '=1)\left(\mathrm{No}^{\prime}=0\right)$ \\
\hline Sex & $\left(\right.$ 'Female'$\left.^{\prime}=1\right)\left(\right.$ 'Male'$\left.^{\prime}=0\right)$ \\
\hline Waiver/Third Party & $\left({ }^{\prime} Y e s '=1\right)(E L S E=0)$ \\
\hline Federal Work-study & $(' Y e s '=1)(E L S E=0)$ \\
\hline Children & $(' Y e s '=1)\left(\mathrm{No}^{\prime}=0\right)$ \\
\hline Academic Programs & $($ 'Transfer' $=1)($ 'Not a transfer' $=0)$ \\
\hline Single Mother & $\left({ }^{\prime} \mathrm{Yes}^{\prime}=1\right)\left(\mathrm{No}^{\prime}=0\right)$ \\
\hline
\end{tabular}




\begin{tabular}{|c|l|}
\hline Continuous Variable & \\
\hline Dependents & Number of people \\
\hline Age & $\begin{array}{l}\text { Age in years. Typical range is from about } 17 \\
\text { years to 65 years. }\end{array}$ \\
\hline Number of Household Members in College & $\begin{array}{l}\text { Number of people, typically ranging from 1 to } \\
4 .\end{array}$ \\
\hline Adjusted Gross Income & $\begin{array}{l}\text { Amount in dollars. Typical range is from 0 to } \\
\text { over 100,000. }\end{array}$ \\
\hline Parent's Adjusted Gross Income & $\begin{array}{l}\text { Amount in dollars. Typical range is from 0 to } \\
\text { over } 100,000 .\end{array}$ \\
\hline Number in Household & $\begin{array}{l}\text { Number of people, typically ranging from 1 to } \\
10 .\end{array}$ \\
\hline Credit Hours Accumulated & $\begin{array}{l}\text { Number of units taken, typically ranging from } 3 \\
\text { to } 187\end{array}$ \\
\hline Enrollment Status & $\begin{array}{l}\text { Number of units taken, typically ranging from } 3 \\
\text { to } 20\end{array}$ \\
\hline
\end{tabular}

Table 12 shows how to interpret logistic regression coefficients. Interpretations are made in terms of what a positive coefficient meant.

\section{Table 12}

Interpretation of Regression Coefficients (B Coefficients) That Were Significant Predictors of Persistence

\begin{tabular}{|c|l|}
\hline Categorical Variable & B Coefficient value interpretation \\
\hline Secondary Education & $\begin{array}{l}\text { Positive regression coefficient means that } \\
\text { having a HS diploma (in contrast to a GED) } \\
\text { is associated with persistence. }\end{array}$ \\
\hline Father's Level of Education & $\begin{array}{l}\text { Positive regression coefficient means that the } \\
\text { higher the level of father's education, the } \\
\text { greater the probability of persisting. }\end{array}$ \\
\hline Mother's Level of Education & $\begin{array}{l}\text { Positive regression coefficient means that the } \\
\text { higher the level of mother's education, the } \\
\text { greater the probability of persisting. }\end{array}$ \\
\hline Marital Status & $\begin{array}{l}\text { Positive regression coefficient means that } \\
\text { being married is associated with persistence. }\end{array}$ \\
\hline Course Delivery Method & $\begin{array}{l}\text { Positive regression coefficient means that } \\
\text { being a distance education student is } \\
\text { associated with persistence. }\end{array}$ \\
\hline Degree Program & $\begin{array}{l}\text { Positive regression coefficient means that } \\
\text { being enrolled in Allied } \\
\text { Health/Business/General Studies is } \\
\text { associated with persistence. }\end{array}$ \\
\hline
\end{tabular}




\begin{tabular}{|c|c|}
\hline Sex & $\begin{array}{l}\text { Positive regression coefficient means that } \\
\text { being a female is associated with persistence. }\end{array}$ \\
\hline Waiver/Third Party & $\begin{array}{l}\text { Positive regression coefficient means that } \\
\text { receiving waiver of } 3^{\text {rd }} \text { party pay is } \\
\text { associated with persistence. }\end{array}$ \\
\hline Federal Work-study & $\begin{array}{l}\text { Positive regression coefficient means that } \\
\text { receiving federal work-study employment is } \\
\text { associated with persistence. }\end{array}$ \\
\hline Children & $\begin{array}{l}\text { Positive regression coefficient means that } \\
\text { having children is associated with } \\
\text { persistence. }\end{array}$ \\
\hline Academic Programs & $\begin{array}{l}\text { Positive regression coefficient means that } \\
\text { being a transfer student is associated with } \\
\text { persistence. }\end{array}$ \\
\hline Dependents & $\begin{array}{l}\text { Positive regression coefficient means that } \\
\text { having dependents is associated with } \\
\text { persistence. }\end{array}$ \\
\hline Single Mother & $\begin{array}{l}\text { Positive regression coefficient means that } \\
\text { being a single mother is associated with } \\
\text { persistence. }\end{array}$ \\
\hline Continuous Variable & B Coefficient value interpretation \\
\hline Age & $\begin{array}{l}\text { Positive regression coefficient means older } \\
\text { age is associated with persistence. }\end{array}$ \\
\hline $\begin{array}{l}\text { Number of Household Members in } \\
\text { College }\end{array}$ & $\begin{array}{l}\text { Positive regression coefficient means that the } \\
\text { larger the number of people in college, the } \\
\text { greater the probability of persisting. }\end{array}$ \\
\hline Adjusted Gross Income & $\begin{array}{l}\text { Positive regression coefficient means higher } \\
\text { AGI is associated with persistence. }\end{array}$ \\
\hline Parent's Adjusted Gross Income & $\begin{array}{l}\text { Positive regression coefficient means higher } \\
\text { AGI is associated with persistence. }\end{array}$ \\
\hline Number in Household & $\begin{array}{l}\text { Positive regression coefficient means that the } \\
\text { larger the family size, the greater the } \\
\text { probability of persisting. }\end{array}$ \\
\hline Credit Hours Accumulated & $\begin{array}{l}\text { Positive regression coefficient means that the } \\
\text { larger the number of cumulative units, the } \\
\text { greater the probability of persisting. }\end{array}$ \\
\hline Enrollment Status & $\begin{array}{l}\text { Positive regression coefficient means that the } \\
\text { larger the number of units taken, the greater } \\
\text { the probability of persisting. }\end{array}$ \\
\hline
\end{tabular}

\section{Sample Characteristics}

All six cohorts were combined and analyzed for the purpose of descriptive statistics. The data is representative at the time in which the student was enrolled in 
MT065. Thus, the initial cohort data was used. The tables show the frequency

distributions for categorical variables and means and standard deviations for continuous variables.

\section{Static Characteristics}

Sex.

As noted in chapter 2 , community college students tend to be equally represented by both sexes (Factbook, 2008; Horn, Peter, \& Rooney, 2002; Provasnik \& Planty, 2008). For KCTCS, in 2008, the percentages for both sexes was 44\% (Factbook, 2008, p.147). However, table 13 shows that $65.5 \%$ of the sample population is female, thus a $2: 1$ ratio of females to males.

\section{Table 13}

Descriptive Statistics: Sex

\begin{tabular}{|c|c|c|c|}
\hline & $\mathrm{N}$ & $\begin{array}{c}\% \text { of all } \\
\text { cases }\end{array}$ & $\begin{array}{c}\% \text { of non- } \\
\text { missing cases }\end{array}$ \\
\hline Male & 10106 & 34.5 & 34.5 \\
\hline Female & 19162 & 65.5 & 65.5 \\
\hline Total & 29268 & 100.0 & 100.0 \\
\hline Missing & 7 & .0 & \\
\hline Total & 29275 & 100.0 & \\
\hline
\end{tabular}

\section{Secondary education.}

Table 14 shows $79.7 \%$ of the non-missing cases earned a high school degree and $20.3 \%$ earned a GED. However, $36.8 \%$ of the sample is missing this information.

\section{Table 14}

Descriptive Statistics: Secondary Education

\begin{tabular}{|r|r|r|r|}
\hline & $\mathrm{N}$ & $\begin{array}{c}\text { \% of all } \\
\text { cases }\end{array}$ & $\begin{array}{c}\text { \% of non- } \\
\text { missing cases }\end{array}$ \\
\hline GED & 3764 & 12.9 & 20.3 \\
\hline
\end{tabular}




\begin{tabular}{|c|c|c|c|c|}
\hline & HS Diploma & 14740 & 50.4 & 79.7 \\
\hline & Total & 18504 & 63.2 & 100.0 \\
\hline & Missing & 10771 & 36.8 & \\
\hline Total & & 29275 & 100.0 & \\
\hline
\end{tabular}

\section{Father's and mother's level of education.}

As noted in chapter 2, in 1999-2000, of the students that reported parents with a high school diploma or less more than $53 \%$ attend a 2 -year institution compared to $46 \%$ of those students who reported parents with some postsecondary education and only $33.5 \%$ with parents with a bachelor's degree or higher (Horn, Peter, \& Rooney, 2002). In $2003-2004,40.8 \%$ of all community college students reported parents' highest level of education as high school or less, $27.1 \%$ with some secondary education and $32.1 \%$ with a bachelor's degree or higher (Provasnik \& Planty, 2008). Thus, generally speaking, as parent's level of education decrease the percentage of these students enrolled in community colleges increase. Table 15 shows that of the non-missing cases, $59.8 \%$ of fathers had a high school level of education. Table 16 shows that a similar amount of mothers, $54.7 \%$, also had a high school level of education. However, the different in the two groups occurs at the elementary and college levels of education. Fathers have $22.1 \%$ and $18.1 \%$ of elementary and college level education, respectively. Mothers have $17.1 \%$ and $28.2 \%$ of elementary and college level education, respectively. Thus, the percentage of mother's level of college education is 10 percentage points higher compared to father's level of college education.

\section{Table 15}

Descriptive Statistics: Father's Education Level

\begin{tabular}{|l|l|l|l|}
\hline & & $\begin{array}{c}\% \text { of all } \\
\text { cases }\end{array}$ & $\begin{array}{c}\% \text { of non- } \\
\text { missing cases }\end{array}$ \\
\hline
\end{tabular}




\begin{tabular}{|l|r|r|r|}
\hline Elementary & 4221 & 14.4 & 22.1 \\
High School & 11398 & 38.9 & 59.8 \\
College & 3450 & 11.8 & 18.1 \\
Total & 19069 & 65.1 & 100.0 \\
. Unknown (missing) & 4256 & 14.5 & \\
Other missing & 5950 & 20.3 & \\
Total & 10206 & 34.9 & \\
Total & 29275 & 100.0 & \\
\hline
\end{tabular}

Table 16

Descriptive Statistics: Mother's Education Level

\begin{tabular}{|l|r|r|r|}
\hline & $\mathrm{N}$ & $\begin{array}{c}\text { \% of all } \\
\text { cases }\end{array}$ & \multicolumn{2}{c|}{$\begin{array}{c}\text { \% of non- } \\
\text { missing cases }\end{array}$} \\
\hline Elementary & 3584 & 12.2 & 17.1 \\
High School & 11457 & 39.1 & 54.7 \\
College & 5905 & 20.2 & 28.2 \\
Total & 20946 & 71.5 & 100.0 \\
Unknown (missing) & 2426 & 8.3 & \\
Other missing & 5903 & 20.2 & \\
Total & 8329 & 28.5 & \\
Total & 29275 & 100.0 & \\
\hline
\end{tabular}

\section{Dynamic Statistics}

\section{Dependency status.}

As noted in chapter 2 , from $1999-2000$ to $2003-2003$ between $50 \%$ and $60 \%$ of all independent students attended a 2 year institution or community college (Horn, Peter, \& Rooney, 2002; Provasnik \& Planty, 2008). For KCTCS, between 2004 and 2008, the percentage of students $18-24$ years of age has ranged from $42 \%$ to $46 \%$ and the percentage of student 25 years of age and older has ranged from $43 \%$ to $45 \%$. Table 17 shows $60.8 \%$ of the non-missing cases were independent students and $39.2 \%$ were dependent, thus, representative of the national average. 


\section{Table 17}

Descriptive Statistics: Dependency Status of Student

\begin{tabular}{|l|r|r|r|}
\hline & $\mathrm{N}$ & $\begin{array}{c}\text { \% of all } \\
\text { cases }\end{array}$ & $\begin{array}{c}\text { \% of non- } \\
\text { missing cases }\end{array}$ \\
\hline Dependent & 9226 & 31.5 & 39.2 \\
Independent & 14314 & 48.9 & 60.8 \\
Total & 23540 & 80.4 & 100.0 \\
Missing & 5735 & 19.6 & \\
\hline Total & 29275 & 100.0 & \\
\hline
\end{tabular}

Age.

As noted in chapter 2 , community colleges tend to enroll the majority of all students over the age of 30 (Horn, Peter, \& Rooney, 2002; Provasnik \& Planty, 2008). Table 18 shows that age ranged from 14 to 85 with a mean of 26.03 and standard deviation of 9.080 .

\section{Table 18}

Descriptive Statistics: Age

\begin{tabular}{|l|r|r|r|r|r|}
\hline & \multicolumn{1}{|c|}{ N } & Minimum & Maximum & Mean & Std. Deviation \\
\hline Age & 29267 & 14 & 85 & 26.03 & 9.080 \\
Valid N (listwise) & 29267 & & & & \\
\hline
\end{tabular}

\section{Marital status.}

Table 19 shows $26.2 \%$ of non-missing cases were married and $73.8 \%$ were single.

The married category is defined by a response on the FAFSA as married or "separated". There were 1,074 "separated" responses that were combined with 5,103 married responses to total the 6,177 married cases.

\section{Table 19}


Descriptive Statistics: Marital Status

\begin{tabular}{|c|c|c|c|}
\hline & $\mathrm{N}$ & $\begin{array}{c}\% \text { of all } \\
\text { cases }\end{array}$ & $\begin{array}{c}\% \text { of non- } \\
\text { missing cases }\end{array}$ \\
\hline Single & 17358 & 59.3 & 73.8 \\
\hline Married & 6177 & 21.1 & 26.2 \\
\hline Total & 23535 & 80.4 & 100.0 \\
\hline Missing & 5740 & 19.6 & \\
\hline Total & 29275 & 100.0 & \\
\hline
\end{tabular}

\section{Single mother, dependents and children.}

As noted in chapter 2 , over $65 \%$ of students who reported one or more dependents other than spouse or as a single parent enroll in a certificate or associate's degree program (Horn, Peter, \& Rooney, 2002). Table 20 shows that $56.8 \%$ of the non-missing cases have no children, while $43.2 \%$ have one or more children. Table 21 shows $16 \%$ are a single mother. Table 22 shows only $4.7 \%$ of the non-missing cases have dependents, while $95.3 \%$ do not have dependents.

\section{Table 20}

Descriptive Statistics: Student with One or More Children

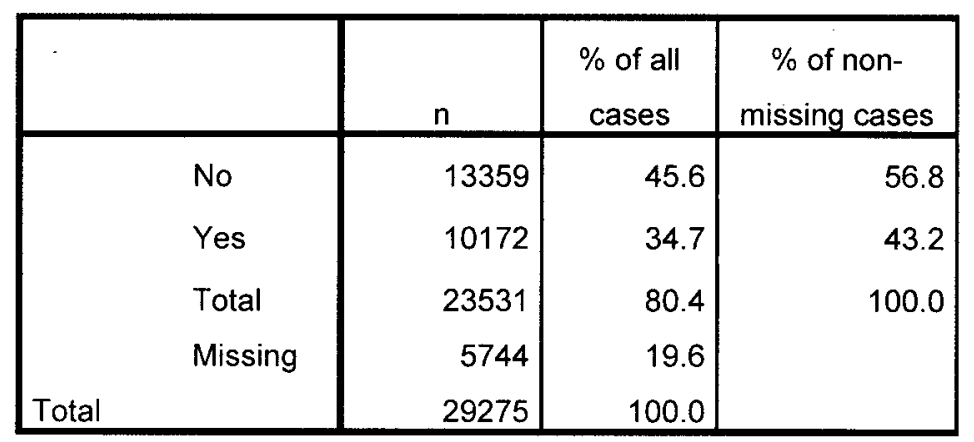

\section{Table 21}

Descriptive Statistics: Single Mother

\begin{tabular}{|l|l|l|}
\hline & $\mathrm{N}$ & $\begin{array}{c}\% \text { of all } \\
\text { cases }\end{array}$ \\
\hline
\end{tabular}




\begin{tabular}{|l|r|r|}
\hline No & 24592 & 84.0 \\
Yes & 4683 & 16.0 \\
Total & 29275 & 100.0 \\
\hline
\end{tabular}

Table 22

Descriptive Statistics: Student with One or More Dependents

\begin{tabular}{|c|c|c|c|c|}
\hline & & $\mathrm{N}$ & $\begin{array}{l}\% \text { of all } \\
\text { cases }\end{array}$ & $\begin{array}{c}\% \text { of non- } \\
\text { missing cases }\end{array}$ \\
\hline & No & 22432 & 76.6 & 95.3 \\
\hline & Yes & 1103 & 3.8 & 4.7 \\
\hline & Total & 23535 & 80.4 & 100.0 \\
\hline & Missing & 5740 & 19.6 & \\
\hline Total & & 29275 & 100.0 & \\
\hline
\end{tabular}

\section{Student's and parent's adjusted gross income.}

As noted in chapter 2, community colleges tend to enroll students with the lowest family incomes (Horn, Peter, \& Rooney, 2002; Provasnik \& Planty, 2008). Table 23 shows the range for student's adjusted gross income from $\$ 0$ to $\$ 673,345$ and the mean is $\$ 12,582$. Table 26 shows parent's adjusted gross income from $\$ 0$ to $\$ 577,427$ and the mean is $\$ 15,034$. Table 24 shows $16.2 \%$ of all independent students reported zero adjusted gross income, while $14.0 \%$ reported $\$ 20,000-\$ 29,999,13.8 \%$ reported $\$ 10,000$ $\$ 14,999$ and $11 \%$ reported $\$ 15,000-\$ 19,999$. Table 25 shows that $42.9 \%$ of all dependents students reported zero adjusted gross income. Table 27 shows $14.2 \%$ of dependent students' parent's reported an adjusted gross income of zero, while $13.1 \%$ reported adjusted gross income between $\$ 20,000-\$ 29,999$ and $10.4 \%$ reported an adjusted gross income between $\$ 30,000-\$ 39,000$.

\section{Table 23}

Descriptive Statistics: Student's Adjusted Gross Income 


\begin{tabular}{|l|l|l|l|l|r|}
\hline & N & Minimum & Maximum & Mean & Std. Deviation \\
\hline AGI & 23540 & .00 & 673345.00 & 12582.1557 & 18428.70163 \\
Valid N (listwise) & 23540 & & & & \\
\hline
\end{tabular}

Table 24

Descriptive Statistics: Independent Student's Adjusted Gross Income by Category

\begin{tabular}{|c|c|c|c|}
\hline & $\mathrm{N}$ & $\begin{array}{l}\% \text { of all } \\
\text { cases }\end{array}$ & $\begin{array}{c}\% \text { of non- } \\
\text { missing cases }\end{array}$ \\
\hline $100000+$ & 62 & .4 & .4 \\
\hline $90000-99999$ & 52 & .4 & .4 \\
\hline $80000-89999$ & 99 & .7 & .7 \\
\hline $70000-79999$ & 160 & 1.1 & 1.1 \\
\hline $60000-69999$ & 270 & 1.9 & 1.9 \\
\hline $50000-59999$ & 376 & 2.6 & 2.6 \\
\hline $40000-49999$ & 695 & 4.9 & 4.9 \\
\hline $30000-39999$ & 1052 & 7.3 & 7.4 \\
\hline $20000-29999$ & 1999 & 14.0 & 14.0 \\
\hline $15000-19999$ & 1572 & 11.0 & 11.0 \\
\hline $10000-14999$ & 1967 & 13.7 & 13.8 \\
\hline $7500-9999$ & 1001 & 7.0 & 7.0 \\
\hline $5000-7499$ & 1016 & 7.1 & 7.1 \\
\hline $2500-4999$ & 990 & 6.9 & 6.9 \\
\hline $1-2499$ & 664 & 4.6 & 4.6 \\
\hline 0 & 2315 & 16.2 & 16.2 \\
\hline Total & 14290 & 99.8 & 100.0 \\
\hline Missing & 24 & .2 & \\
\hline Total & 14314 & 100.0 & \\
\hline
\end{tabular}

\section{Table 25}

Descriptive Statistics: Dependent Student's Adjusted Gross Income by Category

\begin{tabular}{|l|r|r|r|}
\hline & $\mathrm{N}$ & $\begin{array}{c}\text { \% of all } \\
\text { cases }\end{array}$ & $\begin{array}{c}\text { \% of non- } \\
\text { missing cases }\end{array}$ \\
\hline $100000+$ & 4 & .0 & .0 \\
$80000-89999$ & 3 & .0 & .0 \\
\hline
\end{tabular}




\begin{tabular}{|l|r|r|r|}
\hline $70000-79999$ & 2 & .0 & .0 \\
$60000-69999$ & 4 & .0 & .0 \\
$50000-59999$ & 5 & .1 & .1 \\
$40000-49999$ & 4 & .0 & .0 \\
$30000-39999$ & 16 & .2 & .2 \\
$20000-29999$ & 119 & 1.3 & 1.3 \\
$15000-19999$ & 207 & 2.2 & 2.2 \\
$10000-14999$ & 516 & 5.6 & 5.6 \\
$7500-9999$ & 669 & 7.3 & 7.3 \\
$5000-7499$ & 1190 & 12.9 & 12.9 \\
$2500-4999$ & 1477 & 16.0 & 16.0 \\
$1-2499$ & 1043 & 11.3 & 11.3 \\
0 & 3962 & 42.9 & 43.0 \\
Total & 9221 & 99.9 & 100.0 \\
Missing & 5 & .1 & \\
\hline
\end{tabular}

Table 26

Descriptive Statistics: Parent's Adjusted Gross Income

\begin{tabular}{|l|l|r|r|r|r|}
\hline & \multicolumn{1}{|c|}{$\mathrm{N}$} & Minimum & Maximum & Mean & Std. Deviation \\
\hline AGl1 & 23540 & .00 & 577427.00 & 15034.7254 & 29082.03352 \\
Valid N (listwise) & 23540 & & & & \\
\hline
\end{tabular}

Table 27

Descriptive Statistics: Parent's Adjusted Gross Income by Category

\begin{tabular}{|l|r|r|r|}
\hline & $N$ & $\begin{array}{c}\text { \% of all } \\
\text { cases }\end{array}$ & $\begin{array}{c}\text { \% of non- } \\
\text { missing cases }\end{array}$ \\
\hline $100000+$ & 450 & 4.9 & 4.9 \\
$90000-99999$ & 268 & 2.9 & 2.9 \\
$80000-89999$ & 329 & 3.6 & 3.6 \\
$70000-79999$ & 445 & 4.8 & 4.8 \\
$60000-69999$ & 634 & 6.9 & 6.9 \\
$50000-59999$ & 710 & 7.7 & 7.7 \\
$40000-49999$ & 739 & 8.0 & 8.0
\end{tabular}




\begin{tabular}{|l|r|r|r|}
\hline $30000-39999$ & 954 & 10.3 & 10.4 \\
$20000-29999$ & 1202 & 13.0 & 13.1 \\
$15000-19999$ & 729 & 7.9 & 7.9 \\
$10000-14999$ & 678 & 7.3 & 7.4 \\
$7500-9999$ & 263 & 2.9 & 2.9 \\
$5000-7499$ & 232 & 2.5 & 2.5 \\
$2500-4999$ & 144 & 1.6 & 1.6 \\
$1-2499$ & 121 & 1.3 & 1.3 \\
0 & 1305 & 14.1 & 14.2 \\
& 9203 & 99.8 & 100.0 \\
& 23 & .2 & \\
Total & 9226 & 100.0 & \\
\hline
\end{tabular}

\section{Number in household.}

Table 28 shows, for non-missing cases, $19.8 \%$ of independent students have only one person in their household, $27.3 \%$ have two, $23.5 \%$ have three, $17.8 \%$ have four and $2.8 \%$ have five. Independent students who have between seven and 11 household members represent less than $1 \%$. Table 29 shows, for non-missing cases, $18.4 \%$ of dependent students have two persons in their household, $33.4 \%$ have three, $28.8 \%$ have four, $12.8 \%$ have five, $4.2 \%$ have six and $1.6 \%$ have seven. Dependent student who have between 8 and 12 household members represent less than $1 \%$.

\section{Table 28}

Descriptive Statistics: Number in Household (Independent)

\begin{tabular}{|r|r|r|r|}
\hline & $\mathrm{N}$ & $\begin{array}{r}\text { \% of all } \\
\text { cases }\end{array}$ & \multicolumn{2}{c|}{$\begin{array}{c}\text { \% of non- } \\
\text { missing cases }\end{array}$} \\
\hline 1 & 2980 & 10.2 & 19.8 \\
2 & 4104 & 14.0 & 27.3 \\
3 & 3528 & 12.1 & 23.5 \\
4 & 2676 & 9.1 & 17.8 \\
5 & 1169 & 4.0 & 7.8 \\
6 & 418 & 1.4 & 2.8
\end{tabular}




\begin{tabular}{|c|c|c|c|c|}
\hline & 7 & 101 & .3 & .7 \\
\hline & 8 & 31 & .1 & .2 \\
\hline & 9 & 10 & .0 & .1 \\
\hline & 10 & 2 & .0 & .0 \\
\hline & 11 & 1 & .0 & .0 \\
\hline & Total & 15020 & 51.3 & 100.0 \\
\hline & Missing & 14255 & 48.7 & \\
\hline Total & & 29275 & 100.0 & \\
\hline
\end{tabular}

Table 29

Descriptive Statistics: Number in Household (Dependent)

\begin{tabular}{|c|r|r|r|}
\hline & $N$ & $\begin{array}{c}\text { \% of all } \\
\text { cases }\end{array}$ & $\begin{array}{c}\text { \% of non- } \\
\text { missing cases }\end{array}$ \\
\hline 1.00 & 9 & .0 & .1 \\
2.00 & 1624 & 5.5 & 18.4 \\
3.00 & 2941 & 10.0 & 33.4 \\
4.00 & 2538 & 8.7 & 28.8 \\
5.00 & 1131 & 3.9 & 12.8 \\
6.00 & 370 & 1.3 & 4.2 \\
7.00 & 143 & .5 & 1.6 \\
8.00 & 38 & .1 & .4 \\
9.00 & 11 & .0 & .1 \\
10.00 & 2 & .0 & .0 \\
11.00 & 4 & .0 & .0 \\
12.00 & 3 & .0 & .0 \\
Total & 8814 & 30.1 & 100.0 \\
Missing & 20461 & 69.9 & \\
& 29275 & 100.0 & \\
\hline
\end{tabular}

\section{Number of household members in college.}

Table 30 shows, for non-missing cases, $89.7 \%$ of independent students are the only person in their household in college and $9.5 \%$ have one additional person in their household in college. Independent students who have between three and six household 
members in college represent less than $1 \%$. Table 31 shows, for non-missing cases, $82.9 \%$ of dependent students are the only person in their household in college, $15.3 \%$ have one additional person in their household in college and $1.7 \%$ has two additional persons in their household in college. Dependent students who have between four and six household members in college represent less than $1 \%$.

Table 30

Descriptive Statistics: Number of Household Members in College (Independent)

\begin{tabular}{|l|r|r|r|}
\hline & $\mathrm{N}$ & $\begin{array}{c}\text { \% of all } \\
\text { cases }\end{array}$ & $\begin{array}{c}\text { \% of non- } \\
\text { missing cases }\end{array}$ \\
\hline 1 & 13452 & 46.0 & 89.7 \\
2 & 1418 & 4.8 & 9.5 \\
3 & 101 & .3 & .7 \\
4 & 13 & .0 & .1 \\
5 & 3 & .0 & .0 \\
6 & 3 & .0 & .0 \\
& 14990 & 51.2 & 100.0 \\
Total & 14285 & 48.8 & \\
\hline
\end{tabular}

Table 31

Descriptive Statistics: Number of Household Members in College (Dependent)

\begin{tabular}{|l|r|r|r|}
\hline & \multicolumn{1}{|c|}{$\mathrm{N}$} & $\begin{array}{c}\text { \% of all } \\
\text { cases }\end{array}$ & $\begin{array}{c}\text { \% of non- } \\
\text { missing cases }\end{array}$ \\
\hline 1.00 & 7279 & 24.9 & 82.9 \\
2.00 & 1342 & 4.6 & 15.3 \\
3.00 & 147 & .5 & 1.7 \\
4.00 & 11 & .0 & .1 \\
& 8779 & 30.0 & 100.0 \\
Total & 20496 & 70.0 & \\
\hline
\end{tabular}




\section{Federal work-study and waiver/third party.}

Table 32 shows only $1.8 \%$ of students participated in the federal work-study program. Table 33 shows $7.8 \%$ of the students received a waiver and/or financial assistance from a third party.

Table 32

Descriptive Statistics: Federal Work Study

\begin{tabular}{|c|r|r|r|}
\hline & $\mathrm{N}$ & \multicolumn{1}{c|}{$\begin{array}{c}\text { \% of all } \\
\text { cases }\end{array}$} & $\begin{array}{c}\text { \% of non- } \\
\text { missing cases }\end{array}$ \\
\hline No & 28752 & 98.2 & 98.2 \\
Yes & 523 & 1.8 & 1.8 \\
Total & 29275 & 100.0 & 100.0 \\
\hline
\end{tabular}

\section{Table 33}

Descriptive Statistics: Waiver and Third Party

\begin{tabular}{|c|r|r|r|}
\hline & $\mathrm{N}$ & \multicolumn{1}{c|}{$\begin{array}{c}\text { \% of all } \\
\text { cases }\end{array}$} & $\begin{array}{c}\text { \% of non- } \\
\text { missing cases }\end{array}$ \\
\hline No & 26980 & 92.2 & 92.2 \\
Yes & 2295 & 7.8 & 7.8 \\
Total & 29275 & 100.0 & 100.0 \\
\hline
\end{tabular}

\section{Academic}

\section{Grade point average.}

Table 34 shows grade point average ranged from 0.0 to 4.0 . The mean for current GPA was 2.06 and the mean for cumulative GPA was 2.38 .

\section{Table 34}

Descriptive Statistics: Current GPA and Cumulative GPA

\begin{tabular}{|l|r|r|r|r|r|}
\hline & \multicolumn{1}{|c|}{$\mathrm{N}$} & Minimum & Maximum & \multicolumn{1}{c|}{ Mean } & Std. Deviation \\
\hline Current GPA & 29270 & .0000 & 4.0000 & 2.064467 & 1.4948159 \\
\hline
\end{tabular}




\begin{tabular}{|l|l|l|l|l|l|} 
Cumulative GPA & 29270 & .0000 & 4.0000 & 2.383875 & 1.2667346 \\
Valid N (listwise) & 29270 & & & & \\
\hline
\end{tabular}

\section{Enrollment status.}

As noted in chapter 2 , over $54 \%$ of 2 -year students attended part-time for the full year and over $68 \%$ attended part-time for part of the year (Horn, Peter, \& Rooney, 2002;

Provasnik \& Planty, 2008). For KCTCS, between 2005 and 2008 the percentage of students attending full-time ranged from $36 \%$ to $40 \%$. (Factbook, 2008, p. 106). Table 35 shows the range of credit hours taken, in one semester, as three to 29 with a mean of 11.1 credit hours. Table 36 shows $62.7 \%$ of students are full-time (12 credit hours or more) and $17.1 \%$ as three-quarter time ( 9 to 11 hours). Table 37 shows that $76.9 \%$ of dependents enroll in between 11 and 15 credit hours per term, which table 38 shows is an average of 11.99 . Table 39 shows that $64.8 \%$ of dependents enroll in between 11 and 15 credit hours per term, which table 40 shows is an average of 11.11.

\section{Table 35}

Descriptive Statistics: Enrollment Status

\begin{tabular}{|l|l|r|r|r|r|}
\hline & \multicolumn{1}{|c|}{$\mathrm{N}$} & Minimum & Maximum & \multicolumn{1}{c|}{ Mean } & Std. Deviation \\
\hline Units Taken & 29270 & 3.0000 & 29.0000 & 11.101607 & 3.2236614 \\
Valid N (listwise) & 29270 & & & & \\
\hline
\end{tabular}

\section{Table 36}

Descriptive Statistics: Frequency Distribution for Enrollment Status

\begin{tabular}{|l|r|r|r|}
\hline & $\mathrm{N}$ & $\begin{array}{c}\text { \% of all } \\
\text { cases }\end{array}$ & $\begin{array}{c}\text { \% of non- } \\
\text { missing cases }\end{array}$ \\
\hline Missing & 5 & .0 & .0 \\
F & 18359 & 62.7 & 62.7 \\
H & 4443 & 15.2 & 15.2 \\
$\mathrm{~L}$ & 1456 & 5.0 & 5.0 \\
\hline
\end{tabular}




\begin{tabular}{l|r|r|r|}
$N$ & 11 & .0 & .0 \\
$T$ & 5001 & 17.1 & 17.1 \\
Total & 29275 & 100.0 & 100.0 \\
\hline
\end{tabular}

\section{Table 37}

Descriptive Statistics: Dependents Credit Hours by Category

\begin{tabular}{|ll|r|r|r|r|}
\hline & & & & \multicolumn{2}{c|}{$\begin{array}{c}\text { Cumulative } \\
\text { Percent }\end{array}$} \\
\hline Valid & $21-25$ & Frequency & Percent & Valid Percent & .2 \\
& $16-20$ & 514 & .2 & .2 & 5.8 \\
& $11-15$ & 7093 & 76.9 & 7.6 & 82.7 \\
& $6-10$ & 1507 & 16.3 & 16.3 & 99.1 \\
& $0-5$ & 84 & .9 & .9 & 100.0 \\
& Total & 9218 & 99.9 & 100.0 & \\
Missing & System & 8 & .1 & & \\
Total & & 9226 & 100.0 & & \\
\hline
\end{tabular}

Table 38

Descriptive Statistics: Enrollment Status for Dependents

\begin{tabular}{|l|r|r|r|r|r|}
\hline & \multicolumn{1}{|c|}{$\mathrm{N}$} & Minimum & Maximum & \multicolumn{1}{c|}{ Mean } & Std. Deviation \\
\hline Unt Taken & 9223 & 3.0000 & 24.3800 & 11.998772 & 2.5976982 \\
Valid N (listwise) & 9223 & & & & \\
\hline
\end{tabular}

Table 39

Descriptive Statistics: Independents Credit Hours by Category

\begin{tabular}{|c|c|c|c|c|c|}
\hline & & Frequency & Percent & Valid Percent & $\begin{array}{c}\text { Cumulative } \\
\text { Percent }\end{array}$ \\
\hline \multirow[t]{6}{*}{ Valid } & $26-30$ & 1 & .0 & .0 & .0 \\
\hline & $21-25$ & 19 & .1 & .1 & .1 \\
\hline & $16-20$ & 593 & 4.1 & 4.1 & 4.3 \\
\hline & $11-15$ & 9269 & 64.8 & 64.8 & 69.1 \\
\hline & $6-10$ & 4142 & 28.9 & 29.0 & 98.0 \\
\hline & $0-5$ & 282 & 2.0 & 2.0 & 100.0 \\
\hline
\end{tabular}




\begin{tabular}{|c|c|c|c|c|}
\hline & Total & 14306 & 99.9 & 100.0 \\
\hline Missing & System & 8 & .1 & \\
\hline Total & & 14314 & 100.0 & \\
\hline
\end{tabular}

\section{Table 40}

Descriptive Statistics: Enrollment Status for Independents

\begin{tabular}{|l|l|r|r|r|r|}
\hline & \multicolumn{1}{|c|}{$\mathrm{N}$} & Minimum & Maximum & \multicolumn{1}{c|}{ Mean } & Std. Deviation \\
\hline Unt Taken & $\begin{array}{l}14313 \\
14313\end{array}$ & 3.0000 & 29.0000 & 11.116193 & 3.0197318 \\
Valid N (listwise) & & & & \\
\hline
\end{tabular}

\section{Credit hours accumulated.}

Table 41 shows that the minimum number of credit hours accumulated, when a student was enrolled in MT065 was three and the maximum was 255. The mean number of credit hours was 25.6 . Table 42 shows $27.5 \%$ of independent students took MT065 within the first 12 credit hours and 29.6\% took MT065 when they had earned 13-24 credit hours. Table 43 shows $32.3 \%$ of dependent students took MT065 within the first 12 credit hours and 35.7\% took MT065 when they had earned 13-24 credit hours.

\section{Table 41}

Descriptive Statistics: Total Credit Hours Accumulated

\begin{tabular}{|l|r|r|r|r|r|}
\hline & \multicolumn{1}{|c|}{$\mathrm{N}$} & Minimum & Maximum & Mean & Std. Deviation \\
\hline Total Taken Progress & 29268 & 3.0000 & 255.5000 & 25.656931 & 20.8516656 \\
Valid N (listwise) & 29268 & & & & \\
\hline
\end{tabular}

\section{Table 42}

Descriptive Statistics: Independent Students Earned Credits when Enrolled in MT065

\begin{tabular}{|r|r|r|r|}
\hline & $N$ & $\begin{array}{r}\text { \% of all } \\
\text { cases }\end{array}$ & \multicolumn{2}{c|}{$\begin{array}{c}\text { of non- } \\
\text { missing cases }\end{array}$} \\
\hline $48-255$ & 2186 & 15.3 & 15.3 \\
$37-48$ & 1232 & 8.6 & 8.6
\end{tabular}




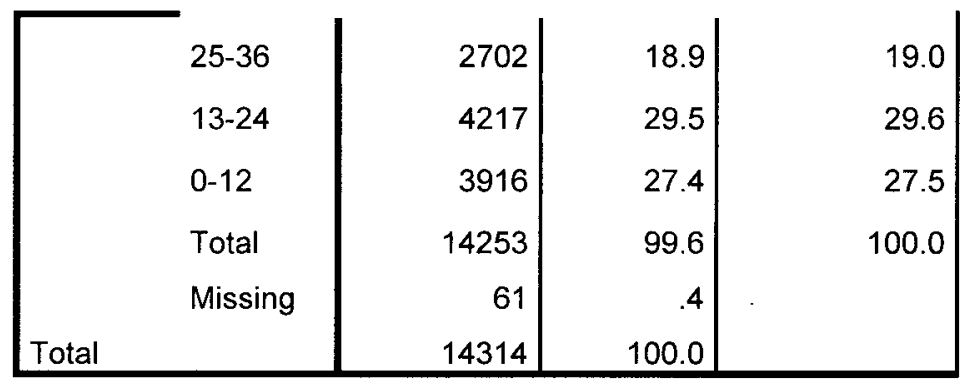

\section{Table 43}

Descriptive Statistics: Dependent Students Earned Credits when Enrolled in MT065

\begin{tabular}{|c|c|c|c|c|}
\hline & & $\mathrm{n}$ & $\begin{array}{l}\% \text { of all } \\
\text { cases }\end{array}$ & $\begin{array}{c}\% \text { of non- } \\
\text { missing cases }\end{array}$ \\
\hline & $48-255$ & 516 & 5.6 & 5.6 \\
\hline & $37-48$ & 624 & 6.8 & 6.8 \\
\hline & $25-36$ & 1809 & 19.6 & 19.6 \\
\hline & $13-24$ & 3283 & 35.6 & 35.7 \\
\hline & $0-12$ & 2975 & 32.2 & 32.3 \\
\hline & Total & 9207 & 99.8 & 100.0 \\
\hline & Missing & 19 & .2 & \\
\hline Total & & 9226 & 100.0 & \\
\hline
\end{tabular}

\section{Academic program.}

Table 44 shows $62.3 \%$ were transfer students and $37.4 \%$ were not transfer students. Table 45 shows that "transfer" is comprised of the following: AA, AAS, AAT, and ASF/AAF programs. Table 45 shows that "not transfer" is comprised of the following: AS, Certificate, Diploma, and Undecided. In addition, Table 45 shows that the majority of transfer students are AAS (43.5\%) degrees and the majority of "not transfer" are undecided $(24.3 \%)$.

Table 44

Descriptive Statistics: Academic Program

\begin{tabular}{|c|c|c|c|}
\hline & & $\begin{array}{c}\% \text { of all } \\
\text { cases }\end{array}$ & $\begin{array}{c}\% \text { of non- } \\
\text { missing cases }\end{array}$ \\
\hline
\end{tabular}




\begin{tabular}{|ll|r|r|r|}
\hline & Not transfer & 10945 & 37.4 & 37.5 \\
& Transfer & 18241 & 62.3 & 62.5 \\
& Total & 29186 & 99.7 & 100.0 \\
Missing & System & 89 & .3 & \\
Total & & 29275 & 100.0 & \\
\hline
\end{tabular}

\section{Table 45}

Descriptive Statistics: Academic Program Transfer and Not Transfer Categories

\begin{tabular}{|l|r|r|r|}
\hline & $\mathrm{N}$ & $\begin{array}{r}\text { \% of all } \\
\text { cases }\end{array}$ & $\begin{array}{r}\text { \% of non-missing } \\
\text { cases }\end{array}$ \\
\hline Not indicated & 89 & .3 & .3 \\
AA & 2669 & 9.1 & 9.1 \\
AAS & 12742 & 43.5 & 43.5 \\
AAT & 4 & .0 & .0 \\
AS & 1107 & 3.8 & 3.8 \\
ASF/AAF & 2830 & 9.7 & 9.7 \\
Certificate & 330 & 1.1 & 1.1 \\
Diploma & 2403 & 8.2 & 8.2 \\
Undecided & 7101 & 24.3 & 24.3 \\
Total & 29275 & 100.0 & 100.0 \\
\hline
\end{tabular}

\section{Degree program.}

Table 46 shows $30.7 \%$ of students are an Allied Health, $13.4 \%$ are General

Studies and $7.3 \%$ are Business majors. No other major accounted for more than $3.9 \%$ of the total population.

Table 46

Descriptive Statistics: Degree Programs by CIP Categories

\begin{tabular}{|l|r|r|r|}
\hline & $\mathrm{N}$ & \% of all cases & \% of non-missing cases \\
\hline Undecided & 5484 & 18.7 & 21.2 \\
Agriculture & 30 & .1 & .1 \\
2 & 29 & .1 & .1 \\
Natural resources/environmental science & 18 & .1 & .1
\end{tabular}




\begin{tabular}{|c|c|c|c|}
\hline Architecture & 10 & .0 & .0 \\
\hline Area and ethnic studies & 2 & .0 & .0 \\
\hline 8 & 3 & .0 & .0 \\
\hline Communication/journalism & 90 & .3 & .3 \\
\hline Communication technologies & 44 & .2 & .2 \\
\hline Computer and information sciences & 649 & 2.2 & 2.5 \\
\hline Personal and culinary services & 150 & .5 & 6 \\
\hline Education & 1021 & 3.5 & 3.9 \\
\hline Engineering & 83 & .3 & .3 \\
\hline Engineering Technologies & 392 & 1.3 & 1.5 \\
\hline Foreign language and literature & 7 & .0 & .0 \\
\hline Family and consumer sciences & 512 & 1.7 & 2.0 \\
\hline 20 & 15 & .1 & .1 \\
\hline Law/legal studies & 12 & .0 & .0 \\
\hline English & 24 & .1 & .1 \\
\hline General studies & 3464 & 11.8 & 13.4 \\
\hline Library science & 3 & .0 & .0 \\
\hline Biological/life sciences & 40 & .1 & .2 \\
\hline Mathematics and statistics & 1 & .0 & .0 \\
\hline Interdisciplinary studies & 504 & 1.7 & 1.9 \\
\hline Parks and recreation & 14 & .0 & .1 \\
\hline Philosophy and religious studies & 4 & .0 & .0 \\
\hline Physical sciences & 10 & .0 & .0 \\
\hline Science technologies & 43 & .1 & .2 \\
\hline Psychology & 186 & .6 & .7 \\
\hline $\begin{array}{l}\text { Homeland security, law enforcement, } \\
\text { firefighting, and protective services }\end{array}$ & 829 & 2.8 & 3.2 \\
\hline Public administration and social services & 513 & 1.8 & 2.0 \\
\hline Social services & 82 & 3 & .3 \\
\hline Construction trades & 347 & 1.2 & 1.3 \\
\hline Mechanic and repair technologies & 599 & 2.0 & 2.3 \\
\hline Precision production & 246 & .8 & 1.0 \\
\hline Transportation and materials moving & 6 & .0 & .0 \\
\hline Visual and performing arts & 65 & .2 & 3 \\
\hline Allied Health & 7934 & 27.1 & 30.7 \\
\hline Business & 1897 & 6.5 & 7.3 \\
\hline
\end{tabular}




\begin{tabular}{|ll|r|r|r|}
\hline & 60 & 6 & .0 & .0 \\
& 90 & 513 & 1.8 & 2.0 \\
& Total & 2588 & 88.4 & 100.0 \\
& & 3394 & & \\
Missing & 2927 & 11.6 &. \\
Total & & 5 & 100.0 & \\
\hline
\end{tabular}

Note. CIP Codes $2,8,20,60$ and 90 were undefined.

\section{Course delivery method.}

Table 47 shows that $95.1 \%$ of students were enrolled in MT065 through an in person course.

Table 47

Descriptive Statistics: Course Delivery Method

\begin{tabular}{|l|r|r|r|}
\hline & $\mathrm{N}$ & $\begin{array}{c}\text { \% of all } \\
\text { cases }\end{array}$ & $\begin{array}{c}\text { \% of non- } \\
\text { missing cases }\end{array}$ \\
\hline In Person & 27826 & 95.1 & 95.1 \\
Distance & 1439 & 4.9 & 4.9 \\
Total & 29265 & 100.0 & 100.0 \\
Total & 10 & .0 & \\
\hline
\end{tabular}

\section{Research Questions}

\section{Statistically Significant Predictor Variables on Persistence}

There were a total of 108 logistic regression analyses to be conducted. Twenty logistic regression analyses were not conducted because there were not enough cases. Thus, 88 logistic regressions were analyzed. Thirty-six logistic regression analyses were not statistically significant. Therefore, 52 logistic regression analyses were statistically significant and 51 of the 52 logistic regression analysis resulted in at least one significant 
predictor variable. Each term-to-term cohort was measured four times. First, the students were divided based on dependency status as recognized by the free application for federal student aid (FAFSA). Next, these two groups were tested once including the predictor variables secondary education, then without secondary education. Removing secondary education substantially increased the sample size.

First, an omnibus test of model coefficients was used to determine if the overall model was significant $(p<.05)$. The model significance is identified in the individual predictor variable charts by the term "model sig". The $p$ or Sig values show whether the model and predictor variables were statistically significant. Throughout the analyses, statistical significance was based on an alpha level of 0.05 . If the logistical regression model was significant, Nagelkerke $\mathrm{R}^{2}$ was also reported. Nagelkerke $\mathrm{R}^{2}$ is "a version of the coefficient of determination for logistic regression. It is a variation on Cox and Snell's $\mathrm{R}^{2}$ which overcomes the problem that this statistic has of not being able to reach its maximum value" (Field, 2005, p.739). The $\operatorname{Exp(B)}$ value is, "an indicator of the change in odds resulting from a unit change in the predictor. As such it is similar to the $b$ coefficient in logistic regression but easier to understand (because it does not require a logarithmic transformation)." (Field, 2005, p.225). "If the value is greater than 1 then it indicates that as the predictor increases, the odds of the outcome occurring increase. Conversely, a value less than 1 indicates that as the predictor increases, the odds of the outcome occurring decrease" (Fields, 2005, p.226). The B value "represents the change in the outcome resulting from a unit change in the predictor variable. The interpretation of this coefficient in logistic regression is very similar in that it represents the change in the logit of the outcome variable associated with a one-unit change in the predictor variable" 
(Fields, 2005, p.239). The Wald statistic, "has a special distribution known as the chisquare distribution. Like the $t$-test in linear regression, the Wald statistic tells us whether the $b$-coefficient for that predictor is significantly different from zero" (Field, 2005, p.224).

In summary, the dependent variable was persistence, which was determined by noting whether the student was enrolled at the beginning of each term or had been awarded a credential. Therefore, the outcome was either yes or no and was coded as 0 for no and 1 for yes. Because the dependent variable was dichotomous and the relationships between the predictor variables and the dependent variable was nonlinear, logistic regression was selected (Cohen \& Cohen, 1983). The predictor variables were entered in four blocks: (a) static characteristics, (b) dynamic characteristics, (c) academic, and (d) instructional delivery method. (The fourth block was used only for the original data cohorts.)

Each research question is accompanied with a table in which the predictor variable was statistically significant. The table lists the predictor variables and shows (a) the cohort, (b) the term in which the cohort's persistence was measured (e.g. re-enrolled, transferred, or graduated), (c) the size of the sample, (d) the dependency status, (e) whether or not secondary education was considered as a variable, (f) whether or not the Omnibus Test of Model Coefficients showed the model to be significant, (g) Nagelkerke R squared of the model, (h) the sig. value of the particular variable and (i) the B coefficient. 


\section{Stagnant Characteristics}

\section{Is there a significant relationship between sex and persistence?}

Table 48 shows the cohorts that had statistically significant regression coefficients for sex. Sex was a significant predictor of persistence $(\mathrm{p}<.05)$ in four of the logistic regression analyses. Within the fall and spring 2007 cohorts, sex resulted in a negative B value in two logistic regression outputs and a positive B coefficient in two logistic regression outputs. A positive regression coefficient means being female is associated with persistence. A negative regression coefficient means being male is associated with persistence. It is noted, that the only analysis for independent students, in which sex was statistically significant, the number of cases was 129.

\section{Table 48}

Cohorts that Had Sex as a Significant Predictor of Persistence

\begin{tabular}{|l|l|l|l|l|l|l|l|l|}
\hline Sex \\
\hline Cohort & Term & $\boldsymbol{n}$ & Dependency & Sec Ed & Model Sig & Nag R $^{2}$ & B & B Sig \\
\hline Fall 2007 & Spring 08 & 355 & Dependent & No & .020 & .138 & .855 & .009 \\
\hline Fall 2007 & Fall 2008 & 196 & Dependent & Yes & .002 & .326 & -2.419 & .001 \\
\hline Fall 2007 & Fall 2008 & 273 & Dependent & No & .016 & .162 & -1.131 & .002 \\
\hline Spring 07 & Fall 2009 & 129 & Independent & Yes & .000 & .546 & 2.015 & .045 \\
\hline
\end{tabular}

Note. Sec Ed means whether the variable secondary education was in the regression model.

Nag $R^{2}$ means Nagelkerke $R^{2}$.

\section{Is there a significant relationship between mother's level of education and} persistence?

Table 49 shows the cohorts that had statistically significant regression coefficients for mother's level of education. Mother's level of education was a significant predictor of persistence $(p<.05)$ in 13 of the logistic regression analyses. Within the fall 2006, 2007, 2008 and spring 2007 and 2008 cohorts, mother's level of education for independent 
students resulted in a negative B value in seven of the eight logistic regression outputs.

Conversely, mother's level of education resulted in a positive B value for dependent students in four of the five logistic regression outputs. The one dependent output that showed a large negative $B$ value had a small sample size $(n=73)$. In addition, all five logistic regression analyses in which mother's level of education was statistically significant for dependent students, the number of cases was less than 150. A positive regression coefficient (as with most dependent students) means that the higher the level of mother's education, the greater the probability of persistence. A negative regression coefficient (as with the independent students) means that the lower the level of mother's education, the greater the probability of persistence.

Table 49

Cohorts that Had Mother's Level of Education as a Significant Predictor of Persistence

\begin{tabular}{|l|l|l|l|l|l|l|l|l|}
\hline \multicolumn{1}{|l|}{ Mother's Level of Education } \\
\hline Cohort & Term & $\boldsymbol{n}$ & Dependency & Sec Ed & Model Sig & Nag R $^{2}$ & B & B Sig \\
\hline Fall 2006 & Fall 2007 & 529 & Independent & No & .000 & .186 & -.562 & .014 \\
\hline Fall 2006 & Spring 08 & 516 & Independent & No & .000 & .189 & -.423 & .027 \\
\hline Fall 2006 & Spring 09 & 129 & Dependent & Yes & .031 & .398 & 1.483 & .019 \\
\hline Fall 2006 & Spring 09 & 147 & Dependent & No & .043 & .335 & 1.130 & .039 \\
\hline Fall 2006 & Fall 2009 & 154 & Independent & No & .000 & .513 & -1.203 & .016 \\
\hline Fall 2006 & Fall 2009 & 73 & Dependent & Yes & .006 & .586 & -2.874 & .023 \\
\hline Fall 2007 & Spring 08 & 558 & Independent & No & .000 & .183 & -.522 & .042 \\
\hline Fall 2008 & Fall 2009 & 187 & Independent & Yes & .000 & .424 & -.875 & .041 \\
\hline Fall 2008 & Spring 10 & 51 & Dependent & No & .015 & .654 & 2.507 & .028 \\
\hline Spring 07 & Fall 2008 & 357 & Independent & No & .000 & .214 & .566 & .038 \\
\hline Spring 08 & Fall 2008 & 318 & Independent & Yes & .000 & .369 & -1.191 & .001 \\
\hline Spring 08 & Fall 2008 & 399 & Independent & No & .000 & .269 & -.555 & .017 \\
\hline Spring 08 & Fall 2008 & 134 & Dependent & Yes & .000 & .582 & 2.392 & .016 \\
\hline
\end{tabular}

Note. Sec Ed means whether the variable secondary education was in the regression model.

Nag $R^{2}$ means Nagelkerke $R^{2}$. 


\section{Is there a significant relationship between father's level of education and persistence?}

Table 50 shows the cohorts that had statistically significant regression coefficients for father's level of education. Father's level of education was a significant predictor of persistence $(p<.05)$ in five of the logistic regression analyses. Within the spring 2007 , 2008 and 2009 cohorts, father's level of education for resulted in a negative B value in all five logistic regression outputs. A negative regression coefficient means that the lower the level of father's education, the greater the probability of persistence. It is noted, all three logistic regression analyses in which father's level of education was statistically significant for dependent students, the number of cases was less than 150 .

\section{Table 50}

Cohorts that Had Father's Level of Education as a Significant Predictor of Persistence

\begin{tabular}{|l|l|l|l|l|l|l|l|l|}
\hline Father's Level of Education \\
\hline Cohort & Term & $\boldsymbol{n}$ & Dependency & Sec Ed & Model Sig & Nag R $^{2}$ & B & B Sig \\
\hline Spring 07 & Fall 2008 & 357 & Independent & No & .000 & .214 & -.590 & .034 \\
\hline Spring 08 & Fall 2008 & 134 & Dependent & Yes & .000 & .582 & -3.739 & .003 \\
\hline Spring 09 & Fall 2009 & 199 & Independent & Yes & .006 & .273 & -.831 & .010 \\
\hline Spring 09 & Fall 2009 & 108 & Dependent & Yes & .000 & .463 & -1.596 & .002 \\
\hline Spring 09 & Fall 2009 & 121 & Dependent & No & .000 & .436 & -1.508 & .003 \\
\hline
\end{tabular}

Note. Sec Ed means whether the variable secondary education was in the regression model.

Nag $R^{2}$ means Nagelkerke $R^{2}$.

\section{Is there a significant relationship between secondary education and persistence?}

Secondary education was not found as a statistically significant predictor variable in any of the logistic regression analyses. Therefore, there is no significant relationship between secondary education and persistence. 


\section{Dynamic Characteristics}

\section{Is there a significant relationship between dependency status and persistence?}

This research question was not directly addressed because separate logistic regression analyses were performed for dependent students and independent students. The variable student dependency status was not used as a predictor variable in the logistic regressions.

\section{Is there a significant relationship between waiver/third party and persistence?}

Table 51 shows the cohorts that had statistically significant regression coefficients for waiver/third party. Waivers and third party financial assistance was a significant predictor of persistence $(p<.05)$ in three of the logistic regression analyses. Within the fall 2007 and spring 2007 and 2008 cohorts, waiver/third party resulted in a positive B value in all three logistic regression outputs. A positive regression coefficient means receiving a waiver or third part financial assistance is associated with persistence.

\section{Table 51}

Cohorts that Had Waiver/Third Party as a Significant Predictor of Persistence

\begin{tabular}{|l|l|l|l|l|l|l|l|l|}
\hline Waiver / Third Party \\
\hline Cohort & Term & $\boldsymbol{n}$ & Dependency & Sec Ed & Model Sig & Nag R $^{2}$ & B & B Sig \\
\hline Fall 2007 & Spring 08 & 558 & Independent & No & .000 & .183 & 2.110 & .041 \\
\hline Spring 07 & Fall 2007 & 754 & Independent & No & .000 & .116 & .983 & .030 \\
\hline Spring 08 & Fall 2008 & 185 & Dependent & No & .000 & .364 & 2.769 & .026 \\
\hline
\end{tabular}

Note. Sec Ed means whether the variable secondary education was in the regression model.

Nag $\mathrm{R}^{2}$ means Nagelkerke $\mathrm{R}^{2}$. 


\section{Is there a significant relationship between the number in household and persistence?}

Table 52 shows the cohorts that had statistically significant regression coefficients for household size. Household size was a significant predictor of persistence $(p<.05)$ in two of the logistic regression analyses. Within the fall 2007 and 2008 cohorts, household size resulted in a positive $\mathrm{B}$ coefficient value in one logistic regression output and a negative B coefficient value on one logistic regression output. However, it is noted, that the output that resulted in a positive B coefficient value was with a sample size of 50 . A negative regression coefficient means the greater the household size, the greater the probability of persistence.

\section{Table 52}

Cohorts that Had Household Size as a Significant Predictor of Persistence

\begin{tabular}{|l|l|l|l|l|l|l|l|l|}
\hline Household Size \\
\hline Cohort & Term & $\boldsymbol{n}$ & Dependency & Sec Ed & Model Sig & Nag R $^{2}$ & B & B Sig \\
\hline Fall 2007 & Fall 2008 & 347 & Independent & Yes & .002 & .224 & -.428 & .030 \\
\hline Fall 2008 & Spring 10 & 50 & Dependent & Yes & .018 & .671 & 1.545 & .046 \\
\hline
\end{tabular}

Note. Sec Ed means whether the variable secondary education was in the regression model.

Nag $\mathrm{R}^{2}$ means Nagelkerke $\mathrm{R}^{2}$.

Is there a significant relationship between adjusted gross income and persistence?

This question was subdivided into two different research questions based on the information collected from the FAFSA. Because the FAFSA collects this information differently for independent and dependent students, the two following research questions were addressed: 


\section{Is there a significant relationship between a student's (and spouse, if}

\section{married) adjusted gross income and persistence?}

Table 53 shows the cohorts that had statistically significant regression coefficients for adjusted gross income. Adjusted gross income was a significant predictor of persistence $(\mathrm{p}<.05)$ in 16 of the logistic regression analyses. Within the fall 2006, 2007, 2008 and spring 2007 cohorts, adjusted gross income was statistically significant in 16 of the logistic regression outputs. Also, in every logistic regression, except two, adjusted gross income was significant for an independent student rather than a dependent student. A positive regression coefficient means an increase in adjusted gross income is associated with persistence.

Table 53

Cohorts that Had Adjusted Gross Income as a Significant Predictor of Persistence

\begin{tabular}{|l|l|l|l|l|l|l|l|l|}
\hline Adjusted Gross Income & \multicolumn{10}{|l|}{$\mid$} \\
\hline Cohort & Term & $\boldsymbol{n}$ & Dependency & Sec Ed & Model Sig & Nag R $^{2}$ & B & B Sig \\
\hline Fall 2006 & Spring 07 & 301 & Independent & Yes & .001 & .281 & $6.36-5$ & .005 \\
\hline Fall 2006 & Spring 07 & 666 & Independent & No & .000 & .156 & $2.55-5$ & .018 \\
\hline Fall 2006 & Fall 2009 & 112 & Independent & Yes & .007 & .479 & $6.27-5$ & .029 \\
\hline Fall 2006 & Fall 2009 & 154 & Independent & No & .000 & .513 & $4.74-5$ & .032 \\
\hline Fall 2007 & Spring 08 & 558 & Independent & No & .000 & .183 & $2.72-5$ & .036 \\
\hline Fall 2007 & Fall 2008 & 347 & Independent & Yes & .002 & .224 & $2.95-5$ & .030 \\
\hline Fall 2007 & Fall 2008 & 428 & Independent & No & .000 & .176 & $2.57-5$ & .006 \\
\hline Fall 2007 & Fall 2008 & 196 & Dependent & Yes & .002 & .326 & $1.43-4$ & .033 \\
\hline Fall 2008 & Fall 2009 & 187 & Independent & Yes & .000 & .424 & $5.68-5$ & .005 \\
\hline Fall 2008 & Fall 2009 & 238 & Independent & No & .000 & .331 & $3.31-5$ & .027 \\
\hline Spring 07 & Spring 08 & 318 & Independent & Yes & .000 & .340 & $6.96-6$ & .005 \\
\hline Spring 07 & Spring 08 & 478 & Independent & No & .000 & .235 & $3.74-5$ & .002 \\
\hline Spring 07 & Spring 08 & 221 & Dependent & No & .007 & .276 & $1.41-4$ & .020 \\
\hline Spring 07 & Spring 09 & 239 & Independent & Yes & .000 & .481 & $1.20-4$ & .003 \\
\hline Spring 07 & Spring 09 & 284 & Independent & No & .000 & .339 & $7.44-5$ & .001 \\
\hline Spring 07 & Fall 2009 & 129 & Independent & Yes & .000 & .546 & $6.30-5$ & .028 \\
\hline
\end{tabular}

Note. Sec Ed means whether the variable secondary education was in the regression model. 
Nag $R^{2}$ means Nagelkerke $R^{2}$. Values of $B$ are presented in scientific number notation. For example, $6.36-5$ means $6.36 \times 10^{-5}=.0000636$.

Is there a significant relationship between a parent's adjusted gross income of a dependent student and persistence?

Table 54 shows the cohorts that had statistically significant regression coefficients for parent's adjusted gross income. Parent's adjusted gross income was a significant predictor of persistence $(\mathrm{p}<.05)$ in three of the logistic regression analyses. Within the fall 2006 cohort, parent's adjusted gross income was statistically significant in three of the logistic regression outputs. Also, in none of the outputs in which parent's adjusted gross income was significant was the accompanied student's adjusted gross income significant. A positive regression coefficient means an increase in parent's adjusted gross income is associated with persistence. It is noted that the one negative B coefficient value is with a sample size of 73 .

\section{Table 54}

Cohorts that Had Parent's Adjusted Gross Income as a Significant Predictor of Persistence

\begin{tabular}{|l|l|l|l|l|l|l|l|l|}
\hline \multicolumn{1}{|l|}{ Parent's Adjusted Gross Income } \\
\hline Cohort & Term & $\boldsymbol{n}$ & Dependency & Sec Ed & Model Sig & Nag R $^{2}$ & B & B Sig \\
\hline Fall 2006 & Spring 07 & 290 & Dependent & Yes & .059 & .170 & $1.45-5$ & .049 \\
\hline Fall 2006 & Spring 07 & 447 & Dependent & No & .000 & .167 & $1.20-5$ & .028 \\
\hline Fall 2006 & Fall 2009 & 73 & Dependent & Yes & .006 & .586 & $-2.77-5$ & .049 \\
\hline
\end{tabular}

Note. Sec Ed means whether the variable secondary education was in the regression model.

Nag $R^{2}$ means Nagelkerke $R^{2}$. Values of $B$ are presented in scientific number notation. For example, $1.45-5$ means $1.45 \times 10^{-5}=.0000145$. 


\section{Is there a significant relationship between age and persistence?}

Table 55 shows the cohorts that had statistically significant regression coefficients for age. Age was a significant predictor of persistence $(p<.05)$ in 19 of the logistic regression analyses. Within the fall 2006, 2007, 2008 and spring 2007 and 2008 cohorts, age for independent students resulted in a positive B value in all 14 logistic regression outputs. Conversely, age resulted in a negative B value for dependent students in three logistic regression outputs. Two additional dependent student outputs showed a very large $B$ value, but this significance is suspect given the small sample size $(n=73$ and $\mathrm{n}=83$ ). A positive regression coefficient (independent students, all students ages 24 and older) means older age is associated with persistence. A negative regression coefficient (dependent students, most students ages 18 to 24 ) means younger age is associated with persistence.

\section{Table 55}

Cohorts that Had Age as a Significant Predictor of Persistence

\begin{tabular}{|l|l|l|l|l|l|l|l|l|}
\hline Age & \multicolumn{1}{|l|}{} \\
\hline Cohort & Term & $\boldsymbol{n}$ & Dependency & Sec Ed & Model Sig & Nag R $^{2}$ & B & B Sig \\
\hline Fall 2006 & Spring 07 & 666 & Independent & No & .000 & .156 & .060 & .003 \\
\hline Fall 2006 & Spring 07 & 447 & Dependent & No & .000 & .167 & -.268 & .026 \\
\hline Fall 2006 & Spring 08 & 251 & Independent & Yes & .006 & .260 & .101 & .011 \\
\hline Fall 2006 & Spring 08 & 516 & Independent & No & .000 & .189 & .084 & .000 \\
\hline Fall 2006 & Spring 08 & 347 & Dependent & No & .006 & .140 & -.289 & .026 \\
\hline Fall 2006 & Fall 2009 & 73 & Dependent & Yes & .006 & .586 & 2.131 & .017 \\
\hline Fall 2006 & Fall 2009 & 83 & Dependent & No & .008 & .514 & 2.154 & .005 \\
\hline Fall 2007 & Spring 08 & 558 & Independent & No & .000 & .183 & .058 & .010 \\
\hline Fall 2007 & Fall 2008 & 347 & Independent & Yes & .002 & .224 & .106 & .001 \\
\hline Fall 2007 & Fall 2008 & 196 & Dependent & Yes & .002 & .326 & -.809 & .009 \\
\hline Fall 2008 & Spring 09 & 300 & Independent & Yes & .007 & .221 & .057 & .040 \\
\hline Fall 2008 & Spring 09 & 372 & Independent & No & .000 & .219 & .048 & .039 \\
\hline Spring 07 & Fall 2007 & 481 & Independent & Yes & .007 & .160 & .065 & .008 \\
\hline Spring 07 & Fall 2007 & 754 & Independent & No & .000 & .116 & .046 & .002 \\
\hline Spring 07 & Spring 08 & 318 & Independent & Yes & .000 & .340 & .101 & .019 \\
\hline Spring 07 & Spring 08 & 478 & Independent & No & .000 & .235 & .070 & .006 \\
\hline
\end{tabular}




\begin{tabular}{|l|l|l|l|l|l|l|l|l|}
\hline Spring 07 & Fall 2008 & 357 & Independent & No & .000 & .214 & .081 & .001 \\
\hline Spring 07 & Spring 09 & 239 & Independent & Yes & .000 & .481 & .165 & .002 \\
\hline Spring 08 & Fall 2008 & 399 & Independent & No & .000 & .269 & .052 & .008 \\
\hline
\end{tabular}

Note. Sec Ed means whether the variable secondary education was in the regression

model.

Nag $\mathrm{R}^{2}$ means Nagelkerke $\mathrm{R}^{2}$.

Is there a significant relationship between federal work-study and persistence?

Table 56 shows the cohorts that had statistically significant regression coefficients for federal work-study. Federal work-study was a significant predictor of persistence $(\mathrm{p}<$ .05 ) in one of the logistic regression analyses. Within the fall 2006 cohort, federal workstudy for independent students resulted in a positive B value in one logistic regression output. This means being a federal work-study student is associated with persistence.

Table 56

Cohorts that Had Federal Work-study as a Significant Predictor of Persistence

\begin{tabular}{|l|l|l|l|l|l|l|l|l|}
\hline \multicolumn{2}{|l|}{ Federal Work-Study } \\
\hline Cohort & Term & $\boldsymbol{n}$ & Dependency & Sec Ed & Model Sig & Nag R & B & B Sig \\
\hline Fall 2006 & Spring 08 & 516 & Independent & No & .000 & .189 & 1.626 & .034 \\
\hline
\end{tabular}

Note. Sec Ed means whether the variable secondary education was in the regression model.

Nag $R^{2}$ means Nagelkerke $R^{2}$.

Is there a significant relationship between the number of household members in college and persistence?

Table 57 shows the cohorts that had statistically significant regression coefficients for number of household members in college. Number of household members in college was a significant predictor of persistence $(\mathrm{p}<.05)$ in six of the logistic regression analyses. Within the fall 2006, 2007, 2008 and spring 2007 cohorts, number of household 
members in college resulted in a negative B value in all six logistic regression outputs.

All six logistic regressions were for independent students. A negative regression coefficient means that the fewer the number of people in college, the greater the probability of persisting.

\section{Table 57}

Cohorts that Had Household Members in College as a Significant Predictor of Persistence

\begin{tabular}{|l|l|l|l|l|l|l|l|l|}
\hline Number of Household Members in College \\
\hline Cohort & Term & $\boldsymbol{n}$ & Dependency & Sec Ed & Model Sig & Nag R $^{\mathbf{2}}$ & B & B Sig \\
\hline Fall 2006 & Fall 2008 & 352 & Independent & No & .013 & .155 & -.881 & .040 \\
\hline Fall 2007 & Fall 2008 & 428 & Independent & No & .000 & .176 & -.760 & .024 \\
\hline Fall 2008 & Spring 09 & 372 & Independent & No & .000 & .219 & -1.347 & .001 \\
\hline Fall 2008 & Fall 2009 & 187 & Independent & Yes & .000 & .424 & -1.513 & .043 \\
\hline Fall 2008 & Fall 2009 & 238 & Independent & No & .000 & .331 & -1.467 & .016 \\
\hline Spring 07 & Spring 09 & 239 & Independent & Yes & .000 & .481 & -2.499 & .007 \\
\hline
\end{tabular}

Note. Sec Ed means whether the variable secondary education was in the regression model.

Nag $R^{2}$ means Nagelkerke $R^{2}$.

\section{Is there a significant relationship between being a single mother and}

\section{persistence?}

Table 58 shows the cohorts that had statistically significant regression coefficients for single mother. Single mother was a significant predictor of persistence $(p<.05)$ in one of the logistic regression analyses. Within the fall 2006 cohort, single mother for independent students resulted in a negative B value in one logistic regression output. A negative $B$ coefficient means that being a single mother is not associated with persistence.

\section{Table 58}

Cohorts that Had Single Mother as a Significant Predictor of Persistence 


\begin{tabular}{|l|l|l|l|l|l|l|l|l|}
\hline Single Mother \\
\hline Cohort & Term & $\boldsymbol{n}$ & Dependency & Sec Ed & Model Sig & Nag R $^{2}$ & B & B Sig \\
\hline Fall 2006 & Fall 2008 & 352 & Independent & No & .013 & .155 & -1.387 & .033 \\
\hline
\end{tabular}

Note. Sec Ed means whether the variable secondary education was in the regression model.

Nag $R^{2}$ means Nagelkerke $R^{2}$.

Is there a significant relationship between having dependents/children and persistence?

Table 59 shows the cohorts that had statistically significant regression coefficients for dependents. Table 60 shows the cohorts that had statistically significant regression coefficients for children. Having dependents and/or children was a significant predictor of persistence $(p<.05)$ in six of the logistic regression analyses. Within the fall 2007, 2008 and spring 2007 and 2008 cohorts, having dependents resulted in a negative B value in all three logistic regression outputs. Having children resulted in two positive B values and one negative B value in the logistic regression outputs. However, it is noted, that the output that resulted in a negative B coefficient value for children was with a sample size of 129. A positive regression coefficient means having dependents is associated with persistence. A negative regression coefficient means having dependents is not associated with persistence.

\section{Table 59}

Cohorts that Had Dependents as a Significant Predictor of Persistence

\begin{tabular}{|l|l|l|l|l|l|l|l|l|}
\hline \multicolumn{1}{|l|}{ Dependents } \\
\hline Cohort & Term & $\boldsymbol{n}$ & Dependency & Sec Ed & Model Sig & Nag R $^{2}$ & B & B Sig \\
\hline Fall 2008 & Spring 09 & 300 & Independent & Yes & .007 & .221 & -1.521 & .011 \\
\hline Fall 2008 & Spring 09 & 372 & Independent & No & .000 & .219 & -1.599 & .002 \\
\hline Spring 07 & Spring 09 & 239 & Independent & Yes & .000 & .481 & -2.632 & .023 \\
\hline
\end{tabular}

Note. Sec Ed means whether the variable secondary education was in the regression model. 
Nag $R^{2}$ means Nagelkerke $R^{2}$.

Table 60

Cohorts that Had Children as a Significant Predictor of Persistence

\begin{tabular}{|c|c|c|c|c|c|c|c|c|}
\hline \multicolumn{9}{|l|}{ Children } \\
\hline Cohort & Term & $n$ & Dependency & Sec Ed & Model Sig & $\operatorname{Nag} R^{2}$ & $\mathbf{B}$ & B Sig \\
\hline Fall 2007 & Fall 2008 & 428 & Independent & No & .000 & .176 & 1.459 & .008 \\
\hline Spring 07 & Fall 2009 & 129 & Independent & Yes & .000 & .546 & -3.610 & .037 \\
\hline Spring 08 & Spring 09 & 187 & Independent & Yes & .011 & .356 & 2.008 & .044 \\
\hline
\end{tabular}

Note. Sec Ed means whether the variable secondary education was in the regression

model.

Nag $R^{2}$ means Nagelkerke $R^{2}$.

Is there a significant relationship between marital status and persistence?

Marital status was not found as a statistically significant predictor variable in any of the logistic regression analyses. Therefore, there is no significant relationship between marital status and persistence.

\section{Academic Factors}

\section{Is there a significant relationship between grade point average and} persistence?

This question was subdivided into two different research questions based on the information provided from the Kentucky Community and Technical College System. As a result, the two following research questions were created: 
Is there a significant relationship between current grade point average and persistence?

Is there a significant relationship between cumulative grade point average and persistence?

As noted earlier, current and cumulative grade point average were removed from the logistic regression analyses performed for the independent students and the dependent students. This decision was made on the basis of both empirical and theoretical considerations.

\section{Is there a significant relationship between academic program and persistence?}

Table 61 shows the cohorts that had statistically significant regression coefficients for academic programs. Academic program was a significant predictor of persistence $(\mathrm{p}$ $<.05)$ in six of the logistic regression analyses. Within the fall 2006 and 2007 cohorts, academic program resulted in a positive B value in all six logistic regression outputs. This means that being a transfer student is associated with persistence. It is noted, that all outputs for dependent students that were statistically significant was with a sample size of less than 150 and resulted in a relatively large B coefficient value.

\section{Table 61}

Cohorts that Had Academic Program as a Significant Predictor of Persistence

\begin{tabular}{|l|l|l|l|l|l|l|l|l|}
\hline \multicolumn{2}{|l|}{ Academic Program } \\
\hline Cohort & Term & $\boldsymbol{n}$ & Dependency & Sec Ed & Model Sig & Nag R $^{2}$ & B $^{\mid}$ & B Sig \\
\hline Fall 2006 & Spring 09 & 147 & Dependent & No & .043 & .335 & 1.574 & .040 \\
\hline Fall 2006 & Fall 2009 & 73 & Dependent & Yes & .006 & .586 & 2.969 & .043 \\
\hline Fall 2006 & Fall 2009 & 83 & Dependent & No & .008 & .514 & 2.812 & .033 \\
\hline Fall 2007 & Spring 08 & 558 & Independent & No & .000 & .183 & .654 & .044 \\
\hline Fall 2007 & Fall 2008 & 347 & Independent & Yes & .002 & .224 & .909 & .021 \\
\hline Fall 2007 & Fall 2008 & 428 & Independent & No & .000 & .176 & .929 & .002 \\
\hline
\end{tabular}


Note. Sec Ed means whether the variable secondary education was in the regression model.

Nag $R^{2}$ means Nagelkerke $R^{2}$.

Is there a significant relationship between degree program and persistence?

Table 62 shows the cohorts that had statistically significant regression coefficients for business majors. Table 63 shows the cohorts that had statistically significant regression coefficients for allied health majors. Table 64 shows the cohorts that had statistically significant regression coefficients for general studies majors. Business, allied health and general studies majors were significant predictor of persistence $(p<.05)$ in 14 of the logistic regression analyses. Within the fall 2006 and 2008 and spring 2007, 2008 and 2009 cohorts, business and general studies majors resulted in a negative B value in 11 of the 12 logistic regression outputs. General studies majors resulted in a positive B value in one logistic regression output. Allied health majors resulted in two positive B coefficient values. A positive regression coefficient means being an allied health or general studies major is associated with persistence. A negative regression coefficient means being a business or general studies major is not associated with persistence. It is noted, that all four outputs for dependent students in the general studies major that were statistically significant was with a sample size of less than 150 .

\section{Table 62}

Cohorts that Had Business Major as a Significant Predictor of Persistence

\begin{tabular}{|l|l|l|l|l|l|l|l|l|}
\hline Business Major \\
\hline Cohort & Term & $\boldsymbol{n}$ & Dependency & Sec Ed & Model Sig & Nag R $^{2}$ & B & B Sig \\
\hline Fall 2006 & Spring 07 & 301 & Independent & Yes & .001 & .281 & -1.533 & .042 \\
\hline Spring 07 & Spring 08 & 478 & Independent & No & .000 & .235 & -1.196 & .040 \\
\hline Spring 08 & Spring 09 & 187 & Independent & Yes & .011 & .356 & -1.990 & .044 \\
\hline
\end{tabular}


Note. Sec Ed means whether the variable secondary education was in the regression

model.

Nag $R^{2}$ means Nagelkerke $R^{2}$.

Table 63

Cohorts that Had Allied Health Major as a Significant Predictor of Persistence

\begin{tabular}{|l|l|l|l|l|l|l|l|l|}
\hline \multicolumn{1}{|l|}{ Allied Health Major } \\
\hline Cohort & Term & $\boldsymbol{n}$ & Dependency & Sec Ed & Model Sig & Nag R $^{2}$ & B $^{\prime}$ & B Sig \\
\hline Spring 07 & Fall 2009 & 129 & Independent & Yes & .000 & .546 & 3.293 & .007 \\
\hline Spring 07 & Fall 2009 & 185 & Independent & No & .000 & .378 & 2.921 & .000 \\
\hline
\end{tabular}

Note. Sec Ed means whether the variable secondary education was in the regression

model.

Nag $R^{2}$ means Nagelkerke $R^{2}$.

\section{Table 64}

Cohorts that Had General Studies Major as a Significant Predictor of Persistence

\begin{tabular}{|l|l|l|l|l|l|l|l|l|}
\hline \multicolumn{1}{|l|}{ General Studies Major } \\
\hline Cohort & Term & $\boldsymbol{n}$ & Dependency & Sec Ed & Model Sig & Nag R $^{2}$ & B & B Sig \\
\hline Fall 2006 & Fall 2009 & 154 & Independent & No & .000 & .513 & -2.731 & .001 \\
\hline Fall 2008 & Fall 2009 & 187 & Independent & Yes & .000 & .424 & -1.669 & .016 \\
\hline Fall 2008 & Fall 2009 & 238 & Independent & No & .000 & .331 & -1.333 & .011 \\
\hline Fall 2008 & Spring 10 & 50 & Dependent & Yes & .018 & .671 & -5.462 & .017 \\
\hline Fall 2008 & Spring 10 & 51 & Dependent & No & .015 & .654 & -5.608 & .018 \\
\hline Spring 07 & Spring 08 & 478 & Independent & No & .000 & .235 & -.925 & .042 \\
\hline Spring 08 & Fall 2008 & 134 & Dependent & Yes & .000 & .582 & 3.24 & .032 \\
\hline Spring 08 & Spring 09 & 283 & Independent & No & .002 & .288 & -1.435 & .022 \\
\hline Spring 09 & Fall 2009 & 121 & Dependent & No & .000 & .436 & -1.362 & .040 \\
\hline
\end{tabular}

Note. Sec Ed means whether the variable secondary education was in the regression model.

Nag $R^{2}$ means Nagelkerke $R^{2}$. 


\section{Is there a significant relationship between credit hours accumulated and}

\section{persistence?}

Table 65 shows the cohorts that had statistically significant regression coefficients for total number of credit hours accumulated. Total number of credit hours accumulated was a significant predictor of persistence $(p<.05)$ in 12 of the logistic regression analyses. Within the fall 2006, 2007, 2008 and spring 2007 cohorts, the total number of credit hours accumulated for independent students resulted in a negative B value in three logistic regression outputs and a positive B value in four logistic regression outputs. Conversely, five logistic regression outputs resulted in a positive B value for dependent students. A positive regression coefficient means (for dependent students) that the greater number of accumulated credit hours, the greater the possibility of persistence. A negative regression coefficient means that the lesser number of accumulated credit hours, the greater the possibility of persistence.

\section{Table 65}

Cohorts that Had Total Number of Credit Hours Accumulated as a Significant Predictor of Persistence

\begin{tabular}{|l|l|l|l|l|l|l|l|l|}
\hline Total Number of Credit Hours Accumulated \\
\hline Cohort & Term & $\boldsymbol{n}$ & Dependency & Sec Ed & Model Sig & Nag R $^{2}$ & B & B Sig \\
\hline Fall 2006 & Spring 08 & 516 & Independent & No & .000 & .189 & -.013 & .005 \\
\hline Fall 2006 & Spring 08 & 347 & Dependent & No & .006 & .140 & .030 & .026 \\
\hline Fall 2006 & Spring 09 & 129 & Dependent & Yes & .031 & .398 & .058 & .032 \\
\hline Fall 2006 & Spring 09 & 147 & Dependent & No & .043 & .335 & .046 & .048 \\
\hline Fall 2006 & Fall 2009 & 154 & Independent & No & .000 & .513 & -.030 & .025 \\
\hline Fall 2007 & Fall 2008 & 428 & Independent & No & .000 & .176 & -.014 & .008 \\
\hline Fall 2008 & Fall 2009 & 187 & Independent & Yes & .000 & .424 & .032 & .015 \\
\hline Fall 2008 & Fall 2009 & 238 & Independent & No & .000 & .331 & .023 & .020 \\
\hline Spring 07 & Spring 08 & 148 & Dependent & Yes & .022 & .367 & .048 & .049 \\
\hline Spring 07 & Spring 08 & 221 & Dependent & No & .007 & .276 & .037 & .022 \\
\hline Spring 07 & Fall 2009 & 129 & Independent & Yes & .000 & .546 & .065 & .006 \\
\hline Spring 07 & Fall 2009 & 185 & Independent & No & .000 & .378 & .027 & .027 \\
\hline
\end{tabular}


Note. Sec Ed means whether the variable secondary education was in the regression model.

Nag $R^{2}$ means Nagelkerke $R^{2}$.

Is there a significant relationship between enrollment status and persistence?

Table 66 shows the cohorts that had statistically significant regression coefficients

for enrollment status. Enrollment Status was a significant predictor of persistence $(\mathrm{p}<$

.05 ) in 31 of the logistic regression analyses. Within the fall 2006, 2007, 2008 and spring

2007 and 2008 cohorts, the number of credit hours taken in the term resulted in a positive

$\mathrm{B}$ value in all 31 logistic regression outputs. This means the larger the number of credit

hours taken in a term, the greater the possibility of persisting.

Table 66

Cohorts that Had Enrollment Status as a Significant Predictor of Persistence

\begin{tabular}{|l|l|l|l|l|l|l|l|l|}
\hline Enrollment Status & \multicolumn{1}{l|}{ ( } \\
\hline Cohort & Term & $\boldsymbol{n}$ & Dependency & Sec Ed & Model Sig & Nag R $^{2}$ & B & B Sig \\
\hline Fall 2006 & Spring 07 & 301 & Independent & Yes & .001 & .281 & .248 & .002 \\
\hline Fall 2006 & Spring 07 & 666 & Independent & No & .000 & .156 & .137 & .001 \\
\hline Fall 2006 & Spring 07 & 290 & Dependent & Yes & .059 & .170 & .242 & .003 \\
\hline Fall 2006 & Spring 07 & 447 & Dependent & No & .000 & .167 & .189 & .001 \\
\hline Fall 2006 & Fall 2007 & 529 & Independent & No & .000 & .186 & .174 & .000 \\
\hline Fall 2006 & Spring 08 & 516 & Independent & No & .000 & .189 & .093 & .017 \\
\hline Fall 2006 & Spring 08 & 347 & Dependent & No & .006 & .140 & .165 & .009 \\
\hline Fall 2006 & Fall 2008 & 352 & Independent & No & .013 & .155 & .164 & .002 \\
\hline Fall 2007 & Spring 08 & 558 & Independent & No & .000 & .183 & .146 & .005 \\
\hline Fall 2007 & Spring 08 & 355 & Dependent & No & .020 & .138 & .195 & .003 \\
\hline Fall 2007 & Fall 2008 & 347 & Independent & Yes & .002 & .224 & .186 & .003 \\
\hline Fall 2007 & Fall 2008 & 428 & Independent & No & .000 & .176 & .154 & .001 \\
\hline Fall 2007 & Fall 2008 & 196 & Dependent & Yes & .002 & .326 & .343 & .002 \\
\hline Fall 2007 & Fall 2008 & 273 & Dependent & No & .016 & .162 & .191 & .002 \\
\hline Fall 2008 & Fall 2009 & 147 & Dependent & Yes & .012 & .270 & .357 & .001 \\
\hline Fall 2008 & Fall 2009 & 165 & Dependent & No & .004 & .255 & .332 & .001 \\
\hline Spring 07 & Fall 2007 & 434 & Dependent & No & .008 & .118 & .160 & .001 \\
\hline Spring 07 & Spring 08 & 478 & Independent & No & .000 & .235 & .131 & .007 \\
\hline Spring 07 & Spring 08 & 148 & Dependent & Yes & .022 & .367 & .453 & .000 \\
\hline Spring 07 & Spring 08 & 221 & Dependent & No & .007 & .276 & .300 & .000 \\
\hline
\end{tabular}




\begin{tabular}{|l|l|l|l|l|l|l|l|l|}
\hline Spring 07 & Fall 2008 & 357 & Independent & No & .000 & .214 & .174 & .000 \\
\hline Spring 07 & Spring 09 & 239 & Independent & Yes & .000 & .481 & .408 & .000 \\
\hline Spring 07 & Spring 09 & 284 & Independent & No & .000 & .339 & .388 & .000 \\
\hline Spring 07 & Fall 2009 & 185 & Independent & No & .000 & .378 & .184 & .026 \\
\hline Spring 08 & Fall 2008 & 318 & Independent & Yes & .000 & .369 & .251 & .000 \\
\hline Spring 08 & Fall 2008 & 399 & Independent & No & .000 & .269 & .211 & .000 \\
\hline Spring 08 & Fall 2008 & 134 & Dependent & Yes & .000 & .582 & .668 & .006 \\
\hline Spring 08 & Fall 2008 & 185 & Dependent & No & .000 & .364 & .400 & .000 \\
\hline Spring 08 & Spring 09 & 187 & Independent & Yes & .011 & .356 & .202 & .034 \\
\hline Spring 08 & Spring 09 & 283 & Independent & No & .002 & .288 & .243 & .002 \\
\hline Spring 08 & Fall 2009 & 216 & Independent & No & .055 & .205 & .198 & .003 \\
\hline
\end{tabular}

Note. Sec Ed means whether the variable secondary education was in the regression

model.

Nag $R^{2}$ means Nagelkerke $R^{2}$.

Is there a significant relationship between course delivery method and persistence?

Table 67 shows the cohorts that had statistically significant regression coefficients for course delivery method. Course delivery method was a significant predictor of persistence $(\mathrm{p}<.05)$ in one of the logistic regression analyses. Within the spring 2007 cohort, course delivery method resulted in a negative B value. A negative regression coefficient means being an "in person" (compared to online) student is associated with persistence.

\section{Table 67}

Cohorts that Had Course Delivery Method as a Significant Predictor of Persistence

\begin{tabular}{|l|l|l|l|l|l|l|l|l|}
\hline Course Delivery Method \\
\hline Cohort & Term & $\boldsymbol{n}$ & Dependency & Sec Ed & Model Sig & Nag R $^{2}$ & B & B Sig \\
\hline Spring 07 & Fall 2007 & 481 & Independent & Yes & .007 & .160 & -1.246 & .022 \\
\hline
\end{tabular}

Note. Sec Ed means whether the variable secondary education was in the regression model.

Nag $R^{2}$ means Nagelkerke $R^{2}$. 


\section{Sequential Logistic Regression for Cohorts with the Variable Instructional Mode}

All of the logistic regression analyses that were performed in this study followed the sequence of variable entry that was previously described: (a) static characteristics, (b) dynamic characteristics, (c) academic, and (d) instructional delivery method. Many of the data files did not contain the variable course delivery method as a possible predictor. However, for six data files, inclusion of instructional mode was possible. A full sequential analysis of each data set is presented below. This provides the reader with an understanding of how the predictor variables changed as each set of variables was entered.

The analyses presented are as follows: (a) Tables 68 to 71 contain variables predicting the Fall 2006 cohort that was enrolled in Spring 2007, (b) Tables 72 to 75 contain variables predicting the Fall 2007 cohort that was enrolled in Spring 2008, (c) Tables 76 to 79 contain variables predicting the Fall 2008 cohort that was enrolled in Spring 2009, (d) Tables 80 to 83 contain variables predicting the Spring 2007 cohort that was enrolled in Fall 2007, (e) Tables 84 to 87 contain variables predicting the Spring 2008 cohort that was enrolled in Fall 2008, and (f) Tables 88 to 91 contain variables predicting the Spring 2009 cohort that was enrolled in Fall 2009.

Each table shows obtained probabilities for two chi-square statistics. The first was the chi-square test for the entry of variables at one of the four steps. The second was the chi-square for the overall model. For step 1, the two numbers are identical, because no variables had been entered prior to step 1 . For example, in Table 68 , the set of variables called static had a non-significant predictive relationship $(p=.375,>.05)$ with enrollment. It was possible for the chi-square for a model to be statistically significant at 
a step or for a model, but to have no significant predictor variables. This can be seen in Table 68 at step 2 , that had a statistically significant model $(p=.025)$ but no predictors with significant coefficients. The column headed by Nag $\mathrm{R}^{2}$ reports the Nagelkerke $\mathrm{R}^{2}$ statistic, which is an estimate of the proportion of variance in the dependent variable (persistence/non-persistence) accounted for by the predictors. As would be expected by the incremental addition of variables, the Nagelkerke $\mathrm{R}^{2}$ generally increases from step 1 through step 4. In Table 68 the values increase from .028 to .283 .

The last three columns in the tables show the list of variables that were statistically significant, the regression coefficient B, and the obtained probability associated with a significance test for B (i.e., "B Sig"). Finally, the last column in the table provides $\operatorname{Exp}(\mathrm{B})$, the odds ratio for the variable. This statistic is the change in odds of being in one of the categories of the outcome when the value of a predictor changes by one unit. For example, at step 4 in Table 68, the odds ratio of the variable enrollment status is 1.271. Each one-unit increase in enrollment status (i.e., number of courses taken) meant the odds were 1.271 greater of being enrolled in Spring 2007.

If a predictor had a positive B coefficient, it meant the odds of being enrolled were higher when the student had higher values on the predictor variable; in such cases $\operatorname{Exp}(\mathrm{B})$ would be greater than 1.00. If a predictor had a negative B coefficient, it meant the odds of being in enrolled were lower when student had higher values on the predictor variable: $\operatorname{Exp}(B)$ would be less than 1.00. For example, at step 4 in Table 68, the odds ratio of the variable business major is .207. Each one-unit increase in the variable (i.e., being a business major rather a major in some other area) meant the odds were .207 less of being enrolled in Spring 2007. 
The Nagelkerke $\mathrm{R}^{2}$ values shown in the 24 tables were analyzed to provide an estimate of how much variance was accounted for by the variables at each step. The median values of Nagelkerke $\mathrm{R}^{2}$ were: (a) step $1, .028$, (b) step $2, .117$, (c) step $3, .175$, and (d) step 4, .176. Mean values were higher, due to several large values that pulled the mean upward. It would be safe to conclude that a typical value for the amount of variance accounted for by all the predictors was approximately $18 \%$.

\section{Table 68}

Results of Sequential Logistic Regression Analyses for Cohort Fall 2006 Term: Spring 2007 Independent Students, Including Secondary Education $(n=301)$

\begin{tabular}{|c|c|c|c|c|c|c|c|c|}
\hline Step & Variables & $\begin{array}{c}\chi^{2} \text { Sig. for } \\
\text { Step }\end{array}$ & $\begin{array}{l}\chi^{2} \text { Sig. for } \\
\text { Model }\end{array}$ & $\mathrm{NagR}^{2}$ & Sig Predictors & B & B Sig & $\operatorname{Exp}(B)$ \\
\hline 1 & Static & .375 & .375 & .028 & None & & & \\
\hline 2 & Dynamic & .016 & .025 & .167 & None & & & \\
\hline 3 & Academic & .004 & .001 & .279 & Adjusted Gross Income & $\sim .000$ & .005 & $\sim .1 .00$ \\
\hline & & & & & Business major & -1.512 & .044 & .221 \\
\hline & & & & & Enrollment status & .246 & .002 & 1.279 \\
\hline 4 & Instruction & .597 & .001 & .281 & Adjusted Gross Income & $\sim .000$ & .005 & $\sim .1 .00$ \\
\hline & & & & & Business major & -1.533 & .042 & .216 \\
\hline & & & & & Enrollment status & .248 & .002 & 1.281 \\
\hline & & & & & & & & \\
\hline
\end{tabular}

Table 69 
Results of Sequential Logistic Regression Analyses for Cohort Fall 2006 Term: Spring

2007 Independent Students, Not-Including Secondary Education $(n=666)$

\begin{tabular}{|c|c|c|c|c|c|c|c|c|}
\hline Step & Variables & $\begin{array}{l}\chi^{2} \text { Sig. for } \\
\text { Step }\end{array}$ & $\begin{array}{l}\chi 2 \text { Sig. for } \\
\text { Model }\end{array}$ & $\mathrm{NagR}^{2}$ & Sig Predictors & $\mathbf{B}$ & B Sig & $\operatorname{Exp}(B)$ \\
\hline 1 & Static & .118 & .118 & .017 & None & & & \\
\hline 2 & Dynamic & .000 & .000 & .114 & Age & .062 & .002 & 1.064 \\
\hline 3 & Academic & .016 & .000 & .155 & Age & .060 & .003 & 1.062 \\
\hline & & & & & Adjusted Gross Income & $\sim .000$ & .018 & $\sim 1.00$ \\
\hline & & & & & Enrollment status & .137 & .001 & 1.147 \\
\hline 4 & Instruction & .598 & .000 & .156 & Age & .060 & .003 & 1.062 \\
\hline & & & & & Adjusted Gross Income & $\sim .000$ & .018 & $\sim 1.00$ \\
\hline & & & & & Enrollment status & .137 & .001 & 1.146 \\
\hline & & & & & & & & \\
\hline
\end{tabular}

Table 70

Results of Sequential Logistic Regression Analyses for Cohort Fall 2006 Term: Spring 2007 Dependent Students, Including Secondary Education $(n=290)$

\begin{tabular}{|c|c|c|c|c|c|c|c|c|}
\hline Step & Variables & $\begin{array}{l}x^{2} \text { Sig. for } \\
\text { Step }\end{array}$ & $\begin{array}{l}\chi^{2} \text { Sig. for } \\
\text { Model }\end{array}$ & NagR $^{2}$ & Sig Predictors & $\mathbf{B}$ & B Sig & $\operatorname{Exp}(B)$ \\
\hline 1 & Static & .521 & .521 & .020 & None & & & \\
\hline 2 & Dynamic & .038 & .080 & .111 & None & & & \\
\hline & & & & & & & & \\
\hline
\end{tabular}




\begin{tabular}{|c|l|l|l|l|l|c|c|c|}
\hline 3 & Academic & .129 & .045 & .168 & Parent's AGI & $\sim .000$ & .049 & $\sim 1.00$ \\
\hline & & & & & Enrollment status & .243 & .003 & 1.275 \\
\hline & & & & & & & & \\
\hline 4 & Instruction & .627 & .059 & .170 & Parent's AGI & $\sim .000$ & .049 & $\sim 1.00$ \\
\hline & & & & & Enrollment status & .242 & .003 & 1.274 \\
\hline & & & & & & & & \\
\hline
\end{tabular}

Table 71

Results of Sequential Logistic Regression Analyses for Cohort Fall 2006 Term: Spring 2007 Dependent Students, Not-Including Secondary Education $(n=447)$

\begin{tabular}{|c|l|l|l|l|l|l|l|c|}
\hline Step & Variables & $\begin{array}{l}x^{2} \text { Sig. for } \\
\text { Step }\end{array}$ & $\begin{array}{l}x^{2} \text { Sig. for } \\
\text { Model }\end{array}$ & NagR $^{2}$ & Sig Predictors & B & B Sig & Exp(B) \\
\hline 1 & Static & .208 & .208 & .018 & None & & & \\
\hline 2 & Dynamic & .000 & .004 & .098 & Parent's AGI & $\sim .000$ & .031 & $\sim 1.00$ \\
\hline 3 & Academic & .005 & .000 & .165 & Age & & & \\
\hline & & & & & Parent's AGI & $\sim .000$ & .028 & $\sim 1.00$ \\
\hline & & & & & Enrollment status & .189 & .001 & 1.202 \\
\hline & & & & & & & & \\
\hline 4 & Instruction & .374 & .000 & .167 & Age & -.268 & .026 & .765 \\
\hline & & & & & Parent's AGI & $\sim .000$ & .028 & $\sim 1.00$ \\
\hline & & & & & Enrollment status & .187 & .001 & 1.206 \\
\hline & & & & & & & & \\
\hline
\end{tabular}

Table 72 
Results of Sequential Logistic Regression Analyses for Cohort Fall 2007 Term: Spring 2008 Independent Students, Including Secondary Education $(n=418)$

\begin{tabular}{|c|c|c|c|c|c|c|c|c|}
\hline Step & Variables & $\begin{array}{l}\chi^{2} \text { Sig. for } \\
\text { Step }\end{array}$ & $\begin{array}{l}\chi^{2} \text { Sig. for } \\
\text { Model }\end{array}$ & $\mathrm{NagR}^{2}$ & Sig Predictors & B & B Sig & $\operatorname{Exp}(B)$ \\
\hline 1 & Static & .253 & .253 & .033 & None & & & \\
\hline 2 & Dynamic & .335 & .276 & .103 & None & & & \\
\hline 3 & Academic & .390 & .292 & .140 & None & & & \\
\hline 4 & Instruction & .022 & .173 & .149 & None & & & \\
\hline & & & & & & & & \\
\hline
\end{tabular}

Table 73

Results of Sequential Logistic Regression Analyses for Cohort Fall 2007 Term: Spring 2008 Independent Students, Not-Including Secondary Education $(n=558)$

\begin{tabular}{|c|c|c|c|c|c|c|c|c|}
\hline Step & Variables & $\begin{array}{l}\chi^{2} \text { Sig. for } \\
\text { Step }\end{array}$ & $\begin{array}{l}\chi^{2} \text { Sig. for } \\
\text { Model }\end{array}$ & NagR $^{2}$ & Sig Predictors & B & B Sig & $\operatorname{Exp}(B)$ \\
\hline 1 & Static & .076 & .076 & .025 & None & & & \\
\hline 2 & Dynamic & .004 & .002 & .119 & Age & .043 & .038 & 1.044 \\
\hline & & & & & Waiver & 2.147 & .037 & 8.556 \\
\hline 3 & Academic & .006 & .000 & .181 & Mother's education level & -.524 & .041 & .592 \\
\hline & & & & & Age & .058 & .010 & 1.060 \\
\hline & & & & & Adjusted Gross Income & $\sim .000$ & .028 & $\sim 1.00$ \\
\hline
\end{tabular}




\begin{tabular}{|c|c|c|c|c|l|c|c|c|}
\hline & & & & Waiver & 2.146 & .038 & 9.951 \\
\hline & & & & & Academic program & .649 & .045 & 1.913 \\
\hline & & & & & Enrollment status & .149 & .004 & 1.160 \\
\hline 4 & Instruction & .463 & .000 & .183 & Mother's education level & -.522 & .042 & .593 \\
\hline & & & & & Age & .058 & .010 & 1.060 \\
\hline & & & & & Adjusted Gross Income & $\sim .000$ & .036 & $\sim 1.00$ \\
\hline & & & & & Waiver & 2.110 & .041 & 8.249 \\
\hline & & & & & Academic program & .654 & .044 & 1.924 \\
\hline & & & & & Enrollment status & .146 & .005 & 1.157 \\
\hline & & & & & & & & \\
\hline
\end{tabular}

Table 74

Results of Sequential Logistic Regression Analyses for Cohort Fall 2007 Term: Spring 2008 Dependent Students, Including Secondary Education $(n=227)$

\begin{tabular}{|c|c|c|c|c|c|c|c|c|}
\hline Step & Variables & $\begin{array}{l}x^{2} \text { Sig. for } \\
\text { Step }\end{array}$ & $\begin{array}{l}\chi^{2} \text { Sig. for } \\
\text { Model }\end{array}$ & $\mathrm{NagR}^{2}$ & Sig Predictors & B & B Sig & $\operatorname{Exp}(B)$ \\
\hline 1 & Static & .354 & .354 & .043 & None & & & \\
\hline 2 & Dynamic & .974 & .864 & .059 & None & & & \\
\hline 3 & Academic & .277 & .693 & .130 & None & & & \\
\hline 4 & Instruction & 641 & .739 & .132 & None & & & \\
\hline & & & & & & & & \\
\hline
\end{tabular}




\section{Table 75}

Results of Sequential Logistic Regression Analyses for Cohort Fall 2007 Term: Spring 2008 Dependent Students, Not Including Secondary Education $(n=355)$

\begin{tabular}{|c|c|c|c|c|c|c|c|c|}
\hline Step & Variables & $\begin{array}{l}\chi^{2} \text { Sig. for } \\
\text { Step }\end{array}$ & $\begin{array}{l}x^{2} \text { Sig. for } \\
\text { Model }\end{array}$ & NagR $^{2}$ & Sig Predictors & B & B Sig & $\operatorname{Exp}(\mathbf{B})$ \\
\hline 1 & Static & .110 & .110 & .028 & None & & & \\
\hline 2 & Dynamic & .434 & .224 & .059 & None & & & \\
\hline 3 & Academic & .008 & .016 & .135 & Sex & .851 & .009 & 2.341 \\
\hline & & & & & Enrollment status & .201 & .003 & 1.223 \\
\hline 4 & Instruction & 420 & .020 & .138 & Sex & .855 & .009 & 2.350 \\
\hline & & & & & Enrollment status & .195 & .003 & 1.216 \\
\hline & & & & & & & & \\
\hline
\end{tabular}

Table 76

Results of Sequential Logistic Regression Analyses for Cohort Fall 2008 Term: Spring 2009 Independent Students, Including Secondary Education $(n=300)$

\begin{tabular}{|c|c|c|c|c|c|c|c|c}
\hline Step & Variables & $\begin{array}{l}\chi^{2} \text { Sig. for } \\
\text { Step }\end{array}$ & $\begin{array}{c}x^{2} \text { Sig. for } \\
\text { Model }\end{array}$ & NagR $^{2}$ & Sig Predictors & B & B Sig & Exp(B) \\
\hline 1 & Static & .701 & .701 & .013 & None & & & \\
\hline & & & & & & & & \\
\hline 2 & Dynamic & .001 & .006 & .173 & Age & .052 & .046 & 1.053 \\
\hline & & & & & Dependents & -1.462 & .012 & .232 \\
\hline & & & & & & & & \\
\hline
\end{tabular}




\begin{tabular}{|c|c|c|c|c|l|c|c|c}
\hline & & & & & & & & \\
\hline 3 & Academic & .276 & .008 & .213 & Age & .055 & .046 & 1.057 \\
\hline & & & & & Dependents & -1.553 & .009 & .212 \\
\hline & & & & & Enrollment status & .124 & .036 & 1.132 \\
\hline 4 & Instruction & .202 & .007 & .221 & Age & & & \\
\hline & & & & & Dependents & -1.521 & .011 & .218 \\
\hline & & & & & & & & \\
\hline
\end{tabular}

Table 77

Results of Sequential Logistic Regression Analyses for Cohort Fall 2008 Term: Spring 2009 Independent Students, Not-Including Secondary Education $(n=372)$

\begin{tabular}{|c|c|c|c|c|c|c|c|c|}
\hline Step & Variables & $\begin{array}{l}\chi^{2} \text { Sig. for } \\
\text { Step }\end{array}$ & $\begin{array}{l}\chi^{2} \text { Sig. for } \\
\text { Model }\end{array}$ & $\mathrm{NagR}^{2}$ & Sig Predictors & $\mathbf{B}$ & B Sig & $\operatorname{Exp}(\mathbf{B})$ \\
\hline 1 & Static & .986 & .986 & .001 & None & & & \\
\hline 2 & Dynamic & .000 & .000 & .184 & Age & .048 & .029 & 1.049 \\
\hline & & & & & Number house in college & -1.326 & .001 & .266 \\
\hline & & & & & Dependents & -1.500 & .002 & .223 \\
\hline 3 & Academic & .237 & .000 & .218 & Age & .048 & .039 & 1.049 \\
\hline & & & & & Number house in college & -1.376 & .001 & .252 \\
\hline & & & & & Dependents & -1.607 & .002 & .201 \\
\hline 4 & Instruction & .825 & .000 & .219 & Age & .048 & .039 & 1.049 \\
\hline
\end{tabular}




\begin{tabular}{|c|c|c|c|c|l|c|c|c}
\hline & & & & Number house in college & -1.347 & .001 & .253 \\
\hline & & & & & Dependents & -1.599 & .002 & .202 \\
\hline
\end{tabular}

Table 78

Results of Sequential Logistic Regression Analyses for Cohort Fall 2008 Term: Spring 2009 Dependent Students, Including Secondary Education $(n=218)$

\begin{tabular}{|c|c|c|c|c|c|c|c|c|}
\hline Step & Variables & $\begin{array}{l}x^{2} \text { Sig. for } \\
\text { Step }\end{array}$ & $\begin{array}{l}\chi^{2} \text { Sig. for } \\
\text { Model }\end{array}$ & $\mathrm{NagR}^{2}$ & Sig Predictors & B & B Sig & Exp(B) \\
\hline 1 & Static & .464 & .464 & .025 & None & & & \\
\hline 2 & Dynamic & .542 & .569 & .064 & None & & & \\
\hline 3 & Academic & .112 & .281 & .131 & None & & & \\
\hline 4 & Instruction & .620 & .326 & .132 & None & & & \\
\hline & & & & & & & & \\
\hline
\end{tabular}

\section{Table 79}

Results of Sequential Logistic Regression Analyses for Cohort Fall 2008 Term: Spring 2009 Dependent Students, Not Including Secondary Education $(n=218)$

\begin{tabular}{|c|c|c|c|c|c|c|c|c}
\hline Step & Variables & $\begin{array}{l}\chi^{2} \text { Sig. for } \\
\text { Step }\end{array}$ & $\begin{array}{l}x^{2} \text { Sig. for } \\
\text { Model }\end{array}$ & NagR & & & & Sig Predictors \\
\hline 1 & Static & .437 & .437 & .017 & None & B Sig & Exp(B) \\
\hline 2 & Dynamic & .509 & .533 & .055 & None & & & \\
\hline & & & & & & & & \\
\hline
\end{tabular}




\begin{tabular}{|c|c|c|c|c|c|c|c|c}
\hline 3 & Academic & .125 & .270 & .113 & None & & & \\
\hline & & & & & & & & \\
\hline 4 & Instruction & .361 & .284 & .118 & None & & & \\
\hline & & & & & & & & \\
\hline
\end{tabular}

\section{Table 80}

Results of Sequential Logistic Regression Analyses for Cohort Spring 2007 Term: Fall 2007 Independent Students, Including Secondary Education $(n=481)$

\begin{tabular}{|c|c|c|c|c|l|c|c|c}
\hline Step & Variables & $\begin{array}{l}\chi^{2} \text { Sig. for } \\
\text { Step }\end{array}$ & $\begin{array}{c}x^{2} \text { Sig. for } \\
\text { Model }\end{array}$ & NagR $^{2}$ & Sig Predictors & B & B Sig & Exp(B) \\
\hline 1 & Static & .161 & .161 & .027 & None & & & \\
\hline 2 & Dynamic & .023 & .018 & .110 & Age & & & \\
\hline & & & & & & .062 & .007 & 1.063 \\
\hline 3 & Academic & .214 & .017 & .143 & Age & & & \\
\hline & & & & & & .065 & .008 & 1.067 \\
\hline 4 & Instruction & .032 & .007 & .160 & Age & & & \\
\hline & & & & & Instruction Mode & -1.246 & .022 & .288 \\
\hline & & & & & & & & \\
\hline
\end{tabular}

\section{Table 81}

Results of Sequential Logistic Regression Analyses for Cohort Spring 2007Term: Fall 2007Independent Students, Not Including Secondary Education $(n=754)$

\begin{tabular}{|c|c|c|c|c|c|c|c|c}
\hline Step & Variables & $\begin{array}{l}x^{2} \text { Sig. for } \\
\text { Step }\end{array}$ & $\begin{array}{l}x^{2} \text { Sig. for } \\
\text { Model }\end{array}$ & NagR $^{2}$ & Sig Predictors & B & B Sig & Exp(B) \\
\hline 1 & Static & .208 & .208 & .010 & None & & & \\
\hline
\end{tabular}




\begin{tabular}{|c|l|l|l|l|l|l|l|l}
\hline & & & & & & & & \\
\hline 2 & Dynamic & .000 & .000 & .110 & Age & .043 & .002 & 1.044 \\
\hline & & & & & Waiver & 1.066 & .017 & 2.903 \\
\hline 3 & Academic & .845 & .000 & .110 & Age & & & \\
\hline & & & & & Waiver & .046 & .001 & 1.047 \\
\hline & & & & & & .962 & .033 & 2.617 \\
\hline 4 & Instruction & .101 & .000 & .116 & Age & & & \\
\hline & & & & & Waiver & .046 & .002 & 1.047 \\
\hline & & & & & & .983 & .030 & 2.673 \\
\hline
\end{tabular}

Table 82

Results of Sequential Logistic Regression Analyses for Cohort Spring 2007 Term: Fall 2007 Dependent Students, Including Secondary Education $(n=243)$

\begin{tabular}{|c|c|c|c|c|c|c|c|c|}
\hline Step & Variables & $\begin{array}{l}\chi^{2} \text { Sig. for } \\
\text { Step }\end{array}$ & $\begin{array}{l}\chi^{2} \text { Sig. for } \\
\text { Model }\end{array}$ & NagR $^{2}$ & Sig Predictors & B & B Sig & $\operatorname{Exp}(B)$ \\
\hline 1 & Static & .308 & .308 & .034 & None & & & \\
\hline 2 & Dynamic & .312 & .290 & .090 & None & & & \\
\hline 3 & Academic & .319 & .271 & .137 & None & & & \\
\hline 4 & Instruction & .505 & .305 & .140 & None & & & \\
\hline & & & & & & & & \\
\hline
\end{tabular}




\section{Table 83}

Results of Sequential Logistic Regression Analyses for Cohort Spring 2007 Term: Fall 2007 Dependent Students, Not Including Secondary Education $(n=434)$

\begin{tabular}{|c|c|c|c|c|c|c|c|c|}
\hline Step & Variables & $\begin{array}{l}\chi^{2} \text { Sig. for } \\
\text { Step }\end{array}$ & $\begin{array}{l}\chi^{2} \text { Sig. for } \\
\text { Model }\end{array}$ & NagR $^{2}$ & Sig Predictors & B & B Sig & $\operatorname{Exp}(\mathbf{B})$ \\
\hline 1 & Static & .497 & .497 & .008 & None & & & \\
\hline 2 & Dynamic & .213 & .287 & .042 & None & & & \\
\hline 3 & Academic & .001 & .005 & .117 & Enrollment status & .158 & .002 & 1.171 \\
\hline 4 & Instruction & .615 & .008 & .118 & Enrollment status & .160 & .001 & 1.173 \\
\hline & & & & & & & & \\
\hline
\end{tabular}

\section{Table 84}

Results of Sequential Logistic Regression Analyses for Cohort Spring 2008 Term: Fall 2008 Independent Students, Including Secondary Education $(n=318)$

\begin{tabular}{|c|c|c|c|c|c|c|c|c|}
\hline Step & Variables & $\begin{array}{l}\chi^{2} \text { Sig. for } \\
\text { Step }\end{array}$ & $\begin{array}{l}\chi^{2} \text { Sig. for } \\
\text { Model }\end{array}$ & NagR $^{2}$ & Sig Predictors & B & B Sig & $\operatorname{Exp}(B)$ \\
\hline 1 & Static & .000 & .000 & .150 & Mother's education level & -1.141 & .000 & .320 \\
\hline 2 & Dynamic & .004 & .000 & .272 & Mother's education level & -.924 & .002 & .397 \\
\hline 3 & Academic & .002 & .000 & .363 & Mother's education level & -1.24 & .000 & .289 \\
\hline & & & & & Enrollment status & .255 & .000 & 1.291 \\
\hline & & & & & & & & \\
\hline
\end{tabular}




\begin{tabular}{|c|c|c|c|c|l|c|c|c}
\hline 4 & Instruction & .228 & .000 & .369 & Mother's education level & -1.191 & .001 & .304 \\
\hline & & & & & Enrollment status & .251 & .000 & 1.285 \\
\hline & & & & & & & & \\
\hline
\end{tabular}

Table 85

Results of Sequential Logistic Regression Analyses for Cohort Spring 2008 Term: Fall 2008 Independent Students, Not Including Secondary Education ( $n=399)$

\begin{tabular}{|c|c|c|c|c|c|c|c|c|}
\hline Step & Variables & $\begin{array}{l}x^{2} \text { Sig. for } \\
\text { Step }\end{array}$ & $\begin{array}{l}\chi^{2} \text { Sig. for } \\
\text { Model }\end{array}$ & NagR $^{2}$ & Sig Predictors & B & B Sig & $\operatorname{Exp}(\mathbf{B})$ \\
\hline 1 & Static & .000 & .000 & .069 & Mother's education level & -.766 & .000 & .465 \\
\hline \multirow[t]{4}{*}{2} & Dynamic & .000 & .000 & .196 & Mother's education level & -.508 & .018 & .602 \\
\hline & & & & & Age & .037 & .039 & 1.037 \\
\hline & & & & & Marital status & 1.69 & .028 & 5.419 \\
\hline & & & & & Children & -1.57 & .034 & .208 \\
\hline \multirow[t]{3}{*}{3} & Academic & .001 & .000 & .269 & Mother's education level & -.549 & .007 & .577 \\
\hline & & & & & Age & .052 & .008 & 1.053 \\
\hline & & & & & Enrollment status & .211 & .000 & 1.235 \\
\hline \multirow[t]{3}{*}{4} & Instruction & .811 & .000 & .269 & Mother's education level & -.555 & .017 & .574 \\
\hline & & & & & Age & .052 & .008 & 1.053 \\
\hline & & & & & Enrollment status & .211 & .000 & 1.235 \\
\hline & & & & & & & & \\
\hline
\end{tabular}




\section{Table 86}

Results of Sequential Logistic Regression Analyses for Cohort Spring 2008 Term: Fall 2008 Dependent Students, Including Secondary Education $(n=134)$

\begin{tabular}{|c|c|c|c|c|c|c|c|c|}
\hline Step & Variables & $\begin{array}{l}\chi^{2} \text { Sig. for } \\
\text { Step }\end{array}$ & $\begin{array}{l}\chi^{2} \text { Sig. for } \\
\text { Model }\end{array}$ & NagR $^{2}$ & Sig Predictors & $\mathbf{B}$ & B Sig & $\operatorname{Exp}(B)$ \\
\hline \multirow[t]{2}{*}{1} & Static & .036 & .008 & .308 & Secondary Education & 1.76 & .045 & 5.81 \\
\hline & & & & & Father's education level & -1.13 & .021 & .323 \\
\hline 2 & Dynamic & .036 & .008 & .308 & Father's education level & -1.76 & .003 & .172 \\
\hline \multirow[t]{5}{*}{3} & Academic & .000 & .000 & .580 & Father's education level & -3.76 & .003 & .023 \\
\hline & & & & & Mother's education level & 2.397 & .016 & 10.99 \\
\hline & & & & & Adjusted Gross Income & .000 & .042 & 1.00 \\
\hline & & & & & General Studies program & 3.232 & .032 & 25.37 \\
\hline & & & & & Enrollment status & .655 & .006 & 1.925 \\
\hline \multirow[t]{4}{*}{4} & Instruction & .693 & .000 & .582 & Father's education level & -3.739 & .003 & .024 \\
\hline & & & & & Mother's education level & 2.392 & .016 & 10.94 \\
\hline & & & & & General Studies program & 3.24 & .032 & 25.55 \\
\hline & & & & & Enrollment status & .668 & .006 & 1.95 \\
\hline & & & & & & & & \\
\hline
\end{tabular}

Table 87

Results of Sequential Logistic Regression Analyses for Cohort Spring 2008 Term: Fall 2008 Dependent Students, Not Including Secondary Education $(n=185)$ 


\begin{tabular}{|c|c|c|c|c|c|c|c|c|}
\hline Step & Variables & $\begin{array}{l}\chi^{2} \text { Sig. for } \\
\text { Step }\end{array}$ & $\begin{array}{l}\chi^{2} \text { Sig. for } \\
\text { Model }\end{array}$ & NagR $^{2}$ & Sig Predictors & B & B Sig & $\operatorname{Exp}(\mathbf{B})$ \\
\hline 1 & Static & .522 & .522 & .018 & None & & & \\
\hline 2 & Dynamic & .000 & .000 & .362 & Father's education level & -.868 & .013 & .420 \\
\hline & & & & & Waiver & 2.34 & .030 & 10.42 \\
\hline 3 & Academic & .000 & .000 & .362 & Waiver & 2.82 & .022 & 16.88 \\
\hline & & & & & Enrollment status & .392 & .000 & 1.48 \\
\hline 4 & Instruction & .619 & .000 & .364 & Waiver & 2.769 & .023 & 15.94 \\
\hline & & & & & Enrollment status & .400 & .000 & 1.49 \\
\hline & & & & & & & & \\
\hline
\end{tabular}

\section{Table 88}

Results of Sequential Logistic Regression Analyses for Cohort Spring 2009 Term: Fall 2009 Independent Students, Including Secondary Education $(n=199)$

\begin{tabular}{|c|c|c|c|c|c|c|c|c|}
\hline Step & Variables & $\begin{array}{l}\chi^{2} \text { Sig. for } \\
\text { Step }\end{array}$ & $\begin{array}{l}\chi^{2} \text { Sig. for } \\
\text { Model }\end{array}$ & $\mathrm{NagR}^{2}$ & Sig Predictors & B & B Sig & $\operatorname{Exp}(B)$ \\
\hline 1 & Static & .009 & .009 & .097 & Father's education level & -.653 & .017 & .521 \\
\hline 2 & Dynamic & .132 & .012 & .197 & Father's education level & -.717 & .021 & .488 \\
\hline 3 & Academic & .137 & .008 & .258 & Father's education level & -.807 & .011 & .446 \\
\hline & & & & & & & & \\
\hline
\end{tabular}




\begin{tabular}{|c|c|c|c|c|c|c|c|c}
\hline 4 & Instruction & .113 & .006 & .273 & Father's education level & -.831 & .010 & .436 \\
\hline & & & & & & & & \\
\hline
\end{tabular}

Table 89

Results of Sequential Logistic Regression Analyses for Cohort Spring 2009 Term: Fall 2009 Independent Students, Not Including Secondary Education ( $n=237)$

\begin{tabular}{|c|c|c|c|c|c|c|c|c|}
\hline Step & Variables & $\begin{array}{l}x^{2} \text { Sig. for } \\
\text { Step }\end{array}$ & $\begin{array}{l}\chi^{2} \text { Sig. for } \\
\text { Model }\end{array}$ & $\mathrm{NagR}^{2}$ & Sig Predictors & B & B Sig & $\operatorname{Exp}(\mathbf{B})$ \\
\hline 1 & Static & .009 & .009 & .069 & Gender & .850 & .012 & 2.34 \\
\hline 2 & Dynamic & .057 & .006 & .170 & None & & & \\
\hline 3 & Academic & .036 & .001 & .241 & None & & & \\
\hline 4 & Instruction & .083 & .001 & .257 & None & & & \\
\hline & & & & & & & & \\
\hline
\end{tabular}

Table 90

Results of Sequential Logistic Regression Analyses for Cohort Spring 2009 Term: Fall 2009 Dependent Students, Including Secondary Education ( $n=108)$

\begin{tabular}{|c|c|c|c|c|c|c|c|c}
\hline Step & Variables & $\begin{array}{c}x^{2} \text { Sig. for } \\
\text { Step }\end{array}$ & $\begin{array}{c}x^{2} \text { Sig. for } \\
\text { Model }\end{array}$ & NagR $^{2}$ & Sig Predictors & B & B Sig & Exp(B) \\
\hline 1 & Static & .006 & .006 & .170 & Father's education level & -1.30 & .002 & .273 \\
\hline & & & & & Mother's education level & .792 & .041 & 2.208 \\
\hline 2 & Dynamic & .151 & .008 & .269 & Father's education level & -1.523 & .001 & .218 \\
\hline
\end{tabular}




\begin{tabular}{|c|c|c|c|c|l|l|l|c}
\hline & & & & & & & & \\
\hline 3 & Academic & .023 & .001 & .407 & Secondary Education & 3.30 & .040 & 27.00 \\
\hline & & & & & Father's education level & -1.617 & .002 & .199 \\
\hline & & & & & & & & \\
\hline 4 & Instruction & .010 & .000 & .463 & Father's education level & -1.596 & .002 & .203 \\
\hline & & & & & & & & \\
\hline
\end{tabular}

Table 91

Results of Sequential Logistic Regression Analyses for Cohort Spring 2009 Term: Fall 2009 Dependent Students, Not Including Secondary Education $(n=121)$

\begin{tabular}{|c|c|c|c|c|c|c|c|c|}
\hline Step & Variables & $\begin{array}{l}x^{2} \text { Sig. for } \\
\text { Step }\end{array}$ & $\begin{array}{l}\bar{x} 2 \text { Sig. for } \\
\text { Model }\end{array}$ & NagR $^{2}$ & Sig Predictors & B & B Sig & $\operatorname{Exp}(B)$ \\
\hline \multirow[t]{2}{*}{1} & Static & .011 & .011 & .120 & Father's education level & -1.06 & .006 & .346 \\
\hline & & & & & Mother's education level & .771 & .033 & .216 \\
\hline 2 & Dynamic & .053 & .005 & .240 & Father's education level & -1.29 & .003 & .274 \\
\hline \multirow[t]{2}{*}{3} & Academic & .003 & .000 & .406 & Father's education level & -1.460 & .003 & .232 \\
\hline & & & & & General Studies program & -1.490 & .025 & .225 \\
\hline \multirow[t]{2}{*}{4} & Instruction & .050 & .000 & .436 & Father's education level & -1.508 & .003 & .221 \\
\hline & & & & & General Studies program & -1.362 & .040 & .256 \\
\hline
\end{tabular}




\section{Summary}

Table 92 shows the predictor variables and shows (a) the cohort, (b) the term in which the cohort's persistence was measured (i.e. did the student re-enroll, transfer, or graduate in this term), (c) the size of the sample, (d) the dependency status, (e) whether or not secondary education was considered as a variable, (f) the Sig. (the Omnibus Test of Model Coefficients), (g) Nagelkerke R squared of the model, (h) the significant predictors, (i) the B coefficient, and (j) the Sig. of the significant predictor

Table 92

All Cohorts and Logistic Regression Analyses

\begin{tabular}{|c|c|c|c|c|c|c|c|c|}
\hline \multicolumn{9}{|c|}{ Cohort: Fall 2006} \\
\hline Term & $n$ & Dependency & Sec Ed & Sig. & NagR $^{2}$ & Sig Predictors & B & B Sig \\
\hline \multirow[t]{3}{*}{ SP 07} & 301 & Independent & Yes & .001 & .281 & Adjusted Gross Income & .000 & .005 \\
\hline & & & & & & Business major & -1.533 & .042 \\
\hline & & & & & & Enrollment status & .248 & .002 \\
\hline \multirow[t]{3}{*}{ SP 07} & 666 & Independent & $\mathrm{No}$ & .000 & .156 & Age & .060 & .003 \\
\hline & & & & & & Adjusted Gross Income & .000 & .018 \\
\hline & & & & & & Enrollment status & .137 & .001 \\
\hline \multirow[t]{2}{*}{ SP 07} & 290 & Dependent & Yes & .059 & .170 & Parent's AGI & .000 & .049 \\
\hline & & & & & & Enrollment status & .242 & .003 \\
\hline \multirow{3}{*}{ SP 07 } & 447 & Dependent & No & .000 & .167 & Age & -.268 & .026 \\
\hline & & & & & & Parent's AGI & .000 & .028 \\
\hline & & & & & & Enrollment status & .187 & .001 \\
\hline FA 07 & 244 & Independent & Yes & .453 & & & & \\
\hline \multirow[t]{2}{*}{ FA 07} & 529 & Independent & No & .000 & .186 & Mother's education level & -.562 & .014 \\
\hline & & & & & & Enrollment status & .174 & .000 \\
\hline FA 07 & 239 & Dependent & Yes & .211 & & & & \\
\hline FA 07 & 358 & Dependent & No & .167 & & & & \\
\hline SP 08 & 251 & Independent & Yes & .006 & .260 & Age & .101 & .011 \\
\hline \multirow[t]{5}{*}{ SP 08} & 516 & Independent & $\mathrm{No}$ & .000 & .189 & Mother's education level & -.423 & .027 \\
\hline & & & & & & Age & .084 & .000 \\
\hline & & & & & & Federal work-study & 1.626 & .034 \\
\hline & & & & & & Enrollment status & .093 & .017 \\
\hline & & & & & & Credit hours accumulated & -.013 & .005 \\
\hline SP 08 & 235 & Dependent & Yes & .722 & & & & \\
\hline \multirow[t]{3}{*}{ SP 08} & 347 & Dependent & No & & .140 & Age & -.289 & .026 \\
\hline & & & & & & Enrollment status & .165 & .009 \\
\hline & & & & & & Credit hours accumulated & .030 & .026 \\
\hline
\end{tabular}




\begin{tabular}{|c|c|c|c|c|c|c|c|c|}
\hline FA 08 & 202 & Independent & Yes & .243 & & & & \\
\hline \multirow[t]{3}{*}{ FA 08} & 352 & Independent & No & .013 & .155 & Number in college & -.881 & .040 \\
\hline & & & & & & Single mother & -1.387 & .033 \\
\hline & & & & & & Enrollment status & .164 & .002 \\
\hline FA 08 & 161 & Dependent & Yes & .376 & & & & \\
\hline FA 08 & 198 & Dependent & No & .219 & & & & \\
\hline SP 09 & 171 & Independent & Yes & .592 & & & & \\
\hline SP 09 & 250 & Independent & No & .297 & & & & \\
\hline \multirow[t]{2}{*}{ SP 09} & 129 & Dependent & Yes & .031 & .398 & Mother's education level & 1.483 & .019 \\
\hline & & & & & & Credit hours accumulated & .058 & .032 \\
\hline \multirow[t]{3}{*}{ SP 09 } & 147 & Dependent & No & .043 & .335 & Mother's education level & 1.130 & .039 \\
\hline & & & & & & Academic program & 1.574 & .040 \\
\hline & & & & & & Credit hours accumulated & .046 & .048 \\
\hline FA 09 & 112 & Independent & Yes & .007 & .479 & Adjusted Gross Income & .000 & .029 \\
\hline \multirow[t]{4}{*}{ FA 09 } & 154 & Independent & No & .000 & .513 & Mother's education level & -1.203 & .016 \\
\hline & & & & & & Adjusted Gross Income & .000 & .032 \\
\hline & & & & & & General Studies program & -2.731 & .001 \\
\hline & & & & & & Credit hours accumulated & -.030 & .025 \\
\hline \multirow[t]{4}{*}{ FA 09 } & 73 & Dependent & Yes & .006 & .586 & Mother's education level & -2.874 & .023 \\
\hline & & & & & & Age & 2.131 & .017 \\
\hline & & & & & & Parent's AGI & .000 & .049 \\
\hline & & & & & & Academic program & 2.969 & .043 \\
\hline \multirow[t]{2}{*}{ FA 09} & 83 & Dependent & No & .008 & .514 & Age & 2.154 & .005 \\
\hline & & & & & & Academic program & 2.812 & .033 \\
\hline SP 10 & 21 & Independent & Yes & & & Not enough cases & & \\
\hline SP 10 & 21 & Independent & No & & & Not enough cases & & \\
\hline SP 10 & 31 & Dependent & Yes & & & Not enough cases & & \\
\hline SP 10 & 31 & Dependent & No & & & Not enough cases & & \\
\hline \multicolumn{9}{|c|}{ Cohort: Fall 2007} \\
\hline Term & $n$ & Dependency & Sec Ed & Sig. & $\operatorname{NagR}^{2}$ & Sig Predictors & B & Sig. \\
\hline SP 08 & 418 & Independent & Yes & .173 & & & & \\
\hline \multirow[t]{6}{*}{ SP 08} & 558 & Independent & No & .000 & .183 & Mother's education level & -.522 & .042 \\
\hline & & & & & & Age & .058 & .010 \\
\hline & & & & & & Adjusted Gross Income & .000 & .036 \\
\hline & & & & & & Waiver & 2.110 & .041 \\
\hline & & & & & & Academic program & .654 & .044 \\
\hline & & & & & & Enrollment status & .146 & .005 \\
\hline SP 08 & 227 & Dependent & Yes & .739 & & & & \\
\hline \multirow[t]{2}{*}{ SP 08} & 335 & Dependent & No & .020 & .138 & Sex & .855 & .009 \\
\hline & & & & & & Enrollment status & .195 & .003 \\
\hline \multirow[t]{4}{*}{ FA 08} & 347 & Independent & Yes & .002 & .224 & Age & .106 & .001 \\
\hline & & & & & & Number family members & -.428 & .030 \\
\hline & & & & & & Adjusted Gross Income & .000 & .030 \\
\hline & & & & & & Academic Program & .909 & .021 \\
\hline
\end{tabular}




\begin{tabular}{|c|c|c|c|c|c|c|c|c|}
\hline & & & & & & Enrollment status & .186 & .003 \\
\hline \multirow{6}{*}{ FA 08} & 428 & Independent & No & .000 & .176 & Number house in college & -.760 & .024 \\
\hline & & & & & & Adjusted Gross Income & .000 & .006 \\
\hline & & & & & & Children & 1.459 & .008 \\
\hline & & & & & & Academic Program & .929 & .002 \\
\hline & & & & & & Enrollment status & .154 & .001 \\
\hline & & & & & & Credit hours accumulated & -.014 & .008 \\
\hline \multirow[t]{4}{*}{ FA 08} & 196 & Dependent & Yes & .002 & .326 & Sex & -2.419 & .001 \\
\hline & & & & & & Age & -.809 & .009 \\
\hline & & & & & & Adjusted Gross Income & .000 & .033 \\
\hline & & & & & & Enrollment status & .343 & .002 \\
\hline \multirow[t]{2}{*}{ FA 08} & 273 & Dependent & No & .016 & .162 & Sex & -1.131 & .002 \\
\hline & & & & & & Enrollment status & .191 & .002 \\
\hline SP 09 & 299 & Independent & Yes & .228 & & & & \\
\hline SP 09 & 338 & Independent & No & .366 & & & & \\
\hline SP 09 & 168 & Dependent & Yes & .487 & & & & \\
\hline SP 09 & 179 & Dependent & No & .575 & & & & \\
\hline FA 09 & 215 & Independent & Yes & .296 & & & & \\
\hline FA 09 & 228 & Independent & No & .375 & & & & \\
\hline FA 09 & 126 & Dependent & Yes & .790 & & & & \\
\hline FA 09 & 131 & Dependent & No & .649 & & & & \\
\hline SP 10 & 28 & Independent & Yes & & & Not enough cases & & \\
\hline SP 10 & 28 & Independent & No & & & Not enough cases & & \\
\hline SP 10 & 54 & Dependent & Yes & .517 & & & & \\
\hline SP 10 & 56 & Dependent & No & .439 & & & & \\
\hline \multicolumn{9}{|c|}{ Cohort: Fall 2008} \\
\hline Term & $n$ & Dependency & Sec Ed & Sig. & NagR $^{2}$ & Sig Predictors & B & Sig. \\
\hline \multirow[t]{2}{*}{ SP 09 } & 300 & Independent & Yes & .007 & .221 & Age & .057 & .040 \\
\hline & & & & & & Dependents & -1.521 & .011 \\
\hline \multirow[t]{3}{*}{ SP 09} & 372 & Independent & No & .000 & .219 & Age & .048 & .039 \\
\hline & & & & & & Number house in college & -1.347 & .001 \\
\hline & & & & & & Dependents & -1.599 & .002 \\
\hline SP 09 & 218 & Dependent & Yes & .326 & & & & \\
\hline SP 09 & 244 & Dependent & No & .284 & & & & \\
\hline \multirow[t]{5}{*}{ FA 09} & 187 & Independent & Yes & .000 & .424 & Mother's education level & -.875 & .041 \\
\hline & & & & & & Number house in college & -1.513 & .043 \\
\hline & & & & & & Adjusted Gross Income & .000 & .005 \\
\hline & & & & & & General studies program & -1.669 & .016 \\
\hline & & & & & & Credit hours accumulated & .032 & .015 \\
\hline \multirow[t]{4}{*}{ FA 09} & 238 & Independent & No & .000 & .331 & Number house in college & -1.467 & .016 \\
\hline & & & & & & Adjusted Gross Income & .000 & .027 \\
\hline & & & & & & General studies program & -1.333 & .011 \\
\hline & & & & & & Credit hours accumulated & .023 & .020 \\
\hline FA 09 & 147 & Dependent & Yes & .012 & .270 & Enrollment status & .357 & .001 \\
\hline FA 09 & 165 & Dependent & No & .004 & .255 & Enrollment status & .332 & .001 \\
\hline
\end{tabular}




\begin{tabular}{|c|c|c|c|c|c|c|c|c|}
\hline SP 10 & 38 & Independent & Yes & & & Not enough cases & & \\
\hline SP 10 & 38 & Independent & No & & & Not enough cases & & \\
\hline \multirow[t]{2}{*}{ SP 10} & 50 & Dependent & Yes & .018 & .671 & Number family members & 1.545 & .046 \\
\hline & & & & & & General studies program & -5.462 & .017 \\
\hline \multirow[t]{2}{*}{ SP 10} & 51 & Dependent & No & .015 & .654 & Mother's education level & 2.507 & .028 \\
\hline & & & & & & General studies program & -5.608 & .018 \\
\hline \multicolumn{9}{|c|}{ Cohort: Spring 2007} \\
\hline Term & $n$ & Dependency & Sec Ed & Sig. & NagR $^{2}$ & Sig Predictors & $\mathbf{B}$ & Sig. \\
\hline \multirow[t]{2}{*}{ FA 07} & 481 & Independent & Yes & .007 & .160 & Age & .065 & .008 \\
\hline & & & & & & Instruction Mode & -1.246 & .022 \\
\hline \multirow[t]{2}{*}{ FA 07} & 754 & Independent & No & .000 & .116 & Age & .046 & .002 \\
\hline & & & & & & Waiver & .983 & .030 \\
\hline FA 07 & 243 & Dependent & Yes & .305 & & & & \\
\hline FA 07 & 434 & Dependent & No & .008 & .118 & Enrollment status & 160 & .001 \\
\hline \multirow[t]{2}{*}{ SP 08} & 318 & Independent & Yes & .000 & .340 & Age & .101 & .019 \\
\hline & & & & & & Adjusted Gross Income & .000 & .005 \\
\hline \multirow[t]{5}{*}{ SP 08 } & 478 & Independent & No & .000 & .235 & Age & .070 & .006 \\
\hline & & & & & & Adjusted Gross Income & .000 & .002 \\
\hline & & & & & & General studies program & -.925 & .042 \\
\hline & & & & & & Business program & -1.196 & .040 \\
\hline & & & & & & Enrollment status & .131 & .007 \\
\hline \multirow[t]{2}{*}{ SP 08} & 148 & Dependent & Yes & .022 & .367 & Enrollment status & .453 & .000 \\
\hline & & & & & & Credit hours accumulated & .048 & .049 \\
\hline \multirow[t]{3}{*}{ SP 08} & 221 & Dependent & No & .007 & .276 & Adjusted Gross Income & .000 & .020 \\
\hline & & & & & & Enrollment status & .300 & .000 \\
\hline & & & & & & Credit hours accumulated & .037 & .022 \\
\hline FA 08 & 266 & Independent & Yes & .070 & & & & \\
\hline \multirow[t]{4}{*}{ FA 08} & 357 & Independent & No & .000 & .214 & Father's education level & -.590 & .034 \\
\hline & & & & & & Mother's education level & .566 & .038 \\
\hline & & & & & & Age & .081 & .001 \\
\hline & & & & & & Enrollment status & .174 & .000 \\
\hline$\overline{\text { FA } 08}$ & 121 & Dependent & Yes & .444 & & & & \\
\hline FA 08 & 175 & Dependent & No & .281 & & & & \\
\hline \multirow[t]{5}{*}{ SP 09 } & 239 & Independent & Yes & .000 & .481 & Age & .165 & .002 \\
\hline & & & & & & Number house in college & -2.499 & .007 \\
\hline & & & & & & Dependents & -2.632 & .023 \\
\hline & & & & & & Adjusted Gross Income & .000 & .003 \\
\hline & & & & & & Enrollment status & .408 & .000 \\
\hline \multirow[t]{2}{*}{ SP 09} & 284 & Independent & No & .000 & .339 & Adjusted Gross Income & .000 & .001 \\
\hline & & & & & & Enrollment status & .388 & .000 \\
\hline SP 09 & 98 & Dependent & Yes & .135 & & & & \\
\hline SP 09 & 115 & Dependent & No & .092 & & & & \\
\hline \multirow[t]{3}{*}{ FA 09} & 129 & Independent & Yes & .000 & .546 & Sex & 2.015 & .045 \\
\hline & & & & & & Adjusted Gross Income & .000 & .028 \\
\hline & & & & & & Children & -3.610 & .037 \\
\hline
\end{tabular}




\begin{tabular}{|c|c|c|c|c|c|c|c|c|}
\hline & & & & & & Allied health program & 3.293 & .007 \\
\hline & & & & & & Credit hours accumulated & .065 & .006 \\
\hline \multirow[t]{3}{*}{ FA 09 } & 185 & Independent & No & .000 & .378 & Allied health program & 2.921 & .000 \\
\hline & & & & & & Credit hours in term & .184 & .026 \\
\hline & & & & & & Credit hours accumulated & .027 & .027 \\
\hline FA 09 & 55 & Dependent & Yes & .182 & & & & \\
\hline FA 09 & 75 & Dependent & No & .199 & & & & \\
\hline SP 10 & 21 & Independent & Yes & & & Not enough cases & & \\
\hline SP 10 & 22 & Independent & No & & & Not enough cases & & \\
\hline SP 10 & 25 & Dependent & Yes & & & Not enough cases & & \\
\hline SP 10 & 26 & Dependent & No & & & Not enough cases & & \\
\hline \multicolumn{9}{|c|}{ Cohort: Spring 2008} \\
\hline Term & $n$ & Dependency & Sec Ed & Sig. & $\mathrm{NagR}^{2}$ & Sig Predictors & B & Sig. \\
\hline \multirow[t]{2}{*}{ FA 08 } & 318 & Independent & Yes & .000 & .369 & Mother's education level & -1.191 & .001 \\
\hline & & & & & & Enrollment status & .251 & .000 \\
\hline \multirow[t]{4}{*}{ FA 08} & 399 & Independent & No & .000 & .269 & Mother's education level & -.555 & .017 \\
\hline & & & & & & Age & .052 & .008 \\
\hline & & & & & & Enrollment status & .211 & .000 \\
\hline & & & & & & Delivery method & -.850 & .016 \\
\hline \multirow[t]{4}{*}{ FA 08 } & 134 & Dependent & Yes & .000 & .582 & Father's education level & -3.739 & .003 \\
\hline & & & & & & Mother's education level & 2.392 & .016 \\
\hline & & & & & & General Studies program & 3.24 & .032 \\
\hline & & & & & & Enrollment status & .668 & .006 \\
\hline \multirow[t]{2}{*}{ FA 08} & 185 & Dependent & No & .000 & .364 & Waiver & 2.769 & .026 \\
\hline & & & & & & Enrollment status & .400 & .000 \\
\hline \multirow[t]{3}{*}{ SP 09} & 187 & Independent & Yes & .011 & .356 & Children & 2.008 & .044 \\
\hline & & & & & & Business program & -1.990 & .044 \\
\hline & & & & & & Enrollment status & .202 & .034 \\
\hline \multirow[t]{2}{*}{ SP 09 } & 283 & Independent & No & .002 & .288 & General studies program & -1.435 & .022 \\
\hline & & & & & & Enrollment status & .243 & .002 \\
\hline SP 09 & 96 & Dependent & Yes & .079 & & & & \\
\hline SP 09 & 118 & Dependent & No & .079 & & & & \\
\hline FA 09 & 142 & Independent & Yes & .100 & & & & \\
\hline FA 09 & 216 & Independent & No & .055 & .205 & Enrollment status & .198 & .003 \\
\hline FA 09 & 68 & Dependent & Yes & .081 & & & & \\
\hline FA 09 & 84 & Dependent & No & .081 & & & & \\
\hline SP 10 & 34 & Independent & Yes & & & Not enough cases & & \\
\hline SP 10 & 34 & Independent & No & & & Not enough cases & & \\
\hline SP 10 & 0 & Dependent & Yes & & & Not enough cases & & \\
\hline SP 10 & 0 & Dependent & No & & & Not enough cases & & \\
\hline \multicolumn{9}{|c|}{ Cohort: Spring 2009} \\
\hline Term & $n$ & Dependency & Sec Ed & Sig. & $\mathrm{NagR}^{2}$ & Sig Predictors & B & Sig. \\
\hline FA 09 & 199 & Independent & Yes & .006 & .273 & Father's education level & -.831 & .010 \\
\hline FA 09 & 237 & Independent & No & .001 & .257 & No significant predictors & & \\
\hline FA 09 & 108 & Dependent & Yes & .000 & .463 & Father's education level & -1.596 & .002 \\
\hline
\end{tabular}




\begin{tabular}{|l|l|l|l|l|l|l|l|l|}
\hline FA 09 & 121 & Dependent & No & .000 & .436 & Father's education level & -1.508 & .003 \\
\hline & & & & & & General Studies program & -1.362 & .040 \\
\hline SP 10 & 34 & Independent & Yes & & & Not enough cases & & \\
\hline SP 10 & 34 & Independent & No & & & Not enough cases & & \\
\hline SP 10 & 0 & Dependent & Yes & & & Not enough cases & & \\
\hline SP 10 & 0 & Dependent & No & & & Not enough cases & & \\
\hline
\end{tabular}

Note. Sec Ed means whether the variable secondary education was in the regression

model.

Nag $R^{2}$ means Nagelkerke $R^{2}$. 


\section{CHAPTER V}

\section{Overview of the Research Problem}

From 1988 to 2006 , between $40 \%$ and $60 \%$ of all first-time community college students are referred to and enroll in at least one developmental education course; some colleges reported as high as 80 percent (e.g. Attewell, Lavin, Domina, \& Levey, 2006; Bers \& Smith, 1991; Bettinger \& Long, 2005; Boughan \& Clagett, 1995; Brawer, 1996). Around twice the number of community college students enroll in developmental education compared to four-year public universities (Attewell, Lavin, Domina, \& Levey, 2006; Levin \& Calcagno, 2008). More students begin college less prepared in math than any other developmental area (e.g. ACT, 2006, 2007, 2008, 2009; Attewell, Lavin, Domina, \& Levey, 2006; Bettinger \& Long, 2005; Cartnal, 1999). In 2009, only $15 \%$ of Kentucky high school graduates who took the ACT test, reached the benchmark in all four areas (e.g. math, English, science and reading); only $26 \%$ reached this benchmark in mathematics (ACT, 2009). In the same 2009 class 74\% "indicated an interest in obtaining a bachelor's degree or higher" (ACT, 2009, p.5).

Distance education plays an important role in the mission of community colleges by providing access for disadvantaged students. In 2003, Parsad and Lewis reported $13 \%$ of institutions used distance education in providing developmental education classes. In the fall of $2000,25 \%$ of two-year institutions used technology in developmental classes compared to $8 \%$ of four-year public and $4 \%$ of private four-year (Parsad \& Farris, 2003). 
Attrition is a challenge for online education (e.g. Carr, 2000; Diaz, 2002; Flood, 2002;

Frankola, 2001; Martinez, 2003; Moody, 2004; Parker, 2003).

Research has shown the first semester (and first courses) and year is most important period for student persistence in distance education (e.g. Chyung, Winiecki, \& Fenner, 1998; Martinez, 2003). Thus, this study will focus on persistence from one semester to the next (Bers \& Smith, 1991; Driscoll, 2007; Jaggars \& Xi, 2010; Napoli \& Wortman, 1996, 1998; Romano, 1995; Webb, 1988) and from one term to the same term in the following year (e.g. from fall to following fall) (Fike \& Fike, 2008). The newly established Kentucky state law regulates that students enroll in developmental math within the first two semesters and take the appropriate credit bearing math class immediately following the developmental math class. Therefore, the student's ability to persistence on a term-by-term basis is important.

\section{Purpose Statement}

The purpose of this quantitative study is to examine the relationship between student demographic information, work and family and academic variables at a public state two-year community and technical college system and student persistence. The Collective Affiliation model, based on previous student persistence research in the Tinto tradition, was created for this particular study. There were nineteen research questions for this study (see chapter 3 for questions). All research questions considered persistence as the dependent variable and tested twenty predictor variables (see chapter 3 for predictor variables). Results may be used to inform persistence theory and models as well as practitioners at community colleges and other institutions with commuter students and distance education programs. 


\section{Review of Methods}

For the purpose of this study, the participants will be any student enrolled in the second sequential developmental math course, MT065. Each group of MT065 students in the fall and spring terms is considered a cohort. These cohorts will be tracked throughout the following fall and spring terms until the spring of 2010 term.

The Kentucky Postsecondary Education Improvement Act of 1997 (House Bill 1) created the Kentucky Community and Technical College System (KCTCS), which is the state of Kentucky's public two-year comprehensive college system. KCTCS was established in 1998 through the merger of the community colleges, which were previously part of the University of Kentucky, and the technical colleges, which were previously part of the Frankfort Cabinet for Workforce Development. This formation created sixteen community and technical colleges operating as one state system (Metamorphosis, 2008). Kentucky faces the same changes that other states in the United States face. "More than half of the first-time freshmen entering Kentucky's colleges are underprepared in at least one subject. Even worse, for those underprepared students, the first-year college drop-out rate is twice the rate of academically prepared freshman" (Kentucky Developmental Education Task Force, 2007, p.5). In the summer of 2010, the Kentucky Community and Technical College System will launch online, modularized, self-paced, open-entry/closed exit developmental math courses (A. Parker, personal communication, October, 10, 2009; Moltz, 2009b). In effort to improve success rates in developmental education and "reduce the time-to-degree for many students", the Kentucky Developmental Education Task Force specifically called for a "self-paced, 
brief, online modules for students with minimal developmental need" (Kentucky Developmental Education Task Force, 2007, p.13).

The conceptual framework used in the study was the Collective Affiliation model, based on previous student persistence research in the Tinto tradition, was created specifically community college, commuter and distance education students. The Collective Affiliation model identifies three spheres of influence: static characteristics, dynamic characteristics and academic factors. Static characteristics are variables such as sex and secondary education. Dynamic characteristics are variables such as age and marital status. Academic factors are variables such as enrollment status and academic program (see illustration \# 9). Delivery method is an academic factor, but was treated differently from the other academic variables. All other variables were entered in blocks (static, dynamic and academic); however, delivery method was entered last. This allowed to test whether delivery method significantly influences persistence, controlling for all other variables.

Data analyses were conducted using the Statistical Package for Social Sciences (SPSS). The statistical procedures used was logistic regression and has proven to be appropriate and successful for determining dichotomous outcomes (Cabrera, Stampen \& Hanse, 1990; Dey \& Astin; 1993; Pedhazur, 1997; Peng, So, Frances \& St. John, 2002; Peng, Lee \& Ingersoll, 2002; Press \& Wilson, 1978; Tinto, 1975). There were 108 logistic regression analyses conducted. Fifty-two logistic regression analyses were statistically significant and 51 of the 52 logistic regression analysis resulted in at least one significant predictor variable. 


\section{Summary of Findings: Static, Dynamic and Academic Spheres}

Table 93 shows the number of times each predictor variable, categorized by the block in which it was entered into the logistic regression equation, resulted as a statistically significant predictor. Table 93 shows that the academic variables as a total and on average where statistically more significant than stagnate and dynamic characteristics; even with there being more than twice as many dynamic characteristics than academic factors. This is true even considering that course delivery was only in six logistical regression analyses, but was still significant $33.3 \%$ of the time. Secondary education was only included in half of the total analyses, but was never significant.

\section{Table 93}

Static, Dynamic and Academic Variables as Statistically Significant Predictors

\begin{tabular}{|l|l|l|l|l|l|}
\hline Static & Sig & Dynamic & Sig & Academic & Sig \\
\hline Sex & 4 & Age & 19 & Enrollment Status & 31 \\
\hline Secondary Education & 0 & Marital Status & 0 & Academic Program & 6 \\
\hline Mother's Ed Level & 13 & Dependents & 3 & Degree Program & 14 \\
\hline Father's Ed Level & 5 & Waiver/Third Party & 3 & Number Hours Accumulated & 12 \\
\hline & & Adjusted Gross Income & 16 & Course Delivery & 1 \\
\hline & & Parent's AGI & 3 & & \\
\hline & & Federal Work-study & 1 & & \\
\hline & & Number in College & 6 & & \\
\hline & & Number in Household & 2 & & \\
\hline & & Single Mother & 1 & & \\
\hline & & Children & 3 & & 64 \\
\hline & & & & & 12.8 \\
\hline TOTAL: & 22 & & 57 & & $45 \%$ \\
\hline AVERAGE: & 5.5 & & 5.18 & & \\
\hline PERCENTAGE: & $15 \%$ & & $40 \%$ & & \\
\hline
\end{tabular}




\section{Static Characteristics}

\section{Mother's level of education.}

This study found that the higher the level of mother's education, the greater the probability of persistence for dependent students. This outcome could result from a personal relationship between a mother and child. If the mother has achieved a higher level of educational achievement (e.g. college degree), this is instilled in the child (dependent student). However, in all five outputs in which mother's level of education was significant for dependent students, the sample size was less than 150 . Therefore, mother's level of education may only have an effect on independent students.

This study found that the lower the level of mother's education, the greater the probability of persistence for independent students. This could result from the adult student recognizing the opportunities that were not afforded to his/her mother because of the lack of education. Therefore, the student is attempting to meet an educational objective. The descriptive statistics showed that $20.2 \%$ (percentage of all cases) or $28.2 \%$ (percentage of all non-missing cases) of student's mothers had a college level of education. This relatively high compared to the number of student's mothers with an elementary level of education and compared to father's with a college level of education. This high number of mothers with a college level of education would seem to affirm the positive influence on mothers of dependent students.

Generational issues could explain this finding. For independent students their mothers would be older than most mothers of dependent students. Likewise, more females are attending and completing college degrees now then decades ago. Thus, 
independent student's mothers would have a lower level of education than dependent students, but both the current independent and dependent students are in contexts in which education is valued for females.

\section{Father's level of education.}

This study found the lower the level of the father's education, the greater the probability of persistence and, if the effects of all other predictors are held constant, the father's level of education has a greater effect on persistence for dependent than independent students. This finding is the same as the finding for mother's level of education. However, in all three outputs in which father's level of education was significant for dependent students, the sample size was less than 150 . Therefore, father's level of education may only have an effect on independent students.

Sex.

In the literature review, some studies found being a female increased persistence, while others found no affect. This study found sex to have mixed results on persistence. In the four analyses in which sex was statistically significant, males and females were equally represented as being associated with persistence. Therefore, no particular conclusion can be drawn from this finding.

\section{Secondary education.}

This study found secondary education was not a statistically significant predictor variable in any of the logistic regression analyses. Therefore, there is no significant relationship between secondary education and persistence. This finding was inconsistent with other studies and the National Center for Education Statistics (NCES), which has identified "high school dropout followed by GED" as risk factor affecting persistence. 
One possible reason for this finding is the sample of the study. The sample, regardless of the student's secondary education (high school diploma or GED), were students who all tested into a developmental math course. Therefore, in other studies, in which secondary education may have noted a difference in academic ability, this study tested students with similar academic ability in mathematics.

\section{Dynamic Characteristics}

\section{Adjusted gross income and parent's adjusted gross income.}

This study found adjusted gross income and parent's adjusted gross income was a statistically significant predictor variable. Adjusted gross income was statistically significant in two of the 16 logistic regression analyses for dependent students; independent students comprised 14 of the 16 regression analyses. The B coefficients for adjusted gross income were relatively small, ranging from .000141 to .00000696 , and the $\operatorname{Exp}(B)$ values were very close to 1 . The size of these values are small because of the in manner in which adjust gross income (parent and students) was utilized in the SPSS analysis. Student adjust gross income, for independent students, was a continuous variable with a range from 0 to 673,345 . A range between $\$ 0$ and $\$ 49,999$ includes $92.9 \%$ of independent students and $99.9 \%$ of dependent students. The $\operatorname{Exp}(\mathrm{B})$ values are, "an indicator of the change in odds resulting from a unit change in the predictor" (Field, 2005, p.225). The predictor, adjust gross income, was measured in one dollar increments. Therefore, the change in odds of one unit of change (e.g. a student's adjusted gross income changing from $\$ 10,031$ to $\$ 10,032$ ) affecting the outcome (e.g. persistence) is very small. Thus, the $\operatorname{Exp}(\mathrm{B})$ values are very close to 1 . However, it is important to note that all adjusted gross income B coefficients were positive. Therefore, an increase in 
adjusted gross income does increases persistence. If these values had been coded in $\$ 10,000$ ranges (e.g. $0, \$ 1-\$ 9,999, \$ 10,000$ to $\$ 19,999, \$ 20,000$ to 29,999 , etc.), then the change in odds resulting in a $\$ 10,000$ change in adjusted gross income could be interpreted as opposed to one dollar change.

Age.

This study found that regarding dependent students, ages 18-24, the younger students were more likely to persist. This is consistent with the literature regarding younger students and in particular, the National Center for Education Statistics (NCES), which identified delayed postsecondary enrollment as a risk factor. This study also found, which is consistent with the literature review regarding online persistence studies, that regarding independent students that older students persisting at a higher rate than younger students.

This finding may be related to work and family responsibilities. Earlier in life (e.g. 18 years of age), prior to marriage, raising children and increasing work-related responsibilities, student may have more time and energy to focus on education. Likewise, later in life, the student may have less responsibilities related to raising children (e.g. children may no longer be living at home) and work-related responsibilities (e.g. possibly retired). In addition, this may relate to the purpose of the educational experience. Younger students may be persisting in attempt to find job placement, career, support a family, (extrinsic) etc., whereas, the older student may be attending college for higher levels of self-satisfaction (intrinsic). 


\section{Federal work-study and waiver/third party.}

This study utilized federal work-study and waiver/third party to represent fulltime employment, which the National Center for Education Statistics (NCES) identified as a risk factor affecting persistence. The descriptive statistics showed that only $1.8 \%$ of the sample was a federal work-study student. However, it is unlikely that federal workstudy students are actually working more than 20 hours per week (J. Davis, personal communication, April 27, 2011).

A larger amount, $7.8 \%$, did receive a waiver/third party and in all three logistics regressions, in which this variable was statistically significant, receiving a waiver/third party was associated with persistence. This finding is consistent with Kember's assertion that an employer that affirms the student's educational goals is more likely to persist.

\section{Number of household members in college and household size.}

This study found the fewer the number of household members and the fewer the number of household members in college, all for independent students, the greater the probability of persisting.

\section{Single mother, dependents and children.}

This study found being a single mother and having dependents is not associated with persistence, which are two risk factors the National Center for Education Statistics (NCES) identified as affecting persistence. However, this study found having children was a mixed result. The $\operatorname{Exp}(B)$ value for: (a) Single Mother was $\operatorname{Exp}(-1.387)=0.250$, (b) Dependent(s) were $\operatorname{Exp}(-1.575)=0.207, \operatorname{Exp}(-1.636)=0.195$, and $\operatorname{Exp}(-2.632)=$ 0.072 , and Children were $\operatorname{Exp}(1.459)=4.302, \operatorname{Exp}(-3.610)=0.027$, and $\operatorname{Exp}(2.008)=$ 7.450. This means that when a student moves from not being a single mother to being a 
single mother (one unit of change) the odds ratio is .25 (or $25 \%$ ) larger and therefore single mothers are $25 \%$ more likely to persistence ( $4: 1$ ratio). Therefore, the impact of these variables is a significant impact. However, without a qualitative component, it is difficult to understand the results of the analyses (e.g. children).

\section{Marital status.}

This study found marital status was not a statistically significant predictor variable in any of the logistic regression analyses. Therefore, there is no significant relationship between marital status and persistence.

\section{Academic}

\section{Academic programs and degree majors.}

This study found, regarding academic programs that being a transfer (i.e. AA, AAS, AAT or ASF/AAF program) student is associated with persistence. The majority of the "not transfer" group (i.e. AS, Certificate, Diploma and Undecided) were undecided students, which constituted $24.3 \%$ of the total sample and $64.9 \%$ of the "not transfer" group. Therefore, for practical purposes, this study found that being in a transferable degree program is associated with persistence compared to being an "undecided" student.

This study found that being a business or general studies major is not associated with persistence. This study found that being an allied health major was associated with persistence. For the two logistic regressions that showed being an allied health major was a positive significant predictor, this was from spring 2007 to fall 2009 , a two-and-a-half-

year period. Allied health programs are highly competitive within the Kentucky Community and Technical College System with extensive waitlists and academic 
requirements. Therefore, it is not surprising that this is a long-term positive predictor of persistence.

\section{Total credit hours accumulated.}

This study found total number of credit hours accumulated, for dependent students, that the greater number of accumulated credit hours, the greater the possibility of persistence. This study found total number of credit hours accumulated, for independent students, was mixed. In none of the 12 logistic regression analyses was total credit hours accumulated a significant predictor from the time in which the student was enrolled in MT065 to the next term. This finding is the same as Calcagno, Crosta, Bailey, and Jenkins (2006), who found the number of credit hours earned has less of an impact on older students (over age 25) on completion than younger students (age 25 and younger).

In addition, the descriptive statistics showed $57.1 \%$ of independent students took MT065 within the first 24 credit hours earned and $76.1 \%$ within the first 36 credit hours earned. Likewise, $68 \%$ of dependent students took MT065 within the first 24 credit hours earned and $87.6 \%$ within the first 36 credit hours earned.

Therefore, Kentucky's state law changes that require development students to take required developmental courses within the first 24 credit hours should have no effect on student's persistence to the next term following enrollment in a developmental math course. Likewise, this change would have only affected $32 \%$ of dependent and $42.9 \%$ of independent students between 2006 and 2010. Thus, this change would not affect the majority of KCTCS students. 


\section{Enrollment status.}

This study found the greater the number of credit hours taken in a term, the greater the possibility of persisting. This predictor variable was found to be the statistically significant in more logistic regression analyses than any other predictor variable. This finding favors dependent students; however, many independent students are unable to enroll in more credit hours because of family and work responsibilities.

\section{Course delivery method.}

This study found, for independent students, that being in an "in person" class compared to an online class is associated with persistence. However, this was only true in one cohort file; the sample had very few students enrolled in an online MT065 course.

\section{Collective Affiliation Model}

As noted in the literature review, Spady and Tinto's social and academic integration models have evolved with regarding to nontraditional students. Through this evolutionary process, social integration has exited and "noncollegiate" (Bean \& Metzer, $1985)$ and "work and social environments" (Kember, 1989a) have taken its place. This is understandable considering the non-college residency, work and family demands. However, these models still favor sociological constraints that evidently have less bearing on nontraditional students compared to traditional students. Therefore, even though the Spady and Tinto constructs remains highly favorable for traditional students, and rightly so, it may be theoretically wiser to look to other conceptual models to best understand this phenomenon. An economic (e.g. cost/benefit analysis) or job satisfaction (e.g. Motivation-Hygiene Theory) model may provide a more robust analysis for community college, commuter and distance education students. These workplace theories regarding 
satisfaction may prove to be useful given the connection between work and education for nontraditional students. Kember utilized the concept of a "cost/benefit analysis" to describe the decision-making process by which the student determined persistence, but never directly extrapolates on how this internal decision is made. The factors in his model lead to this decision, but how these factors are compared to one another to determine an outcome is not explained nor may this be the same process for every student. This point was previously stated in the creation of the Collective Affiliation model. Each time the student makes a cost/benefit analysis of persistence, there is potential for the factors to change. For example, we may not have a statistically significant different between students with one, two or three children. However, we may find that when the number of children changes from one to two or two to three, then the student stops persisting.

Likewise, Spady, Tinto, Kember, Bean and Metzner all used the terms "satisfaction" and/or "motivation" (e.g. goal commitment) as a psychological component of the persistence model. This component may have a greater impact, but are more difficult to measure without the assistance of an additional instrument. Collection of biographical, academic and other existing institutional information is more readily available and accessible for research purposes. Nonetheless, it would be particularly beneficial to collect this information and test this hypothesis as a means of further understanding the unique aspects of community college, commuter and distance education students.

Also, Kember's two-track model demonstrates that the Motivation-Hygiene Theory could be applicable to student persistence. Kember recognizes that some factors produce a positive outcome (e.g. persistence) while other factors produce a negative 
outcome (e.g. drop-out). The following is an example of how Herzberg's Motivation Hygiene theory, using these predictor variables, could be applied in this setting. Herzberg noted that not all factors caused satisfaction or dissatisfaction. He categorized some factors as negative and others as positive. The negative factors could only cause negative or neutral satisfaction, but positive factors could only cause positive or neutral satisfaction (Herzberg, 1962). It is possible that course delivery method is not a factor that predicts student persistence at an institution; rather, it is a factor that determines if the student will even be enrolled at an institution. Thus, the factor does influence persistence positively or negatively; it can only negatively affect attendance and as an extension, persistence. Similarly, as Kolowich (2010a) reported, "many online learners are adults who are back in school because they want to advance or change their careers" (para.9). It would be reasonable for these students to view their education goals as parallel to their career goals. Thus, educational satisfaction and persistence could be influenced by similar variables. Also, "Herzberg suggests that factors that lead to job satisfaction are primarily intrinsic, whereas factors leading to job dissatisfaction are primarily extrinsic" (Pardee, 1990, p.9). This concept fits perfectly with Kember's intrinsic and extrinsic motivation concept in his two-track model.

In addition, if affiliation is retained as a primary means of understanding persistence, for community college, commuter and distance education students, then with whom or what is student collectively affiliating. For dependent students, it is, again, safe to assume that the change in residency requires these students to affiliate with a new community and context. Therefore, the dependent student is affiliating with a new community (students, staff and faculty). However, for online, commuter and other adult 
learners, the main source of interaction is inside the classroom (Karp, Hughes \& O'Gara 2008; Townsend \& Wilson, 2006, 2008-2009), physically or virtually. Therefore, if there is "affiliation" occurring to what or with who the affiliation is occurring is not clearly defined. For example, when an online student drops out of a particular course has the student lost affiliation with the institution, the course itself, the other students or the professor. Since there is no defined new community or context, this affiliation may be different for each individual student. Also, this may be another aspect that further supports the notion that nontraditional students' sociological characteristics should not be tested for the purpose of persistence, but rather psychological aspects.

Grade point average is an example of a psychological factor. It was not considered as a predictor variable because when initial logistic regression analyses were conducted, grade point average was so highly correlated to persistence that it was the only variable that was statistically significant. Thus, this relationship showed that the relationship between grade point average and persistence would be better characterized as an outcome rather than predictor. Kember, who first considered grade point average a predictor variable, changed his model based on similar findings. Kember (1995) said, "the quantitative analysis, though, suggested that GPA functioned to some extent as an intervening variable between academic incompatibility and drop-out" (p.128). With regard to collective affiliation, grade point average appears to have the greatest impact because it serves as direct and immediate feedback from the institution regarding acceptance. For example, if a student fails a class, then this is similar to the institution saying, "You do not belong here". Kember (1995) also noted this regarding grade point average by saying, "presumably students who receive low grades, after working through 
a module or course, tend to be discouraged from continuing with further modules" (p.128). This discouragement comes directly from the institution/faculty members awarding of grades. Similarly, even though not tested in this study, interaction with faculty would have the same affect because it is a direct response from the institution. Also, the participants in this student were all developmental math students. As noted by Young (2002), "while Tinto's work has gained acceptance and notoriety, it does not speak directly to the essence of the underprepared student's most basic concern: that he/she is not ready for college-level work" (p.7). This academic factor (e.g. "not ready for academic work") can have both a sociological as well as a psychological effect. The fact that a student tests into a developmental course may be perceived as negative feedback from the institution (i.e. you don't belong here). 
Based on these results, a new Collective Affiliation model was developed.

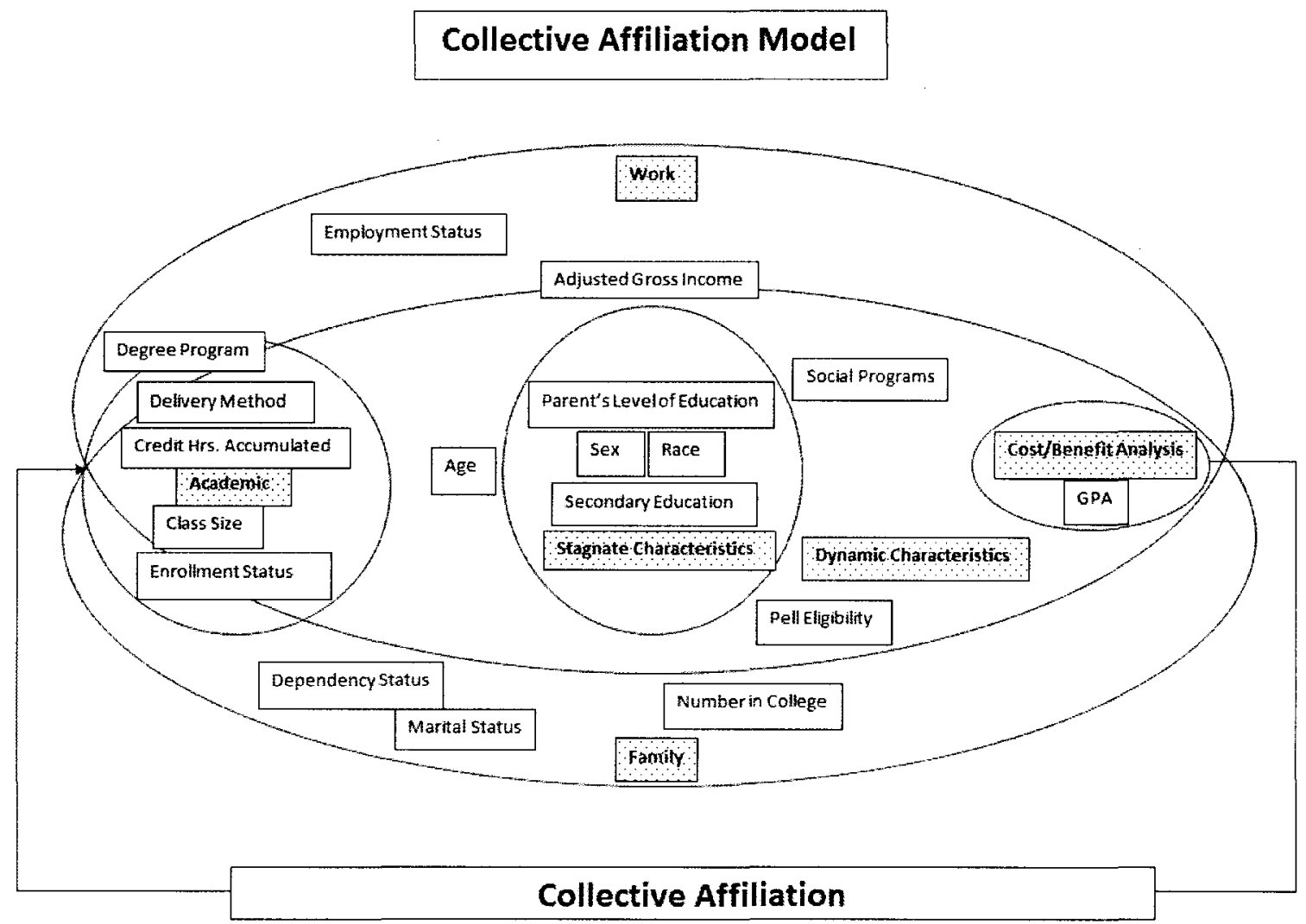

\section{Collective Affiliation Model compared to Spady and Tinto}

The Collective Affiliation model draws upon the work of Spady, Tinto, Bean and Metzner and Kember. The findings from this study confirm Bean and Metzner and Kember's assertion that the social integration of community college, commuter and distance education do not affect student persistence the same as traditional students. Likewise, for these nontraditional students, the non-collegiate and family and work environments play a greater role than on-campus social relationships. This study found that academic variables play the greatest role in determining student persistence, which disagrees with Tinto's claim that social integration determines student persistence. The Collective Affiliation model affirms a cost/benefit analysis on the part of the student's 
persistence/drop-out decision process and proposes that psychological factors may more greatly contribute to this decision than sociological factors. This may be particularly true for students in developmental classes.

\section{Practical Implications and Policies}

\section{Course delivery method.}

Course delivery method was a significant predictor of persistence $(\mathrm{p}<.05)$ in only one of the logistic regression analyses. This one analysis showed a negative regression coefficient This means, for independent students, being in an "in person" (compared to distance education) course is associated with persistence. This could be a critical finding since the Kentucky Community and Technical College System intends to create additional online development math courses and the emphasis on adult learners returning to college to obtain a degree at community colleges (Moltz, 2011).

However, first, this finding only occurred in one of the six cohort files and once within a total of twenty-four logistic regression analyses. Therefore, if any conclusion can be drawn from these analyses, the clearest conclusion is that the delivery method has little to no effect on persistence. This may be the result of the small amount of students whom were enrolled in an online MT065 course.

Secondly, the course delivery method itself may not be the actual impetus for why online students are withdrawing from the course. Jaggers (2011) said, "many student supports are built around a campus infrastructure, and online students may have difficultly accessing them" (p.2). For online education to be successful institutions cannot expect fully online students to take advantage of on-campus student support services. All the academic advantages and assistance that is afforded to in-person students must also 
be transported and re-aligned for the online student, regardless of location. These services must not meet the needs of the institution, but the needs of the students. Jaggers (2011) affirmed the same idea by stating, "support services must be seamlessly integrated into the space in which students already live and work" (p.2).

Thirdly, the self-paced, modularized online courses will be distinctly different from traditional 16-week (or 8-week) online courses. The distinction between these two warrants additional study to determine the effect of each course delivery method. As Jaggers (2011) stated, "if community colleges and other institutions that predominately serve low-income and underprepared students wish to draw new enrollees via online coursework, they may need to consider how to design and fund fully online degree programs" (p.2). The Kentucky Community and Technical College System has already engaged in this effort. The self-paced, modularized developmental math courses will be part of "KCTCS Learn on Demand", which already offers business administration, nursing, information technology and other degree programs that are fully online and modularized.

In conclusion, persistence rates for online courses are not a rationale for limiting student's options regarding course delivery methods. Course delivery methods should be seen as means of access. For nontraditional students, often times, if online courses are not an option for a student to take a class, then the student is denied access and persistence is never a factor. Likewise, this study measured persistence rates as opposed to success rates. 


\section{Nontraditional student needs.}

This study verified what has been illuminated in other persistence studies: single parents and other students with children and dependents are at a high risk of drop out. Also, this study showed that these factors have a potentially greater impact on students than other factors. Community colleges and other institutions will need to address success not only through meeting the academic needs in the classroom, but also in the personal lives of students. Students with childcare needs post a unique opportunity for student support. The ability to provide on-campus childcare or develop relationships with other off-campus childcare services for community college and other commuter students is important for academic success. Having on campus childcare compared to a relationship with an off-campus childcare service may have an impact on the student's psychological aspect of belonging. If the campus provides on-campus child care this may give a greater sense of belonging and support rather than having to leave the campus for student support services.

Likewise, for online students, technical support and computer literacy is paramount for success. Independent students was the group that the one logistic regression that showed an online course delivery method as lowering the odds of persisting. One possible reason for this affecting independent compared to dependent students maybe the exposure to computers and other forms of technology. Therefore, access to technical support and assistance with technology must be available to the student in a consistent and timely manner, particularly with online learners.

In summary, colleges have the ability to and an obligation to assist in student success. This ability to move from failure to success is the reason for the recycling loop 
in Two-track and Collective Affiliation models. Kember (1995) noted, "the inclusion of the recycling loop is important as it provides a mechanism for switching from one track to the other. It allows students to take charge of their own destiny. It means that the college and the faculty can influence students' academic progress and suggests they have a moral obligation to try to influence students towards the positive track" (p.128-129). As determined in this study and others, students do not enter college with static characteristics that predetermined success or failure. Therefore, the college has an obligation to provide these support services for the good of the students and the greater good of society.

\section{Non-institutionally controlled variables and stereotypes.}

One important finding was the lack of effect secondary education and sex had on persistence. Likewise, the dynamic variable marital status had no effect. When the student enters higher education the institution has no control over these static and dynamic variables. Thus, it is positive to find these predictor variables to have little to no effect on persistence. Gender-related stereotypes greatly affect students and faculty and impact student success. For example, females are often viewed as less successful in areas of math and science. However, this study, which used developmental math students as the sample population, showed that females and males are as equally likely to persist.

\section{College grading policies and faculty feedback.}

Given this study's finding on the impact of grade point average as a means of institutional feedback, this highlights the importance of college grading policies regarding developmental education courses. Some colleges assign finals grades in

developmental courses differently than other credit-bearing courses. For example, rather 
than assigning an "F" for a failing grade, some institutions may assign a grade (e.g. "N") that does not indicate "failure", but rather "needing improvement". In a developmental education context, the student is simply gaining additional knowledge and skills before they are able to enter the credit-bearing course. Therefore, grades and faculty feedback could be more open-ended and ongoing until the students are ready for definitive, positive or negative, feedback in the form of a grade.

\section{Academic advising.}

This study showed an increased amount of credit hours in the semesters is associated with an increase in persistence. The number of credit hours per semester is a function on academic integration. Also, this study showed that dependent students are more likely to enroll with a greater number of credit hours than independent students. Often, independent students are unable to enroll in a greater number of credit hours because of family and work responsibilities. However, through flexible scheduling and appropriate academic advising this may be possible.

This study also showed that students enrolled in a transferable degree program are more likely to persist than students that are not enrolled in a transferable degree program. The majority of students who were not in a transferable degree program were in an "undecided" status. This shows that having an educational objective is a first step toward persisting. After a student has an educational objective, the appropriate academic advising can assist the student in completing the objective in a timely manner. Also, with a clear educational path, the student may be able to enroll in a greater number of credit hours in effort to finish the object in a shorter amount of time. This would increase academic integration. Even though nontraditional and other independent students are 
more likely to enroll in a fewer number of credit hours, the academic encouragement to do so may increase the students commitment and motivation level. These two aspects, as earlier noted, may have a significant impact on persistence from a psychological perspective. As noted in the literature review, Taplin and Jegede (2001) found that the number of hours worked was not the determining factor in the students' success, but the intensity of the workload and regularity of the work. Therefore, a highly motived worker may also translate into a highly motived student. Thus, rather than assuming that nontraditional and other independent students are unable to enroll in a greater number of credit hours, this population's added family and work responsibilities may translate into a successful student.

\section{Future Research}

\section{Grade point average.}

This study excluded college GPA as a predictor variable. It would be beneficial to conduct the same logistic regression analyses when grouping students by GPA as means to assess differentiation between students that are getting positive feedback from the institution compared to students who are getting negative feedback from the institution based on changes in GPA. For example, a study should conduct the same logistic regression analyses that were conducted in this study, but take the particular independent and dependent students and separate them by grade point average. One group would be students with 3.0 grade point average and above and another group would be students with a 2.5 grade point average and below. 


\section{Nontraditional student conceptual frameworks.}

More studies need to be conducted utilizing conceptual frameworks that develop a nuanced understanding of academic integration and address nontraditional needs of students. Bean and Metzner (1985) successfully introduced nontraditional students and Kember $(1989 ; 1995)$ successfully introduced online students into the conversation regarding persistence; however, other forms of nontraditional education and minority groups of students still lack the theoretical underpinning and data-driven research to support a better understand of the needs of these students and quality of their educational experience. Also, this study has limitations that necessitate replication to verify findings. For example, in no logistic regression was secondary education found to be statistically significant even though this is often cited in the literature a risk factor. It is likely that this predictor variable was not statistically significant because the sample was all

developmental math students. Regardless of the student's secondary education, all students either tested into developmental level math at the basic algebra level or lower. Therefore, the student's prior means of education is not a factor because all the students are underprepared and have, essentially, the same skill level. Thus, it is not the past preparation that would predict future persistence, but rather current experiences. Future studies could diversify the sample and will likely find secondary education and other predictor variables to be significant.

\section{Change in predictor variables.}

Studies need to be conducted in which the change of a predictor variable as opposed to the predictor variables itself are examined to determine persistence. Rather than quantitatively measuring how no child compared to one child compared to two 
children compared to three children, etc. affects student persistence from one term to the next; studies should measure the effect on persistence when these predictor variables change and the amount of change that occurs. For example, if a student begins classes with one child and persists to graduation with one child, then having one child may not have a large effect on persistence. However, if the same student has one child at the start of college and two child at the start of year two in college, then three child at the start of year three in college and drops out after the next semester, then the change from one to two and two to three children could have a large effect on persistence. This change from one to three children could have a greater effect on persistence than a student who enters colleges with three children then persists to graduation with three children. Quantitatively having three children would be associated with non-persistence in the first case, but persistence in the second case. Thus, studies that attempt to gain a better and deeper understanding of these variables will prove a more robust understanding of persistence.

\section{Modularized online developmental math.}

Even though studies (Jaggers, 2011; Phillips, 2011), have reported that an online delivery method for developmental education does not increase persistence resulting in at least one college completely abandoning online developmental education (Jaschik, 2011), these studies did not take into consideration the differences between "traditional" online education and newer forms of online learning made possible by technology. Phillips (2011) noted, "many online courses are developed by simply importing the face-to-face materials to a course web site and adding a discussion board". These courses are not, and may not statistically be the same as, the proposed online, self-paced, modularized developmental math course being developed by the Kentucky Community and Technical 
College System. More studies that focus particularly on these modularized courses is necessary to determine their impact on student persistence.

\section{Qualitative research.}

A study of this nature would be greatly served with both a quantitative and qualitative component. As noted, some of the results (e.g. children, mother's level of education) are difficult to interpret without the assistance of some form of qualitative research. Any study that attempts to under student persistence from a sociological perspective would be greatly enhanced and find a more robust outcome if mixed methods were applied to give a fuller picture of the outcomes.

\section{Conclusion}

This study adds to the persistence literature in three ways. First, from a theoretical framework, this study confirms that academic factors have a greater effect on persistence than entry characteristics and social, family and work factors on community college, commuter and distance education students. However, the study calls into question the validity of a sociological persistence model as it relates to community college, commuter and distance education students enrolled in developmental courses and proposes that psychological factors may have a greater effect on persistence for this particular student group.

Secondly, the study furthers the literature, both practically and theoretically, regarding an understanding of nontraditional and developmental students, online and traditional course delivery methods and persistence rates. Even though the online sample of students was small, the study gives insight into the nuances of developmental students, particularly developmental math students. 
Thirdly, the study shows how systematic policies at the state and college level have a direct impact on student success. For example, the state of Kentucky, the state law changes that require development students to take required developmental courses within the first 24 credit hours should have no effect on student's persistence to the next term following enrollment in a developmental math course. Likewise, this change would have only affected $32 \%$ of dependent and $42.9 \%$ of independent students between 2006 and 2010. Thus, this change would not affect the majority of KCTCS students. 


\section{REFERENCES}

References marked with an asterisk indicate studies included in the meta-analysis.

ACT, Inc., College readiness and the impact of course rigor from 1995-2005 (2005).

Report from ACT National Report. Retrieved from http://www. act.org/news/ data/05/charts/text.html\#two

ACT, Inc., College readiness and the impact of course rigor (2006). Report from ACT National Report, Section III. Retrieved from http://www.act.org/news/data 106/pdf/three.pdf

ACT, Inc., College readiness and the impact of course rigor (2007). Report from ACT National Report, Section III. Retrieved from http://www.act.org/news/data /07/pdf/three.pdf

ACT, Inc., College readiness and the impact of course rigor (2008). Report from ACT National Report, Section III. Retrieved from http://www.act.org/news/data/08/pdf /three.pdf

ACT, Inc., Measuring college and career readiness (2009). Report from ACT Measuring college and career readiness: Kentucky, class of 2009. Retrieved from http://www /news/data/09/pdf/output/ACT_Kentucky_Output.pdf

Allen, I. E., \& Seaman, J. (2007). Online nation: Five years of growth in online learning. Retrieved from http://www.sloan-c.org/publications/survey/pdf/online_nation.pdf

Allen, I. E., \& Seaman, J. (2010). Learning on demand: Online education in the United 
States, 2009. Retrieved from http://www.sloanconsortium.org/publications/survey /pdf/learningondemand.pdf

Amey, M. J., \& Long, P. N. (1998). Developmental course work and early placement: Success strategies for underprepared community college students. Community College Journal of Research and Practice, 22(1), 3-11.

Aragon, S. R., \& Johnson, E. S. (2008). Factors influencing completion and noncompletion of community college online courses. The American Journal of Distance Education, 22, 146-158.

Ashar, H., \& Skenes, R. (1993). Can Tinto's student departure model be applied to nontraditional students? Adult Education Quarterly, 43(2), 90-100.

Astin, A. W. (1984). Student involvement: A developmental theory for higher education. Journal of College Student Personnel, 25(4), 297-307.

Attewell, P., Lavin, D., Domnia, T., \& Levey, T. (2006). New evidence on college remediation. The Journal of Higher Education, 77(5), 886-924.

*Axelson, R., \& Torres, D. (1995). Modeling first-semester integration and departure of community college students. Paper presented at the Annual forum of the Association for Institutional Research, Boston, MA.

Bahr, P. R. (2007). Double jeopardy: Testing the effects of multiple basic skill deficiencies on successful remediation. Research in Higher Education, 48(6), 695-725. doi: 10.1007/s11162-006-9047-y

Bahr, P. R. (2008). Does mathematics remediation work?: A comparative analysis of academic attainment among community college students. Research in Higher Education, 49, 420-450. doi: 10.1007/s11162-008-90890-4 
Bailey, T. (2009). Challenge and opportunity: Rethinking the role and function of developmental education in community college. New Directions for Community Colleges, 145, 11-30.

Bailey, T. R., \& Alfonso, M. (2005). Paths to persistence: An analysis of research on program effectiveness at community colleges. Lumina Foundation for Education New Agenda Series, 6(1), 1-35. Retrieved from http://www.luminafundation.org/ publication/PathstoPersistence.pdf

Bailey, T., \& Cho, S. (2010, September). Issue Brief: Developmental education in community colleges. Prepared for: The White House Summit on Community College. Retrieved from http://ccrc.tc.columbia.edu/Publication.asp?UID=815

Bailey, T., Jeong, D. W., \& Cho, S. (2009, November). Referral, enrollment, and completion in developmental education sequences in community colleges (CCRC Working Paper no. 15), Community College Research Center Teachers College, Columbia University, New York, NY.

Baird, L. L. (1991). Academic, personal and situational factors in retention in community colleges (Report No. 90-1). Lexington, KY: The Office of Higher Education Research, College of Education, University of Kentucky.

Bean, J. P., \& Metzner, B. S. (1985). A conceptual model of nontraditional undergraduate student attrition. Review of Educational Research, 55(4), 485-540.

Bernard, R. M., \& Amundsen, C. L. (1989). Antecedents to dropout in distance education: Does one model fit all? Journal of Distance Education, 4(2), 25-56

Berge, Z. \& Huang, Y. (2004). A model for sustainable student retention: A holistic perspective on the student dropout problem with special attention to e-learning. 
DEOSNEWS, 13(5), Retrieved from http://www.ed.psu.edu/acsde/deos/deosnews /deosnews13_5.pdf

*Bers, T. H., \& Smith, K. E. (1991). Persistence of community college students: The influence of student intent and academic social integration. Research in Higher Education, 32(5), 539-556.

Bettinger, E. P., \& Long, B. T. (2005). Remediation at the community college: Student participation and outcomes. New Directions for Community Colleges, 129(1), 1726.

Billings, D. M. (1988). Print: A conceptual model of correspondence course completion. American Journal of Distance Education, 2(2), 23-35. doi: 10.1080/089236488 09526621

Biswas, R. R. (2007). Accelerating remedial math education: How institutional innovation and state policy interact. Retrieved from Achieving the Dream website: http://www.achievingthedream.org/_pdfs/_publicpolicy/RemedialMath .$p d f$

Boatman, A. \& Long, B. T. (2010, September). Does remediation work for all students? How the effects of postsecondary remedial and developmental courses vary by level academic preparation (NCPR Working Paper), Community College Research Center Teachers College, Columbia University, New York, NY.

Borglum, K., \& Kubala, T. (2000). Academic and social integration of community college students: A case study. Community College Journal of Research and Practice, 24, 567-576.

Boston, W., Diaz, S. R., Gibson, A. M., Ice, P., Richardson, J., \& Swam, K. (2009). An 
exploration of the relationship between indicators of the community of inquiry framework and retention in online programs. Journal of Asynchronous Learning Networks, 13(3), 67-83.

Boughan, K. (1988). New approaches to the analysis of academic outcomes: Modeling student performance at a community college. Paper presented at the Annual Forum of the Association for Institutional Research, Minneapolis, MN.

Boughan, K., \& Clagett, C. A. (1995). A student outcomes typology for community colleges:Identifying achievers with longitudinal cohort analysis. Paper presented at the Annual Conference of the North East Association for Institutional Research, Burlington, VA.

Boylan, H. R., Bliss, L. B., \& Bonham, B. S. (1997). Program components and their relationship to student performance. Journal of Developmental Education, 20(3), $2-7$.

Boylan, H. R., \& Bonham, B. S. (2007). 30 years of developmental education: A retrospective. Journal of Developmental Education, 30(3), 2-4.

Brants, L., \& Struyven, K. (2009). Literature review on online remedial education: A European perspective. Retrieved from http://www.fdewb.unimaas.nl leduc_v2/STEP/Documents/2_Brants_Literature_Scan.pdf

Brawer, F. B. (1996). Retention-attrition in the nineties. Retrieved from ERIC database (ED393510)

Braxton, J. M., \& Lien, L. A. (2000). The viability of academic integration as central construct in Tinto's interactionalist theory of student departure. In Braxton, J. M. 
(Ed) Reworking the Student Departure Puzzle (pp. 11-28). Nashville, TN:

Vanderbilt University Press

Breindel, M. D. (1997). Persistence of new students who entered college of the desert, fall 1991 and fall 1992. Retrieved from ERIC database (ED405050)

Brooks-Leonard, C. (1991). Demographics and academic factors associated with first to second term retention in a two year college. Community/Junior College Research Quarterly, 15, 57-69.

Bryk, A. S. \& Treisman, U. (2010, April). Make math a gateway, not gatekeeper. The Chronicle of Higher Education. Retrieved from http://chronicle.com/article/Make-Math-a-Gateway-Not-a-/65056/

Cabrera, A. F., Castaneda, M. B., Nora A., \& Hengstler, D. (1992). The convergence two theories of college persistence. The Journal of Higher Education, 63(2), 143164.

Cabrera, A. F., Nora, A., Castaneda, M. B. (1993). College persistence: Structural equations modeling test of an integrated model of student retention. The Journal of Higher Education, 64(2), 123-139.

Cabrera, A. F., Stampen, J. O., \& Hansen, W. L. (1990). Exploring the effects of ability to pay on persistence in college. The Review of Higher Education, 13(3), 303-336.

Calcagno, J. C., Crosta, P., Bailey, T., \& Jenkins, D. (2006, October). Stepping stones to a degree the impact of enrollment pathways and milestones on older community college student outcomes (Number 32). Community College Research Center. New York, New York: Columbia University.

Campbell, J. W., \& Blakey, L. S. (1996). Assessing the impact of early remediation in the 
persistence and performance of underprepared community college students. Paper presented at the Annual Form of the Association for Institutional Research, Albuquerque, NM.

Carey, R., Kleiman, G., Russell, M., Venable, J. D., \& Louie, J. (2008). Online courses for math teachers: Comparing self-paced and facilitated cohort approaches. The Journal of Technology, Learning, and Assessment, 7(3), 4-35.

Carr, S. (2000, February 11). As distance education comes of age, the challenge is keeping students. The Chronicle of Higher Education, pp. A39. Retrieved from http://chronicle.com/article/As-Distance-Education-Comes/14334/

Cartnal, R. (1999). Preliminary success and retention rates in selected math courses. Retrieved from ERIC database (ED442480)

Cheung, L. L. W., \& Kan, A. C. N. (2002, May/June). Evaluation of factors related to students performance in a distance-learning business communication course. Journal of Education for Business, 257-263.

Choy, S. (2001). Students whose parents did not go to college (NCES 2001-126). Retrieved from United States Department of Education, Office of Educational Research and Improvement, National Center for Education Statistics website: http://nces.ed.gov/pubsearch/pubsinfo.asp?pubid=2001126

Chyung, Y., Winiecki, D. J., \& Fenner, J. (1998). A case study: Increase enrollment by reducing dropout rates in adult distance education. Retrieved from ERIC database (ED422848)

Clagett, C. A. (1996). Correlates of success in the community college: Using research to 
inform campus retention efforts. Journal of Applied Research in the Community College, 4(1), 49-68.

Clergy, S. (2006a, February). Developmental math. Data notes: Keeping informed about achieving the dream data, 1(1), 1-2. Retrieved from .http://www.achievingthedreamorg/_images/_index03/February_2006_ Developmental_Math.pdf

Clergy, S. (2006b, March). Credits, persistence attainment. Data notes: Keeping informed about achieving the dream data, 1(2), 1-3. Retrieved from .http://www.achievingthedream.org/_images/_index03/DataNotes-Mar-2006.pdf

Clergy, S. (2006c, May). Do pell grants make a difference. Data notes: Keeping informed about achieving the dream data, 1(4), 1-3. Retrieved from http://www.achievingthedream.org/_pdfs/DataNotes/May2006.pdf

Clergy, S. (2006d, July/August). Developmental education. Data notes: Keeping informed about, achieving the dream data, 1(6), 1-3. Retrieved from http://www.achievingthedream.org/_pdfs/DataNotes/DataNotes-JulAug-2006.pdf Clergy, S. (2007a, May/June). Achieving the dream students and financial aid. Data notes: Keeping informed about achieving the dream data, 2(2), 1-3. Retrieved from http://www.achievingthedream.org/_pdfs/datanotes/DataNotes-MayJune2007.pdf

Clergy, S. (2007b, November/December). Enrollment status and student outcomes. Data notes: Keeping informed about achieving the dream data, 2(4), 1-3. Retrieved from http://www.achievingthedream.org/_pdfs /data notes/DataNotes-NovDec- 
2007.pdf

Clergy, S. (2008a, March/April). Outcome differences across age groups. Data notes: Keeping informed about achieving the dream data, 3(2), 1-3. Retrieved from http://www.achievingthedream.org/_pdfs/datanotes/DataNotes-MarApr08.pdf

Clergy, S. (2008b, July/August). Developmental education: Completion status and outcomes. Data notes: Keeping informed about achieving the dream data, 3(4), 1-4. Retrieved from http://www.achievingthedream.org/_pdfs/datanotes.Data Notes_JulyAugust_08.pdf

Clergy, S. (2008c, September/October). Students earning zero credits. Data notes: Keeping informed about achieving the dream data, 3(5), 1-3. Retrieved from http://www.achievingthedream.org/_pdfs/datanotes/DataNotesSeptOct08.pdf

Clergy, S. (2008d, November/December). Outcome status by developmental status and gender. Data notes: Keeping informed about achieving the dream data, 3(6), 1-3. Retrieved from http://www.achievingthedream.org/Portal/Modules /93124149$3 \mathrm{fd} 5-469 \mathrm{e}-9369-84 \mathrm{f} 74 \mathrm{a} 02 \mathrm{a} 5 \mathrm{f} 8$.asset?

Clergy, S. (2009b, May/June). Characteristics of students who stop out. Data notes: Keeping informed about achieving the dream data, 4(3), 1-4. Retrieved from http://www.achievingthedream.org/Portal/Modules/4ea58a5a-d8b9-46e7-91b953bb34993b09.asset?

Cofer, J., \& Somers, P. (2000). Within-year persistence of students at two-year colleges. Community College Journal of Research and Practice, 24, 785-807.

Cohen, J. \& Cohen, P. (1983). Applied Multiple Regression / Correlation Analysis for the 
Behavioral Sciences ( $2^{\text {nd }}$ ed.). Hillsdale, NJ: Lawrence Erlbaum Associates, Publishers

Colleges cope with rising demand for remedial courses. (2009, January/December 2008). American Teacher, 93(4), 7.

Collins, M. L. (2009). Setting up success in developmental education: How state policy can help community colleges improve student outcomes. Retrieved from Achieving the Dream website: http:/www.achievingthedream.org /Portal/Modules/aeb219f8-58b2-43fb-8cf7-ee42a3dee72a.asset?

Colorado Commission on Higher Education. (2009). 2008 Legislative report on remedial education. Denver, CO.

Community colleges and states selected to boost college graduation rates by improving remedial courses and strategies (2009, June). Retrieved from http://www.gatesfoundation.org/press-releases/Pages/raising-graduation-ratescommunity-colleges-090622.aspx

Community college learning, retention, advance with innovative technology platforms (2008,February). Retrieved from http://www.pearsoned.com/pr_2009/021909a .htm

Community College Survey of Student Engagement. (2006). Act on fact: Using data to improve student success, 2006 findings. Austin, TX: Community College Leadership Program, The University of Texas at Austin.

Conklin, K. A. (1995). Community college students' persistence and goal attainment: A 15-year longitudinal study. Retrieved from ERIC database (ED384404).

Conklin, K. A. (1997). Course attrition: A 5-year perspective on why students drop 
classes. Community College Journal of Research and Practice, 21(8), 753-759.

Conway, K. M. (2009). Exploring persistence of immigrant and native students in an urban community college. The Review of Higher Education, 32(3), 321-352.

Craig, A. J., \& Ward, C. V. L. (2007-2008). Retention of community college students: Related student and institutional characteristics. Journal of College Student Retention, 9(4), 505-517.

Curran, C. (2001). The phenomenon of on-line learning. European Journal of Education, $36(2), 113-132$.

Curtis, J. W. (2002). Student outcomes in developmental education 1994-95 through 1999-2000. Retrieved from ERIC database (ED459900)

Definition of Developmental Education (2009). Retrieved from DevEd/definition.html Definition of Retention (2009). Retrieved from http://nces.ed.gov/ipeds/glossary /index.asp?searchtype=term \&keyword $=$ retention $\&$ Search $=$ Search

Deil-Amen, R. (2003, August). Leaving college: Do existing models of college dropout apply to community college students? Paper presented at the annual meeting of the American Sociological Association, Atlanta, GA. Retrieved from http://www.allacademic.com/meta/p_mla_apa_research_citation/1/0/6/9/5/pages 1 06957/p106957-1.php

Deil-Amen, R. (2005, August). Do traditional models of college dropout apply to nontraditional students at non-traditional colleges? Paper presented at the annual meeting of the American Sociological Association, Philadelphia, PA. Retrieved from http://www.allacademic.com/meta/p22512_index.html 
Deil-Amen, R., \& Rosenbaum, J. E. (2002). The unintended consequences of stigma-free remediation. Sociology of Education, 75(3), 249-268.

Details of proposed student aid and fiscal responsibility act unfold (2009, July). News from NASFAA. Retrieved from http://www.nasfaa.org/publications/2009//n3221 gensummary071609.html

Dey, E. L., \& Astin, A. W. (1993). Statistical alternatives for studying college student retention:A comparative analysis of logit, probit, and linear regression. Research in Higher Education, 34(5), 569-581.

Diaz, D. R. (2002, May/June). Online drop rates revisited. The Technology Source Archives. Retrieved from http://technologysource.org/article/online_drop_ rates_revisited/

Dille, B., \& Mezack, M. (1991). Identifying predictors of high risk among community college telecourse students. American Journal of Distance Education, 5(1), 24-35. doi: $10.1080 / 08923649109562729$.

Doherty, W. (2006). An analysis of multiple factors affecting retention in web-based community college courses. Internet and Higher Education, 9, 245-255.

Dougherty, K. J., \& Reid, M. (2007, April). Fifty state of achieving the dream: State policies to enhance access to and success in community colleges across the United States Community College Research Center. New York, New York. Columbia University.

Driscoll, A. K. (2007, August). Beyond access: How the first semester matters for community college students' aspirations and persistence (Issue Brief No. 07-2). University of California: Policy Analysis for California Education 
Dupin-Bryant, P. A. (2004). Pre-entry variables related to retention in online distance education. The American Journal of Distance Education, 18(4), 199-206.

Durkheim, E. (1951). Suicide: A study in sociology (J. A. Spaulding \& G. Simpson, Trans.). New York: The Free Press.

Easterling, D. N., Patten, J. E., \& Krile, D. J. (1998). Patterns of progress: Student persistence isn't always where you think it is. Retrieved from ERIC database (ED421185)

Eisenberg, E., \& Dowsett, T. (1990). Student drop-out from a distance education project course: A new method of analysis. Distance Education, 11(2), 231-253.

Emerging technologies ready to reshape community colleges (2009, December 9). Bill and Melinda Gates Foundation. Retrieved from http://www.gatesfoundation.org/press-releases/Pages/fundamental-changes-tocommunity-college-education-091203.aspx

Epper. R. M., \& Baker, E. D. (2009). Technology solutions for developmental math an overview of current and emerging practices. Retrieved from http:/www.gatesfoundation.org/learning/documents/technology-soultions-fordevelopmental-math-jan-2009.pdf

Farahani, G. (1993). Non-returning student survey, the Charles County Community College. Retrieved from ERIC database (ED360028)

Feldman, M. J. (1993). Factors associated with one-year retention in a community college. Research in Higher Education, 34(4), 503-512.

Field, A. (2005). Discovering statistics using SPSS (2 ${ }^{\text {nd }}$ ed.). London: SAGE Publications Ltd. 
Fike, D. S., \& Fike, R. (2007). Does faculty employment status impact developmental mathematics outcomes? Journal of Developmental Education, 31(1), 2-11.

Fike, D. S., \& Fike, R. (2008). Predicators of first-year student retention in the community college. Community College Review, 36(2), 68-88. doi:

$10.1177 / 0091552108320222$

Fischbach, R. (1990). Persistence among full-time students at Illinois Central College. Retrieved from ERIC database (ED325190)

Flood, J. (2002). Read all about it: Online learning facing $80 \%$ attrition rates. The Online Journal of Distance Education, 3(2), Retrieved from http://tojde.anadolu.edu.tr/tojde6/articles/jim2.htm

Finnegan, C. F., Morris, L. V., \& Lee, K. (2009). Differences by course discipline on student behavior, persistence, and achievement in online undergraduate general education. Journal of College Student Retention, 10(1), 39-54.

*Fox, R. (1986). Application of a conceptual model of college withdrawal to disadvantaged students. American Educational Research Journal, 23, 415-424.

Frankola, K. (2001). Why online learners drop out. Workforce, 10, 53-63.

Fujita, E., \& Oromaner, M. (1992). The study of attrition at Hudson County Community College. Retrieved from ERIC database (ED351083)

Garrison, D. R. (1987). Researching dropout in distance education. Distance Education, $8(1), 95-101$

Gates, A. G., \& Creamer, D. G. (1984). Two-year college attrition: Do student or institutional characteristics contribute the most? Community/Junior College 
Education, 20(4), 1-4.

Gerlich, R. N., Mills, L. H., \& Sollosy, M. (2009). An evaluation of predictors of achievement of selected outcomes in a self-paced online course. Research in Higher Education Journal, 4, 1-14.

Gleason, B. J. (2004, December). Retention issues in online programs: A review of literature. Paper presented at the Second AIMS International Conference on Management, IIM, Kolkotta, India. Retrieved from http://thinairlabs.com/papers/216.pdf

Goel, M. (2002, June). Educational objectives and retention at two community colleges. Paper presented at the Annual Forum of the Association for Institutional Research, Toronto,Canada.

Gonzalez, J. (2010, April). Lessons learned: Using data to help students pass remedial courses. The Chronicle of Higher Education. Retrieved from http://chronicle.com/article/Lessons-Learned-Using-datato $/ 65055 / ? \mathrm{sid}=\mathrm{cc} \& u t m \_s o u r c e=c c \& u t m \_$medium $=$en

Grimes, S. K. (1997). Underprepared community college students: Characteristics, persistence and academic success. Community College Journal of Research and Practice, 21(1), 47-56.

Grosset, J. (1989). A conceptual framework for describing the causes of student attrition. Retrieved from ERIC database (ED310819)

Grosset, J. M. (1991). Patterns of integration, commitment, and student characteristics and retention among younger and older students. Research in Higher Education, 
32(2), 159-178.

Halpin, R. L. (1990). An application of the Tinto model to the analysis of freshman persistence in a community college. Community College Review, 17(4), 22-32.

Hawley, T. H., \& Harris, T. A. (2005-2006). Student characteristics related to persistence for first-year community college students. Journal of College Student Retention, $7(1-2), 117-142$.

Herzberg, F. (1962). Work and the nature of man. New York, NY: Thomas Y. Crowell Company.

Heverly, M. A. (1999) Predicting retention from students' experiences with college processes. Journal of College Student Retention, 1(1), 3-11.

Hippensteel, D. G., St. John, E. P., \& Starkey, J. B. (1996). Influence of tuition and student aid on within-year persistence by adults in 2-year colleges. Community College Journal of Research and Practice, 20(3), 233-242.

Horn, L. (1998). Stopouts or stayouts? Undergraduates who leave college in their first year (NCES 1999-087). Retrieved from United States Department of Education, Office of Educational Research and Improvement, National Center for Education Statistics website: http://nces.ed.gov/pubsearch/pubsinfo.asp?pubid=1999087

Horn, L., \& Berger, R. (2004). College persistence on the rise? Changes in 5-year degree completion and postsecondary persistence rates between 1994 and 2000 (NCES 2005-156). Retrieved from United States Department of Education, Institute of Educational Sciences, National Center for Education Statistics website: http://nces.edd.gov/pubsearch/pubsinfo.asp?pubid=2005156

Horn, L., \& Peter, K., \& Rooney, K. (2002). Profile of undergraduates in U.S. 
postsecondary institutions: 1999-2000 (NCES 2002-168). Retrieved from United States Department of Education, Office of Educational Research and Improvement, National Center for Education Statistics website: http://nces.ed.gov/pubsearch/pubsinfo.asp?pubid=2002168

Horn, L. J., \& Premo, M. D. (1995). Profiles of undergraduates in U.S. postsecondary education institutions: 1992-1993, with an essay on undergraduates at risk (NCES 96-237). Retrieved from United States Department of Education, Office of Educational Research and Improvement, National Center for Education Statistics website: http://nces.ed.gov/pubsearch/pubsinfo.asp?pubid=2006184

Hoyles, C., Newman, K., \& Noss, R. (2001). Changing patterns of transition from school to university mathematics. International Journal of Mathematics Education in Science Technology, 32(6), 829-845.

Hoyt, J. E. (1999). Remedial education and student attrition. Community College Review, $27(2), 51-73$.

Ignash, J. M. (1999). Who should provide postsecondary remedial/developmental education? New Directions for Community Colleges, 100, 5-20.

Illich, P. A., Hagan, C., \& McCallister, L. (2004). Performance in college-level courses among students concurrently enrolled in remedial courses: Policy implications. Community College Journal of Research and Practice, 28, 435-453. doi: $10.1080 / 10668920490444463$

Inan, F. A., Yukselturk, E., \& Grant, M. M. (2009). Profiling potential dropout students by individual characteristics in an online certificate program. International Journal of Instructional Media, 36(2), 163-176. 
Jacobson, E. (2005). Increasing attendance using email: Effect on developmental math performance. Journal of Developmental Education, 29(1), 18-26.

Jacobson, E. (2006). Computer homework effectiveness in developmental mathematics. Journal of Developmental Education, 29(3), 2-8.

Jaggers, S. S. (2011, March). Online learning: Does it help prepare low-income and underprepared students? (No. 52) Community College Research Center Teachers College, Columbia University, New York, NY. Retrieved from http://ccrc.tc.columbia.edu/Publication.asp?UID=879

Jaggers, S. S., \& Xu, D. (2010, September). Online learning in the Virginia community college system. Community College Research Center Teachers College, Columbia University, New York, NY. Retrieved from http://ccrc.tc.columbia.edu/Publication.asp?UID $=813$

Jaschik, S. (2009, October 9). Remediation worries and successes. Inside Higher Education. Retrieved from http:/www.insidehighered.com/news/2009/10/09/acct Jaschik, S. (2010a, March 30). Replicating Success. Inside Higher Education. Retrieved from http:/www.insidehighered.com/news/2010/03/30/lfi

Jaschik, S. (2010b, April 19). The completion agenda. Inside Higher Ed Retrieved from http://www.insidehighered.com/news/2010/04/19/completion

Jaschik, S. (2011, June 1). Follow the F grades. Inside Higher Ed Retrieved from http://www.insidehighered.com/news/2011/06/01/community_college_examines high_failure_courses

Jenkins, D. \& Boswell, K. (2002). State policies on community college remedial 
education: Findings from a national survey. Retrieved from ERIC database (ED470465)

Johnson, M., \& Kuennen E. (2004). Delaying developmental mathematics: The characteristics and costs. Journal of Developmental Education, 28(2), 24-29.

Joughin, G., Lai, T., \& Cottman, C. (1992, November). Distance learners' approaches to studying: The nature of 'deep' and 'surface' approaches reconsidered. Paper presented at the International Council for Distance Education $16^{\text {th }}$ World Conference, Bangkok, Thailand.

Kangas, J. (1992a). Evergreen Valley Green College: Persistence of new college students from arithmetic, algebra, and int algebra. Retrieved from ERIC database (ED353031)

Kangas, J. (1992b). San Jose City College: Persistence of new college students from arithmetic, algebra, and int algebra through transfer level math, fall 1988-spring 1992. Retrieved from ERIC database (ED353030)

Kangas, J. (1992c). Success and retention rates for gateway U classes. Retrieved from ERIC database (ED349049)

Karp, M. M., Hughes, K. L., \& O'Gara, L. (2008, May). An exploration of Tinto 's integration framework for community college students (CCRC Working Paper no. 12), Community College Research Center Teachers College, Columbia University, New York, NY.

Kember, D. (1981). Some factors affecting attrition and performance in a distance education course at the University of Papua New Guinea. Distance Education, 2(2), 164-188. 
Kember, D. (1989a). A longitudinal-process model of drop-out from distance education. The Journal of Higher Education, 60(3), 278-301.

Kember, D. (1989b). An illustration, with case studies, of a linear process model of dropout from distance education. Distance Education, 10(2), 196-211.

Kember, D. (1990). The use of a model to derive interventions which might reduce dropout from distance education course. Higher Education, 20(1), 11-24.

Kember, D. (1995). Open learning courses for adults: A model of student progress. Englewood Cliffs, NJ: Education Technology Publications, Inc.

Kember, D., \& Harper, G. (1987). Implications for instruction arising from the relationship between approaches to studying and academic outcomes. Instructional Science, 16, 35- 46.

Kember, D., Lai, T., Murphy, D., Siaw, I., \& Yuen, K. S. (1992). Student progress in distance education: Identification of explanatory constructs. British Journal of Educational Psychology, 62(3). 285-298.

Kember, D., Lai, T., Murphy, D., Siaw, I., \& Yuen, K. S. (1994). Student progress in distance education courses: A replication study. Adult Education Quarterly, 45(1). 286-301.

Kember, D., Murphy, D., Siaw, I., \& Yuen, K. S. (1991). Towards a causal model of student progress in distance education: Research in Hong Kong. American Journal of Distance Education, 5(2), 3-15. doi: 10.1080/08923649109526742

Kemp, W. C. (2002). Persistence of adult learners in distance education. The American Journal of Distance Education, 16(2), 65-81. 
Kentucky Community and Technical College System, Office of Research and Policy Analysis. (2008). Factbook 2008-2009. Retrieved from http://www.kctcs.edu/ about_kctcs/ /media/System_Office /About/Factbook\%2009/Factbook\% 2008-09-2.ashx

Kentucky Community and Technical College System Student Assessment and Placement Policy (2009). Retrieved from http://legacy.kctcs.edu/employee/policies /volumeII/4_13\%20approved\%2010-29-09.pdf

Kentucky Developmental Education Task Force, Kentucky Council on Higher Education (2007.). Securing Kentucky's future: A plan for improving college readiness and success. Retrieved from http://cpe.ky.gov/NR/rdonlyres/CBAA5350-E515-42E28D8B-B5E61286135C/0/DevEdTaskForce_FullReport_FINALFORWEB.pdf

Kentucky predicting sharp increase in remedial classes, costs (2009, December). Community College Week, Retrieved fromhttp://www.ccweek.com/news /templates/template.aspx?articleid=1546\&zoneid $=3$

Kerka, S. (1996). Distance learning, the internet and the World Wide Web. (1996) Retrieved from ERIC database (ED395214)

Khalili, A., \& Shashaani, L. (1994). The effectiveness of computer applications: A metaanalysis. Journal of Research on Computing in Education, 27(1)

Kielbaso G., Dirkx, J. M., Min, Y., \& Allen, A. (1998). A study of student retention and attrition in a community college's developmental education program. Retrieved from ERIC database (ED450861)

Killough, A. C. (2009, June 11). Obama administration joins effort to fix remedial education. The Chronicle of Higher Education. Retrieved from 
http://www.chronicle.com

Kim, S. Y. (2002, April). The influences of student and institutional characteristics on two-year college student attrition in Korea. Paper presented at the Annual Meeting of the American Educational Research Association, New Orleans, LA.

King, M. C., \& Crouse, T. T. (1997). Opening the bottleneck: Using computer-mediated learning to increase success and productivity in developmental algebra. Community College Journal, 68(1), 18-22.

Kinser, K., \& Deitchman, J. (2007-2008). Tenacious persisters: Returning adult students in higher education. Journal of College Student Retention, 9(1), 75-94.

Kolajo, E. F. (2004). From developmental education to graduation: A community college experience. Community College Journal of Research and Practice, 28, 365-371. doi: $10.1080 / 10668920490424078$

Kolowich, S. (2010a, March 10). Student clubs, virtually. Inside Higher Education. Retrieved from http://www.insidehighered.com/news/2010/03/10/clubs

Kolowich, S. (2010b, March 29). The human element. Inside Higher Education. Retrieved from http://www.insidehighered.com/news/2010/03/29/lms

Kolowich, S. (2010c, April 5). The specialist. Inside Higher Education. Retrieved from http://www.insidehighered.com/news/2010/04/05/statistics

Kolowich, S. (2011, March 10). Adapting to developmental ed. Inside Higher Education. Retrieved from http://www.insidehighered.com/news/2011/03/10/companies look_to_improve_developmental_and_remedial_education_products_using_adapt ive_learning_technology

Kozeracki, C. A. (2002). Issues in developmental education. Community College Review, 
29(4), 83-100.

Kuh, G. D. (2001). Assessing what really matters to student learning: Inside the national survey of student engagement. Change, 33(3), 10-17, 66.

Lajubutu, O. A., \& Yang, F. (1998, May). Predictive factors for students' success at a mid-sized rural community college. Paper presented at the Annual Forum of the Association for Institutional Research, Minneapolis, MN.

Lau, L. K. (2006) Institutional factors affecting student retention. Research in Higher Education, 124(1), 126-136.

Lesik, S. A. (2007). Do developmental mathematics programs have a casual impact on student retention? An application of discrete-time survival and regressiondiscontinuity analysis. Research in Higher Education, 48(5), 583-608. dio:10.1007/s111620069036-1

Levin, H. M., \& Calcagno, J. C. (2008). Remediation in the community college: An evaluator's perspective. Community College Review, 35(3), 181-207.

Lewin, T. (2008, March 14). Report urges changes in teaching math. New York Times. Retrieved from http://www.nytimes.com/2008/03/14/education/14math.html

Lewis, L., \& Farris, E. (1996). Remedial education at higher education institutions in fall 1995 (NCES 97-584). Retrieved from United States Department of Education, Office of Educational Research and Improvement, National Center for Education Statistics website: http://nces.ed.gov/pubsearch/pubsinfo.asp?pubid=97584

Liu, S., Gomez, J., Khan, B., \& Cherng-Jyh, Y. (2007). Toward a learner-oriented community college online course dropout framework. International Journal on ELearning, 6(4), 519-542. 
Long, P. N., \& Amey, M. J. (1993, November). A study of underprepared students at one community college: Assessing the impact of students and institutional input, environmental, and output variables on student success. Paper presented at the annual meeting of the Association for the Study of Higher Education, Pittsburg, PA.

Maack, S. C. (2002). Whatever happened to students who entered in fall 1995? Persistence at Rio Hondo College. Retrieved from ERIC database (ED466878)

MacDonald, R. B., \& O’Hear M. F. (1996). A critical review of research in developmental education: Part II. Journal of Developmental Education, 19(3), 814.

Mann, R. A., \& Walker, K. J. (1981, October). Attrition, retention, and transfer within the Kentucky system of public higher education. Paper presented at the Joint Conference of the Southern Association for Institutional Research and the North Carolina Association for Institutional Research, Charlotte, NC.

Maricopa Community Colleges Institutional Effectiveness Office and Maricopa Governance (2003). Report on the Maricopa Community College 's governing board's goals and measures. Retrieved from http://www.maricopa. edu/gvbd/goals/2003/appdx1.pdf

Maryland Higher Education Commission (1996). A study of remedial education at Maryland public campuses, Retrieved from ERIC database (ED404971)

Marti, C. N. (2008). Latent postsecondary persistence pathways: Educational pathways in American two-year colleges. Research in Higher Education, 49, 317-336. doi: $10.1007 / \mathrm{s} 11162-007-9083-2$. 
Martinez, M. (2003). High attrition rates in e-learning: Challenges, predictors, and solutions. The E-Learning Developers' Journal, 1-7.

Mason, H. P. (1998). A persistence model for African American male urban community college students. Community College Journal of Research and Practice, 22(8), $751-760$

McCabe, R. H. (2003). Yes we can! A community college guide for developing America's underprepared. Phoenix, AZ: League for Innovation in the Community College.

McGrath, D., \& Spear, M. B. (1987). The politics of remediation. New Directions for Community Colleges, 57, 11-21.

Mendoza, P., Mendez, J. P., \& Malcolm, Z. (2009). Financial aid and persistence in community colleges: Assessing the effectiveness of federal and state financial aid programs in Oklahoma. Community College Review, 37(2), 112-135.

Merisotis, J. P., \& Phipps, R. A. (2000). Remedial education in colleges and universities: What's really going on? The Review of Higher Education, 24(1), 67-85.

Metamorphosis: Kentucky Community \& Technical College System (2008). Louisville, KY: Welch Printing.

Metz, G. W. (2002, October). Challenges and changes to Tinto 's persistence theory. Paper presented at the Annual Meeting of the Mid-Western Educational Research Association, Columbus, $\mathrm{OH}$.

Metzner, B. S., \& Bean, J. P. (1987). The estimation of a conceptual model of nontraditional undergraduate student attrition. Research in Higher Education, $27(1), 15-38$.

Meyer, K. A., Bruwelheide, J., \& Poulin, R. (2009). Why they stayed: Near-perfect 
retention in an online certification program in library media. Journal of Asynchronous Learning Networks, 13(3), 129-145.

Mohammadi, J. (1994). Exploring retention and attrition in a two-year public community college. Retrieved from ERIC database (ED382257)

Moltz, D. (2009a, May). Competing completing initiatives. Inside Higher Ed, Retrieved from http://www.insidehighered.com/news/2009/05/05/completion

Moltz, D. (2009b, December). Boosting math standards. Inside Higher Ed, Retrieved from http://www.insidehighered.com/news/2009/12/21/math

Moltz, D. (2010, April). Retooling remediation. Inside Higher Ed, Retrieved from http://www.insidehighered.com/news/2010/04/14/developmental

Moltz, D. (2011, April). Completion agenda for baby boomers, Inside Higher Ed, Retrieved from http://www.insidehighered.com/news/2011/04/27/ community_colleges_encouraging_baby_boo boomers_to_complete degrees_and_certificates

Moody, J. (2004). Distance education why are the attrition rates so high? The Quarterly Review of Distance Education, 5(3), 205-201.

Moore, C., Shulock, N., \& Offenstein, J. (2009). Steps to success: Analyzing milestone achievement to improve community college student outcomes. Retrieved from Institute for Higher Education Leadership \& Policy website http://www.csus.edu/ihelp/PDFs/R_CCC_Milestones.pdf

Moore, K., Bartkovich, J., Fetzner, M., \& Ison, S. (2003). Success in cyberspace: Student retention in online courses. Journal of Applied Research in the Community College, 10(2), 107-118. 
Moore, N. (1995). Persistence and attrition at San Juan College. Retrieved from ERIC database (ED330159)

Morgan, C. K., \& Tam, M. (1999). Unraveling the complexities of distance education student attrition. Distance Education, 20(1), 96-108.

Mori, R. (2002). Entrance examinations and remedial education in Japanese higher education.Higher Education, 43, 27-42.

Morris, L. V., Wu, S., \& Finnegan, C. L. (2005). Predicting retention in online general education courses. American Journal of Distance Education, 19(1), 23-36. doi: 10.1207/s15389286ajde1901_3

Munro, B. H. (1981). Dropout from higher education: Path analysis of a national sample. American Educational Research Journal, 18(2), 133-141.

Murtaugh, P. A., Burns, L. D, \& Schuster, J. (1999). Predicting the retention of university students. Research in Higher Education, 40, 355-371.

Muse Jr., H. E. (2003). The web-based community college study: An examination of factors that lead to success and risk. Internet and Higher Education, 6, 241-261.

Mutter, P. (1992). Tinto's theory of departure and community college persistence. Journal of College Student Development, 33(4), 310-317.

* Napoli, A. (1995). An examination of the relative importance of academic and social integration among community college students. Unpublished manuscript, Suffolk Community College, Long Island, New York.

Napoli, A. R., \& Wortman, P. M. (1996). A meta-analysis of the impact of academic and social integration of persistence of community college students. Journal of Applied Research in the Community College, 4(1), 5-21. 
Napoli, A. R., \& Wortman, P. M. (1998). Psychosocial factors related to retention and early departure of two-year community college students. Research in Higher Education 39(4), 419-455.

Nippert, K. (2000-20001). Influences on the educational degree attainment of two-year college students. Journal of College Student Retention, 2(1), 29-40.

Nishimoto, J. K., \& Hagedorn, L. S. (2003, April). Retention, persistence, and course taking patterns of Asian Pacific Americans attending urban community colleges. Paper presented at the Annual Meeting of the American Educational Research Association, Chicago, IL.

Nora, A. (1987). Determinants of retention among Chicano college students: A structural model. Research in Higher Education. 26(1), 31-59.

Nora, A., Attinasi Jr., L. C. \& Matonak, A. (1990). Testing qualitative indicators of precollege factors in Tinto's attrition model: A community college student population. The Review of Higher Education, 13(3), 337-356.

O'Hear, M. F., \& MacDonald, R. B. (1995). A critical review of research in developmental education: Part I. Journal of Developmental Education, 19(2), 2-6. Pantages, T. J. \& Creedon, C. F. (1978). Studies of college attrition: 1950-1975. Review of Educational Research, 48(1), 49-101.

Pardee, R. L. (1990). Motivational theories of Maslow, Herzberg, McGregor \& । McClelland: A literature review of selected theories dealing with job satisfaction and motivation, Retrieved from ERIC database (ED316767)

Park, C. L., Boman, J., Care, W. D., Edwards, M., \& Perry, B. (2008-2009). Persistence 
and attrition: What is being measured? Journal of College Students Retention, $10(2), 223-234$.

Park, J. (2007). Factors related to learner dropout in online learning. Retrieved from ERIC database (ED504556)

Park, J., \& Choi, H. J. (2009). Factors influencing adult learners' decisions to drop out or persist in online learning. Educational Technology \& Society, 12(4), 207-217.

Parker, A. (1995). Distance education attrition. International Journal of Educational Telecommunications, $1(4), 389-406$.

Parker, A. (1999). A study of variables that predict dropout from distance education, International Journal of Educational Technology, 1(2). Retrieved from http://www.ed.uiuc.edu/ijet/v1n2/parker/index.html.

Parker, A. (2003). Identifying predictors of academic persistence in distance education. United States Distance Learning Association Journal, 17(1)

Parsad, B., \& Lewis, L. (2003). Remedial education at degree-granting postsecondary institutions in fall 2000 (NCES 2004-010). Retrieved from United States Department of Education, Institute of Educational Sciences, National Center for Education Statistics website: http://nces.ed.gov/pubsearch/pubsinfo. asp?pubid $=2004010$

Parsad, B., \& Lewis, L. (2008). Distance education at degree-granting postsecondary institutions: 2006-20007 (NCES 2009-044). Retrieved from United States Department of Education, Institute of Educational Sciences, National Center for Education Statistics website: http://nces.ed.gov/pubs2009/2009044.pdf

Pascarella, E. T. (1985). The influence of on-campus living versus commuting to college 
on intellectual and interpersonal self-concept. Journal of College Student Personnel, 26, 292-299.

Pascarella, E. T., \& Chapman, D. W. (1983a). A multiinstitutional, path analytic validation of Tinto's model of college withdrawal. America Educational Research Association, 20(1), 87-102.

Pascarella, E. T., \& Chapman, D. W. (1983b). Validation of a theoretical model of college withdrawal: Interaction effects in a multi-institutional sample. Research in Higher Education Journal, 19(1), 25-48.

*Pascarella, E. T., Duby, P. B., \& Iverson, B. (1983). A test and re-conceptualization of a theoretical model of college withdrawal in a commuter institution setting. Sociology of Education, 56, 88-100.

Pascarella, E. T., Duby, P. B., Miller, V. A., \& Rasher, S. P. (1981). Preenrollment variables and academic performance as predictors of freshman year persistence, early withdrawal, and stopout behavior in an urban, nonresidential university. Research in Higher Education Journal, 15, 329-349.

*Pascarella, E. T., Smart, J. C., \& Ethington, C.A. (1986, February). Long-term persistence of two-year college students. Paper presented at the annual meeting of the Association for the Study of Higher Education, San Antonio, TX.

Pascarella, E. T., \& Terenzini, P. T. (1978). Student-faculty informal relationships and freshman year educational outcomes. Journal of Educational Research, 71, 183189.

Pascarella, E. T., \& Terenzini, P. T. (1979). Student-faculty informal contact and college 
persistence: A further investigation. Journal of Educational Research, 72, 214218.

Pascarella, E. T., \& Terenzini, P. T. (1980). Predicting freshman persistence and voluntary dropout decisions from a theoretical model. The Journal of Higher Education, 5l(1), 60- 75.

Pascarella, E. T., \& Terenzini, P. T. (1991). How College Affects Students Volume 1. San Francisco, CA: Jossey-Bass.

Pascarella, E. T., \& Terenzini, P. T. (2005). How College Affects Students Volume 2. San Francisco, CA: Jossey-Bass.

Patterson, B. \& McFadden, C. (2009). Attrition in online and campus degree programs. Online Journal of Distance Learning Administration, 12(2). Retrieved from http://www.westga.ed/ distance/ojdla/summer122/patterson112.html

Pedhazur, E. J. (1997). Multiple regression in behavioral research ( $3^{\text {rd }}$ ed.) Toronto, Canada: Nelson Thomson Learning.

Peng, C. Y. J., Lee, K. L., \& Ingersoll, G. M. (2002). An introduction to logistic regression analysis and reporting. The Journal of Education Research, 96(1), 314.

Peng, C. Y. J., So, T. S. H., Stage, F. K., \& St. John, E. P. (2002). The use and interpretation of logistic regression in higher education journals: 1988-1999. Research in Higher Education, 43(3), 259-293.

Perry, M., Bahr, P.R., Rosin, M., \& Woodward, K.M. (2010). Course-taking patterns, 
policies, a and practices in developmental education in the California Colleges. Retrieved from http://www.edsource.org/assets/files/ccstudy/FULL-CCDevelopmentalCoursetaking.pdf

Peschke, J. (2009). Moving ahead to the future be going back to the past: Mathematics education online. Journal of Computers oin Mathematics and Science Teaching, 28(2), 123-133.

Pezzullo, D. (1978). About student attrition/retention in the community college: A brief highlighting literature since 1973 on community college student attrition/retention. Retrieved from ERIC database (ED160179)

Phillip, A. (2011, April) Community colleges offer online courses to address specific needs of remedial students. Retrieved from http://diverseeducation.com /article/15015

Phipps, R. (1998). College remediation: what it is, what it costs what's at stake. Retrieved from ERIC database (ED429525)

Phipps, R., \& Merisotis, J. (1999, April). What's the difference?: A review of contemporary research on the effectiveness of distance learning in higher education. Retrieved from http://www.ihep.org/assets/files/publications/sz/WhatDifference.pdf

Powell, R., Conway, C., \& Ross, L. (1990). Effects of student predisposing characteristics on student success. The Journal of Distance Education, 5(1), 5-19.

Press, S. J. \& Wilson, S. (1978). Choosing between logistic regression and discriminate analysis. Journal of the American Statistical Association, 73(364), 699-705. 
Price, L. A. (1993). Characteristics of early student dropouts at Allegany Community College and recommendations for early intervention. Retrieved from ERIC database (ED361051)

Provasnik, S., \& Planty, M. (2008). Community colleges special supplement to the condition of education 2008 (NCES 2008-033). Retrieved from United States Department of Education, Institute of Educational Sciences, National Center for Education Statistics website: http://nces.ed.gov/pubsearch/pubsinfo.asp?pubiddepartments=2008033

Ramsden, P., \& Entwistle, N. J. (1981). Effects of academic departments on students' approaches to studying. British Journal of Educational Psychology, 51, 368-383.

Richards, C. N., \& Ridley, D. R. (1997). Factors affecting college students' persistence in on-line computer-managed instruction. College Student Journal, 31(4), 490-495.

Richardson, J. T. E. (2000). The Distance Education Student Progress Inventory. In Researching Student Learning: Approaches to Studying in Campus-Based and Distance Education (pp. 124-136). Retrieved from http://labspace.open .ac.uk/file.php/3374/H804_1_chap8.pdf

Rienties, B., Templeaar, D., Dijkstra, J., Rehm, M., \& Gijselaers, W. (2008). Longitudinal study of online remedial education effects. In N. P. Barky, M. Clements, J. Ravn, K. Smith (Eds.), The Power of Technology for Learning (pp. 43-59). The Netherlands.

Rienties, B., Templeaar, D., Waterval, D., Rehm, M., \& Gijselaers, W. (2006). Remedial online teaching a summer course. Industry \& Higher Education, 20(5), 327-336. Roberts, D. (1984). Ways and means of reducing early student drop-out rates. Distance 
Education, 5(1), 50-71.

Roberts, D., Boyton, B., Buete, S., \& Dawson, D. (1991). Applying Kember's linearprocess model to distance education at Charles Stuart University-Riverina, Distance Education, 12(1), 54-84.

Romano, R. M. (1995). First-year retention and attrition at a community college. Journal of Applied Research in the Community College, 2(2), 169-177.

Romano, R. M., \& Millard, T. (2006). If community college students are do poor, why do only $16.9 \%$ of them receive pell grants? Community College Journal of Research and Practice, 30, 321-337. doi: 10.1080/10668920500479226

Ross, L. R., \& Powell, R. (1990). Relationships between gender and success in distance education courses: A preliminary investigation. Research in Distance Education, 2(2), 10-11.

Roueche, J. E., \& Roueche, S. D. (1999). High stakes, high performance: Making remedial education work. Washington, DC: Community College Press.

Rovai, A. P. (2003). In search of higher persistence rates in distance education online programs.Internet and Higher Education, 6, 1-16.

Royer, M. (2006, November). Student success and retention in online courses. Retrieved

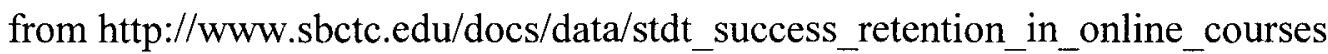
bcc.pd

Russell, M., Kleiman, G., Carey, R., \& Douglas, J. (2009). Comparing self-paced and cohort-based online courses for teachers. Journal of Research on Technology in Education, 41(4), 443-466.

Scales, K. (1984). A study of the relationship between telephone contact and persistence. 
Distance Education, 5(2), 268-276.

Schoenecker, C., Bollman, L., \& Evans, J. (1996, May). Developmental education outcomes at Minnesota community colleges. Paper presented at the Annual Forum of the Association for Institutional Research, Albuquerque, NM.

Shavelson, R. J. (1996). Statistical reasoning for the behavioral sciences $\left(3^{\text {rd }} \mathrm{ed}\right.$.). Needham Heights, MA: Allyn and Bacon.

Shaw, K. M. (1997). Remedial education as ideological battleground: Emerging remedial education policies in the community college. Educational Evaluation and Public Analysis, 19(3), 284-296.

Shin, N., \& Kim, J. (1999). An exploration of learner progress and drop-out in Korea National Open University. Distance Education, 20(1), 81-95.

Shults, C. (2000). Remedial education: Practices and policies in community colleges. Retrieved from ERIC database (ED448811)

Simmons, D. L. (1995). Retraining dislocated workers in the community college: Identifying factors for persistence. Community College Review, 23(2), 47-59.

Singer, J. D., \& Willett, J. B. (2003). Applied longitudinal data analysis: Modeling change and event occurrence. New York: Oxford University Press.

Smith, D., O’Hear, M., Baden, W., Hayden, D., Gorham, D., Ahuja, Y., \& Jacobsen, M. (1996). Factors influencing success in developmental math: An observational study. Research \& Teaching in Developmental Education, 13(1), 33-43.

Solving America's math problem: Monterey Institute for Technology and Education 
receives $\$ 5$ million for developmental math project (2009, October). Retrieved from http://www.montereyinstitute.org/pdf/Developmental_Math_Solutions _Gates_Grant.pdf

Sorey, K. C. \& Duggan, M. H. (2008). Differential predictors or persistence between community college adult and traditional-aged students. Community College Journal of Research and Practice, 32, 75-100. doi: 10.1080/10668922070138096

7

Spady, W. G. (1970). Dropouts from higher education: An interdisciplinary review and synthesis. Interchange, 1, 64-85.

Spady, W. G. (1971). Dropouts from higher education: Toward an empirical model. Interchange, 2(3), 28-62.

Spence, D. J. (2007). Traditional and online student reactions to the video tutor component of MyMathLab. Paper presented at International Conference on Technology and Collegiate Mathematics. Retrieved from http://archives.math. utk.edu/ICTCM/VOL19/LS12/paper.pdf

Spence, D. J., \& Usher, E. L. (2007). Engagement with mathematics courseware in traditional and online remedial learning environments: Relationship to selfefficacy and achievement. Journal of Educational Computing Research, 37(3), 267-288.

St. John, E. P., \& Starkey, J. B. (1994). The influence of costs on persistence by traditional college-age students in community college. Community College Journal of Research and Practice, 18(2), 201-213.

St. John, E. P., Hu, S., \& Weber, J. (2001). State policy and the affordability of public 
higher education: The influence of state grants on persistence in Indiana. Research in Higher Education, 42(4), 401-427.

St. John, E. P., Oescher, J., \& Andrieu, S. (1992). The influence of prices on within-year persistence by traditional college-age students in four-year colleges. The Journal of Student Financial Aid, 22(1), 27-38.

Stage, F. K. (1989). Motivation, academic and social integration, and the early dropout. American Educational Research Journal, 26(3), 385-402.

Stahl, V. V.\& Pavel., D. M. (1992). Assessing the Bean and Metzner model with community college student data. Retrieved from ERIC database (ED344639)

Stevens, J. (2002). Applied multivariate statistics for the social sciences $\left(4^{\text {th }} \mathrm{ed}\right.$.). Mahwah, NJ:Lawrence Erlbaum.

Stoecker, J., Pascarella, E. T., \& Wolfle, L. M. (1988). Persistence in higher education: A 9-year test of a theoretical model. Journal of College Student Development, 29(3), 196-209.

Strauss, L. C., \& Volkwein, J. F. (2004). Predictors of student commitment at two-year and four-year institutions. Journal of Higher Education, 75(2), 203-227.

Summers, M. D. (2003). Attrition research at community colleges. Community College Review, 30(4), 64-84. doi: 10.1177/009155210303000404

Swager, S., Campbell, J. W., \& Orlowski, M. A. (1995, May). An analysis of student motivations for withdrawal in a community college. Paper presented at the Annual Forum of the Association for Institutional Research. Boston, MA.

Sweet, R. (1986). Student dropout in distance education: An application of Tinto's model. Distance Education, 7(2), 201-231. 
Taplin, M., \& Jegede, O. (2001). Gender differences in factors influencing achievements of distance education students. Open Learning, 16(2), 133-154. doi:10.1080 /02680510120050307

Taylor, J. C., et al. (1986). Student persistence in distance education: A cross-cultural, multi-institutional perspective. Distance Education, 7, 68-91.

Terenzini, P. T., Lorang, W. G., \& Pascarella, E. T. (1981). Predicting freshman persistence and voluntary dropout decisions: A replication. Research in Higher Education, 15(2), 109-127.

Terenzini, P. T., \& Pascarella, E. T. (1977). Voluntary freshman attrition and patters of social and academic integration in a university: A test of a conceptual model. Research in Higher Education, 6, 25-43.

Terenzini, P. T., \& Pascarella, E. T. (1978). The relation of students' precollege characteristics and freshman year experience to voluntary attrition. Research in Higher Education, 9, 347-366.

Tempelaar, D., Rienties, B., Rehm, M., Dijkstra, J., Arts, M., \& Blok, G. (2006). An online summer course for prospective international students to remediate deficiencies in math prior knowledge: the case of ALEKS. Retrieved from http://webalt.math.helsinki.fi/webalt2006/content/e31/e157/e161 /6_zDR2j2uQcB.pdf

Thompson, E. (1999). Can the distance education student progress (DESP) inventory be used as a tool to predict attrition in distance education? Higher Education Research \& Development, 18(1), 77-84.

Thompson, G. (1984). The cognitive style of field-dependence as an explanatory 
construct in distance education drop-out. Distance Education, 5, 286-293.

Thompson, M. M. (1998). Distance learners in higher education. In C. C. Gibson (Ed.), Distance Learners in Higher Education: Institutional Responses for Quality Outcomes (pp.9-24). Atwood Publishing: Madison, WI.

Tidewater Community College, Office of Institutional Effectiveness. (2001). Distance Learning Report. Retrieved from http://www.tcc.edu/welcome/collegeadmin /OIE/reports/DLrpt01.pdf

Tierney, W. G. (1992). An anthropological analysis of student participation in college. The Journal of Higher Education, 63(6), 603-618.

Tinto, V. (1975). Dropout from higher education: A theoretical synthesis of recent research. Review of Educational Research, 45(1), 89-125.

Tinto, V. (1982). Limits of theory and practice in student attrition. Journal of Higher Education, 53(6), 687-700.

Tinto, V. (1988). Stages of student departure: Reflections on the longitudinal character of student leaving. The Journal of Higher Education, 59(4), 438-455.

Tinto, V. (1997). Colleges as communities: Exploring the educational character of student persistence. The Journal of Higher Education, 68(6), 599-623.

Tinto, V. (1998). Colleges as communities: Taking research on student persistence seriously. The Review of Higher Education, 12(2), 167-177.

Tinto, V. \& Cullen, J. (1973). Dropout in higher education: A review and theoretical synthesis of recent research. Retrieved from ERIC database (ED078802)

Townsend, B. K., Donaldson, J., \& Wilson, T. (2009). Marginal or monumental? 
Visibility of community colleges selected in higher education journals. Community College Journal of Research and Practice, 33(9), 708-720.

Townsend, B. K., \& Wilson, K. B. (2006). "A hand hold for a little bit”: Factors facilitating the sense of community college transfer students. Journal of College Student Development, 47(4), 439-456.

Townsend, B. K., \& Wilson, K. B. (2008-2009). The academic and social integration of persisting community college transfer students. Journal of College Student Retention, 10(4), 405-423.

Tyler-Smith, K. (2006). Early attrition among first time eLearners: A review of factors that contribute to drop-out, withdrawal and non-completion rates of adult learners undertaking eLearning programmes. MERLOT Journal of Online Learning and Teaching, 2(2), 73-85.

Umoh, U. J., Eddy, J., \& Spaulding, D. J. (1994). Factors related to student retention in community college developmental education mathematics. Community College Review,22(2), 37-47. doi: 10.1177/009155219402200205

Valasek, T. (2001). Student persistence in web-based courses: Identifying a profile for success. Retrieved from ERIC database (ED466276)

Virginia Community Colleges Office of Institutional Research and Effectiveness (2008, August).Student Success Snapshot, 2, 1-24.

Voorhees, R. A. (1987). Toward building models of community college persistence: A logit analysis. Research in Higher Education, 26(2), 115-129.

Waits, T., \& Lewis, L. (2003). Distance education at degree-granting postsecondary 
institutions: 2000-20001 (NCES 2003-017). Retrieved from United States Department of Education, Institute of Educational Sciences, National Center for Education Statistics website: http://nces.ed.gov/pubs2003/2003017.pdf

Walker, J. (1995). [Review of the book Open learning courses for adults: A model of student progress, by D. Kember ]. Distance Education, 16(1), 174-176.

Washington State Board for Community and Technical Colleges (2006). Role of precollege (developmental and remedial) education for recent high school graduates attending Washington community and technical colleges. (report no. 06-5) Retrieved from http://www.sbctc.edu/docs/data/research_reports/resh _06_5_systemsumm.pdf

Washington State Board for Community and Technical Colleges (2007). Role of precollege (developmental and remedial) education for recent high school graduates attendingWashington community and technical colleges. (report no. 07-2) Retrieved from http://www.sbctc.edu/College/education/resh_rpt_07_2_ systemsummary_precollege.pdf

Washington State Board for Community and Technical Colleges (2009). Role of precollege (developmental and remedial) education for recent high school graduates attending Washington community and technical colleges. (report no. 09-3) Retrieved from http://www.sbctc.edu/docs/data/research_reports/resh 093_role_of_pre-college_education.pdf

Waycaster, P. (2001) Factors impacting success in community college developmental mathematics courses and subsequent courses. Community College Journal of 
Research and Practice, 25, 403-16.

Webb, M. (1989). A theoretical model of community college student degree persistence. Community College Review, 16(4), 42-49.

Webb, M. W. (1988). Freshman year retention at three campuses of a large urban community college district: 1983-1986. Community and Junior College Quarterly of Research and Practice, 12(3), 213-242.

Wild, L., \& Ebbers, L. (2002). Rethinking student retention in community college. Community College Journal of Research and Practice, 26, 503-519. doi: $10.1080 / 02776770290041864$

Willging, P. A., \& Johnson, S. D. (2009). Factors that influence students' decision to dropout of online courses. Journal of Asynchronous Learning Networks, 13(3), $115-127$

Windham, P. (1995, August). The importance of work and other factors to attrition: $A$ comparison of significancy and odds ratios for different outcomes. Paper presented at the Annual Conference of the Southeastern Association for Community College Research, Charlotte, NC.

Williamson, D. R., \& Creamer, D. G. (1988). Student attrition in 2- and 4-year colleges: Application of a theoretical model. Journal of College Student Development, $29(3), 210-217$

Whittington, L. A. (1995). Factors impacting on the success of distance education students of the University of the West Indies: A review of the literature. Retrieved from ERIC database (ED453740)

Woodley, A., Lange, P. D, \& Tanewski, G. (2001). Student progress in distance 
education: Kember's model re-visited. The Journal of Open and Distance Learning, 16(2), 113-131. doi: 10.1080/02680510123105

Woodley, A. \& Parlett, M. (1983). Student drop-out. Teaching at a Distance, 24, 2-23.

Wolfe, J. S. (1993). Institutional integration, academic success and persistence of firstyear commuter and resident students. Journal of College Student Development, $34,321-326$.

Wolf-Wendel, L., Ward, K., \& Kinzie, J. (2009). A tangled web of terms: The overlap and unique contribution of involvement, engagement, and integration to understanding college student success. Journal of College Student Development, $50(4), 407-428$.

Xenos, M., Pierrakeas, P., \& Pintelas, P. (2002). A survey on student dropout rates and dropout causes concerning the students in the course of informatics of the Hellenic Open University, Computers \& Education, 39, 361-377.

Yorke, M. (2004). Retention, persistence, and success in on-campus higher education, and their enhancement in open and distance learning. Open Learning, 19(1), 1932.

Young, K. (2002). Retaining underprepared students enrolled in remedial courses at the community college. Retrieved from ERIC database (ED467850)

Yukselturk, E., \& Bulut, S. (2007). Predictors for student success in an online course. Educational Technology \& Society, 10(2), 71-83.

Zavarella C. A., \& Ignash, J. M. (2009). Instructional delivery in developmental mathematics: Impact on retention. Journal of Developmental Education, 32(3), 2- 
13.

Zhai, L., \& Monzon, R. (2001, November). Community college student retention: Student characteristics and withdrawal reasons. Paper presented at the Annual Meeting of California Association for Institutional Research. Sacramento, CA.

Zhao, J. C. (1999, June). Factors affecting academic outcomes of underprepared community college students. Paper presented at the Association for Institutional Research Annual Forum, Seattle, WA. 


\section{APPENDIX A}

Undergraduate Distance Classes

\begin{tabular}{|c|c|c|c|c|c|c|c|c|}
\hline Author(s) & Year & $\mathbf{N}$ & Collection & Method(s) & Context(s) & Increased & No Affect & Decreased \\
\hline $\begin{array}{l}\text { Richard \& } \\
\text { Riley }\end{array}$ & 1997 & 69 & Survey & Chi-Squared & $\begin{array}{l}1 \text { University } \\
\text { (VA) }\end{array}$ & $\begin{array}{l}\text { Degree } \\
\text { Objective }\end{array}$ & & \\
\hline $\begin{array}{l}\text { Dupin- } \\
\text { Bryant }\end{array}$ & 2004 & 464 & Survey & $\begin{array}{l}\text { Discriminant } \\
\text { Analysis }\end{array}$ & $\begin{array}{l}1 \text { University } \\
\text { (UT) }\end{array}$ & $\begin{array}{l}\text { High GPA, } \\
\text { Previous Online } \\
\text { Classes }\end{array}$ & & \\
\hline $\begin{array}{l}\text { Dille \& } \\
\text { Mezack }\end{array}$ & 1991 & 151 & 3 Surveys & $\begin{array}{l}\text { ANOVA, Chi- } \\
\text { Squared, } \\
\text { Multiple } \\
\text { Regression }\end{array}$ & $\begin{array}{l}\text { 1 Community } \\
\text { College } \\
\text { (Southwest) }\end{array}$ & $\begin{array}{l}\text { High GPA, } \\
\text { Older, Married }\end{array}$ & $\begin{array}{l}\text { Sex, Number } \\
\text { of Children, } \\
\text { Enrollment } \\
\text { Status }\end{array}$ & \\
\hline $\begin{array}{l}\text { Morris, Wu, } \\
\text { \& Finnegan }\end{array}$ & 2005 & 211 & Survey & $\begin{array}{l}\text { Predictive } \\
\text { Discriminant } \\
\text { Analysis }\end{array}$ & $\begin{array}{l}6 \text { Universities } \\
\text { (GA) }\end{array}$ & $\begin{array}{l}\text { Math Ability, } \\
\text { Financial Aid }\end{array}$ & $\begin{array}{l}\text { Age, Sex, } \\
\text { Enrollment } \\
\text { Status, GPA } \\
\end{array}$ & \\
\hline Park \& Choi & 2009 & 147 & Survey & $\begin{array}{l}\text { Chi-squared } \\
\text { MANOVA, } \\
\text { Logistic } \\
\text { Regression } \\
\text { Analysis } \\
\end{array}$ & $\begin{array}{l}1 \text { University } \\
\text { (Midwest) }\end{array}$ & & Age, Sex & \\
\hline $\begin{array}{l}\text { Inan, } \\
\text { Yukselturk, } \\
\text { \& Grant }\end{array}$ & 2009 & 146 & Survey & Chi-squared & $\begin{array}{l}\text { 1 University } \\
\text { (Turkey) }\end{array}$ & & $\begin{array}{l}\text { Age, Sex, } \\
\text { Employment, } \\
\text { Previous } \\
\text { Online Course }\end{array}$ & \\
\hline Yukselturk \& & 2007 & 80 & 4 Questionnaires & Correlation & 1 University & & Age, Sex & \\
\hline
\end{tabular}




\begin{tabular}{|c|c|c|c|c|c|c|c|c|}
\hline Bulut & & & $\begin{array}{l}\text { and Semi- } \\
\text { structured } \\
\text { Interviews }\end{array}$ & $\begin{array}{l}\text { and Regression } \\
\text { Tests }\end{array}$ & (Turkey) & & & \\
\hline Parker & 1999 & 94 & $\begin{array}{l}\text { Student } \\
\text { Information } \\
\text { Sheet, Locus of } \\
\text { Control }\end{array}$ & $\begin{array}{l}\text { Correlation, } \\
\text { Discriminant } \\
\text { Analysis }\end{array}$ & $\begin{array}{l}3 \text { Community } \\
\text { Colleges (AZ) }\end{array}$ & & $\begin{array}{l}\text { Sex, Age, } \\
\text { Number of } \\
\text { Distance } \\
\text { Courses } \\
\text { Completed, } \\
\text { Employed }\end{array}$ & \\
\hline $\begin{array}{l}\text { Gerlich, } \\
\text { Mills, \& } \\
\text { Sollosy }\end{array}$ & 2009 & 40 & $\begin{array}{l}\text { University } \\
\text { Database }\end{array}$ & $\begin{array}{l}\text { Multiple } \\
\text { Regression, } \\
\text { Regression } \\
\text { Analysis }\end{array}$ & $\begin{array}{l}\text { 1 University } \\
\text { (Southwest) }\end{array}$ & High GPA & Age, Sex & \\
\hline $\begin{array}{l}\text { Xenos, } \\
\text { Pierrakeas, \& } \\
\text { Pintelas }\end{array}$ & 2002 & 1230 & $\begin{array}{l}\text { Student Registry, } \\
\text { Tutor's Records, } \\
\text { Questionnaire- } \\
\text { based Survey, } \\
\text { Telephone } \\
\text { Interviews }\end{array}$ & $\begin{array}{l}\text { Multivariate } \\
\text { Methods, } \\
\text { Correlation } \\
\text { Analysis }\end{array}$ & $\begin{array}{l}\text { 1 University } \\
\text { (Greece) }\end{array}$ & Female & $\begin{array}{l}\text { Marital Status, } \\
\text { Age }\end{array}$ & \\
\hline $\begin{array}{l}\text { Cheung \& } \\
\text { Kan }\end{array}$ & 2002 & 168 & $\begin{array}{l}\text { University } \\
\text { Records }\end{array}$ & $\begin{array}{l}\text { Two-way } \\
\text { Cross } \\
\text { Tabulations, } \\
\text { Chi-squared } \\
\text { Testing }\end{array}$ & $\begin{array}{l}1 \text { University } \\
\text { (Hong Kong) }\end{array}$ & Female & $\begin{array}{l}\text { Age, Marital } \\
\text { Status, } \\
\text { Enrollment } \\
\text { Status }\end{array}$ & \\
\hline $\begin{array}{l}\text { Aragon \& } \\
\text { Johnson }\end{array}$ & 2008 & 305 & $\begin{array}{l}\text { Survey, College } \\
\text { Management } \\
\text { Information } \\
\text { System }\end{array}$ & $\begin{array}{l}\text { Chi-Squared, T } \\
\text { Test, Content } \\
\text { Analysis }\end{array}$ & $\begin{array}{l}1 \text { Community } \\
\text { College } \\
\text { (Midwest) }\end{array}$ & Female, GPA & $\begin{array}{l}\text { Age, Financial } \\
\text { Aid Eligibility, } \\
\text { Enrollment } \\
\text { Status } \\
\end{array}$ & \\
\hline
\end{tabular}




\begin{tabular}{|c|c|c|c|c|c|c|c|c|}
\hline $\begin{array}{l}\text { Tidewater } \\
\text { Community } \\
\text { College }\end{array}$ & 2001 & 3075 & $\begin{array}{l}3 \text { Surveys, } \\
\text { TCC's Student } \\
\text { Information } \\
\text { System }\end{array}$ & & $\begin{array}{l}1 \text { Community } \\
\text { College (VA) }\end{array}$ & High GPA & $\begin{array}{l}\text { Number of } \\
\text { Credit Hours } \\
\text { Accumulated }\end{array}$ & \\
\hline Kemp & 2002 & 121 & $\begin{array}{l}2 \text { Surveys, } \\
\text { Student Records }\end{array}$ & $\begin{array}{l}\text { Stepwise } \\
\text { Discriminant } \\
\text { Analysis, } \\
\text { ANOVA }\end{array}$ & $\begin{array}{l}1 \text { University } \\
\text { (Canada) } \\
\text { (Ages 30-45) }\end{array}$ & & $\begin{array}{l}\text { Sex, Taken or } \\
\text { Completed } \\
\text { Previous } \\
\text { Distance } \\
\text { Education } \\
\text { Course, } \\
\end{array}$ & $\begin{array}{l}\text { High Work } \\
\text { Commitment }\end{array}$ \\
\hline Muse, Jr. & 2003 & 1028 & $\begin{array}{l}\text { Background } \\
\text { information, } \\
\text { Distributed } \\
\text { Learning Survey, } \\
\text { Online } \\
\text { Readiness } \\
\text { Instrument, } \\
\text { Questionnaire of } \\
\text { Semi-structured } \\
\text { Retrospective } \\
\text { Questions }\end{array}$ & $\begin{array}{l}\text { Factor } \\
\text { Analysis, } \\
\text { Discriminant } \\
\text { Function } \\
\text { Analysis }\end{array}$ & $\begin{array}{l}1 \text { Community } \\
\text { College (MD) }\end{array}$ & $\begin{array}{l}\text { High GPA, } \\
\text { Older, Worked } \\
\text { More Hours }\end{array}$ & & \\
\hline Valasek & 2001 & 59 & $\begin{array}{l}\text { Online Study } \\
\text { Survey, Student } \\
\text { Records }\end{array}$ & $\begin{array}{l}\text { Chi-squared } \\
\text { Analysis }\end{array}$ & $\begin{array}{l}1 \text { Community } \\
\text { College (NJ) }\end{array}$ & $\begin{array}{l}\text { Older, High } \\
\text { GPA }\end{array}$ & & \\
\hline $\begin{array}{l}\text { Ross \& } \\
\text { Powell }\end{array}$ & 1990 & & University Data & $\begin{array}{l}\text { Chi-Squared } \\
\text { Statistic }\end{array}$ & $\begin{array}{l}1 \text { University } \\
\text { (Canada) }\end{array}$ & Female & & \\
\hline Doherty & 2006 & $\begin{array}{l}10,46 \\
6\end{array}$ & $\begin{array}{l}\text { University's } \\
\text { Student }\end{array}$ & $\begin{array}{l}\text { Logistic } \\
\text { Regression }\end{array}$ & $\begin{array}{l}2 \text { Community } \\
\text { Colleges }\end{array}$ & $\begin{array}{l}\text { Female, More } \\
\text { Credit Hours }\end{array}$ & & $\begin{array}{l}\text { More Credit } \\
\text { Hours per }\end{array}$ \\
\hline
\end{tabular}




\begin{tabular}{|c|c|c|c|c|c|c|c|}
\hline & & & $\begin{array}{l}\text { Information } \\
\text { System }\end{array}$ & & (NV) & $\begin{array}{l}\text { Accumulated, } \\
\text { Older }\end{array}$ & Term \\
\hline $\begin{array}{l}\text { Taplin \& } \\
\text { Jegede }\end{array}$ & 2001 & 712 & $\begin{array}{l}\text { Questionnaire, } \\
\text { Telephone } \\
\text { Interview }\end{array}$ & & $\begin{array}{l}1 \text { University } \\
\text { (Hong Kong) }\end{array}$ & Married & $\begin{array}{l}\text { Employed } \\
\text { Less than } 20 \\
\text { Hours }\end{array}$ \\
\hline Parker & 1995 & 170 & $\begin{array}{l}\text { Student } \\
\text { Information } \\
\text { Sheet, Rotter's I- } \\
\text { E Locus of } \\
\text { Control, } \\
\text { Interviews }\end{array}$ & $\begin{array}{l}\text { Discriminant } \\
\text { Analysis }\end{array}$ & $\begin{array}{l}1 \text { Community } \\
\text { College } \\
\text { (Southwest) }\end{array}$ & & Employment \\
\hline $\begin{array}{l}\text { Moore, } \\
\text { Bartkovich, } \\
\text { Fetzner, \& } \\
\text { Ison }\end{array}$ & 2003 & 1719 & $\begin{array}{l}\text { Archival Student } \\
\text { Records, Student } \\
\text { Survey }\end{array}$ & $\begin{array}{l}\text { Logistic } \\
\text { Regression }\end{array}$ & $\begin{array}{l}1 \text { Community } \\
\text { College }\end{array}$ & $\begin{array}{l}\text { Older than } 25, \\
\text { Less } \\
\text { Accumulated } \\
\text { Credit Hours, } \\
\text { Less than Full- } \\
\text { time Enrollment }\end{array}$ & \\
\hline
\end{tabular}


Traditional Community College Classes

\begin{tabular}{|c|c|c|c|c|c|c|c|c|}
\hline Author(s) & Year & $\mathbf{N}$ & Collection & Method(s) & Context(s) & Increased & No Affect & Decreased \\
\hline $\begin{array}{l}\text { Kielbaso, } \\
\text { Dirkx, Min, } \\
\text { Allen }\end{array}$ & 1998 & 14 & $\begin{array}{l}\text { Survey, } \\
\text { College } \\
\text { Database }\end{array}$ & $\begin{array}{l}\text { ANOVA, } \\
\text { Interviews }\end{array}$ & $\begin{array}{l}1 \text { Community } \\
\text { College (MI) }\end{array}$ & Female & & \\
\hline Amey \& Long & 1998 & 313 & $\begin{array}{l}\text { Student } \\
\text { Transcripts }\end{array}$ & MANOVA & $\begin{array}{l}\text { 1 Community } \\
\text { College (KS) }\end{array}$ & $\begin{array}{l}\text { Full-time } \\
\text { Enrollment }\end{array}$ & & \\
\hline Hoyt & 1999 & 7683 & $\begin{array}{l}\text { College } \\
\text { Database }\end{array}$ & $\begin{array}{l}\text { Logistic } \\
\text { Regression }\end{array}$ & $\begin{array}{l}1 \text { Community } \\
\text { College (UT) }\end{array}$ & $\begin{array}{l}\text { A or B GPA, } \\
\text { Financial Aid, } \\
\text { Full-time } \\
\text { Enrollment, } \\
\text { Parent with } \\
\text { College Degree }\end{array}$ & & $\begin{array}{l}\text { Full-time } \\
\text { Employment, } \\
\text { Low SES, } \\
\text { Single Parent }\end{array}$ \\
\hline Zhao & 1999 & 1249 & $\begin{array}{l}\text { College } \\
\text { Records }\end{array}$ & $\begin{array}{l}\text { Logistic } \\
\text { Regression, } \\
\text { Stepwise }\end{array}$ & $\begin{array}{l}1 \text { Community } \\
\text { College (MD) }\end{array}$ & $\begin{array}{l}\text { More Credit } \\
\text { Hours } \\
\text { Accumulated, } \\
\text { High GPA, More } \\
\text { Credit Hours per } \\
\text { Term }\end{array}$ & & \\
\hline $\begin{array}{l}\text { Umoh, Eddy, } \\
\text { \& Spaulding }\end{array}$ & 1991 & & & & $\begin{array}{l}\text { Community } \\
\text { College }\end{array}$ & & $\begin{array}{l}\text { Age, Sex, } \\
\text { GPA, Parent's } \\
\text { Level of } \\
\text { Education }\end{array}$ & \\
\hline $\begin{array}{l}\text { Smith, O'Hear, } \\
\text { Baden, } \\
\text { Hayden, } \\
\text { Gorham, Ahuja } \\
\text { \& Jacobsen }\end{array}$ & 1996 & 218 & $\begin{array}{l}5 \text { Sections of } \\
2 \\
\text { Developmenta } \\
1 \text { Math } \\
\text { Classes }\end{array}$ & $\begin{array}{l}\text { Ethnographic } \\
\text { Observations }\end{array}$ & $\begin{array}{l}14 \text {-year } \\
\text { Commuter } \\
\text { Campus }\end{array}$ & $\begin{array}{l}\text { High GPA, More } \\
\text { Credit Hours } \\
\text { Accumulated }\end{array}$ & Age, Sex & \\
\hline
\end{tabular}




\begin{tabular}{|c|c|c|c|c|c|c|c|c|}
\hline $\begin{array}{l}\text { Gates \& } \\
\text { Creamer }\end{array}$ & 1984 & 4854 & $\begin{array}{l}\text { National } \\
\text { Longitudinal } \\
\text { Study of High } \\
\text { School Class } \\
\text { of } 1972\end{array}$ & $\begin{array}{l}\text { Standard } \\
\text { Regression }\end{array}$ & $\begin{array}{l}\text { Multiple } \\
\text { Two-year } \\
\text { Colleges } \\
\text { (NLS) }\end{array}$ & $\begin{array}{l}\text { Full-time } \\
\text { Enrollment, } \\
\text { Higher SES, } \\
\text { Vocational } \\
\text { Compared to } \\
\text { Academic } \\
\text { Program }\end{array}$ & Sex & \\
\hline $\begin{array}{l}\text { St. John \& } \\
\text { Barkley }\end{array}$ & 1994 & 1827 & NPSAS-1987 & $\begin{array}{l}\text { Logistic } \\
\text { Regression }\end{array}$ & $\begin{array}{l}\text { Traditional- } \\
\text { aged National } \\
\text { Two-year } \\
\text { Colleges }\end{array}$ & $\begin{array}{l}\text { Employment, } \\
\text { GED compared } \\
\text { to HS Diploma, } \\
\text { Freshman } \\
\text { compared to } \\
\text { Continuing } \\
\text { Status, Lower } \\
\text { GPA, Vocational } \\
\text { over Academic } \\
\text { Degree Program }\end{array}$ & $\begin{array}{l}\text { Mother's Level } \\
\text { of Education, } \\
\text { Marital Status, } \\
\text { Dependency } \\
\text { Status, } \\
\text { AGI/Income }\end{array}$ & $\begin{array}{l}\text { Full-time } \\
\text { Enrollment, } \\
\text { Grant } \\
\text { Awarded }\end{array}$ \\
\hline $\begin{array}{l}\text { Hippensteel, } \\
\text { St. John \& } \\
\text { Barkley }\end{array}$ & 1996 & 2786 & NPSAS-1987 & $\begin{array}{l}\text { Logistic } \\
\text { Regression }\end{array}$ & $\begin{array}{l}\text { Nontraditional } \\
\text {-aged } \\
\text { National two- } \\
\text { year Colleges }\end{array}$ & $\begin{array}{l}\text { Higher SES, } \\
\text { Lower GPA }\end{array}$ & $\begin{array}{l}\text { Mother's Level } \\
\text { of Education, } \\
\text { Marital Status, } \\
\text { Dependency } \\
\text { Status, } \\
\text { Employment, } \\
\text { GED or HS } \\
\text { Diploma, } \\
\text { Vocational or } \\
\text { Academic } \\
\text { Degree }\end{array}$ & \\
\hline
\end{tabular}




\begin{tabular}{|c|c|c|c|c|c|c|c|c|}
\hline & & & & & & & Program & \\
\hline $\begin{array}{l}\text { Hawley \& } \\
\text { Harris }\end{array}$ & $\begin{array}{l}2005- \\
2006\end{array}$ & 133 & $\begin{array}{l}\text { CIRP } \\
\text { Freshman } \\
\text { Survey }\end{array}$ & $\begin{array}{l}\text { Factor } \\
\text { Analysis, } \\
\text { Discriminant } \\
\text { Function } \\
\text { Analysis } \\
\end{array}$ & $\begin{array}{l}1 \text { Community } \\
\text { College (MD) }\end{array}$ & High GPA & & $\begin{array}{l}\text { Family } \\
\text { Responsibility }\end{array}$ \\
\hline Craig \& Ward & 2008 & 1729 & $\begin{array}{l}\text { Institutional } \\
\text { Database }\end{array}$ & $\begin{array}{l}\text { ANOVA, } \\
\text { Stepwise, } \\
\text { Logistic } \\
\text { Regression }\end{array}$ & $\begin{array}{l}1 \text { Community } \\
\text { College (New } \\
\text { England) }\end{array}$ & High GPA & Age & \\
\hline Fischbach & 1990 & 75 & $\begin{array}{l}\text { Telephone } \\
\text { Survey }\end{array}$ & $\begin{array}{l}\text { ANOVA, } \\
\text { ANCOVA, } \\
\text { Multiple } \\
\text { Regression, } \\
\text { Stepwise, } \\
\text { Discriminant } \\
\text { Analysis }\end{array}$ & $\begin{array}{l}1 \text { Community } \\
\text { College (IL) }\end{array}$ & High GPA & $\begin{array}{l}\text { Sex, Degree } \\
\text { Program }\end{array}$ & \\
\hline Maack & 2002 & 2182 & $\begin{array}{l}\text { Institutional } \\
\text { Database }\end{array}$ & $\begin{array}{l}\text { Logistic } \\
\text { Regression }\end{array}$ & $\begin{array}{l}1 \text { Community } \\
\text { College (CA) }\end{array}$ & $\begin{array}{l}\text { High GPA, } \\
\text { Female, More } \\
\text { Credit Hours } \\
\text { Accumulated }\end{array}$ & Dependent(s) & Employment \\
\hline $\begin{array}{l}\text { Bettinger \& } \\
\text { Long }\end{array}$ & 2005 & & $\begin{array}{l}\text { Application } \\
\text { and Transcript } \\
\text { Information }\end{array}$ & Descriptive & $\begin{array}{l}19 \\
\text { Community } \\
\text { Colleges } \\
(\mathrm{OH})\end{array}$ & $\begin{array}{l}\text { Female, } \\
\text { Younger, Higher } \\
\text { GPA }\end{array}$ & & \\
\hline Romano & 1995 & 1454 & Survey & $\begin{array}{l}\text { Multiple } \\
\text { Regression } \\
\text { Analysis, }\end{array}$ & $\begin{array}{l}1 \text { Community } \\
\text { College (NY) }\end{array}$ & & & $\begin{array}{l}\text { Financial Aid, } \\
\text { Non-transfer } \\
\text { Degree }\end{array}$ \\
\hline
\end{tabular}




\begin{tabular}{|c|c|c|c|c|c|c|c|c|}
\hline & & & & \begin{tabular}{|l|} 
Discriminant \\
Analysis \\
\end{tabular} & & & & Program \\
\hline Grimes & 1997 & 140 & $\begin{array}{l}\text { MAPS test, } \\
\text { LASSI, Adult } \\
\text { Nowicki- } \\
\text { Strickland } \\
\text { Locus of } \\
\text { Control, } \\
\text { Culture Free } \\
\text { Self Esteem } \\
\text { Inventory, } \\
\text { Form AD, } \\
\text { Questionnaire } \\
\end{array}$ & $\begin{array}{l}\text { MANOVA, } \\
\text { MANCOVA }\end{array}$ & $\begin{array}{l}1 \text { Community } \\
\text { College }\end{array}$ & $\begin{array}{l}\text { High GPA, } \\
\text { Older }\end{array}$ & & \\
\hline Mason & 1998 & 93 & $\begin{array}{l}\text { Interviews, } \\
\text { Survey, } \\
\text { College } \\
\text { Database } \\
\end{array}$ & ANOVA & $\begin{array}{l}1 \text { Community } \\
\text { College (IL) }\end{array}$ & $\begin{array}{l}\text { High GPA, } \\
\text { Supportive } \\
\text { Parent/Wife }\end{array}$ & & \\
\hline Fike \& Fike & 2008 & 9200 & $\begin{array}{l}\text { College } \\
\text { Database }\end{array}$ & $\begin{array}{l}\text { Multiple } \\
\text { Logistic } \\
\text { Regression }\end{array}$ & $\begin{array}{l}1 \text { Community } \\
\text { College (TX) }\end{array}$ & $\begin{array}{l}\text { Fall to Spring: } \\
\text { Father having } \\
\text { some College } \\
\text { Education, } \\
\text { Financial aid, } \\
\text { Full-time } \\
\text { Enrollment } \\
\text { Fall to Fall: Take } \\
\text { Internet Course, } \\
\text { Father having } \\
\text { some College } \\
\end{array}$ & $\begin{array}{l}\text { Fall to Spring: } \\
\text { Mother having } \\
\text { some College } \\
\text { Education, } \\
\text { Sex, Age } \\
\text { Fall to Fall: } \\
\text { Age }\end{array}$ & \\
\hline
\end{tabular}




\begin{tabular}{|c|c|c|c|c|c|c|c|c|}
\hline & & & & & & $\begin{array}{l}\text { Education, } \\
\text { Mother having } \\
\text { some College } \\
\text { Education, } \\
\text { Financial aid, } \\
\text { Full-time } \\
\text { Enrollment } \\
\end{array}$ & & \\
\hline Simmons & 1995 & 633 & $\begin{array}{l}\text { Registration } \\
\text { Forms, } \\
\text { Databases }\end{array}$ & $\begin{array}{l}\text { Discriminant } \\
\text { Analysis }\end{array}$ & $\begin{array}{l}6 \text { Community } \\
\text { Colleges } \\
\text { (WA) }\end{array}$ & $\begin{array}{l}\text { Full-time } \\
\text { Enrollment, } \\
\text { High GPA, }\end{array}$ & $\begin{array}{l}\text { Age, } \\
\text { Employment, } \\
\text { Sex }\end{array}$ & \\
\hline Grosset & 1991 & 449 & Questionnaire & $\begin{array}{l}\text { Factor } \\
\text { Analysis, } \\
\text { Discriminant } \\
\text { Function } \\
\text { Analysis }\end{array}$ & $\begin{array}{l}\text { 1 Community } \\
\text { College } \\
\text { (Northeast) }\end{array}$ & Dependent(s) & & $\begin{array}{l}\text { Increased } \\
\text { Employment } \\
\text { Hours }\end{array}$ \\
\hline Feldman & 1993 & 1140 & $\begin{array}{l}\text { College } \\
\text { Database }\end{array}$ & $\begin{array}{l}\text { Logistic } \\
\text { Regression, } \\
\text { ANOVA }\end{array}$ & $\begin{array}{l}1 \text { Community } \\
\text { College (NY) }\end{array}$ & & & $\begin{array}{l}\text { Ages 20-24, } \\
\text { Part-time } \\
\text { Enrollment, } \\
\text { Males, } \\
\text { Certificate } \\
\text { Program }\end{array}$ \\
\hline $\begin{array}{l}\text { Mendoza, } \\
\text { Mendez \& } \\
\text { Malcolm }\end{array}$ & 2009 & 48292 & State Data Set & $\begin{array}{l}\text { Stepwise HWF } \\
\text { Logistic } \\
\text { Regression }\end{array}$ & $\begin{array}{l}\text { All Oklahoma } \\
\text { Community } \\
\text { Colleges }\end{array}$ & $\begin{array}{l}\$ 40,00 \text { or more } \\
\text { Income }\end{array}$ & & $\begin{array}{l}\$ 20,00 \text { or less } \\
\text { Income }\end{array}$ \\
\hline Conway & 2009 & 1667 & $\begin{array}{l}\text { ACT data, } \\
\text { Admissions } \\
\text { and Course } \\
\text { Enrollment }\end{array}$ & $\begin{array}{l}\text { ANOVA, } \\
\text { Stepwise } \\
\text { Regression }\end{array}$ & $\begin{array}{l}1 \text { Community } \\
\text { College (18- } \\
24 \text { age only) }\end{array}$ & $\begin{array}{l}\text { High School } \\
\text { Diploma, Female }\end{array}$ & & \\
\hline
\end{tabular}




\begin{tabular}{|c|c|c|c|c|c|c|c|c|}
\hline & & & Data & & & & & \\
\hline Daniels & 1990 & 2243 & $\begin{array}{l}\text { Entering } \\
\text { Student } \\
\text { Survey }\end{array}$ & ANOVA & $\begin{array}{l}1 \text { Community } \\
\text { College (NJ) }\end{array}$ & $\begin{array}{l}\text { Academic/Transf } \\
\text { er Degree } \\
\text { Program }\end{array}$ & & $\begin{array}{l}\text { Undecided } \\
\text { Degree } \\
\text { Program }\end{array}$ \\
\hline $\begin{array}{l}\text { Campbell \& } \\
\text { Blakey }\end{array}$ & 1996 & 3283 & $\begin{array}{l}\text { Computer } \\
\text { Database }\end{array}$ & $\begin{array}{l}\text { Multiple } \\
\text { Regression }\end{array}$ & $\begin{array}{l}\text { 1 Community } \\
\text { College } \\
\text { (Midwest) }\end{array}$ & High GPA & & \\
\hline $\begin{array}{l}\text { Kinser \& } \\
\text { Deitchman }\end{array}$ & 2007 & 84 & $\begin{array}{l}\text { Surveys, } \\
\text { Interviews }\end{array}$ & $\begin{array}{l}\text { ANOVA, } \\
\text { Interviews }\end{array}$ & $\begin{array}{l}1 \text { Community } \\
\text { College }\end{array}$ & $\begin{array}{l}\text { Dependent(s), } \\
\text { Older }\end{array}$ & $\begin{array}{l}\text { Sex, } \\
\text { Employment } \\
\text { Status }\end{array}$ & \\
\hline Clagett & 1996 & 2386 & Tracking Files & $\begin{array}{l}\text { Logistic } \\
\text { Regression }\end{array}$ & $\begin{array}{l}1 \text { Community } \\
\text { College (MD) }\end{array}$ & $\begin{array}{l}\text { More Credit } \\
\text { Hours per Term, } \\
\text { More } \\
\text { Accumulated } \\
\text { Credit Hours, } \\
\text { High GPA } \\
\end{array}$ & $\begin{array}{l}\text { Socio- } \\
\text { economic } \\
\text { Status, Sex }\end{array}$ & \\
\hline Breindel & 1997 & 4616 & $\begin{array}{l}\text { MIS Data } \\
\text { Tapes }\end{array}$ & Descriptive & $\begin{array}{l}1 \text { Community } \\
\text { College (CA) }\end{array}$ & $\begin{array}{l}\text { Full-time } \\
\text { Enrollment } \\
\text { Status }\end{array}$ & & \\
\hline Moore & 1995 & 111 & $\begin{array}{l}\text { Interviews, } \\
\text { Telephone } \\
\text { Survey, } \\
\text { Student } \\
\text { Information } \\
\text { System }\end{array}$ & Descriptive & $\begin{array}{l}1 \text { Community } \\
\text { College (NM) }\end{array}$ & $\begin{array}{l}\text { Full-time } \\
\text { Enrollment } \\
\text { Status }\end{array}$ & & \\
\hline Farahani & 1993 & 283 & Survey & Descriptive & $\begin{array}{l}1 \text { Community } \\
\text { College (MD) }\end{array}$ & & & \begin{tabular}{|l} 
Job Demands \\
\end{tabular} \\
\hline Denison \& & 2003 & 678 & Survey, & Forward & 1 Community & High GPA, & & \\
\hline
\end{tabular}




\begin{tabular}{|c|c|c|c|c|c|c|c|c|}
\hline Secolsky & & & $\begin{array}{l}\text { System-wide } \\
\text { Database }\end{array}$ & $\begin{array}{l}\text { Blockwise } \\
\text { Logistic } \\
\text { Regression, } \\
\text { ANOVA } \\
\end{array}$ & College (NJ) & $\begin{array}{l}\text { Female, } \\
\text { Associate } \\
\text { Degree compare } \\
\text { to Transfer }\end{array}$ & & \\
\hline Mohammadi & 1994 & 3843 & $\begin{array}{l}\text { Administrativ } \\
\text { e Database, } \\
\text { College } \\
\text { Records }\end{array}$ & $\begin{array}{l}\text { Exploratory } \\
\text { Data Analysis, } \\
\text { Logistic } \\
\text { Regression }\end{array}$ & $\begin{array}{l}1 \text { Community } \\
\text { College (VA) }\end{array}$ & $\begin{array}{l}\text { More Credit } \\
\text { Hours } \\
\text { Accumulated, } \\
\text { More Credit } \\
\text { Hours per Term } \\
\end{array}$ & Age, Sex & \\
\hline Goel & 2002 & 2981 & Database & $\begin{array}{l}\text { Multiple } \\
\text { Stepwise } \\
\text { Regression }\end{array}$ & $\begin{array}{l}2 \text { Community } \\
\text { Colleges (TX } \\
\& \text { IL) }\end{array}$ & $\begin{array}{l}\text { High GPA, } \\
\text { Younger, } \\
\text { Unknown } \\
\text { Educational } \\
\text { Objective } \\
\end{array}$ & & $\begin{array}{l}\text { Part-time } \\
\text { Enrollment }\end{array}$ \\
\hline Conklin & 1995 & 641 & 8 Surveys & Descriptive & $\begin{array}{l}17 \\
\text { Community } \\
\text { Colleges (KS) } \\
\text { (full-time } \\
\text { only) }\end{array}$ & & & $\begin{array}{l}\text { Social } \\
\text { Economic } \\
\text { Status } \\
\text { (highest } \\
\text { income had } \\
\text { lowest } \\
\text { persistence) }\end{array}$ \\
\hline Conklin & 1997 & 10,663 & Survey & Descriptive & $\begin{array}{l}1 \text { Community } \\
\text { College (KS) }\end{array}$ & & & $\begin{array}{l}\text { Work } \\
\text { Schedule } \\
\text { Conflicts }\end{array}$ \\
\hline $\begin{array}{l}\text { Zhai \& } \\
\text { Monzon }\end{array}$ & 2001 & 18,449 & $\begin{array}{l}\text { Student } \\
\text { Records, } \\
\text { Survey } \\
\text { Questionnaire }\end{array}$ & Descriptive & $\begin{array}{l}3 \text { Community } \\
\text { Colleges (CA) }\end{array}$ & Age 23-34 & & $\begin{array}{l}\text { Income of } \\
\$ 33,000 \text { or } \\
\text { Higher, Full- } \\
\text { time and Part- }\end{array}$ \\
\hline
\end{tabular}




\begin{tabular}{|c|c|c|c|c|c|c|c|c|}
\hline & & & & & & & & \begin{tabular}{|l|} 
time \\
Employment, \\
Low GPA, \\
Female, Age \\
17 or Under, \\
Financial \\
Difficulties, \\
Family \\
Obligations \\
\end{tabular} \\
\hline Price & 1993 & 172 & $\begin{array}{l}\text { Student } \\
\text { Records }\end{array}$ & Descriptive & $\begin{array}{l}1 \text { Community } \\
\text { College (MD) }\end{array}$ & & & \begin{tabular}{|l|} 
Single, \\
Female, \\
Nontraditional \\
Age, \\
Unemployed, \\
Part-time \\
Enrollment \\
Status, Non \\
Degree \\
Program \\
\end{tabular} \\
\hline $\begin{array}{l}\text { Swager, } \\
\text { Campbell \& } \\
\text { Orlowski }\end{array}$ & 1995 & 15,918 & $\begin{array}{l}\text { Student } \\
\text { Withdrawal } \\
\text { Form }\end{array}$ & Descriptive & $\begin{array}{l}1 \text { Community } \\
\text { College }\end{array}$ & $\begin{array}{l}\text { Age (mixed } \\
\text { results based on } \\
\text { degree) }\end{array}$ & Sex, GPA & \begin{tabular}{|l|} 
Conflict with \\
Work, Age \\
(mixed results \\
based on \\
degree) \\
\end{tabular} \\
\hline $\begin{array}{l}\text { Lajubutu, } \\
\text { Oyebanjo \& } \\
\text { Yang }\end{array}$ & 1998 & 2262 & $\begin{array}{l}\text { Student } \\
\text { Tracking Files }\end{array}$ & $\begin{array}{l}\text { Stepwise } \\
\text { Logistic } \\
\text { Regression }\end{array}$ & $\begin{array}{l}1 \text { Community } \\
\text { College (MD) }\end{array}$ & $\begin{array}{l}\text { High GPA, More } \\
\text { Credit Hours } \\
\text { Accumulated, } \\
\text { More Credit }\end{array}$ & & \\
\hline
\end{tabular}




\begin{tabular}{|c|c|c|c|c|c|c|c|c|}
\hline & & & & & & Hours per Term & & \\
\hline Windham & 1995 & 1425 & $\begin{array}{l}\text { FETPIP } \\
\text { Follow-up } \\
\text { System and } \\
\text { College } \\
\text { Record } \\
\text { System }\end{array}$ & \begin{tabular}{|l|} 
Logistic \\
Regression
\end{tabular} & $\begin{array}{l}1 \text { Community } \\
\text { College (FL) }\end{array}$ & $\begin{array}{l}\text { High GPA, } \\
\text { Younger, Part- } \\
\text { time } \\
\text { Employment } \\
\text { Full-time } \\
\text { Enrollment }\end{array}$ & & $\begin{array}{l}\text { Full-time } \\
\text { Employment, } \\
\text { High School } \\
\text { Diploma }\end{array}$ \\
\hline Kim & 2002 & 3710 & Survey & $\begin{array}{l}\text { Logistic } \\
\text { Regression }\end{array}$ & $\begin{array}{l}18 \\
\text { Community } \\
\text { Colleges } \\
\text { (Korea) }\end{array}$ & & & $\begin{array}{l}\text { Female } \\
\text { (depending on } \\
\text { parent's fin } \\
\text { aid), Male } \\
\text { (depending on } \\
\text { mother's job } \\
\text { and transfer } \\
\text { plan) }\end{array}$ \\
\hline $\begin{array}{l}\text { Brooks- } \\
\text { Leonard }\end{array}$ & 1991 & 796 & $\begin{array}{l}\text { Course } \\
\text { Registration } \\
\text { Form }\end{array}$ & $\begin{array}{l}\text { One and Two- } \\
\text { Way ANOVA }\end{array}$ & $\begin{array}{l}1 \text { Technical } \\
\text { College (IN) }\end{array}$ & $\begin{array}{l}\text { Younger, Full- } \\
\text { time Enrollment, } \\
\text { Part-time } \\
\text { Employment, } \\
\text { High GPA, } \\
\text { Associate of } \\
\text { Science and } \\
\text { Technical } \\
\text { Certificate } \\
\text { Programs }\end{array}$ & $\begin{array}{l}\text { Income Level, } \\
\text { Marital Status, } \\
\text { Sex, Secondary } \\
\text { Education }\end{array}$ & \\
\hline $\begin{array}{l}\text { Cofer \& } \\
\text { Somers }\end{array}$ & 2000 & 7507 & $\begin{array}{l}\text { NPSAS:96 } \\
\text { National } \\
\text { Database }\end{array}$ & $\begin{array}{l}\text { Logistic } \\
\text { Regression }\end{array}$ & $\begin{array}{l}\text { Community } \\
\text { Colleges } \\
\text { (USA) }\end{array}$ & $\begin{array}{l}\text { Parents have } \\
\text { College Degree, } \\
\text { Dependent }\end{array}$ & $\begin{array}{l}\text { Degree } \\
\text { Program, } \\
\text { Marital Status, }\end{array}$ & \\
\hline
\end{tabular}




\begin{tabular}{|c|c|c|c|c|c|c|c|c|}
\hline & & & & & & $\begin{array}{l}\text { Status, Full-time } \\
\text { Enrollment, } \\
\text { High GPA, Over } \\
\text { Age of } 30, \\
\text { Financial Aid, } \\
\text { High School } \\
\text { Diploma }\end{array}$ & $\begin{array}{l}\text { Income Level, } \\
\text { Sex, Race }\end{array}$ & . \\
\hline Baird & 1991 & 1938 & $\begin{array}{l}\text { Survey, ACT } \\
\text { Assessment, } \\
\text { System } \\
\text { Records }\end{array}$ & $\begin{array}{l}\text { Discriminant } \\
\text { Analysis }\end{array}$ & $\begin{array}{l}\text { All } 13 \\
\text { Kentucky } \\
\text { Community } \\
\text { Colleges } \\
\end{array}$ & $\begin{array}{l}\text { High GPA, } \\
\text { Transfer } \\
\text { Programs, Full- } \\
\text { time Enrollment }\end{array}$ & & $\begin{array}{l}\text { Married, } \\
\text { Employed, } \\
\text { Male, } \\
\text { Dependent(s) }\end{array}$ \\
\hline Nippert & $\begin{array}{l}2000- \\
2001\end{array}$ & 262 & CIRP Surveys & $\begin{array}{l}\text { Multiple } \\
\text { Regression }\end{array}$ & $\begin{array}{l}\text { National } \\
\text { Community } \\
\text { Colleges }\end{array}$ & $\begin{array}{l}\text { Academic } \\
\text { Activities, GPA, } \\
\text { Female }\end{array}$ & $\begin{array}{l}\text { Parental } \\
\text { Income, } \\
\text { Marital Status }\end{array}$ & Employment \\
\hline
\end{tabular}




\section{APPENDIX B}

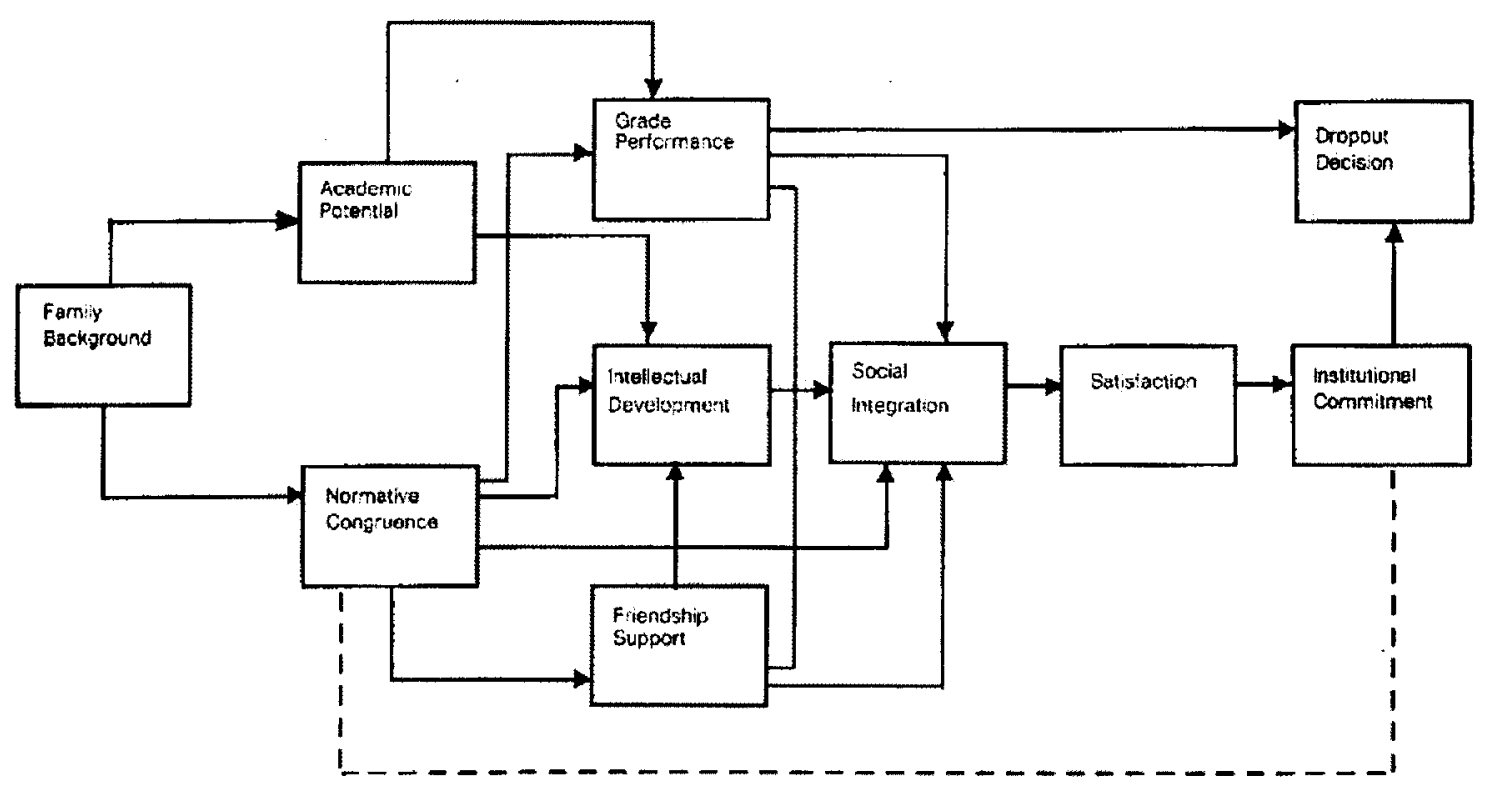

Illustration \# 1: William G. Spady, 1970

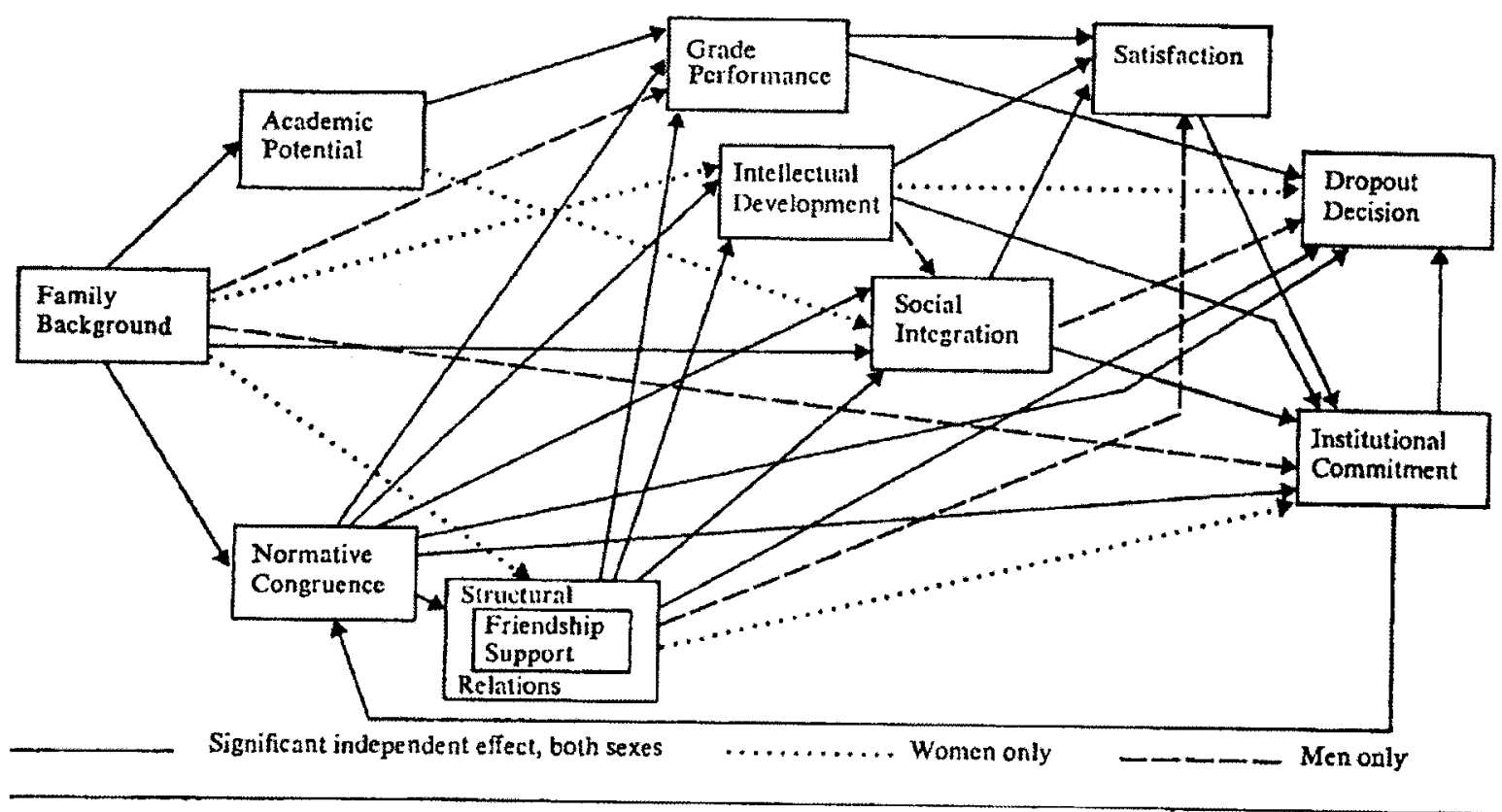

Illustration \# 2: William G. Spady, 1971 


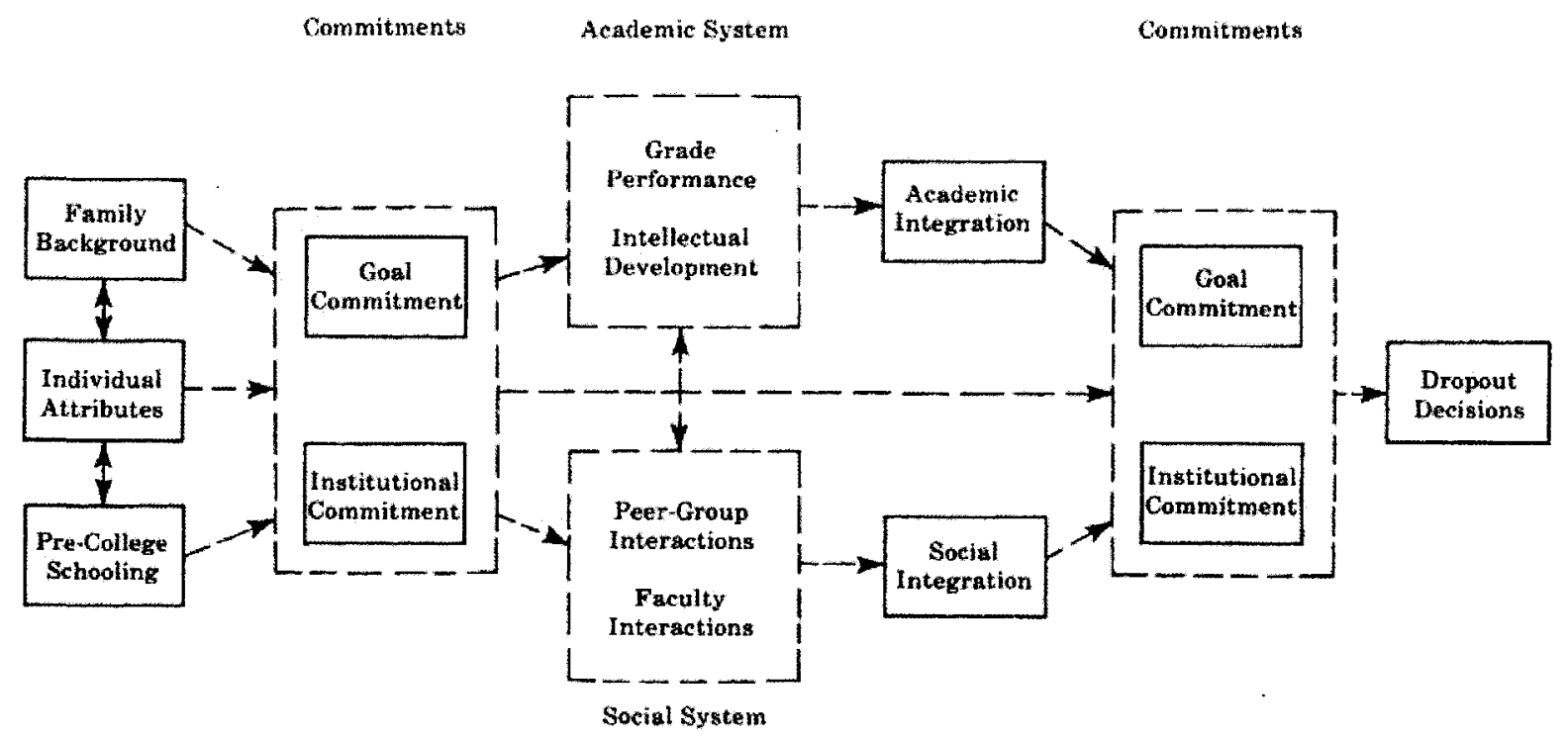

Illustration \# 3: Vincent Tinto, 1975 


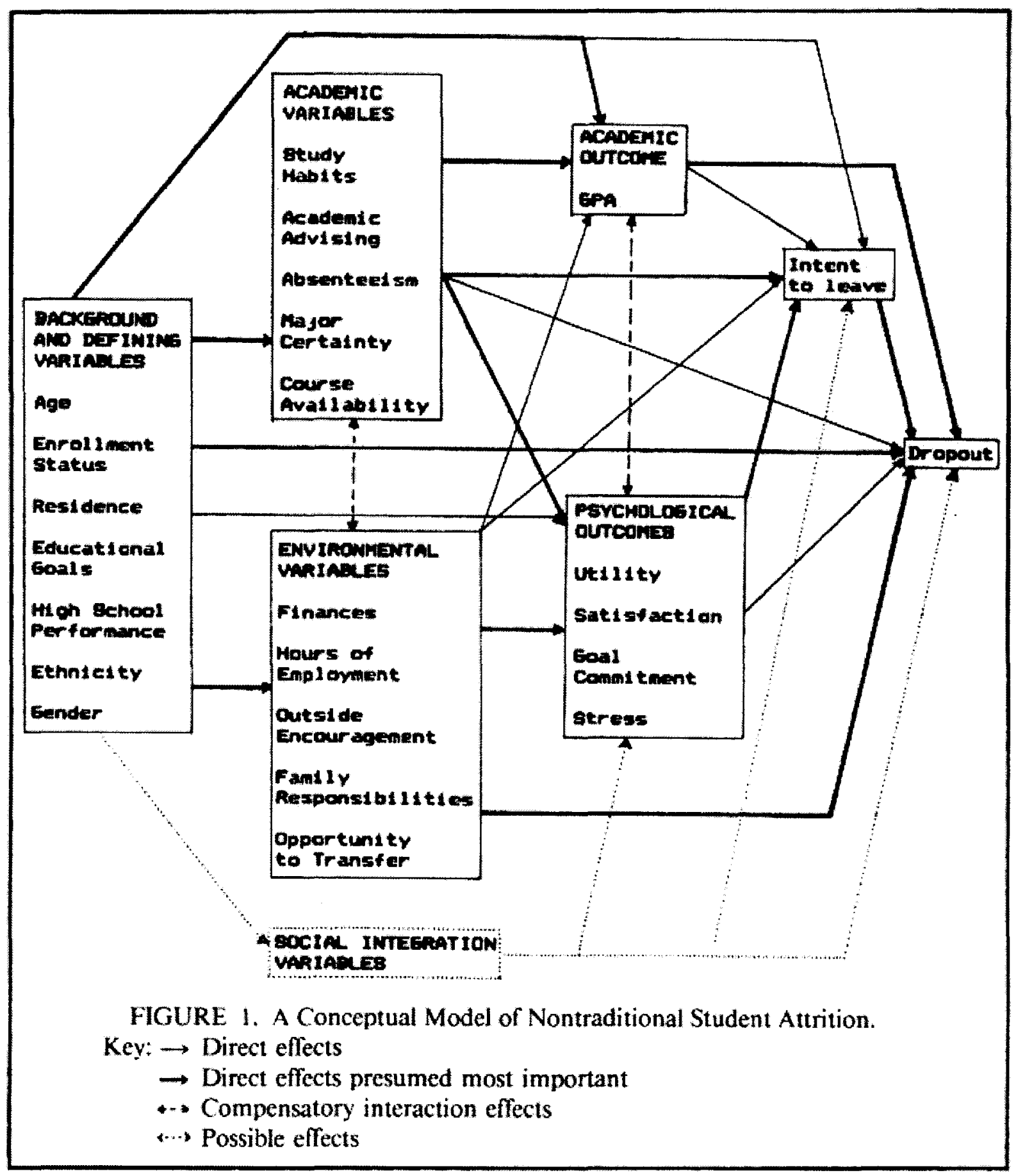

Illustration \# 4: Bean and Metzner, 1985 


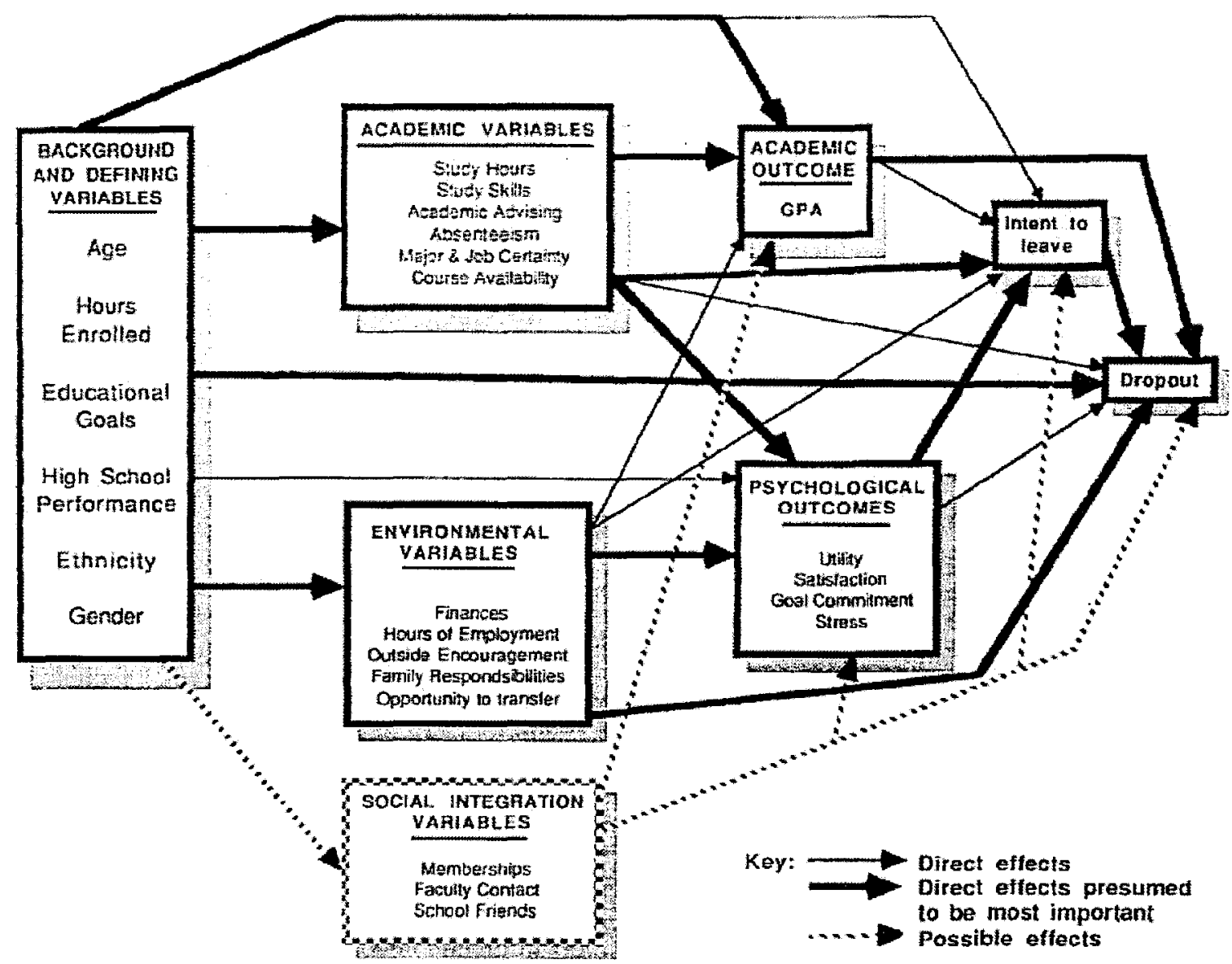

Illustration \# 5: Bean and Metzner, 1987

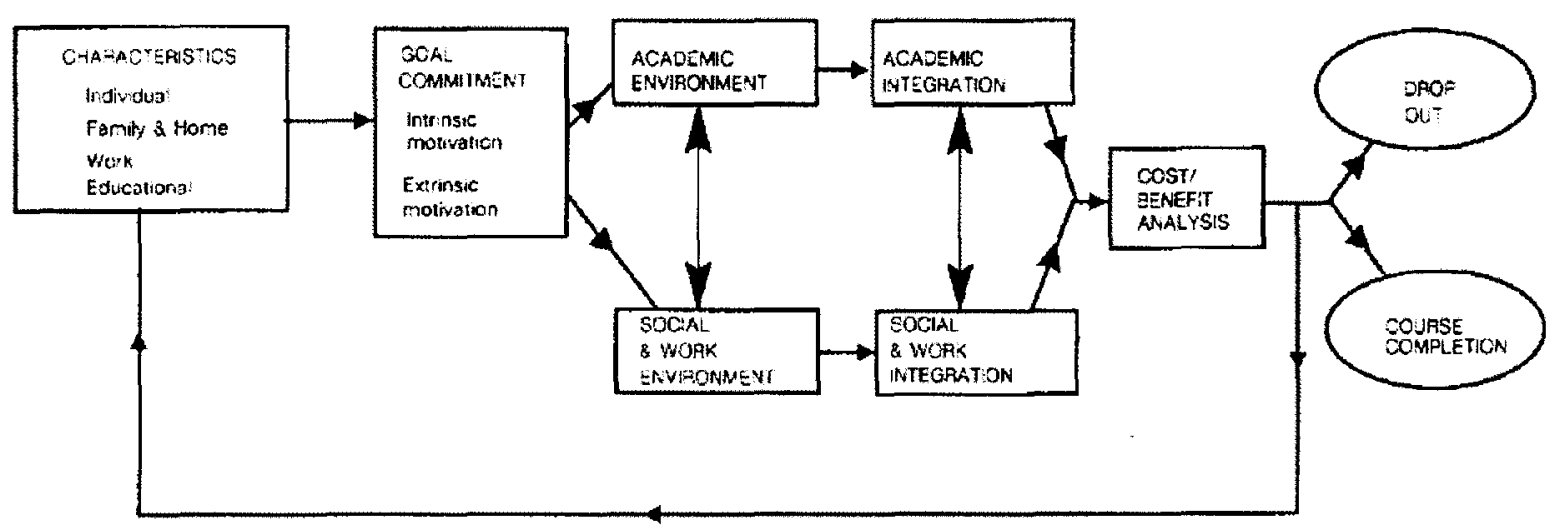

Illustration \# 6: Kember, 1989 


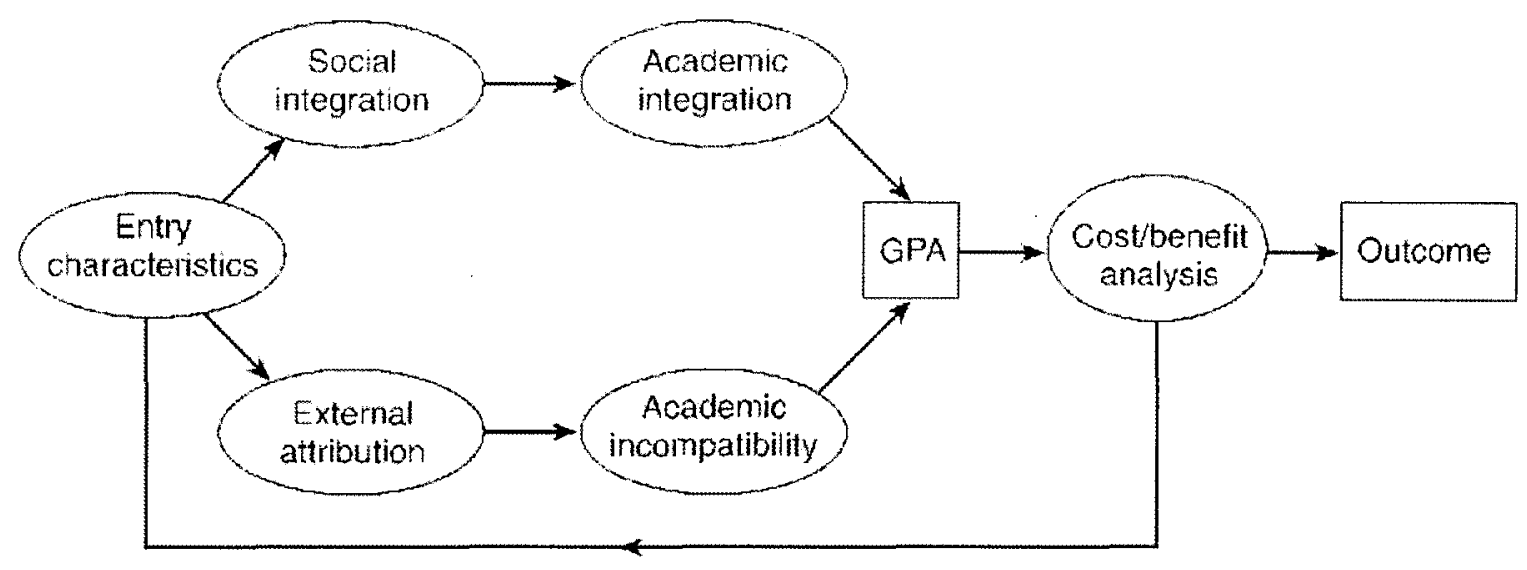

Illustration \# 7: Kember, 1995

\section{Collective Affiliation Model}

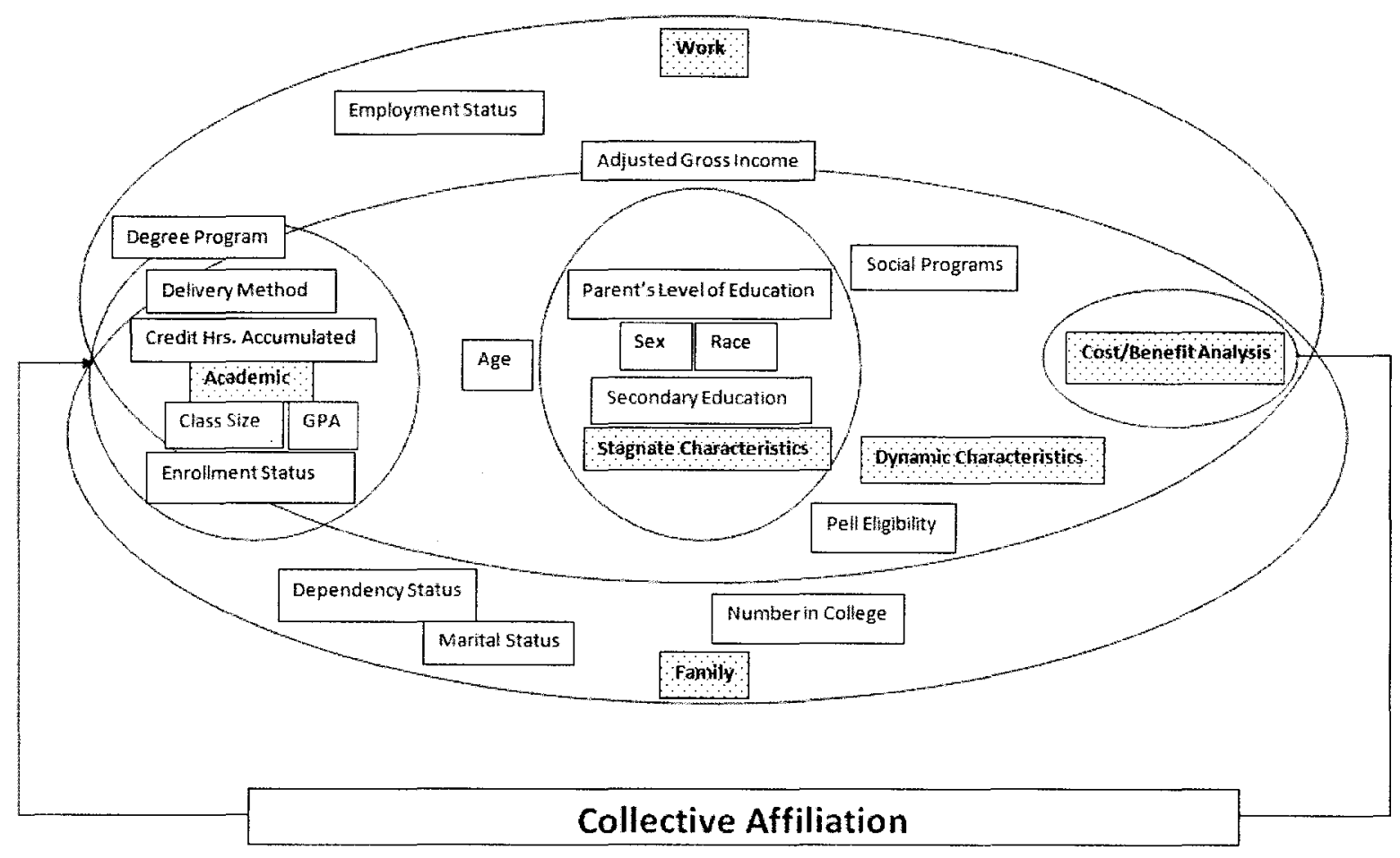

Illustration \# 8, The Collective Affiliation Model, 2010 


\begin{tabular}{|c|c|c|c|}
\hline \multirow{2}{*}{ Stagnate Characteristics } & \multicolumn{3}{|c|}{ Collective Affiliation } \\
\cline { 2 - 4 } & Family & Womic Characteristics & \\
\hline Sex & Dependency Status & Federal Work-study & Degree Program \\
\hline $\begin{array}{c}\text { Secondary Education } \\
\text { Father's Level of } \\
\text { Education }\end{array}$ & Age & Age & Delivery Method \\
\hline $\begin{array}{c}\text { Mother's Level of } \\
\text { Education }\end{array}$ & Dependents & Dependents & Credit Hours \\
& & Accumulated \\
\hline & Adjust Gross Income & Adjust Gross & Enrollment Status \\
& & Income & Academic Program \\
\hline & Children & & \\
\hline & Number in College & & \\
\hline & Number in Household & & \\
\hline
\end{tabular}

Illustration \# 9: Variables Classified 


\section{CURRICULUM VITA}

\section{Jeffrey Cody Davidson, Ph.D.}

\section{Education}

2011 Doctor of Philosophy, Educational Leadership and Organizational Development University of Louisville, College of Education and Human Development Louisville, KY

Emphasis: Postsecondary Administration

Dissertation: The Collective Affiliation of Community College, Commuter and Distance Education Students:

Developmental Math and Dropout

2004 Master of Business Administration

Gardner-Webb University

Boiling Springs, NC

Emphasis: International Business

2004 Master of Divinity

Gardner-Webb University

Boiling Springs, NC

2001 Bachelor of Arts

Communication Arts \& Religion

Georgetown College

Georgetown, KY

\section{Teaching Experience}

Adjunct Business Administration \& Management Professor, Bluegrass Community \& Technical College

Year, Term

2008, Spring

\section{Credit Hrs Course}

3 MGT 288: Self-Management

KCTCS Online Business Facilitator, Elizabethtown Community \& Technical College

Year, Term

2008, Summer

2008, Summer

2008, Summer

2010, Fall

2011, Summer

\section{Credit Hrs Course}

0.5

0.5

0.5

1.0

0.6
BA 2836: Special Topics in Management

BA 2674: Property Law

BA 2675: Research \& Negotiable Instruments

BA 2122: Break-Even Analysis

BA 2844: Communication and Teamwork 
Adjunct Online Humanities Professor, Maysville Community \& Technical College

$\begin{array}{ll}\text { Year, Term } & \text { C } \\ \text { 2009, Spring } & 3 \\ \text { 2009, Fall } & 3 \\ \text { 2010, Spring } & 3 \\ \text { 2010, Summer } & 3 \\ \text { 2010, Fall } & 3 \\ \text { 2011, Spring } & 3 \\ \text { 2011, Summer } & 3 \\ \text { 2011, Fall } & 3\end{array}$

\section{Credit Hrs Course}

3

3

3

3

3

3

3
RS 130: Introduction to Comparative Religion

RS 130: Introduction to Comparative Religion RS 130: Introduction to Comparative Religion RS 130: Introduction to Comparative Religion RS 130: Introduction to Comparative Religion REL 130: Introduction to Comparative Religion REL 130: Introduction to Comparative Religion REL 130: Introduction to Comparative Religion

\section{Presentations}

Davidson, J. C., \& Wilson, K. B. (May, 2011) The theoretical framework for a comprehensive distance education and community college student retention model. Paper presented at the Association of Institutional Researchers Forum. Toronto, Canada.

Davidson, J. C. \& Wilson, K. B. (May, 2011) KCTCS developmental math students and factors affecting persistence. Paper presented at New Horizons Conference. Lexington, KY.

Davidson, J. C., \& Wilson, K. B. (April, 2011) Gaining respect: Using FAFSA information to leverage financial aid with student retention efforts. Paper presented at the Kentucky Association of Student Financial Aid Administrators Spring Conference. Lexington, KY.

Davidson, J. C., \& Wilson, K. B. (October, 2010) The theoretical framework for a comprehensive distance education and community college student retention model. Paper presented at the Kentucky Association of Institutional Researchers Annual Conference. Louisville, KY.

*2010 KAIR Best Paper Award

Davidson, J. C. \& Barlow, M. (February, 2008). Financial aid and the impact on Kentucky students. Paper presented at the College Personnel Association of Kentucky Annual Conference. Louisville, KY.

\section{Professional Experience}

03/09 - present Financial Aid Account Reconciliation, Kentucky Community \& Technical College System Office

10/07-03/09 Associate Director of Financial Aid, Bluegrass Community \& Technical College

02/07 - 10/07 Assistant Director of Financial Aid, Bluegrass Community \& Technical College

01/06-01/07 Financial Aid Coordinator, Bluegrass Community \& Technical 
College

09/04 - 12/05 Graduate Admissions Counselor, Georgetown College

01/03 - 05/04 Admissions Counselor, Gardner-Webb University

\section{Service}

Bluegrass Community \& Technical College: BCTC Presidential Appointment to Budget Alignment Advisory Team 2008-2009, Tuition Appeals Committee 2007, Professional \& Organizational Development Grant Committee 2006-2009, Distance Learning Action Team 2006-2007, Retention Action Team 2007-2008, Staff Council 2007-2008

BCTC Search Committees: Assistant Registrar \& Associate Vice-President for Retention

KASFAA: Nominations Committee 2006-2007, Public Relations Committee 2007-2009, Budget Committee 2007-2008

\section{Honors}

Gardner-Webb University: SOD Student Association Vice-President, Leadership Scholar Georgetown College: Academic Dean's List, Outstanding Student Leadership Finalist, Diversity Committee,

Baptist Student Union Executive Council President, Lambda Phi Eta, National Communications Honors Society, Trustee Partner

Lincoln County High School: Senior Superlative "Most Dependable" 